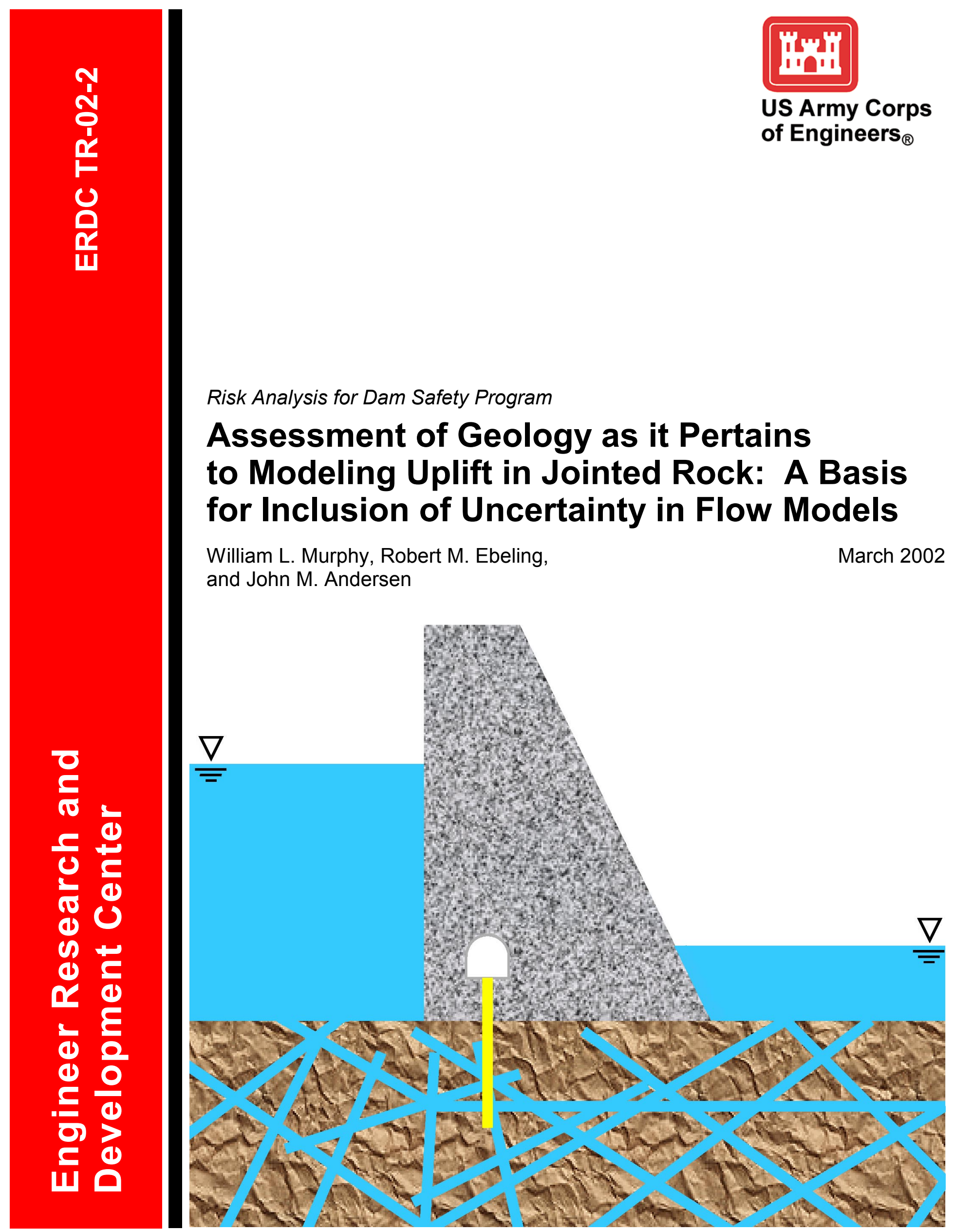


The contents of this report are not to be used for advertising, publication, or promotional purposes. Citation of trade names does not constitute an official endorsement or approval of the use of such commercial products.

The findings of this report are not to be construed as an official Department of the Army position, unless so designated by other authorized documents. 


\section{Assessment of Geology as it Pertains to Modeling Uplift in Jointed Rock: A Basis for Inclusion of Uncertainty in Flow Models}

by William L. Murphy, John M. Andersen

U.S. Army Engineer Research and Development Center Geotechnical and Structures Laboratory 3909 Halls Ferry Road

Vicksburg, MS 39180-6199

Robert M. Ebeling

U.S. Army Engineer Research and Development Center Information Technology Laboratory 3909 Halls Ferry Road

Vicksburg, MS 39180-6199

Final report

Approved for public release; distribution is unlimited

$\begin{array}{cl}\text { Prepared for } & \text { U.S. Army Corps of Engineers } \\ & \text { Washington, DC 20314-1000 } \\ \text { Under } & \text { Work Unit 6 }\end{array}$




\section{Contents}

Preface xii

Conversion Factors, Non-SI to SI Units of Measurement................................ xiii

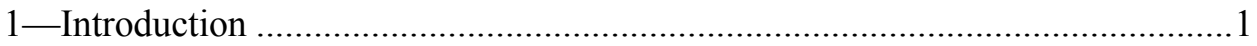

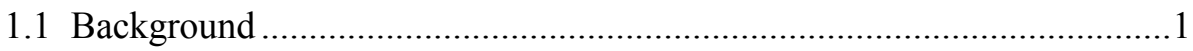

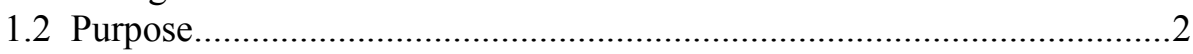

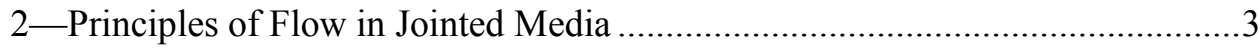

2.1 Groundwater Flow and Uplift Pressure in Discontinuous Rock................3

2.1.1 Analytical methods in uplift prediction.........................................

2.1.2 Joint aperture and uplift pressure distribution................................ 4

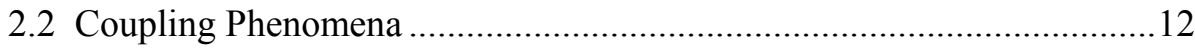

2.3 Considerations in Assessing Hydraulic Conductivity of Joints ...............13

2.3.1 Permeability and hydraulic conductivity..................................... 13

2.3.2 Flow in joints: The cubic law .....................................................14

2.3.3 Mechanical and conducting aperture and JRC.............................15

2.3.4 Laminar and turbulent flow in joints ........................................17

2.4 Determination of Rock Mass Hydraulic Conductivity.............................19

2.4.1 Methods using pressure and pumping tests...................................19

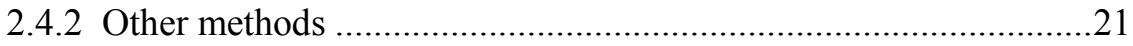

2.5 Approaches in Computing Hydraulic Conductivity of Jointed Rock

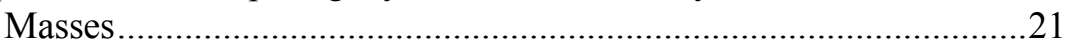

2.6 Uncertainty in Determining Hydraulic Properties of Jointed Rock .........23

3 - Geological Considerations in Uplift Analysis and Foundation

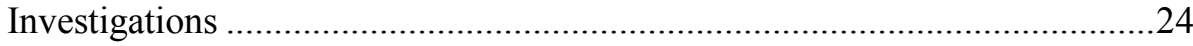

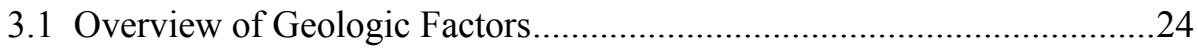

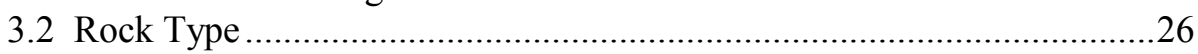

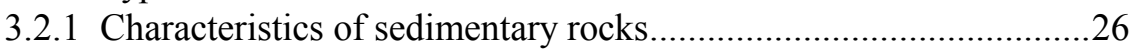

3.2.2 Characteristics of igneous rocks ..............................................27

3.2.3 Characteristics of metamorphic rocks .........................................29

3.2.4 Problems with sedimentary rocks in dam foundations..................29

3.2.5 Problems with igneous rocks in dam foundations..........................30

3.2.6 Problems with metamorphic rocks in dam foundations ..................33

3.3 Problems Associated with Weathering ....................................................33

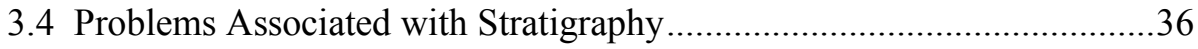




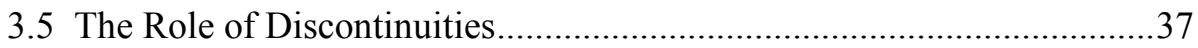

3.5.1 Describing and measuring discontinuities in rock ..........................38

3.5.2 Effects of joint condition on groundwater flow ...........................42

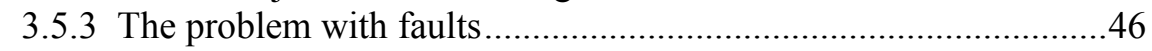

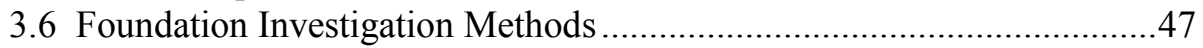

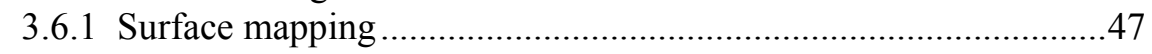

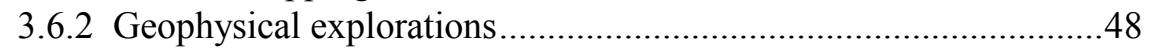

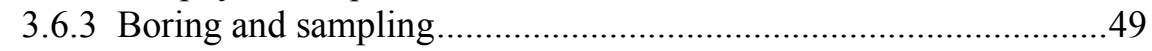

3.6.4 Borehole examination and testing...............................................50

3.6.5 Exploratory excavations (tunnels, shafts, drifts, test pits,

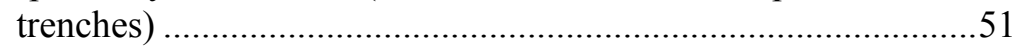

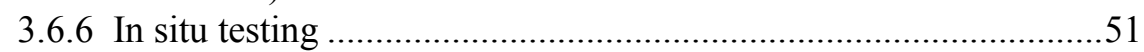

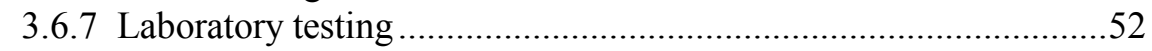

3.6.8 Groundwater and foundation seepage investigations ....................52

4-Selection of Case History for Uplift Investigation .......................................56

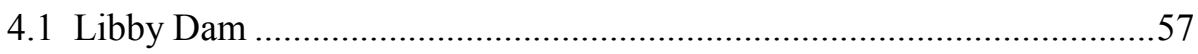

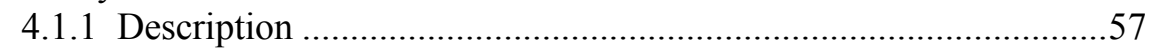

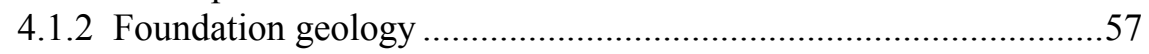

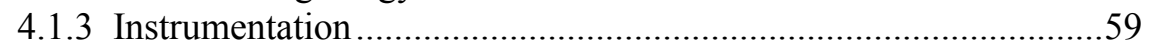

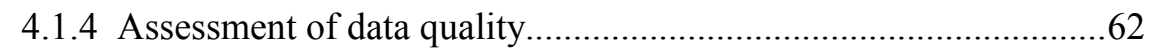

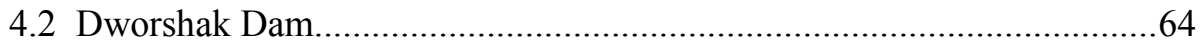

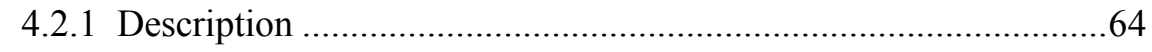

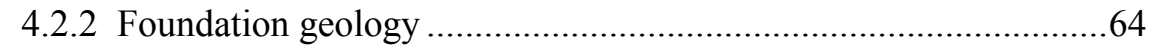

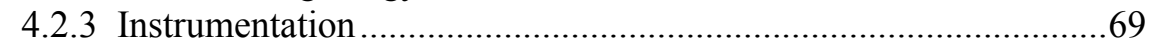

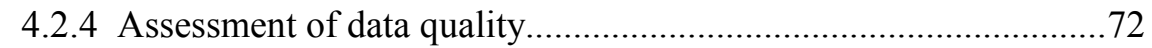

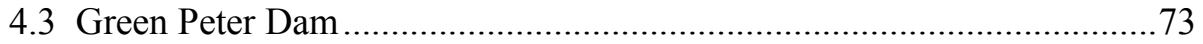

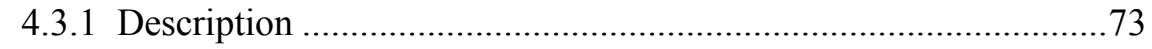

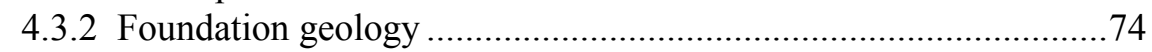

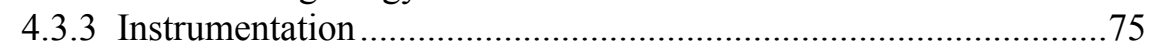

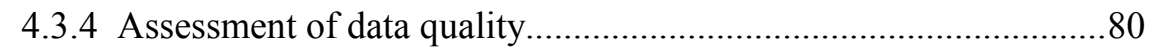

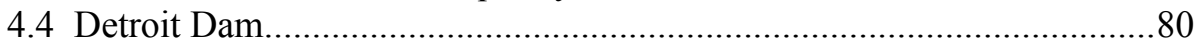

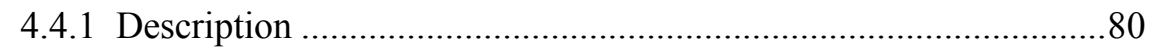

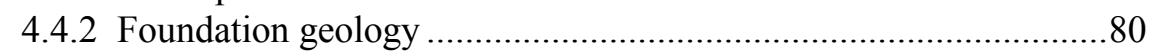

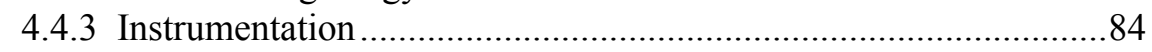

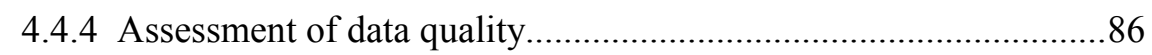

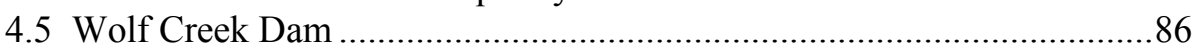

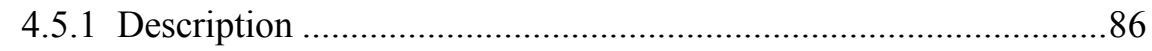

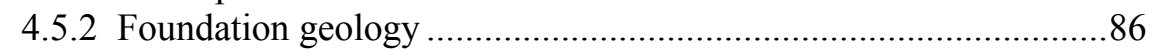

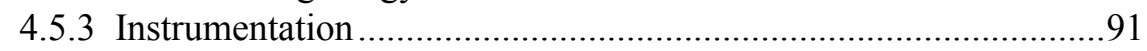

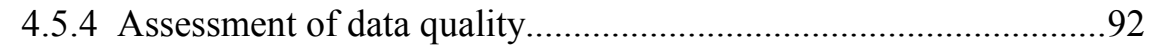

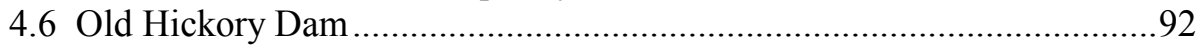

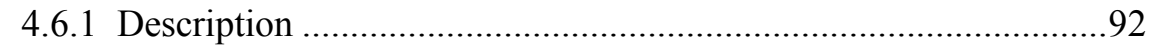

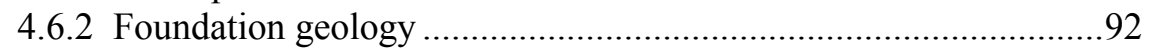

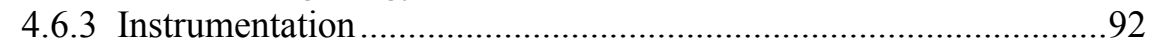

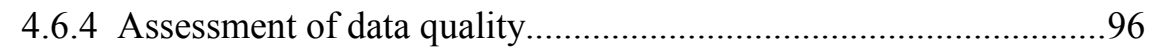

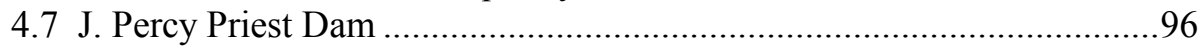

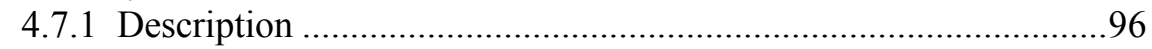

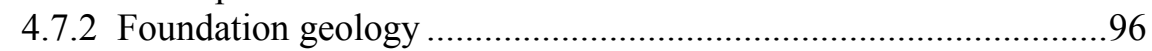

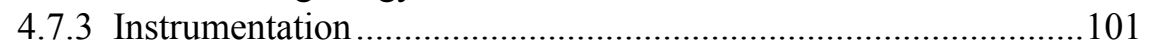




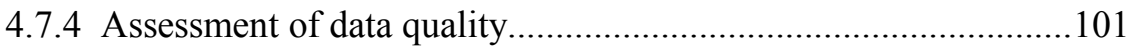

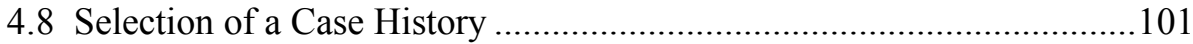

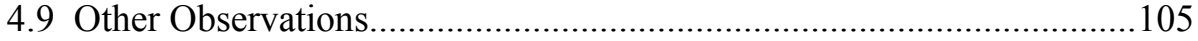

5-Hydraulic Properties of Jointed Rock from Pressure Tests at Libby Dam ....107

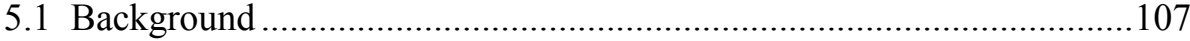

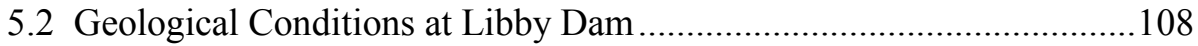

5.3 Computation of Equivalent Hydraulic Conductivity …........................111

5.3.1 Principles and assumptions...................................................111

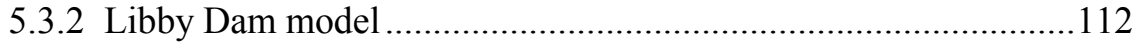

5.3.3 Pressure tests versus pumping tests ............................................119

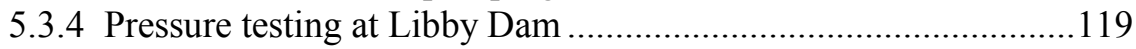

5.3.5 Results for Libby Dam model ......................................................121

5.4 Computation of Parallel Plate Aperture and Joint Hydraulic

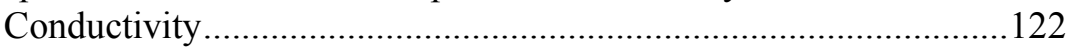

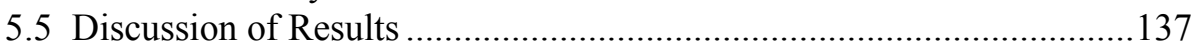

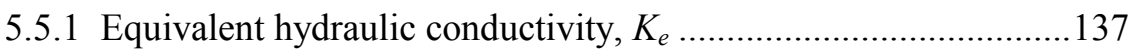

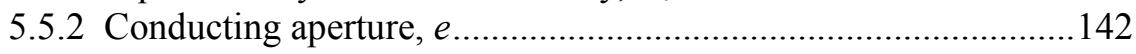

6-Analysis of Uplift Pressures at Libby Dam ................................................147

6.1 Calculation of Uplift Pressures from Gauge Readings ........................149

6.2 Variation of Uplift Pressure with Time ................................................150

6.3 Variation in Uplift Pressure Within the Foundation.............................162

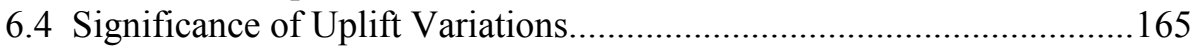

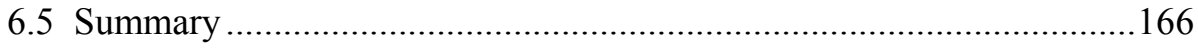

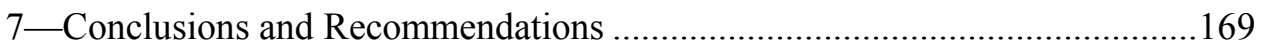

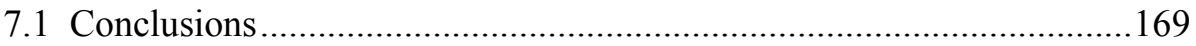

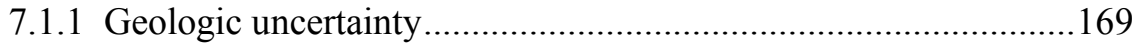

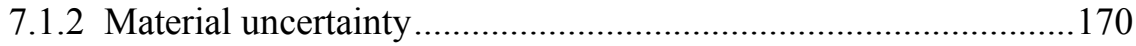

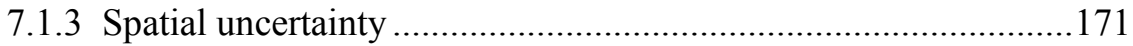

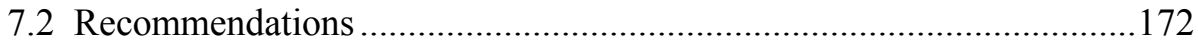

7.2.1 Geologic data for uplift modeling ............................................172

7.2.2 Additional research exercise for existing dams...........................175

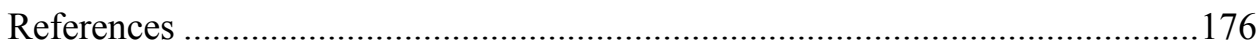

Appendix A: Explanation of Snow's Equation for Flow Through Fractures ......A1

Appendix B: Derivation of Darcy's Equation of Radial Flow to a Borehole

(Equation 2.11) ................................................................................... $\mathrm{B} 1$

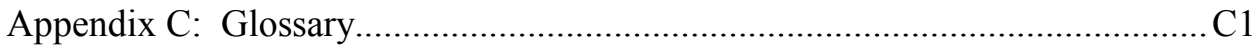

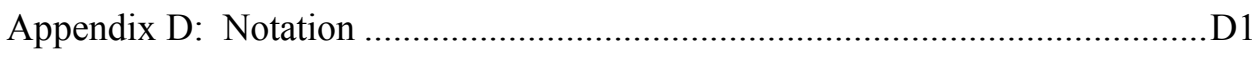

SF 298 


\section{List of Figures}

Figure 2.1. Distribution of uplift pressures in dam foundation for uniform hydraulic conductivity in a porous medium. 5

Figure 2.2. Natural rock joint with mechanical aperture $E$ and equivalent parallel plates with conducting aperture $e$. 6

Figure 2.3. Distribution of uplift pressure in (a) joint of uniform aperture, (b) two-joint network, and (c) tapered joint

Figure 2.4. Nonlinear response of uplift pressure (as head) to rising reservoir headwater at six positions along a continuous joint of uniform aperture.

Figure 2.5. Variation in uplift pressure (head) along (a) uniform, (b) tapered heel to toe, and (c) tapered toe to heel. $e$ is joint aperture....

Figure 2.6. Variation in uplift pressure with changes in joint hydraulic conductivity (changes in joint aperture) with rising reservoir levels at a point in a dam foundation

Figure 2.7. Hyperbolic model for joint deformation ...................................12

Figure 2.8. Empirical curves relating mechanical aperture $(E)$, conducting aperture $(e)$, and joint roughness coefficient

Figure 2.9. Range of validity of Darcy's law

Figure 3.1. Distribution of major categories of rock in the conterminous United States

Figure 3.2. Volcanic and metamorphic rocks in the United States .28

Figure 3.3. Geologic map of wall of excavation for Block 21, foundation of Green Peter Dam

Figure 3.4. Relations between geologic structure in abutment of Malpasset Dam and arch.

Figure 3.5. Geologic section along axis of Red Rock Dam, looking upstream

Figure 3.6. (a) Joint orientation or attitude defined by strike and dip of joint plane (shaded). (b) Joint system consisting of joint sets 1 and 2

Figure 3.7. Results of finite element joint orientation study 41 
Figure 3.8. Relationship of fluid conductivity to the distribution of open fractures in a rock mass

Figure 3.9. Influence of joint length on uplift pressure distribution

Figure 3.10. Influence of relative joint aperture and joint inter-

connectivity on uplift pressure distribution .45

Figure 4.1. Libby Dam, plan and view looking upstream ............................58

Figure 4.2. Libby Dam, upstream gallery longitudinal section ....................60

Figure 4.3. View upstream of part of upstream grout/drainage gallery, Libby Dam.

Figure 4.4. Total head recorded on Gauge P23R1 versus forebay reading, 1989, Libby Dam .62

Figure 4.5. Readings for 6 years from Gauge P23C1, Libby Dam................63

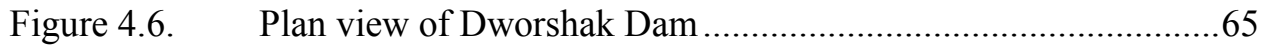

Figure 4.7. Elevation of Dworshak Dam, looking upstream ........................66

Figure 4.8. Section through Dworshak Dam at station $25+40$...................67

Figure 4.9. Plan of exploration borings for Dworshak Dam (March 1971) .68

Figure 4.10. Locations of uplift gauges, Dworshak Dam...............................70

Figure 4.11. Detail of instrumentation, monoliths 23 and 25,

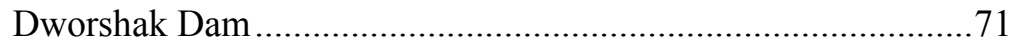

Figure 4.12. Forebay level versus Gauge P23X reading, Dworshak

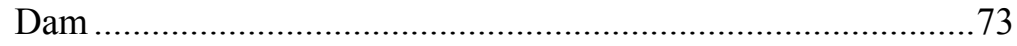

Figure 4.13. Forebay level versus Gauge P230 reading, Dworshak

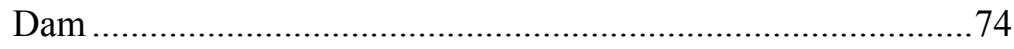

Figure 4.14. Forebay level versus Gauge P230 reading, 1987,

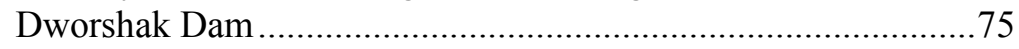

Figure 4.15. Plan of Green Peter Dam ...................................................... 76

Figure 4.16. Sections through Green Peter Dam............................................77

Figure 4.17. Plan of Green Peter Dam showing locations of borings

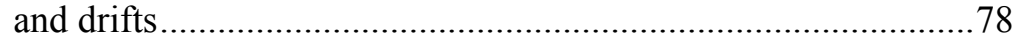

Figure 4.18. Goelogic section along base line, Green Peter Dam ...................79

Figure 4.19. Locations of pressure measurement instruments, Green

Peter Dam .81

Figure 4.20. Plan view of Detroit Dam .82 
Figure 4.21. Elevation view of Detroit Dam ..............................................83

Figure 4.22. Sections through Detroit Dam ..................................................84

Figure 4.23. Locations of piezometers, Detroit Dam ....................................85

Figure 4.24. Details of instrumentation at Detroit Dam ................................87

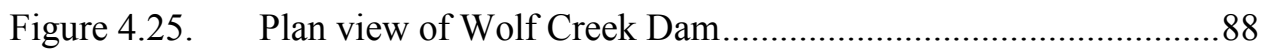

Figure 4.26. Sections through Wolf Creek Dam ...........................................89

Figure 4.27. Boring locations, Wolf Creek Dam..........................................90

Figure 4.28. Uplift cells in Wolf Creek Dam.................................................91

Figure 4.29. Plan and section of Old Hickory Dam .....................................93

Figure 4.30. Boring locations, Old Hickory Dam ........................................94

Figure 4.31. Uplift instruments in Old Hickory Dam ...................................95

Figure 4.32. Plan and section of J. Percy Priest Dam....................................97

Figure 4.33. Sections through concrete portion of J. Percy Priest Dam ..........98

Figure 4.34. Locations of borings, J. Percy Priest Dam ................................99

Figure 4.35. Geologic section, foundation of J. Percy Priest Dam.................100

Figure 3.36. Geologic section along axis of J. Percy Priest Dam ..................102

Figure 4.37. Locations of piezometers and uplift gauges, J. Percy

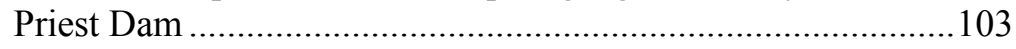

Figure 4.38. Plan view of J. Percy Priest Dam showing locations of

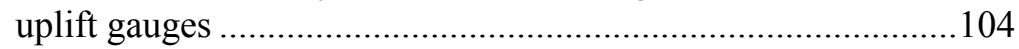

Figure 5.1. Location of Libby Dam, Kootenai River, Montana ..................109

Figure 5.2. Mapped discontinuities on foundation floor, monoliths 22, 23, and 24, Libby Dam ....................................................110

Figure 5.3. Schematic of borehole pressure tests, Libby Dam ....................114

Figure 5.4. Locations of boreholes, monolith 23 area, Libby Dam ..............120

Figure 5.5. Summary log of boring D-92, monolith 23 area, Libby Dam ...121

Figure 5.6. Summary log of boring D-93, monolith 23 area, Libby Dam ...122

Figure 5.7. Summary log of boring D-94, monolith 23 area, Libby Dam ...123

Figure 5.8. Summary log of boring D-125, monolith 23 area, Libby

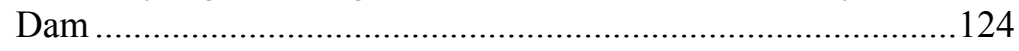

Figure 5.9. Summary log of boring D-126, monolith 23 area, Libby

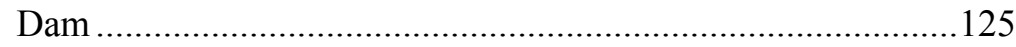


Figure 5.10. Summary log of boring D-184A, monolith 23 area, Libby

Dam.

Figure 5.11. Summary log of boring D-188, monolith 23 area, Libby

Dam

Figure 5.12. Summary log of boring D-278, monolith 23 area, Libby

Dam

Figure 5.13. Equivalent hydraulic conductivity, number of joints per

test interval, equivalent joint aperture, and equivalent

joint hydraulic conductivity, borehole D-92, monolith 23,

Libby Dam

Figure 5.14. Equivalent hydraulic conductivity, number of joints per

test interval, equivalent joint aperture, and equivalent

joint hydraulic conductivity, borehole D-93, monolith 23,

Libby Dam

Figure 5.15. Equivalent hydraulic conductivity, number of joints per

test interval, equivalent joint aperture, and equivalent

joint hydraulic conductivity, borehole D-94, monolith 23,

Libby Dam

Figure 5.16. Equivalent hydraulic conductivity, number of joints per test interval, equivalent joint aperture, and equivalent joint hydraulic conductivity, borehole D-125, monolith 23, Libby Dam.

Figure 5.17. Equivalent hydraulic conductivity, number of joints per test interval, equivalent joint aperture, and equivalent joint hydraulic conductivity, borehole D-126, monolith 23, Libby Dam.

Figure 5.18. Equivalent hydraulic conductivity, number of joints per test interval, equivalent joint aperture, and equivalent joint hydraulic conductivity, borehole D-184A, monolith 23, Libby Dam.

Figure 5.19. Equivalent hydraulic conductivity, number of joints per test interval, equivalent joint aperture, and equivalent joint hydraulic conductivity, borehole D-188, monolith 23, Libby Dam.

Figure 5.20. Equivalent hydraulic conductivity, number of joints per test interval, equivalent joint aperture, and equivalent joint hydraulic conductivity, borehole D-278, monolith 23, Libby Dam.

Figure 5.21. Variation in equivalent hydraulic conductivity with elevation in nine boreholes near monolith 23. From foundation pressure tests, Libby Dam. 138 
Figure 5.22. Geologic cross section through foundation of monolith 23, Libby Dam.

Figure 5.23. Relationship of equivalent hydraulic conductivity $\left(K_{e}\right)$ of pressure-tested zones to difference (range) in $K_{e}$ for test pairs, Libby Dam

Figure 5.24. Joint conducting aperture, $e$, versus elevation, Libby

Dam monolith 23

Figure 5.25. Joint conducting aperture, $e$, versus depth below top of rock, Libby Dam monolith 23 .... 144

Figure 5.26. Average rock fracture openings (in microns) versus depth below overburden (top of rock) at dam sites. 145

Figure 6.1. Instrument and drain locations, monolith 23, Libby Dam 148

Figure 6.2. Upstream grout and drainage gallery, monolith 23, Libby Dam, looking upstream.

Figure 6.3. Downstream drainage gallery, monolith 23, Libby Dam, looking upstream

Figure 6.4. Detail of uplift cell and installation, Libby Dam 151

Figure 6.5. Uplift pressure at monolith 23, Libby Dam, L1-5, 19811990 152

Figure 6.6. Uplift pressure at monolith 23, Libby Dam, L1-5, 19911999 153

Figure 6.7. Uplift pressure at monolith 23, Libby Dam, C1-4, 19811990 154

Figure 6.8. Uplift pressure at monolith 23, Libby Dam, C1-4, 19911999 155

Figure 6.9. Uplift pressure at monolith 23, Libby Dam, C5-8, 19811990 156

Figure 6.10. Uplift pressure at monolith 23, Libby Dam, C5-8, 19911999

Figure 6.11. Uplift pressure at monolith 23, Libby Dam, R1-5, 19811990 158

Figure 6.12. Uplift pressure at monolith 23, Libby Dam, R1-5, 19911999

Figure 6.13. Uplift pressure at monolith 23, Libby Dam, for calendar year 1990 
Figure 6.14. Plot of dependence of L1, C1, and R1 (in ft) on forebay elevation (ft), monolith 23, Libby Dam, for calendar year 1999

Figure 6.15. Recorded uplift pressures in 1990 versus design pressures, monolith 23, Libby Dam.

Figure 6.16. Recorded uplift pressures in 1999 versus design pressures, monolith 23, Libby Dam. 164

Figure 6.17. Section through drains, monolith 23, Libby Dam 167

Figure 6.18. Effect of drains on piezometric surface (idealized). 168

Figure 7.1. Recommended four-step approach to modeling of uplift pressures in rock foundations

Figure A.1. Snow's solid of dimensions $W$, broken by parallel plane fractures

\section{List of Tables}

Table 2.1 Classifications of Mechanical Aperture ..........................................

Table 3.1 A Classification of the Common Igneous Rocks ......................27

Table 3.2 Classification of Degree of Weathering of Rocks.......................36

Table 3.3 Material Filling Discontinuities and Associated Problems .........42

Table 3.4 Popular Diamond Core Bit Core and Hole Diameters ................49

Table $3.5 \quad$ In Situ Tests for Rock and Soil .............................................52

Table 3.6 Laboratory Classification and Index Tests for Rock...................53

Table $3.7 \quad$ Instruments for Measuring Piezometric Pressure ........................54

Table 4.1 Summary of Uplift Data Assessment ........................................105

Table 5.1 Estimates of Borehole Interval and Joint Hydraulic

Properties from Borehole Pressure Tests, Monolith 23,

Libby Dam 115

Table 5.2 Statistical Information on Computed Values of Equivalent Aperture, $e$ 142

Table 6.1 Pressure Observations in 1990 and 1999 165 


\section{Preface}

This report describes an analysis of geologic factors affecting uncertainty in the prediction and modeling of uplift beneath concrete gravity dams. This study was conducted by the Geotechnical and Structures Laboratory (GSL) and the Information Technology Laboratory (ITL), Vicksburg, MS, U.S. Army Engineer Research and Development Center (ERDC), in support of Work Unit 6 (Uplift Uncertainty and Probabilistic Models) of the Risk Analysis for Dam Safety Program, Mr. H. Wayne Jones, ITL, Program Manager.

Dr. Robert M. Ebeling, ITL, was principal investigator for the work unit. The report was prepared and written by Messrs. William L. Murphy and John M. Andersen, GSL, and Dr. Ebeling. Mr. Timothy D. Ables was Acting Director, ITL, and Dr. Michael J. O'Connor was Director, GSL, during the conduct of this study.

The authors acknowledge the assistance of the following Corps District and Division personnel in providing data and guidance for this study: Lawrence Mann, Steve Meyerholtz, Richard Garrison, Rick Eckerlin, and Lola Schiefelbein, U.S. Army Engineer District, Seattle; Michelle LeFlore, U.S. Army Engineer District, Walla Walla; James Griffiths, U.S. Army Engineer District, Portland; James Gunnels and Jody (John) Stanton, U.S. Army Engineer District, Nashville; and Dale Munger, U.S. Army Engineer Division, Northwestern. Thanks also to Vickie Parrish and Gloria Naylor, Computer-Aided Engineering Division, ITL, for their assistance with report illustrations.

At the time of publication of this report, Dr. James R. Houston was Director of ERDC, and COL John W. Morris III, EN, was Commander and Executive Director.

The contents of this report are not to be used for advertising, publication, or promotional purposes. Citation of trade names does not constitute an official endorsement or approval of the use of such commercial products. 


\section{Conversion Factors, Non-SI to SI Units of Measurement}

Non-SI units of measurement used in this report can be converted to SI units as follows:

\begin{tabular}{|l|c|l||}
\hline Multiply & By & To Obtain \\
\hline \hline cubic feet & 0.02832 & cubic meters \\
\hline cubic feet per minute & 28.312 & liters per minute \\
\hline degrees & 0.01745 & radians \\
\hline feet & 0.3048 & meters \\
\hline inches & 2.54 & centimeters \\
\hline inches & 25.4 & mm \\
\hline inches & 25,400 & microns \\
\hline mile & 1.609 & kilometer \\
\hline pounds (force) per cubic foot & 157.08767 & newtons per cubic meter \\
\hline pounds (force) per square foot & 47.88026 & pascals \\
\hline pounds (force) per square inch & 6894.757 & pascals \\
\hline square feet & 0.0929 & square meters \\
\hline square inches & 0.00064516 & square meters \\
\hline \hline
\end{tabular}




\section{Introduction}

\subsection{Background}

Uplift is one of the major forces affecting the stability of rock-founded concrete dams. Stability problems associated with uplift can occur for many reasons. For example, problems often arise during the determination of magnitude and distribution of uplift pressures and corresponding uplift force within foundations in heterogeneous rock that contains discrete rock discontinuities. Another problem is that it is often difficult to extrapolate distributions of uplift pressures within the rock foundation to reservoir levels above the pool of record. A third example of problems related to uplift is that if the drains are not maintained over time, their ability to dissipate uplift pressures diminishes. Consequently, the reliability of the dam deteriorates with time even if the pool elevation is held constant.

Uplift pressures are controlled by the flow regime within the rock foundation. The flow regime is a function of site-specific geology. Both the geological interpretation and the analytical procedures used to calculate flow within the foundation introduce uncertainties into the calculation of uplift pressures. A risk assessment of a dam must account for uncertainties in all factors that impact the computation of uplift pressures. Currently no methodologies and corresponding analytical procedures are available for assessing all of the uncertainties in computed uplift pressures in a risk assessment of rock-founded concrete gravity dams.

The goal of research in uplift uncertainty and probabilistic modeling is to develop a methodology, analytical procedures, and software for the assessment of uplift pressures and forces within rock foundations for use in the assessment of the reliability of rock-founded concrete gravity dams. Uncertainties in the geology, the flow regimes, and the flow models are to be included in the statistical and probabilistic mathematical uplift model.

Uncertainty in modeling of uplift pressure in rock foundations manifests itself in three areas: geologic uncertainty, material uncertainty, and spatial uncertainty. Geologic uncertainty arises in describing and mapping the stratigraphy, the geologic structure, and the degree of weathering characterizing a foundation. Material uncertainty pertains primarily to estimates or measurements of rock mass hydraulic conductivity, particularly from field-test-derived data. Spatial uncertainty is represented in the ways properties vary throughout the foundation and beyond and between sampling points. 


\subsection{Purpose}

The objectives of the study documented in this report were (1) to identify and characterize geological factors affecting the prediction and modeling of flow and the development of uplift pressures in rock foundations beneath concrete dams; (2) to identify the degree and kinds of uncertainty in uplift prediction resulting from geological investigations of dam foundations, particularly in the description, testing, and quantification of rock discontinuities; and (3) to select a case history for assessing the uncertainties associated with geological and uplift analysis of the foundation of a large concrete dam. This report lays the groundwork for the development of a systematic characterization of foundation geology in the context of development of flow models to predict foundation uplift pressures. Numerical flow modeling will permit prediction of uplift pressures over time and the extrapolation of uplift pressures to levels above the pool of record. 


\section{Principles of Flow in Jointed Media}

\subsection{Groundwater Flow and Uplift Pressure in Discontinuous Rock}

\subsubsection{Analytical methods in uplift prediction}

Uplift is a major force affecting the stability of concrete gravity dams founded on rock. Uplift forces decrease the resistance of the dam to sliding. There are several problems associated with analysis of uplift and its effects on dam stability. Problems arise when trying to determine the magnitude and distribution of uplift pressures and resultant uplift forces in foundations that are heterogeneous and that have discrete rock discontinuities ${ }^{1}$ (e.g., joints, faults, and bedding planes). Another problem is extrapolating foundation uplift pressures to pools above the pool of record. Stability problems arise if drains are not maintained, because the ability of drains to dissipate uplift pressures diminishes with time. Similarly, discontinuities may close and become less permeable with time as rising pool levels compress the foundation, resulting in higher uplift pressures. Nonuniform stresses imposed by the dam may differentially deform discontinuities, resulting in tapered joints with varying apertures and variable distribution of uplift pressures.

Conventional equilibrium methods of analysis of the stability of gravity dams involve assumptions regarding the loading and resisting forces that act on a dam. Analyses of loading and resisting forces consider the magnitude and distribution of uplift pressures and effective compressive stresses, respectively, acting normal to the base of the dam (Pace and Ebeling 1998). Uplift pressure is pore pressure, defined at any point in the foundation as the unit weight of water $\left(\gamma_{w}\right)$ times the depth below the piezometric surface. Pore pressure reduces the effective stress on potential failure planes, such as the base of a gravity dam situated on rock, and thereby lowers the resistance to shear failure along a plane. The relationship is shown mathematically in the familiar expression: ${ }^{2}$

1 Throughout this report, for brevity, the term joint or jointed is substituted for the more general term discontinuity or discontinuous. In many cases, joints are the proper and intended reference. It should be understood, however, that other discontinuities, including bedding planes, shears, etc., are equally pertinent.

2 For convenience, symbols and unusual abbreviations are listed and defined in the Notation (Appendix D). Engineering and hydraulic terms are defined in the Glossary (Appendix C). 
$\tau=c+(\sigma-u) \tan \varphi$

where

$\tau=$ the shear strength, or shear stress required to cause sliding along a plane

$c=$ cohesion of the rock/rock or concrete/rock interface

$\sigma=$ the normal stress component of load on the plane

$u=$ the pore (uplift) pressure produced by the head of groundwater

$\varphi=$ the angle of internal friction along the potential failure plane

The term $(\sigma-u)$ is the effective stress on the plane resulting from the reduction in normal stress by the pore, or uplift, pressure. In rock foundations, uplift pressures commonly develop in discrete discontinuities within the rock mass.

Following Stone and Webster Engineering Corporation (1992), uplift pressures can be reported as equivalent piezometric head in feet of water (gauge pressure in psi, times $2.31 \mathrm{ft}^{1}$ of water per psi, plus the elevation of the gauge). Reporting uplift pressures as piezometric head allows comparison directly with reservoir (headwater) and tailwater elevations. Uplift pressures are controlled by the flow regime within the rock foundation. The flow regime is a function of sitespecific geology, especially the distribution and geometry of the discontinuities through which groundwater flows. Both the geological interpretation of foundation conditions and the analytical procedures used to calculate flow within the foundation introduce uncertainty into the prediction of uplift pressures.

Grenoble et al. (1995) studied the influence of deformation of discontinuities on uplift pressures in concrete gravity dams (also in Stone and Webster Engineering Corporation (1992), for the Electric Power Research Institute (EPRI)). They state that stability calculations often assume that the rock mass behaves like a porous medium and that foundation uplift pressure is distributed linearly from the upstream face of the dam (or from the position of the drains) to the toe (Figure 2.1$)^{2}$. In considerations of flow and developed uplift pressures, the foundation rock mass cannot be treated as a porous medium unless the joint spacing is so small that the rock is effectively a continuum. In jointed rock masses, the distribution of uplift pressure is controlled by the geometry and hydraulic conductivity of the intersecting joints that make up the flow paths beneath the dam.

\subsubsection{Joint aperture and uplift pressure distribution}

Flow through a joint (or a pipe) is a function of the aperture (size of the opening) and joint roughness. Joint aperture, discussed further in Chapter 3 of this report, can be measured in the field with techniques such as borehole camera surveys. Aperture determines the effective porosity and hydraulic conductivity of

\footnotetext{
1 A table of factors for converting non-SI units of measurement to metric (SI) units is found on page xiii.

2 Non-site-specific uplift pressure distribution used in the design and analysis of Corps dams is given in EM 1110-2-2200 and discussed in Ebeling et al. (2000).
} 


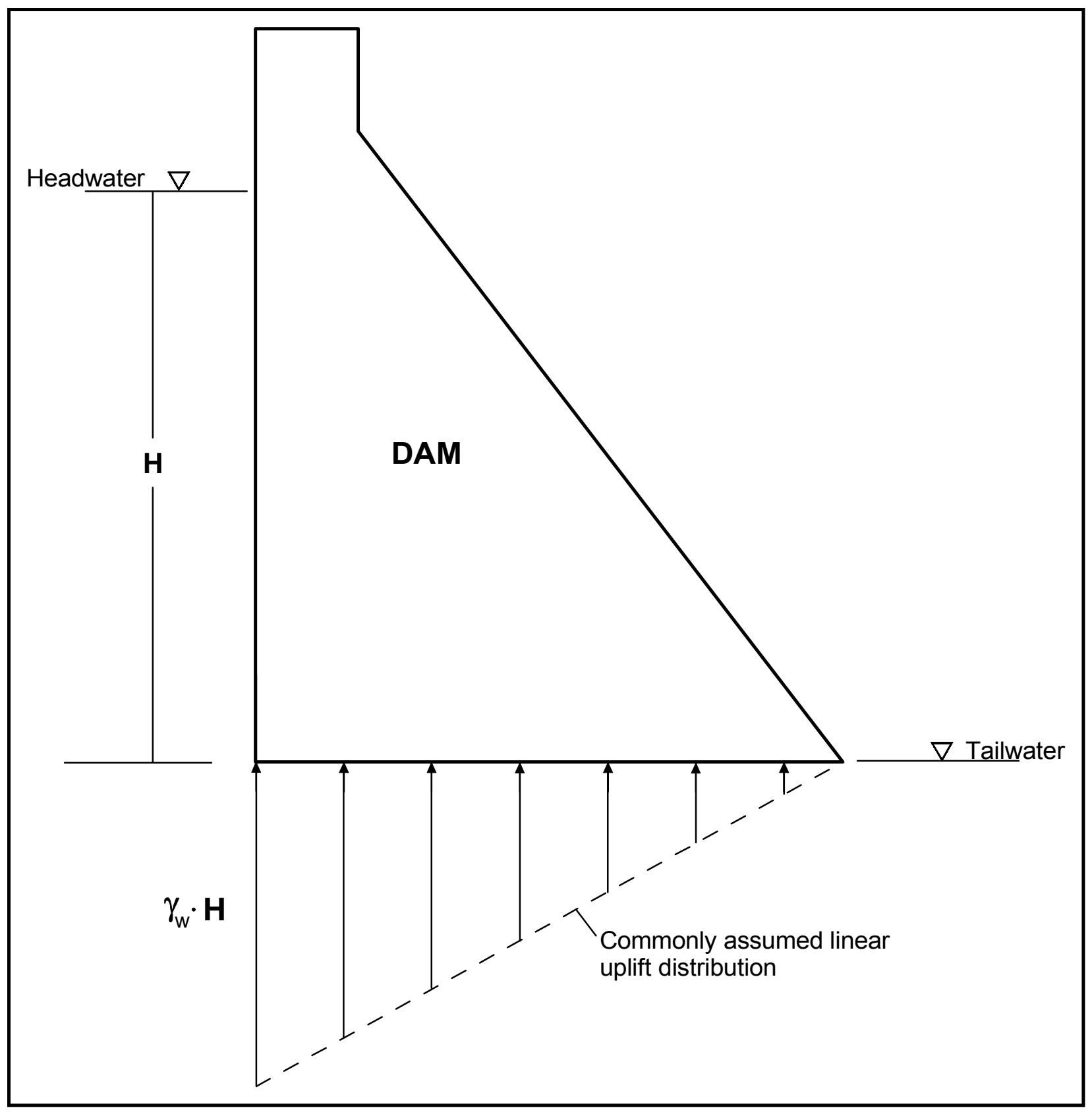

Figure 2.1. Distribution of uplift pressures in dam foundation for uniform hydraulic conductivity in a porous medium (after Ebeling, Pace, and Morrison 1997)

a jointed rock mass and ultimately affects the distribution of uplift pressure beneath a dam. Field measurements of rock joints provide what is known as a mechanical aperture (Barton, Bandis, and Bakhtar 1985). A mechanical aperture has a degree of asperity, or roughness, manifested by irregularities or undulations on its surface. Joint roughness affects the flow of water through the joint. Mathematical simulation of flow through the joint requires that the mechanical joint aperture be reduced to a pair of smooth parallel plates, or a conducting aperture, for computations of laminar flow and hydraulic conductivity. The mechanical aperture is designated $E$ and the equivalent, or conducting, aperture is designated 
$e$. The conducting aperture is the distance between two smooth, parallel plates that would allow the same flow as a mechanical (joint) aperture with rough walls. Conducting aperture $e$ is always smaller than mechanical aperture $E$ except in the case of smooth-walled joints. Figure 2.2 illustrates the concept. Mechanical aperture is measured directly from a rock sample or, in the field, on exposed joints. Conducting aperture is estimated from permeability or pressure tests.

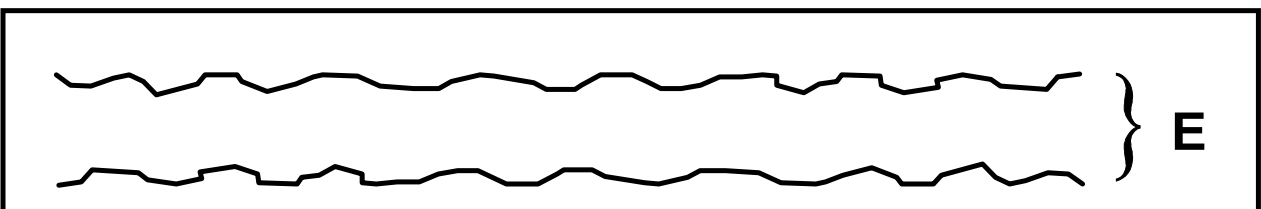

Rough, natural joint with mechanical aperture $E$

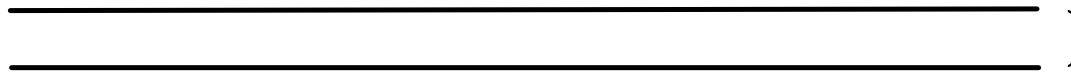

Smooth, parallel plates with conducting aperture e $<E$

Figure 2.2. Natural rock joint with mechanical aperture $E$ and equivalent parallel plates with conducting aperture $e$ (not to scale).

The terms open and tight joints or discontinuities will be used often in this report. Snow (1968) defined open fractures as those having apertures of $35 \mu \mathrm{m}$ $(0.35 \mathrm{~mm})$ or greater. His apertures were apparently equivalent, smooth-walled, conducting apertures computed from borehole pressure tests. Bieniawski (1979), for his Rock Mass Rating System for tunnel design, considered joints open at mechanical apertures of 2,500 $\mu \mathrm{m}(2.5 \mathrm{~mm})$ or greater. International Society for Rock Mechanics (ISRM) (1978), proposing discontinuity descriptors for rock mass classification, defined open joints as those with mechanical apertures of $500 \mu \mathrm{m}(0.5 \mathrm{~mm})$ or greater. Ebeling, Pace, and Morrison (1997) adopted a mechanical aperture of $250 \mu \mathrm{m}(0.25 \mathrm{~mm})$ as the lower limit of open joints from work reported in Lee and Farmer (1993), who used data from Barton (1973). Headquarters, U.S. Army Corps of Engineers (1994), applied a similar classification scheme to discontinuities in his discussion of rock mass characterization for rock foundations. Table 2.1 shows the aperture classification used by Lee and Farmer (1993) (and Ebeling, Pace, and Morrison 1997) and by Nicholson. The relative importance of mechanical and conducting apertures to flow modeling and prediction is discussed further in this chapter and in Chapter 5. Following work by 


\begin{tabular}{|c|c|}
\hline \multicolumn{2}{|c|}{$\begin{array}{l}\text { Table } 2.1 \\
\text { Classifications of Mechanical Aperture of Ebeling, Pace, and } \\
\text { Morrison (1997) after Lee and Farmer (1993) and Barton (1973) }\end{array}$} \\
\hline Mechanical Aperture, $\mathrm{mm}(\mu \mathrm{m})^{1}$ & Class \\
\hline$<0.1(<100)$ & Very tight \\
\hline $0.10-0.25(100-250)$ & Tight \\
\hline $0.25-0.50(250-500)$ & Partly open \\
\hline $0.50-2.50(500-2,500)$ & Open \\
\hline $2.50-10.0(2,500-10,000)$ & Moderately wide \\
\hline$>10(>10,000)$ & Wide \\
\hline \multicolumn{2}{|c|}{$\begin{array}{l}\text { Mechanical aperture classification of Nicholson (after Headquarters, U.S. Army Corps of } \\
\text { Engineers, 1994): } \\
\text { (1) Very tight: separations of less than } 0.1 \mathrm{~mm}(<100 \mu \mathrm{m}) \text {. } \\
\text { (2) Tight: separations between } 0.1 \text { and } 0.5 \mathrm{~mm}(100 \mu \mathrm{m} \text { and } 500 \mu \mathrm{m}) \text {. } \\
\text { (3) Moderately open: separations between } 0.5 \text { and } 2.5 \mathrm{~mm}(500 \mu \mathrm{m} \text { and } 2,500 \mu \mathrm{m}) \text {. } \\
\text { (4) Open: separations between } 2.5 \text { and } 10 \mathrm{~mm}(2,500 \mu \mathrm{m} \text { and } 10,000 \mu \mathrm{m}) . \\
\text { (5) Very wide: separations between } 10 \text { and } 25 \mathrm{~mm} 10,000 \mu \mathrm{m} \text { and } 25,000 \mu \mathrm{m} \text {. }\end{array}$} \\
\hline
\end{tabular}

Ebeling and others, a tight joint in this report is assumed to be one with a mechanical aperture less than about $250 \mu \mathrm{m}(0.25 \mathrm{~mm})$.

Grenoble et al. (1995) simulated foundation loading using finite element analysis and measured uplift pressures on 17 dams over a period of a year. Their studies showed that rising reservoir levels differentially deformed discontinuities in the foundation and caused the hydraulic conductivity in rock joints to increase at the heel and to decrease at the toe, a condition simulated by a tapered joint. If the hydraulic conductivity does not change, the uplift pressure beneath the dam is linearly proportional to the headwater pressure (reservoir level). However, if joint hydraulic conductivity changes because of induced joint deformations (i.e., the taper of the joint changes with rising reservoir levels), the relationship between uplift pressure and headwater pressure is nonlinear. The next several paragraphs discuss the relationship of uplift pressure with reservoir loading. Note that one relationship is the variation in uplift pressure with distance along the dam base, and the other is the variation in uplift pressure at a point within the foundation as headwater pressure changes.

Change in aperture in the direction of flow causes uplift pressure to follow a curved rather than a linear distribution. Figure 2.3a shows the linear pressure distribution within a joint of constant aperture from the heel to the toe of a dam. Figure $2.3 \mathrm{~b}$ shows the pressure distribution in a joint network represented by a large-aperture pipe and a small-aperture pipe. Most of the pressure loss occurs in the smaller pipe because of high frictional losses. The result is, in effect, a nonlinear pressure distribution between the heel and toe. Figure $2.3 \mathrm{c}$ shows the analogy extended to nonlinear pressure distribution for a tapered joint, for which the aperture changes (steps down) continuously from the heel to the toe.

Changes in loading of the dam foundation, for example by rising reservoir levels, can decrease joint aperture near the toe and increase joint aperture near the heel. Pressure against the upstream face of the dam tilts the dam. Deformation of 


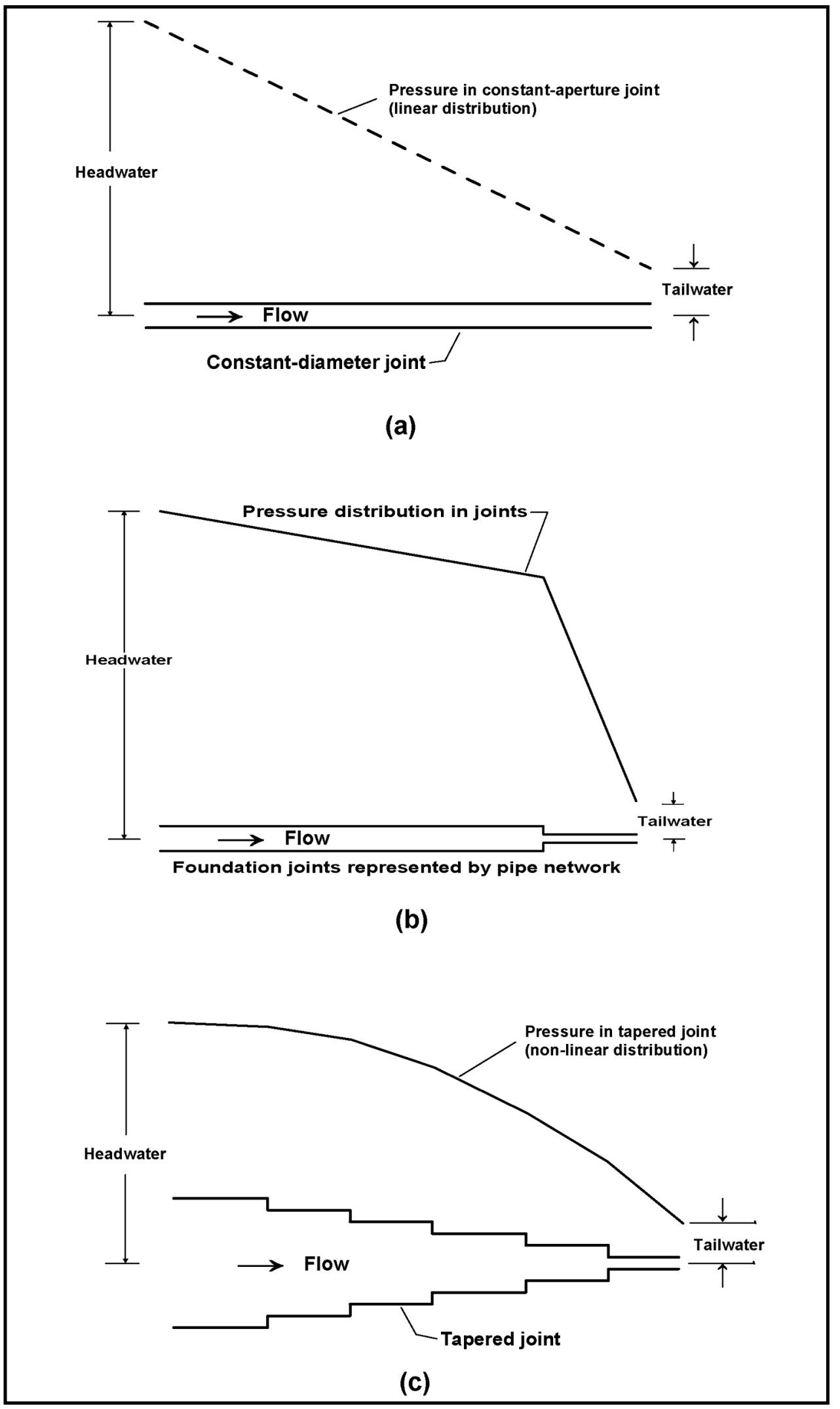

Figure 2.3. Distribution of uplift pressure in (a) joint of uniform aperture, (b) twojoint network, and (c) tapered joint (after Grenoble et al. 1995) 
joints affects the hydraulic conductivity and the uplift pressures that develop in the dam foundation. Ebeling and Pace (1996b) and Pace and Ebeling (1998) investigated the effect of foundation loading (increasing pool elevation) on uplift pressures using finite element modeling. In their model, they varied the pool elevation, which resulted in changes in stresses on foundation joints during reservoir loading (and unloading when the pool was lowered). Figure 2.4 shows the nonlinear change in uplift pressure (as head) with rising reservoir (headwater) elevation, measured at six locations along the joint. The nonlinear variation in uplift head with headwater elevation along the joint reflects the changes in aperture with loading and unloading along the joint. The nonlinear response of uplift pressure to reservoir height was obtained in what are considered tight joints, i.e., joints with mechanical apertures less than about $250 \mu \mathrm{m}(0.25 \mathrm{~mm})$. Stone and Webster Engineering Corporation (1992) reported that of 17 dams and locks investigated for uplift stability evaluation, two dams and one lock wall showed a nonlinear response (in gauge readings) of uplift pressure to reservoir elevation changes, eight showed linear responses, and six had insufficient data for a determination.

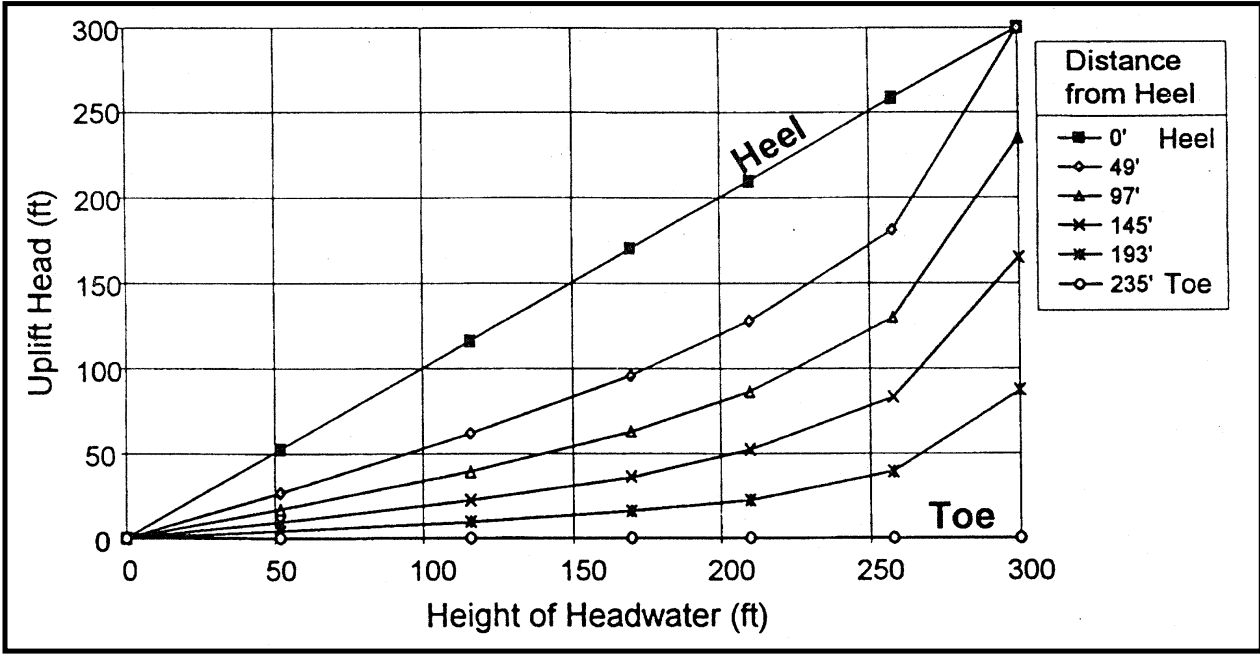

Figure 2.4. Nonlinear response of uplift pressure (as head) to rising reservoir headwater at six positions along a continuous joint of uniform aperture (Ebeling and Pace 1996b)

Ebeling and Pace (1996a) expanded the discussion of the influence of joint aperture by looking at the effect of tapered joints on the distribution of uplift pressure across the base of the dam. The direction of the taper influenced distribution of uplift pressure. A joint of uniform aperture across the base of the dam produced a linear pressure response (Figure 2.5a). A taper with a larger aperture at the heel than at the toe produced an uplift pressure distribution that is greater than the conventional linear assumption (i.e., the pressure increased more rapidly along the length of the dam, Figure 2.5b). A taper with a smaller aperture at the heel than at the toe of a dam produced an uplift pressure distribution that is less than the conventional linear assumption (i.e., the pressure increased more slowly along the length of the dam, Figure 2.5c). 


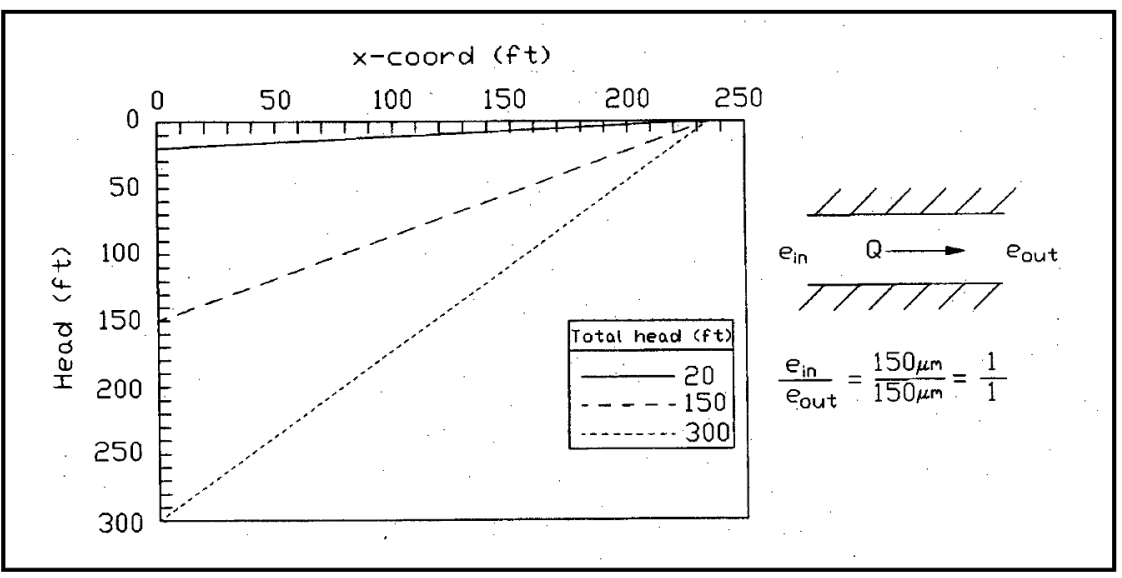

(a)

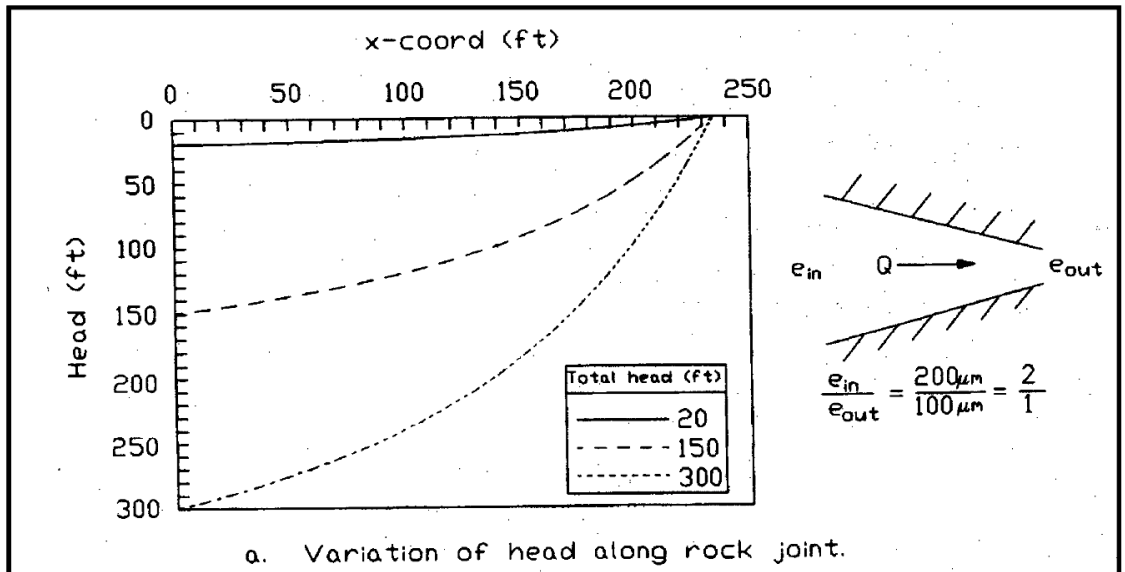

(b)

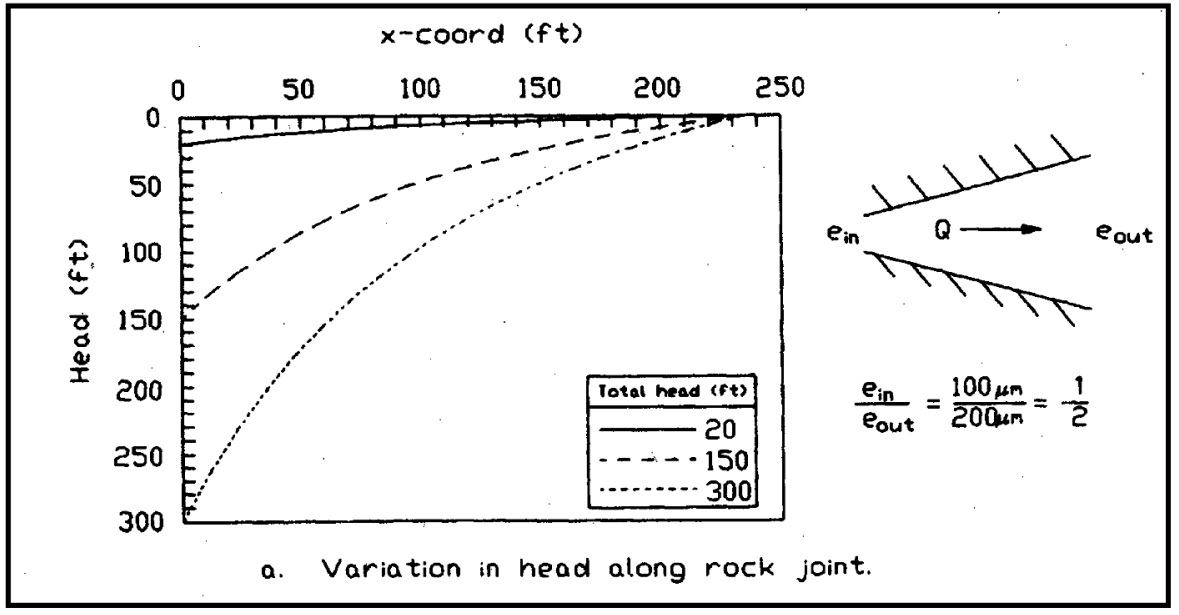

(c)

Figure 2.5. Variation in uplift pressure (head) along (a) uniform, (b) tapered heel to toe, and (c) tapered toe to heel. $e$ is joint aperture (Ebeling and Pace 1996a or Ebeling, Pace, and Morrison 1997) 
Grenoble et al. (1995) illustrated the nonlinearity effect of changing joint taper at a point in the dam foundation as headwater elevations increased (Figure 2.6). If joint taper and hydraulic conductivity do not change, the uplift pressure at a point changes linearly with rising headwaters. If joint taper increases with rising headwater (joint hydraulic conductivity decreases toward the toe), uplift pressure at the point increases nonlinearly.

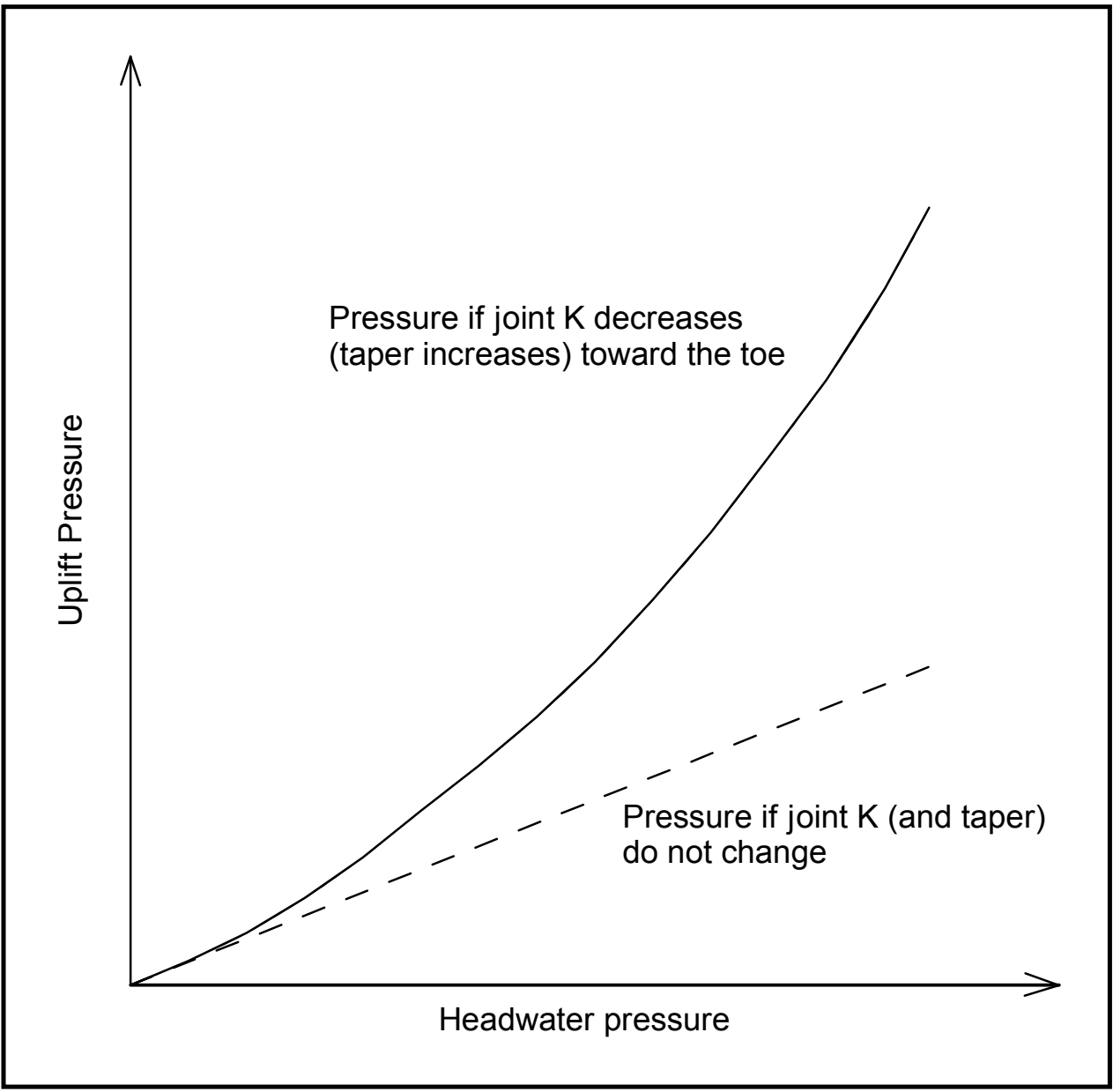

Figure 2.6. Variation in uplift pressure with changes in joint hydraulic conductivity (changes in joint aperture) with rising reservoir levels at a point in a dam foundation (after Grenoble et al. 1995)

Chapter 3 discusses other geological aspects of discontinuities in controlling the distribution of uplift pressure in a dam foundation, including joint aperture, joint length, and joint interconnectivity. Risk assessment of a dam must account for uncertainties in all factors that impact the computation of uplift pressures. To compute realistic deterministic or probabilistic estimates of uplift pressures within a rock foundation, investigative methods must be formulated to permit the development of a realistic fluid flow model for a rock foundation with discontinuities. Stone and Webster Engineering Corporation (1992) provide an excellent evaluation of the effects of geologic conditions on uplift pressure distributions for several existing large concrete gravity dams. 


\subsection{Coupling Phenomena}

Ebeling, Pace, and Morrison (1997) discussed the relationship between uplift pressures developed beneath a dam and the stresses imposed on the foundation by the dam and reservoir. Changes in loading imposed on the rock joints change the joint apertures, which change the hydraulic conductivity of the joints and ultimately the uplift pressures developed in the foundation. Uplift pressures in turn affect the stresses imposed by the structure on the foundation. Uplift pressures developed in the foundation are said to be coupled to the loadings applied by the structure. Uplift pressures are usually nonlinear since the rock joint aperture varies across the width of a structure. A tapered joint will produce a nonlinear uplift pressure distribution, as shown earlier. Coupling phenomena and nonlinearity are applicable in general to tight joints. A mathematical relationship between the deformation of joints and the applied loading (or unloading) has been established from laboratory tests on several different rock types and joints. The deformation of a joint with applied normal stress is commonly referred to as joint closure or joint opening. Bandis (1980) modeled joint deformation as a hyperbolic function applied to jointed rock. Figure 2.7 illustrates Bandis' hyperbolic relationship between normal stress $\left(\sigma_{n}\right)$ and joint closure $\left(V_{j}\right)$.

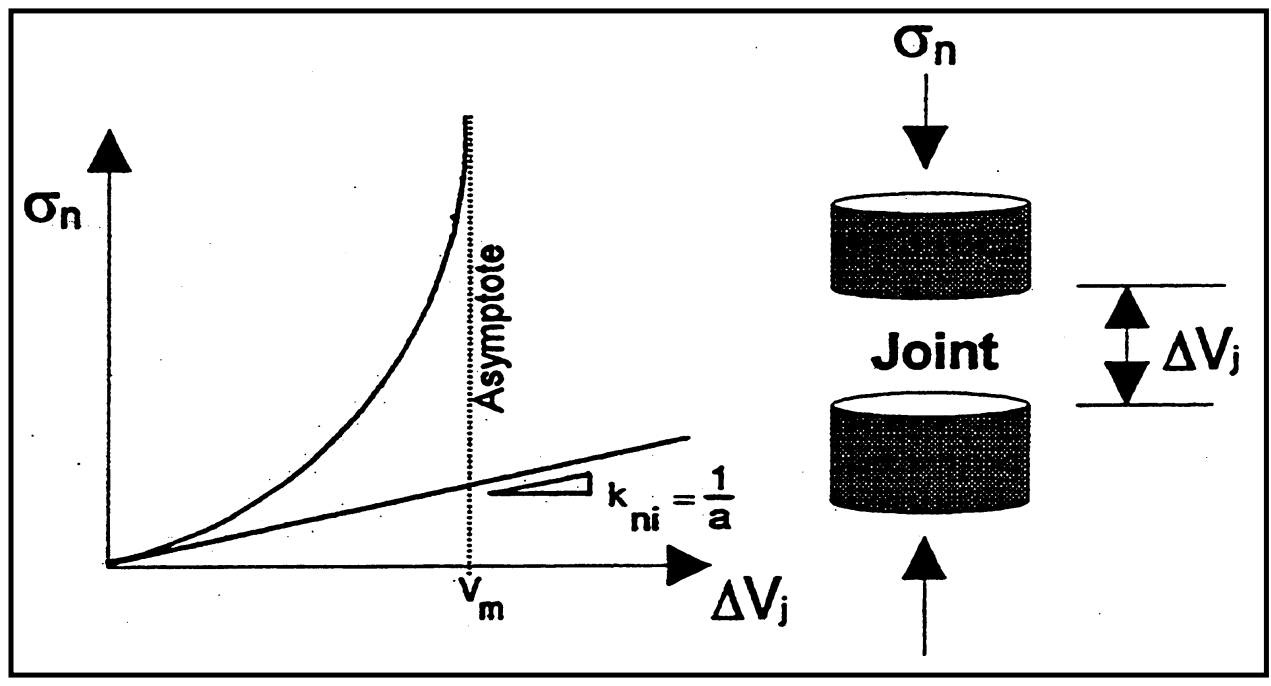

Figure 2.7. Hyperbolic model for joint deformation (Ebeling, Pace, and Morrison 1997, after Bandis 1980). $\sigma_{n}=$ effective normal stress, $\Delta V_{j}=$ joint closure, $V_{m}=$ maximum joint closure

Ebeling, Pace, and Morrison (1997) observed several relationships from Bandis' (1980) joint closure model. The maximum closure (the asymptote, $V_{m}$ ) is generally 0.3 to 0.9 times the average initial joint aperture. Actual contact areas at maximum closure generally range from 40 to 70 percent of the total sample area. The maximum closure for samples with similar initial mechanical aperture depends primarily on the joint wall compressive strength (JCS) of the rock. The maximum closure decreases linearly as the joint roughness coefficient (JRC) increases, irrespective of the JCS. Weathered joints produce larger maximum closure than unweathered because weathered joints usually have larger initial mechanical aperture and lower JCS than unweathered joints. 
Ebeling, Pace, and Morrison (1997, Chapter 5) used a modified version of Bandis' hyperbolic relationship and finite element methods to model the response of dam foundations to reservoir loading. Their work showed that changes in the loading of a dam foundation by raising and lowering the reservoir deformed foundation joints and led to nonlinear changes in developed uplift pressures beneath the dam.

\subsection{Considerations in Assessing Hydraulic Conductivity of Joints}

The preferred method for determining uplift pressures beneath dams is the use of accurate piezometric instrumentation data. When instrumentation data are not available or when the reservoir levels to be analyzed exceed those for which the piezometric measurements were made, other procedures must be used to establish the distribution of flow and the corresponding uplift pressures. One method widely used by engineers to establish uplift pressures along a section within a rock foundation is to compute uplift pressures from flow within rock joints. Ebeling and Pace (1996a) investigated the fundamentals of flow through jointed rock and how the dimensions of rock joints, especially joint aperture, influence computed uplift pressures.

\subsubsection{Permeability and hydraulic conductivity}

Hydraulic conductivity, $K$, is the quantifiable ability of a medium to transmit a fluid under a pressure gradient. Measurements of hydraulic conductivity consider the properties of the fluid and the medium. Hydraulic conductivity has units of velocity (length $L /$ time $T$ ) but is actually a measure of the volume of a fluid flowing through a cross-sectional area per unit of time under a dimensionless hydraulic gradient $\left(L^{3} / L^{2} / T\right)$. Intrinsic permeability, or simply permeability, $k$, is a general term for the ability of a soil or rock to transmit fluid under a hydraulic gradient. Permeability does not consider the properties of the fluid. Permeability has units of length squared $\left(L^{2}\right)$. Previous literature has variably used the terms coefficient of permeability and permeability for hydraulic conductivity. Discussions in this report designate $K$ as hydraulic conductivity and $k$ as permeability, in keeping with recent usage. $K$ (for water) is related to $k$ by the expression

$$
K=k\left(\gamma_{w} / \mu_{w}\right)
$$

where $\gamma_{w}$ and $\mu_{w}$ are the unit weight and dynamic viscosity of water, respectively.

The relationship of hydraulic conductivity to flow rate $(Q)$ in a porous medium was established by Darcy as

$$
Q=K i A
$$

where 
$Q=$ flow rate in volume per unit time

$K=$ hydraulic conductivity of the medium and fluid

$i=$ hydraulic gradient (or $\delta h / \delta l$ for one-dimensional flow, where $\delta h / \delta l$ is

incremental change in head, $h$, over length, $l$ )

$A=$ area across which flow occurs

\subsubsection{Flow in joints: The cubic law}

Using Darcy's law and substituting an open joint for the porous medium, the equation for a single joint may be written (Ebeling and Pace 1996a)

$$
Q=K_{j} \cdot i \cdot A R E A_{\text {flow }}
$$

where $K_{j}$ is the hydraulic conductivity of a single joint, and $A R E A_{\text {flow }}(e$ times unit width) is the area of flow at any position along the joint. Note that $Q$ is the flow rate per unit width of the joint.

The joint hydraulic conductivity $K_{j}$ can be expressed as (Ebeling and Pace (1996b)

$$
K_{j}=\left(\gamma_{w} / 12 \mu_{w}\right) \cdot e^{2}
$$

where $\mathrm{e}$ is the conducting aperture (in units of length).

Equation 2.5 is derived as follows: intrinsic permeability, $k$, is expressed in units of length squared. If $d$ is the pore size of a medium, then $k=C d^{2}$, where $C$ is a dimensionless shape factor (Freeze and Cherry 1979; Davis and DeWiest 1966). Working from this basic relationship, Snow (1968) showed that for a single planar joint of aperture $e$ (Appendix A), intrinsic permeability, $k=e^{2} / 12$ (see Appendix A for an explanation of Snow's equation). Hydraulic conductivity, $K$, which considers properties of the fluid and of the medium, is related to $k$ by Equation 2.2. Substituting Snow's relationship for $k$ into Equation 2.2 yields Equation 2.5. Thus, joint hydraulic conductivity, $K_{j}$, is proportional to the square of the conducting aperture, $e$. Fluid properties $\left(\gamma_{w} / 12 \mu_{w}\right)$ are introduced into the equation because Snow's relationship was derived for intrinsic permeability, $k$, but it is hydraulic conductivity, $K$, that is sought in Equation 2.5.

The cubic law (Ebeling and Pace 1996a) establishes the relationship between the conducting aperture, $e$, and $Q$ (as flow rate per unit width) as follows from Equations 2.4 and 2.5:

$$
Q=\left(\gamma_{w} / 12 \mu_{w}\right) \cdot e^{2} \cdot i \cdot e(e=\text { area at unit width })
$$

or

$$
Q=\left(\gamma_{w} / 12 \mu_{w}\right) \cdot e^{3} \cdot i(\text { the cubic law) }
$$




\subsubsection{Mechanical and conducting aperture and JRC}

As discussed in this section and in Chapter 5, the roughness of joint walls controls the ease with which water flows through the joint. Joint roughness also determines the ratio of mechanical (actual) to conducting (equivalent) aperture. Rougher or more undulating joint walls result in a higher $E / e$ than do smooth, flat walls.

A relationship exists between conducting aperture, $e$, and mechanical aperture, $E$ (Barton, Bandis, and Bakhtar 1985):

$$
e=(\mathrm{JRC})^{2.5} /(E / e)^{2}
$$

or

$$
E / e=\left(\mathrm{JRC}^{2.5} / e\right)^{0.5}
$$

where JRC is the joint roughness coefficient of Barton (1973). The equation is for SI units and is valid only for values of $E \geq e$ and within a range of aperture of 1 to 1,000 $\mu \mathrm{m}$ (Ebeling, Wahl, and Pace 1997).

Equation 2.8 is an empirical relationship developed by Barton, Bandis, and Bakhtar (1985) from laboratory and in situ flow tests in real joints and between smooth cut surfaces. They provide a family of curves for predicting the relationship between JRC, $E$, and $e$, using Equation 2.8 (Figure 2.8). The curves imply several behavioral features. Plane, smooth surfaces with a JRC $=0$ have theoretical conducting apertures equal to mechanical apertures. Extremely rough joint surfaces will deviate from $E=e(E / e=1)$ even at very large apertures. The rougher the natural joint, the greater will be the ratio of $E$ to $e$.

Barton described simple tilt tests for determining values of JRC for samples of jointed rock (Barton 1973; Barton and Choubey 1977). Values of JRC ranged from 0 for smooth joints to 20 for rough joints with many asperities. Citing Barton, Bandis, and Bakhtar (1985), Ebeling, Wahl, and Pace (1997) stated that 15 is a typical upper value for JRC.

Barton (1982) suggested another form of Equation 2.8,

$$
e=E^{2} / \mathrm{JRC}^{2.5}
$$

with which $e$ could be calculated knowing measured values of JRC and mechanical aperture $E$. Conversely, $E$ could be estimated knowing the other two variables. Realistically, however, estimates of conducting aperture, $e$, are obtained from steady-state flow tests on isolated joints or zones of joints. The cubic law, Equation 2.7, provides the relationship for estimating $e$ from flow tests. From constanthead pressure tests in boreholes, and rearranging Equation 2.7, the equivalent parallel plate aperture of each joint, $e$, is calculated using the following relationships. 


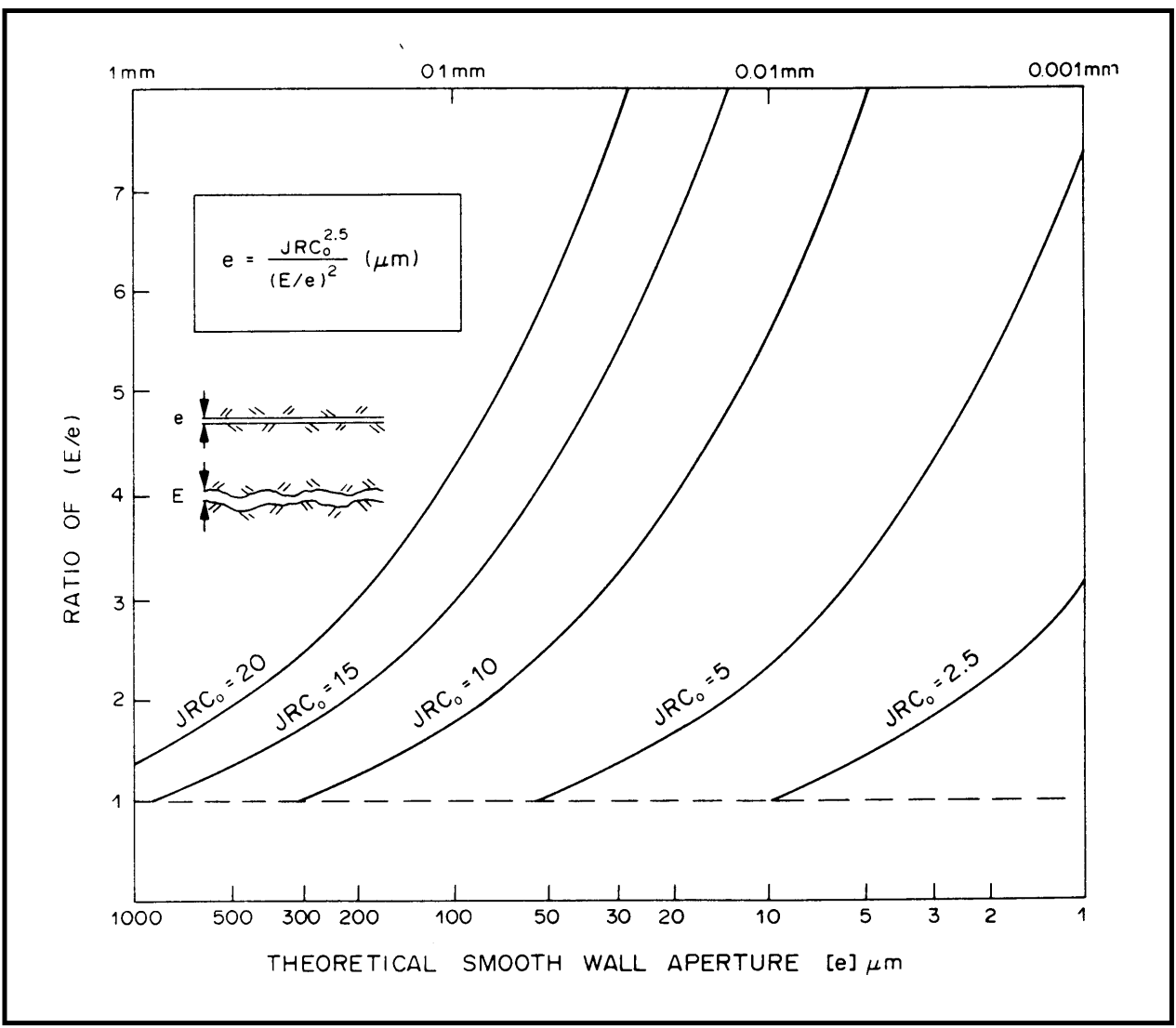

Figure 2.8. Empirical curves relating mechanical aperture $(E)$, conducting aperture (e), and joint roughness coefficient (JRC). Developed from flow test data (after Barton, Bandis, and Bakhtar 1985)

Darcy's equation for radial flow to a borehole during a pressure test is ${ }^{1}$

$$
Q=2 \pi l K_{e} H / \ln \left(R / r_{o}\right)
$$

where

$Q=$ observed steady-state volume flow rate

$K_{e}=$ equivalent hydraulic conductivity

$H=$ excess head in test section

$R=$ radius of influence of test

$r_{o}=$ borehole radius

By replacing the length of the test section, $l$, by the product $(\mathrm{Ne})$ in Equation 2.11, where $N$ is the number of joints intersecting the test section and $e$ is the equivalent parallel plate aperture, and replacing $K_{e}$ by $K_{j}$ of Equation 2.5 to invoke the cubic law (Equation 2.7) (Zeigler 1976, Appendix B7), the following expression is produced:

1 See Appendix B for a derivation of Equation 2.11. 


$$
Q=2 \pi N e\left(e^{2} \gamma_{w} / 12 \mu_{w}\right) H / \ln \left(R / r_{o}\right)
$$

or

$$
e=\left[\frac{Q \ln \left(R / r_{o}\right) \cdot \frac{12 \mu_{w}}{\gamma_{w}}}{2 \pi N H}\right]^{1 / 3}
$$

Chapter 5 applies these relationships to the estimation of $K_{e}, e$, and $K_{j}$ from pressure test data for Libby Dam.

\subsubsection{Laminar and turbulent flow in joints}

Estimates of the hydraulic conductivity of jointed rock masses using Darcy's law are valid only for laminar flow. It is important to understand the relationship between the size of joint openings (aperture), joint roughness, and laminar flow. Todd (1980) discussed the range of validity of Darcy's law for flow in porous media. By analogy with flow in a tube, the Reynolds number $\left(R_{e}\right)$ was employed to define the limit of flows described by Darcy's law. Experiments showed that Darcy's law is valid for porous media, i.e., that flow is laminar, for a Reynolds number up to about 10 .

Ebeling, Wahl, and Pace (1997) discussed the importance of determining whether flow within a rock joint is laminar or turbulent. The cubic law assumes a linear relationship between Darcian velocity (or specific discharge) and the hydraulic gradient and thus is valid only for laminar flow conditions. The Reynolds number is a dimensionless number expressing the ratio of inertial to viscous forces in flow. Specifically,

$$
R_{e}=v D_{h} \nu
$$

where

$$
\begin{aligned}
R_{e}= & \text { Reynolds number } \\
v= & \text { mean specific discharge (mean volume rate of flow) } \\
D_{h}= & \text { equivalent hydraulic diameter }=2 \text { times the conducting aperture } e \text { (four } \\
& \text { times the average flow passage area divided by the perimeter (Iwai } \\
& \text { 1976)) } \\
v= & \text { kinematic viscosity }=g \mu_{w} / \gamma_{w}, \text { where } g=\text { acceleration by gravity (Zeigler } \\
& 1976, \mathrm{p} 9)
\end{aligned}
$$


Zeigler $(1976)^{1}$ provided the following relationships for laminar, transitional (nonlinear laminar), and turbulent flow, respectively, in rock fissures:

$$
\begin{aligned}
v= & K_{j} i \text { (laminar flow) } \\
v^{m 1}= & K_{j}^{\prime} i \text { (hydraulically smooth regime }- \text { turbulent flow } \\
& \quad[\text { nonlinear laminar flow }]) \\
v^{m 2}= & K_{j}^{\prime} i \text { (rough regime }- \text { turbulent flow) }
\end{aligned}
$$

where $K_{j}^{\prime}$ is the turbulent fissure hydraulic conductivity. Equations 2.15 through 2.17 were derived in work by Sharp (1970) and Louis (1969). The exponent $m$ is generally between 1 and 2 (Zeigler 1976, Appendix B4), with $m 1<m 2$. Equation 2.16 illustrates that the change in $v$ is not linear with respect to the hydraulic conductivity in the transitional range.

The higher the Reynolds number, the more likely is turbulence to occur. The equivalent hydraulic diameter $D_{h}$ for confined flow in a rock joint is defined as four times the average flow passage area divided by the perimeter and is equal to two times the conducting aperture $e$ (Ebeling, Wahl, and Pace 1997, citing Iwai 1976). So $D_{h}=2 e$, and

$$
R_{e}=v(2 e) / v,
$$

which is the expression for the Reynolds number for flow between smooth parallel plates.

The critical $R_{e}$ is the Reynolds number at which nonlinear laminar flow starts to occur. Flow in cylindrical pipes is laminar for $R_{e}<2,100$ and turbulent for $R_{e} \gg 2,100$. For values of $R_{e}$ between 2,100 and 4,000 , the flow is transitional between laminar and turbulent. For open flow in parallel walls, the critical $R_{e}$ is 1,000 . For flow in an open channel, the critical $R_{e}$ is 500 .

A geometric dependence on $R_{e}$ delineating laminar and turbulent flow also exists for flow in rock joints. Iwai (1976) showed from studies of flow in rock joints that turbulent flow was evident when the Reynolds number exceeded a value of 100 . The critical Reynolds number decreases with increasing aperture roughness. Freeze and Cherry (1979) presented a curve relating flow condition to specific discharge and Reynolds number (Figure 2.9). The curve shows that nonlinear laminar flow can occur for Reynolds numbers between 5 and 100. Nonlinear laminar flow is a transitional state between laminar and turbulent flow. Laminar and Darcian flow are typical when the Reynolds number is less than about 5 . As Freeze and Cherry state, specific discharge (Darcian velocity, $K^{*} i$ ) and Reynolds numbers are high in wide rock joints.

A key relationship expressed by Ebeling, Wahl, and Pace (1997) is that the critical $R_{e}$ value decreases with increasing roughness. The point at which linear laminar flow becomes nonlinear laminar flow is lower in rough joints. Louis (1969) defined a surface roughness index, $S$, in terms of roughness and equivalent hydraulic diameter (equal to $2 e$ ):

\footnotetext{
1 Zeigler (1976) provides a rigorous and thorough review and evaluation of the theory of flow in fractured rock and of practices for determining rock mass hydraulic properties. He also presents derivations of most of the equations of flow used in this report.
} 


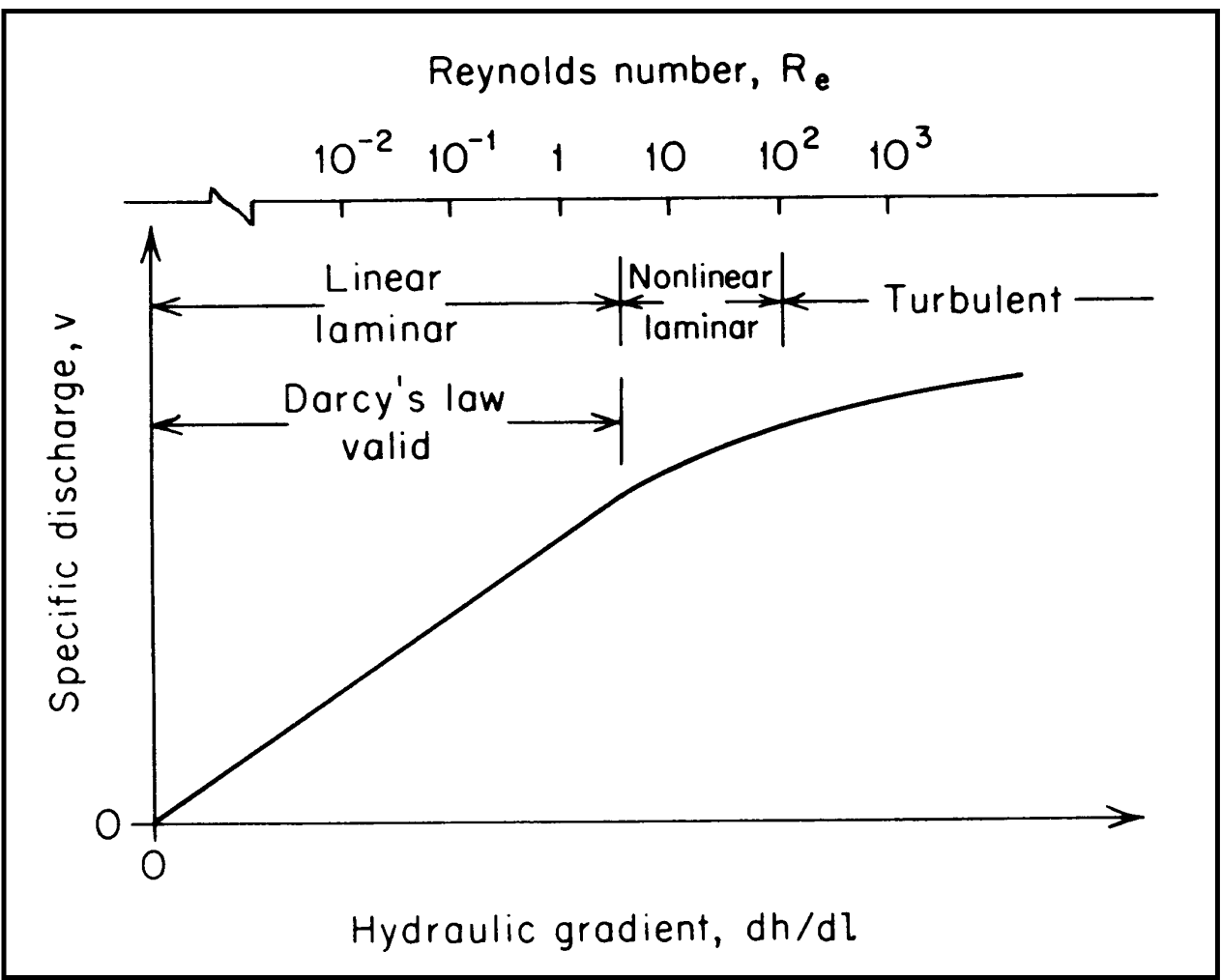

Figure 2.9. Range of validity of Darcy's law (after Freeze and Cherry 1979,

Figure 2.28)

$$
S=R_{r} / D_{h}
$$

where

$$
\begin{aligned}
R_{r} & =\text { height of surface asperities } \\
D_{h} & =\text { equivalent hydraulic diameter }=2 e
\end{aligned}
$$

As Ebeling, Wahl, and Pace (1997) stated, a key aspect of Equation 2.19 is that joint roughness (as $R_{r}$ ) is related to joint aperture. In addition, the critical Reynolds number, $R_{e}$, decreases with increasing surface roughness. The greater the aperture, the less important to roughness is the height of asperities.

\subsection{Determination of Rock Mass Hydraulic Conductivity}

\subsubsection{Methods using pressure and pumping tests}

Zeigler (1976) summarized field and laboratory methods of determining the hydraulic conductivity of jointed rock masses. Field tests include injection (pressure) tests, pumping tests, and tracer tests. Laboratory tests include controlled tests on large specimens representative of the rock mass or on smaller specimens representing a single discontinuity. Injection or pressure tests inject water into a 
borehole or isolated section of borehole under a constant pressure and flow rate. Injection tests can be conducted with water or with air. Hydraulic conductivity is related to the flow rate and the hydraulic pressure. Pumping tests commonly extract water from the rock mass through a borehole (or well). Hydraulic conductivity is computed from observations of well discharge and drawdown in the well or in nearby observation wells. A tracer test injects a tracer, such as a radioisotope, a dye, or a salt solution into a well. Hydraulic conductivity is computed using the dilution rate or travel time of the tracer to another well or other discharge point. The following paragraphs summarize Zeigler's review of test methods.

Water pressure test. In this test, water is pumped into a borehole at constant flow rate and pressure. Water enters the borehole along its entire length or in an isolated section sealed off by one or two packers. The test is often called a packer test or, particularly in Europe, a Lugeon test. Hydraulic conductivity is usually computed assuming laminar flow into a homogeneous and isotropic medium. The choice of test equipment and procedures affects the quality of the water pressure test. An important problem in pressure testing is the loss of pressure caused by frictional resistance along the flow pipe between the ground surface and the test section. Despite inherent difficulties, the test has advantages that make it popular. It is rapid and simple to conduct and, by conducting tests within intervals along the entire length of the borehole, a conductivity profile can be obtained. The test is usable above and below the groundwater table. Tests can be conducted in small boreholes, including the popular NX size. Procedures for conducting water pressure tests and interpreting the results are presented in Bennett and Anderson (1982), Zeigler (1976), and Geotechnical Laboratory (1993).

Pressure drop test. The pressure drop test is conducted by pressurizing a borehole test section to a known value, then stopping the water flow and observing the rate of pressure drop. The test is usually conducted to supplement a water pressure test. The pressure drop test requires less water than a pressure test, making it suitable for areas of limited water supply. The pressure drop test can use lower initial pressures than the water pressure test and is less likely to cause widening of discontinuities.

Air pressure test. The air pressure test is similar to the water pressure test but with air substituted for water as the injection fluid. Flow conductivities computed from air pressure tests must be converted to water hydraulic conductivity. The air pressure test has the advantage of a virtually unlimited supply of air for surface application. However, the conversion of air conductivity to hydraulic conductivity can lead to erroneous results in certain cases.

Pumping tests. Pumping tests are an established means of determining hydraulic properties of a large volume of rock mass. Water is pumped from a well, typically at a constant rate over a certain time period varying from hours to days. The hydraulic conductivity of the aquifer is related to measured drawdowns in the well or in observation wells and to well discharge based on assumptions concerning the type of flow (confined, unconfined, or semiconfined), properties of the aquifer, and flow boundary conditions. Isotropic and anisotropic solutions for hydraulic conductivity from pumping tests are available. Unlike water pressure 
tests, pumping tests are limited to testing strata below the groundwater table.

Pumping tests are difficult to perform in small-diameter boreholes because in-hole pumps are required. The major disadvantage of pumping tests is the large amount of time required to conduct the test. Pumping tests evaluate flow in a much larger volume of the rock mass than do pressure tests.

\subsubsection{Other methods}

Tracer tests. Tracer tests inject an inert solution (tracer) into an aquifer via a borehole or well. The dilution rate of the tracer at the injection well (tracer dilution method) or its travel time to another well (tracer travel time method) can be used to compute hydraulic conductivity. Test strata may be isolated between packers to determine a conductivity profile. Radioisotopes, salt solutions, and fluorescent dyes are commonly used as tracers. Detection of the tracer is by visual examination of samples or with optical-chemical probes at the detection site. Tracer tests involve a large portion of the rock mass, thus de-emphasizing the effects of zones of exceptionally high or low conductivity within the mass. The tests are rapid and relatively simple to perform, and avoid unnatural conditions that can result from high injection pressures in other types of tests.

Laboratory tests. Two laboratory tests have been suggested for determining the hydraulic conductivity of jointed rock (Zeigler 1976). The first measures the conductivity of a large representative sample, such as those on 1-ft cube blocks containing more than one discontinuity. The second is to measure the hydraulic conductivity of a single joint. One investigator studied flow through a single joint by locking in place upper and lower halves of a rock specimen, measuring the flow through the joint, and applying the equivalent parallel plate concept to compute individual joint hydraulic conductivity.

\subsection{Approaches in Computing Hydraulic Conductivity of Jointed Rock Masses}

Bennett and Anderson (1982) summarized solutions and approaches developed by others for computing hydraulic properties of rock masses from borehole pressure tests. Correct interpretation of pressure test results requires that assumptions and boundary conditions used in their analysis be valid. Too often, equations of flow are indiscriminately applied without considering whether the underlying assumptions and boundary conditions are reasonably satisfied by actual field conditions.

Two approaches are used to calculate hydraulic conductivity from pressure tests. The first is the continuum approach. Analysis of flow of an incompressible fluid (water) through saturated rock or soil is usually made assuming Darcy's law to be valid: i.e., there is a linear relationship between hydraulic gradient and flow velocity. In the continuum approach to analyzing flow in discontinuous, or jointed, rock masses, flow is assumed to occur uniformly throughout the mass rather than through individual discontinuities. The hydraulic conductivity 
determined in this approach is called the equivalent hydraulic conductivity. The following conditions must be reasonably met for this approach to be valid:

a. The rock mass is homogeneous, isotropic, and saturated.

$b$. All flow is radial and symmetric about the borehole axis.

c. The borehole test section is vertical.

d. Flow is steady-state; i.e., equilibrium has been established between the pumping rate or injection pressure and the head in the rock mass near the borehole.

e. Flow is laminar; i.e. turbulent flow does not occur.

$f$. A linear relationship exists between pressure (or gradient) and flow rate; i.e., Darcy's law is valid.

g. There is no leakage around the packers that isolate the test section.

$h$. Inertial terms are negligible; i.e., the change in pressure caused by the acceleration of flow into the rock mass is negligible.

When conditions $a$ through $h$ are reasonably met, the equivalent hydraulic conductivity of a pressure-tested zone of rock may be computed from constanthead (constant-pressure) tests using equations developed by Hvorslev (1951) for Darcian flow to a well. One form of Hvorslev's equation was presented as Equation 2.11 earlier in this chapter. Chapter 5 uses this equation to compute equivalent hydraulic conductivities in the foundation of Libby Dam. Other equations have been developed for analyses of pressure drop tests and air pressure tests (Bennett and Anderson 1982 and Zeigler 1976).

In the discontinuum approach to analyzing flow through rock, the mass is modeled as a system of blocks of low or negligible permeability (hydraulic conductivity) bounded by planar joints having a much higher hydraulic conductivity than the intact rock mass. The spacing and aperture of all joints intersecting the borehole test section and the effects of secondary joint systems, those joints that do not intersect the borehole but do intersect the primary joints, must be considered. Pressure losses occurring at those intersections and flow occurring through them can be important in some cases. Flow through fissures (joints) has generally been modeled using the smooth parallel plate analogy developed by Snow $(1965,1968)$. Radial flow governed by Darcy's law is assumed, and flow is assumed to occur only through the joints intersecting the borehole test section. For a discontinuum approach, the parameter for hydraulic conductivity in Darcy's equation (Equation 2.11) is replaced by parameters describing the equivalent parallel plate aperture, $e$, and the number of joints intersecting the test section (Equations 2.12 and 2.13), as discussed earlier in this chapter. Finite element models have also been developed to simulate and analyze flow in jointed media (for example, Ebeling, Pace, and Morrison 1997).

Bennett and Anderson (1982) state that most references to rock mass analysis emphasize the homogeneous, isotropic case of hydraulic property distribution and treat anisotropy as a special condition. They stress, however, that isotropic, homogeneous rock is the exception, and anisotropic, nonhomogeneous rock the rule. In 
practical design cases, continuum analyses will most likely be used, largely because of difficulties in defining individual fissure conductivities and structural orientations of complex fissure networks in the field (Zeigler 1976). Bennett and Anderson (1982) further suggest that test boreholes are commonly drilled vertically, without regard for rock structure, and pressure tests in them cannot adequately assess directional anisotropy in hydraulic conductivity. Carefully designed inclined boreholes maximize intersection of other joint sets and permit the contribution of each joint set to overall rock mass hydraulic conductivity and seepage. Another method of assessing anisotropy is the installation of additional vertical boreholes at different bearings from the vertical test hole and within the zone of influence and monitoring pressure differences within the monitoring holes.

\subsection{Uncertainty in Determining Hydraulic Properties of Jointed Rock}

Uncertainty arises in measuring or estimating $E$ and $e$, in measuring asperity or roughness in the field, and in extrapolating measurements in boreholes or surface exposures to the entire foundation rock mass. Equations for modeling of flow in jointed rock require values of conducting aperture. Because joint apertures change with distance from the measuring point, such as a borehole, measured $E$ may not accurately describe joint widths within the conducting rock mass. Measurements of mechanical apertures, $E$, must be converted to conducting apertures, $e$, for modeling purposes. There is a great deal of uncertainty in estimating conducting aperture from measured mechanical apertures because of the nonlinear relationship between real and conducting aperture and the dependence on a measurement of asperity or JRC. Extrapolation of measured joint features from the measuring point to the rest of the rock mass further weakens the relationship. Back-calculation of $e$ from aquifer testing is susceptible to errors in measurement precision, validity of assumptions made to compute aquifer properties from Darcy's law, accuracy of joint count in the borehole log, the introduction of nonlinear or laminar flow during testing, and the possibility of artificially widening joints by hydrofracturing.

Another aspect of flow in jointed rock that is difficult to monitor or ascertain during foundation investigation is persistence of jointing throughout the rock mass. Joints may tighten or cease at some unknown distance from the observation point. Or they may become wider, and may introduce nonlinear or turbulent flow. Joints may or may not intersect other joints. It is always difficult to make a threedimensional assessment based on a limited number of one- or two-dimensional measurements.

The effects on the joint system with time must also be considered. Changing reservoir levels deform the foundation through the moment-induced stresses resulting from reservoir loading of the upstream face of the concrete dam and through pore pressures developed within the joint system. There are practical difficulties associated with making in situ measurements beneath an existing dam. Analytical procedures, such as the finite element method of analysis, may be used to gain insight into the magnitude and geometry of these changes. 


\section{Geological Considerations in Uplift Analysis and Foundation Investigations}

\subsection{Overview of Geologic Factors}

Uplift pressure develops in the saturated rock mass beneath gravity dams as a result of the head imposed by the reservoir. Foundation treatment must both minimize the leakage of reservoir water beneath the dam and manage the uplift pressures that develop from restricted flow. As Deere (1981) stated:

"Full reservoir pressure imposes severe performance requirements on the ... foundation rock of a high concrete dam. The rock must resist the bearing and shear stresses transmitted by the dam as well as the uplift and seepage stresses associated with seepage flow beneath and around the dam. [At the same time,] the quantity of leakage must also be of reasonably small magnitude."

Flow of water in most rock is in the discontinuities that exist within the rock mass. Stone and Webster Engineering Corporation (1992) suggest that the ideal foundation with respect to uplift pressures is one that is impervious immediately below the heel of the dam and free-draining downstream. Under these ideal conditions, the impervious cutoff blocks most of the seepage, and the free-draining zone allows any seepage water bypassing the cutoff to flow freely to the tailwater and prevents the development of excessive uplift pressures.

Some rocks have a primary porosity of interconnected pores between grains that conducts water under pressure. However, most groundwater flow in rock occurs through the network of discontinuities cutting the rock mass. The role of flow and pressure in discontinuities is discussed in detail later in this chapter. Other features of rock affect the stability and hydraulic characteristics of rock foundations. The kind, or classification, of rock present in the foundation may affect the velocity of groundwater flow and the distribution of pressure within the rock mass. Different rock types present different problems in foundation investigation and in control of uplift pressures following reservoir filling. Geologic classification commonly recognizes three broad divisions of rock: sedimentary, igneous, and metamorphic. Igneous rock is further distinguished as intrusive or extrusive, or volcanic. Figure 3.1 shows the distribution of the major categories of 


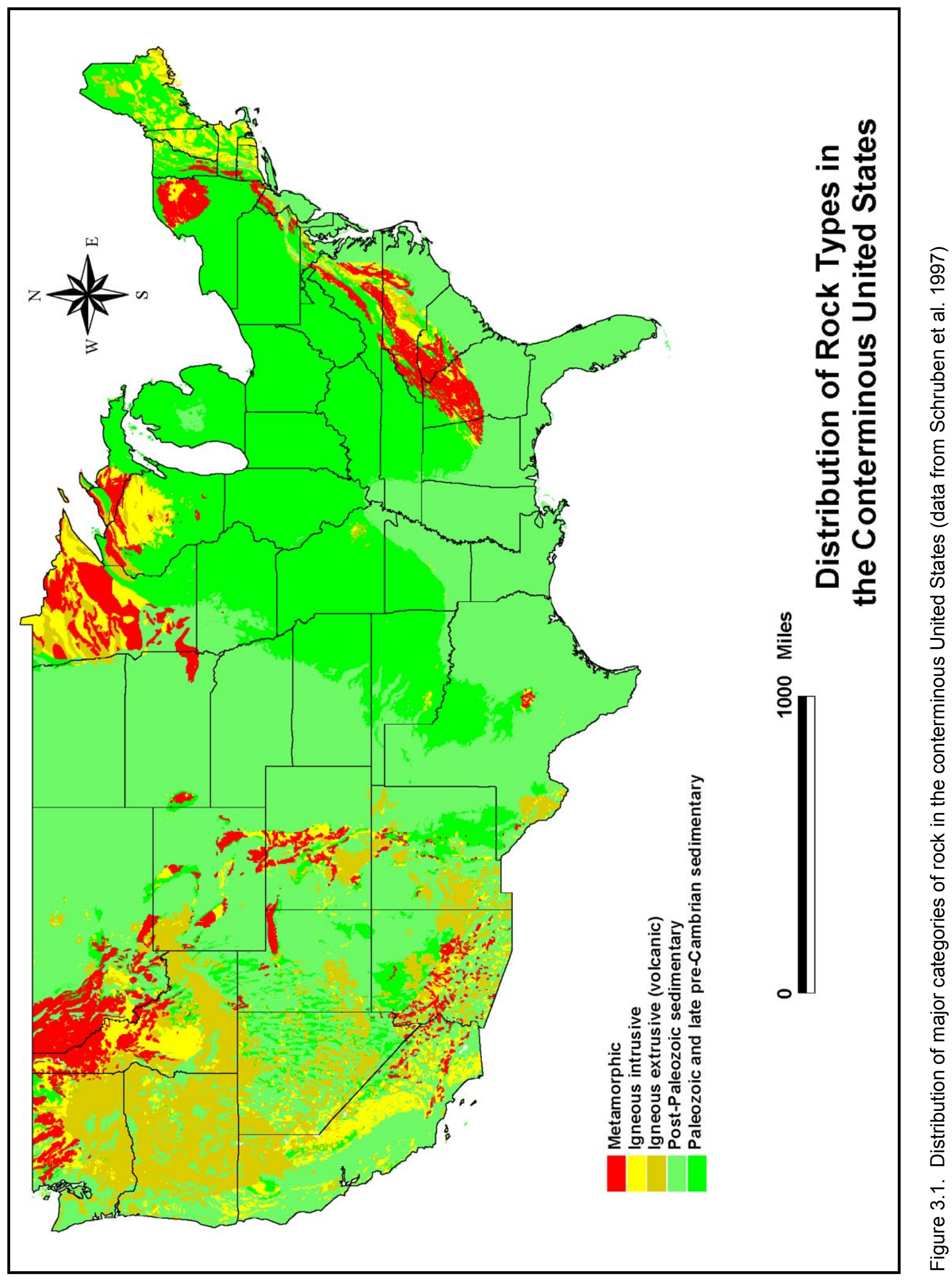


rock in the United States and where these rock types appear at or very near the ground surface.

Weathering, the disintegration and decomposition of rock in place by mechanical and chemical processes, weakens the rock mass and increases rock mass hydraulic conductivity by widening discontinuities. Rock is attacked by weathering agents on exposed surfaces, such as excavation walls and natural outcrops, and along joints and other discontinuities that extend into the rock mass. The zone of weathering is most pronounced near discontinuities and exposed surfaces. The degree of weathering in a rock mass depends on (a) the area of exposed surface, (b) the age of the exposed surface, (c) the extent of access to the rock mass along discontinuities and through pores, (d) the chemical composition (mineral content) and texture of the rock, (e) the environment or climate, and (f) the position and chemistry of the ground water.

Site stratigraphy, which describes the sequence of rock layers occurring in the foundation, can create considerable anisotropy in the foundation when strata alternate with depth. A site with variable stratigraphy is more difficult to investigate because a greater number of samples must be taken to accommodate the changing rock properties. There is a degree of uncertainty in determining when enough samples and a sufficient number and spacing of borings, adits, or other sampling accesses have been achieved. A monolithic foundation can be evaluated with a minimum of borings and samples. The foundation picture is complicated even more when site stratigraphy is disturbed by geologic structure. Sedimentary units originally deposited horizontally may be folded or tilted so that units occurring at a depth in one part of the foundation will occur deeper or shallower in another part because of dip. Faults may displace the entire sequence laterally or vertically by feet or tens of feet, making correlation of strata across the site difficult. Where a fault brings nonpervious beds adjacent to pervious strata at the fault contact, foundation drainage may be blocked, leading to buildup of pore and uplift pressures.

\subsection{Rock Type}

\subsubsection{Characteristics of sedimentary rocks}

Sedimentary rock consists of particles that have been eroded and deposited originally as soft materials and have hardened and gained strength through time. Compression of deposits by accumulating thicknesses of sediments further lithifies and indurates the material. Sedimentary rock is commonly subdivided into chemical, organic, and mechanical deposits. Chemical deposits form by materials precipitating out of water solution or through evaporation of salt-laden bodies of water. Examples of chemically derived sedimentary rocks are limestone, gypsum, and anhydrite. Organic rock forms from deposits of vegetative and animal remains. Coal is an example of an organic sedimentary rock. Mechanically deposited rock, also called clastic sedimentary rock, consists of accumulations of fragments of older rocks ranging from clay to boulder-sized particles. Clastic sediments are carried and deposited by wind, water, ice, or gravity. Examples of clastic sedimentary rocks are shale, sandstone, and glacial till. 


\subsubsection{Characteristics of igneous rocks}

Intrusive rocks are derived from molten magma injected into the earth's crust where it cools slowly enough to form visible crystals within the rock. Examples of intrusive rocks are granite, syenite, and diorite. Extrusive rocks are derived from molten magma ejected into the air or onto the earth's surface. They form volcanic deposits of flows (for example, basalt or rhyolite) or pyroclastics (for example, tuff or agglomerate). Intermediate forms of igneous rocks with textures containing both fine and coarse crystals also occur. Table 3.1 is a classification of the common igneous rocks. Igneous intrusive rocks typically occur in mountainous regions, where they often form the core of mountain ranges. Areas of igneous intrusives include the Appalachians, the Adirondacks of upstate New York, the Rockies, the Sierras of California, and the northern Cascades of Washington. PreCambrian granitic intrusives occupy much of northern Minnesota. Most of the volcanic rocks in the United States occur in the geologically active western states, especially Washington, Oregon, Idaho, California, Nevada, and Arizona. The great outpourings of lava flows in the western states are generally very young, of late Tertiary age.

Figure 3.2 shows the distribution of volcanic and metamorphic rocks in the conterminous United States.

\begin{tabular}{|c|c|c|c|c|c|c|}
\hline \multicolumn{7}{|c|}{$\begin{array}{l}\text { Table } 3.1 \\
\text { A Classification of the Common Igneous Rocks }\end{array}$} \\
\hline \multirow[b]{2}{*}{ Texture } & \multicolumn{2}{|c|}{ Light-colored (acidic) } & \multicolumn{2}{|c|}{ Intermediate in color } & \multirow[b]{2}{*}{$\begin{array}{l}\text { Dark-colored } \\
\text { (Basic) }\end{array}$} & \multirow[b]{2}{*}{ Ultra-basic $^{1}$} \\
\hline & Quartz-rich & $\begin{array}{l}\text { Quartz- } \\
\text { deficient }\end{array}$ & Quartz-rich & Quartz-deficient & & \\
\hline \multicolumn{7}{|c|}{ Gradational change depending on kind and amount of feldspar present } \\
\hline $\begin{array}{l}\text { Coarse texture } \\
\text { (plutonic, }^{\text {intrusive, }} \\
\text { phaneritic) }\end{array}$ & GRANITE & SYENITE & $\begin{array}{l}\text { QUARTZ } \\
\text { MONZONITE } \\
\text { (GRANODIORITE) } \\
\text { to QUARTZ } \\
\text { DIORITE } \\
\text { (TONALITE) } \\
\end{array}$ & $\begin{array}{l}\text { MONZONITE to } \\
\text { DIORITE }\end{array}$ & GABBRO & $\begin{array}{l}\text { PERIDOTITE, } \\
\text { PYROXENITE, } \\
\text { DUNITE, etc. }\end{array}$ \\
\hline \multirow{2}{*}{$\begin{array}{l}\text { Contrasting } \\
\text { texture } \\
\text { (nonuniform } \\
\text { grain size, or } \\
\text { porphyritic) }\end{array}$} & $\begin{array}{l}\text { GRANITE } \\
\text { PORPHYRY }\end{array}$ & & & $\begin{array}{l}\text { MONZONITE } \\
\text { PORPHYRY }\end{array}$ & \multirow{2}{*}{$\begin{array}{l}\text { DIABASE OR } \\
\text { DOLERITE }\end{array}$} & \\
\hline & $\begin{array}{l}\text { RHYOLITE } \\
\text { PORPHYRY }\end{array}$ & & & $\begin{array}{l}\text { LATITE } \\
\text { PORPHYRY }\end{array}$ & & \\
\hline $\begin{array}{l}\text { Fine texture or } \\
\text { glassy (volcanic, } \\
\text { extrusive, } \\
\text { aphanitic) }\end{array}$ & $\begin{array}{l}\text { RHYOLITE } \\
\text { (OBSIDIAN } \\
\text { is a glassy } \\
\text { form of } \\
\text { rhyolite) }\end{array}$ & TRACHYTE $^{3}$ & $\begin{array}{l}\text { QUARTZ LATITE to } \\
\text { DACITE }^{3}\end{array}$ & $\begin{array}{l}\text { LATITE to } \\
\text { ANDESITE }^{3}\end{array}$ & BASALT $^{4}$ & \\
\hline \multicolumn{7}{|c|}{$\begin{array}{ll}1 & \text { Composed wholly of dark minerals, often only one mineral. } \\
2 & \text { A pegmatite is a very coarse-grained rock, with most grains larger than } 1 \mathrm{~cm} \text {; some may exceed } 1 \mathrm{~m} \text { in diameter. } \\
3 & \text { Light-colored, fine-grained igneous rocks are sometimes called FELSITE. } \\
4 & \text { Dark-colored, fine-grained igneous rocks are sometimes called TRAPROCK. } \\
\end{array}$} \\
\hline
\end{tabular}



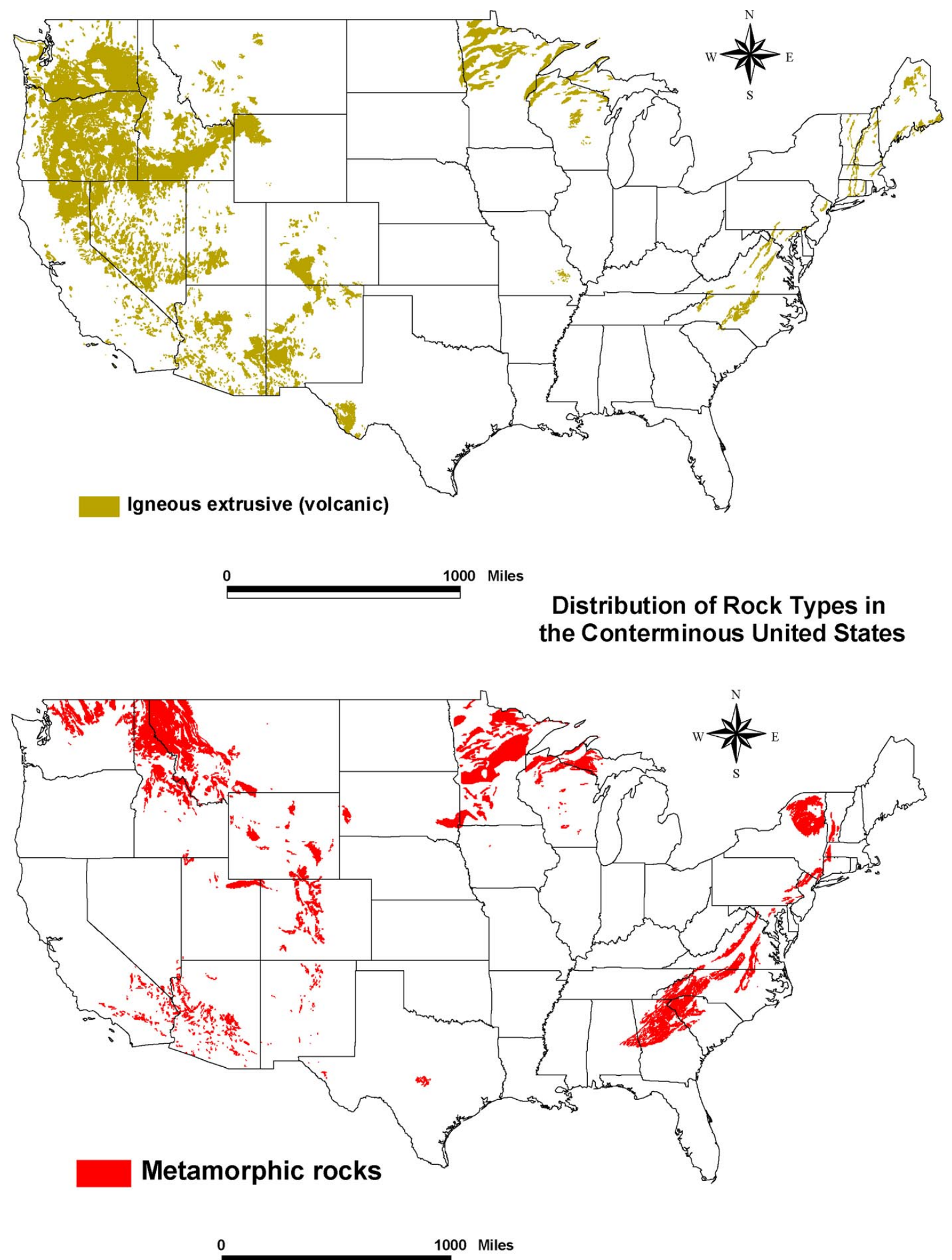

Distribution of Rock Types in the Conterminous United States

Figure 3.2. Volcanic and metamorphic rocks in the United States (data from Schruben et al. 1997) 


\subsubsection{Characteristics of metamorphic rocks}

Metamorphic rocks are rocks that have been altered by heat and pressure, usually as a result of mountain-building processes or tectonic plate interaction. Most pre-Cambrian sedimentary rocks older than 800 million years have been metamorphosed and are called metasediments. The metasediments have been sufficiently altered by metamorphic processes of heat and pressure that they have lost their original sedimentary structure, fabric, or texture. For example, sandstones have been altered to hard quartzites. Other examples of metamorphic rocks are marble, slate, schist, and gneiss. Metamorphic rocks occur in areas of mountain building, for example in the Appalachians and Rockies, and in areas of tectonic rifting and regional faulting, as in southern California and Arizona. They also are found in the very old, pre-Cambrian rocks of central and northern Minnesota where part of the Canadian Shield is exposed (see Figure 3.2).

\subsubsection{Problems with sedimentary rocks in dam foundations}

Goodman (1990) summarized the properties of different rock types with respect to dam design and construction. Sandstone and other coarse-grained clastic rocks may exhibit two kinds of hydraulic conductivity. These rocks are porous to varying extent and may be pervious to groundwater if the porosity is high enough and the pores are connected. Intergranular porosity is often called primary porosity. Clastic rocks are commonly jointed and have bedding planes along which flow can occur. These discontinuities make up the secondary porosity in the rock mass. If intergranular porosity is low or if the pores are partially filled with cementing materials ${ }^{1}$ or fines, the secondary porosity of the discontinuities will dominate groundwater flow. Goodman stresses the need for field conductivity testing to determine the hydraulic conductivity and other engineering characteristics of clastic rock masses. Some sandstones can be grouted effectively, but very fine-grained or clayey sandstones may be hard to seal by grouting. Foundation exploration must be able to determine the stratigraphy and structure (the morphology) of the sandstone bodies. Some sandstone deposits, particularly alluvial or deltaic formations, are of limited lateral extent and may thin, thicken, or disappear in a short distance. Hard, cemented sandstones tend to have open joints that can produce excessive seepage beneath the dam.

Shales and other fine-grained clastic sedimentary rocks need special attention in foundation investigations. Shales (as well as mudstones and claystones) may be expansive because of particular clays composing them, or they may have a propensity to slake, to disintegrate with changing moisture conditions. Foundation investigations should strive to describe these rocks adequately. Shaley or clayey rocks usually have very low hydraulic conductivity because of their fine-grained nature and clay content. Some shale formations, however, have well-developed joint networks in the field and may be quite pervious. Field conductivity tests are preferred to laboratory tests of individual samples because the latter will overlook the effects of the joint network on hydraulic conductivity of the rock mass.

\footnotetext{
1 The grains of sandstones and siltstones are often partially cemented together by chemicals
} brought out of solution, such as calcium carbonate (calcite) and silicon dioxide (silica). 
Stone and Webster Engineering Corporation (1992) described the effects of a prominent shear zone in the shale foundation of Morris Sheppard Dam in Texas. The shear zone was parallel to the near-horizontal bedding and ran through the foundation above the dam to downstream of the spillway and in fact had caused the spillway to slide. Investigations indicated that the shear zone was acting as a conduit, distributing water under high uplift pressure beneath the base of most of the spillway. The uplift pressure was eventually controlled by drilling 147 drains into the shear zone near the heel.

Shales and sandstones often occur together in alternating, interbedded, and cyclical layers. This poses a special problem because flow is restrained to the sandstone layers, and pressures in each sandstone bed can be different from pressures in other beds isolated by shale layers. Flow velocities in the sandstone layers may be higher because the area of flow is reduced by the presence of the impermeable shales. Higher flow velocities can lead to piping or erosion of weakly cemented sandstones if not controlled.

Limestones and other precipitate rocks may be soluble in water, particularly along planes of weakness, such as bedding and joints. Groundwater flow paths along these discontinuities may widen to the point of producing conduit flow with high velocities. Solution-formed cavities and caves commonly form. The primary concern for dams constructed on soluble rock is, of course, the loss of reservoir retention by excessive seepage through the foundation. But uplift pressures may vary greatly within the foundation, depending on how the system of joints and bedding planes interconnects with solution cavities.

Douglas Dam is a 203-ft-high concrete gravity dam founded on solution limestone in Tennessee. Stone and Webster Engineering Corporation (1992) described conditions in the foundation of the dam. Major solution features (sinks, conduits, and caves) existed beneath the river at the dam site prior to excavation. An extensive weathered zone of highly permeable limestone extended to a depth of over $200 \mathrm{ft}$ below the channel. To treat these conditions, the solution cavities were cleaned and filled with concrete. The deeply weathered zone was treated by an extensive grouting program. Uplift pressure measurements after dam construction showed piezometric levels beneath the dam to be lower than the tailwater. Preconstruction remediation of the potentially troublesome karst features was effective in controlling seepage and in reducing uplift pressures.

\subsubsection{Problems with igneous rocks in dam foundations}

Intrusive igneous rocks have little or no primary porosity for conveying groundwater. They are commonly jointed, however, and can have substantial fracture porosity. Weathering of near-surface igneous bodies breaks up mineral grain boundaries and increases hydraulic conductivity in the weathered zone. Intrusive rock masses are commonly bounded by irregular contacts. It may be difficult during field exploration to determine the limits of intrusive rock bodies. They may have a regular system of joints reflecting regional tectonic stresses. Many igneous rock bodies also have a subhorizontal set of open, stress-relief joints near the ground surface caused by weathering and unloading of the rock 
mass by erosion of overlying rock. This phenomenon is also called sheeting. The effects of stress relief and weathering decrease with depth, so joint frequency and aperture usually decrease with depth in the foundation.

Areas of volcanic rocks cause special problems in foundation investigations. The texture of volcanic rock can vary within a construction site from hard, dense lava flows to soft tuffs (deposits of volcanic ash). Volcanic deposits can be parallel-bedded similarly to sedimentary rocks, or massive and irregularly shaped, with lateral changes from one rock type and texture to another over a short distance. Hard lava rock may overlie older but softer tuff deposits at depth. Volcanic deposits can be very heterogeneous and difficult to describe adequately during foundation investigations. Groundwater is conveyed through pores in pyroclastic materials and some vesicular basalts, along contacts and shear zones between deposits, and through joints developed in the more brittle rocks.

The foundation of Green Peter Dam, in west-central Oregon, illustrates the complexity associated with volcanic sequences. Figure 3.3 is a geologic map of the wall of the excavation for Block 21 of the foundation of Green Peter Dam. The foundation is in dipping, alternating layers of basalt flow, flow breccia, and tuff. The rock mass is cut by basalt intrusives (dikes). Shear zones of highly fractured rock developed in the tuff beds. Faults and joints persist throughout the foundation rock mass. Water flows from the planar features varied considerably from feature to feature and from place to place within the foundation. Some of the shear zones had to be accessed through drifts blasted into the foundation rock. Foundation remediation methods included rock bolting, presplitting and line drilling to prevent overbreakage, contact grouting, emplacement of a grout curtain, drainage tunnels, and a drainage curtain.

Stone and Webster Engineering Corporation (1992) gave an example of foundation treatment designed to control uplift pressures in layered basalts beneath McNary Dam in southeastern Washington. The foundation consists of roughly horizontal basalt flows approximately $100 \mathrm{ft}$ thick separated by an interbed of lacustrine (lake-deposited) sediments about $50 \mathrm{ft}$ thick. The upper several feet of basalt are severely jointed and pervious. The lower basalts are columnar-jointed with moderate hydraulic conductivity. The sedimentary interbed is tuffaceous, generally fine-grained and clayey, and is relatively impervious. Corps District personnel constructed a grout curtain from a gallery near the heel of the dam. The grout holes were bottomed in the impervious sedimentary interbed to form a cutoff wall. Monitoring of piezometric pressures in drain holes downstream of the grout curtain indicated little increase in uplift pressures. The rock was sufficiently permeable to allow seepage to drain freely to the tailwater. Measurements in adjacent massive basalts, which lacked open, interconnected joints, revealed much higher uplift pressures.

A particular kind of joint unique to extrusive rocks such as basalt is columnar jointing. Columnar joints form near vertically at right angles to the direction of flow of a lava body, in roughly hexagonal prisms. The columns form as a result of cooling of the lava and stress relief. Columnar-jointed lavas can be very permeable to groundwater. The lava flow containing the columnar joints, however, is limited in extent. Foundation investigation should define the limits of the flow to 


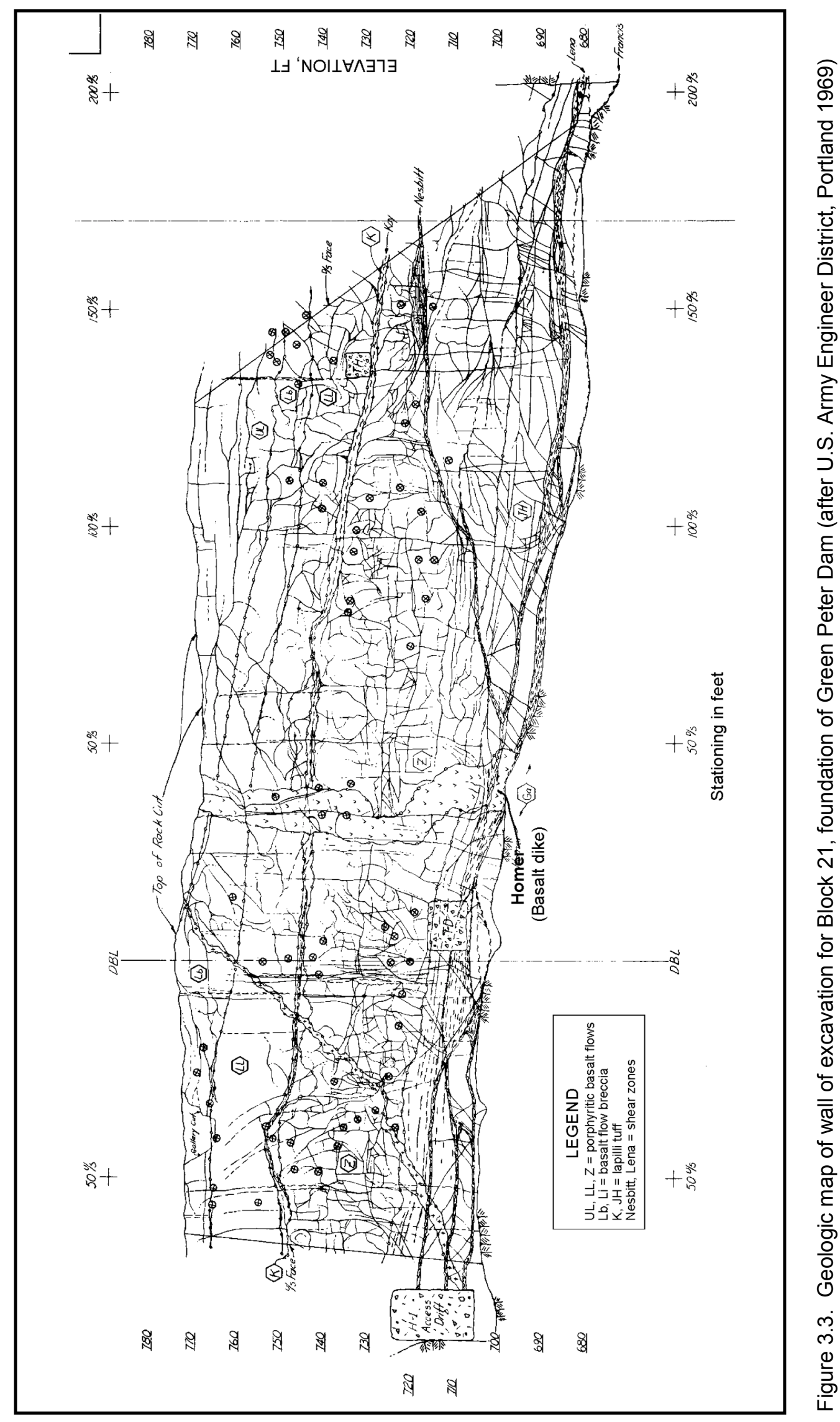


allow a determination of where in the foundation high flow zones will occur and where they may be curtailed by adjacent rocks.

\subsubsection{Problems with metamorphic rocks in dam foundations}

Metamorphic rocks can be especially problematic for dam foundations in a number of ways. These rocks often occur in complex assemblages with widely varying properties. Because of their usually great age and their history of formation in regions of high stress, they commonly contain joints, faults, foliation, and shear zones. These are planes of weakness along which failure can occur and along which groundwater can move. Metamorphic rocks are sometimes severely folded and contorted, forming complex failure and flow paths. Metamorphism often forms schistose zones characterized by weak, platy minerals aligned in a direction parallel to bedding. Schistose zones have a low resistance to movement and comprise potential failure paths in an excavation or foundation.

Goodman (1990) provided an example of dam failure attributed to uplift pressures developed in metamorphic rock at Malpasset Dam. A wedge of rock was created by the intersection of a steeply inclined foliation shear and a fault under the left abutment. When the reservoir filled, water pressure in the schistose rock rose because joints in the rock closed and prevented free drainage through the abutment. The wedge of rock yielded under the thrust of the reservoir and dam and the elevated uplift pressures in the joints. A diagram presented by Bellier (1977) illustrates the adverse orientations of foliation and structure that probably led to the Malpasset failure (Figure 3.4). The diagram is a plan and sections through the left and right abutments of the arch dam. Failure occurred in the left abutment (circled on the diagram). Bellier explained that the thrust of the arch into the left abutment was parallel to the direction of foliation in the metamorphosed rock. Thrust stresses were concentrated in a narrow section of the abutment bounded by the arch and a downstream fault. The subsurface "dam" thus formed prevented drainage of groundwater as the reservoir filled. Thrust of the arch further worsened the condition by compressing foliation joints within the isolated zone and reducing their hydraulic conductivity. Investigators estimated that the hydraulic conductivity of the zone decreased by a factor of 100 to 1,000 . Pore pressures increased on the downstream face of the slice. The resultant force of the arch thrust and the elevated pore pressures produced an ascending movement of the left abutment rock, as shown by the dashed arrow in Section BB of Figure 3.4.

\subsection{Problems Associated with Weathering}

Weathering, the process of breaking down rock in place by mechanical and chemical means, changes the engineering characteristics of rock. Mechanical, or physical, weathering of rock occurs by many processes. Water that seeps into pores and open discontinuities, particularly in temperate climates, may freeze and expand, breaking the rock and rock grains by frost wedging. Thermal expansion and contraction from severe daily temperature variations, especially in arid regions, cracks rock or causes it to spall and disintegrate. Clay-rich rocks can be 


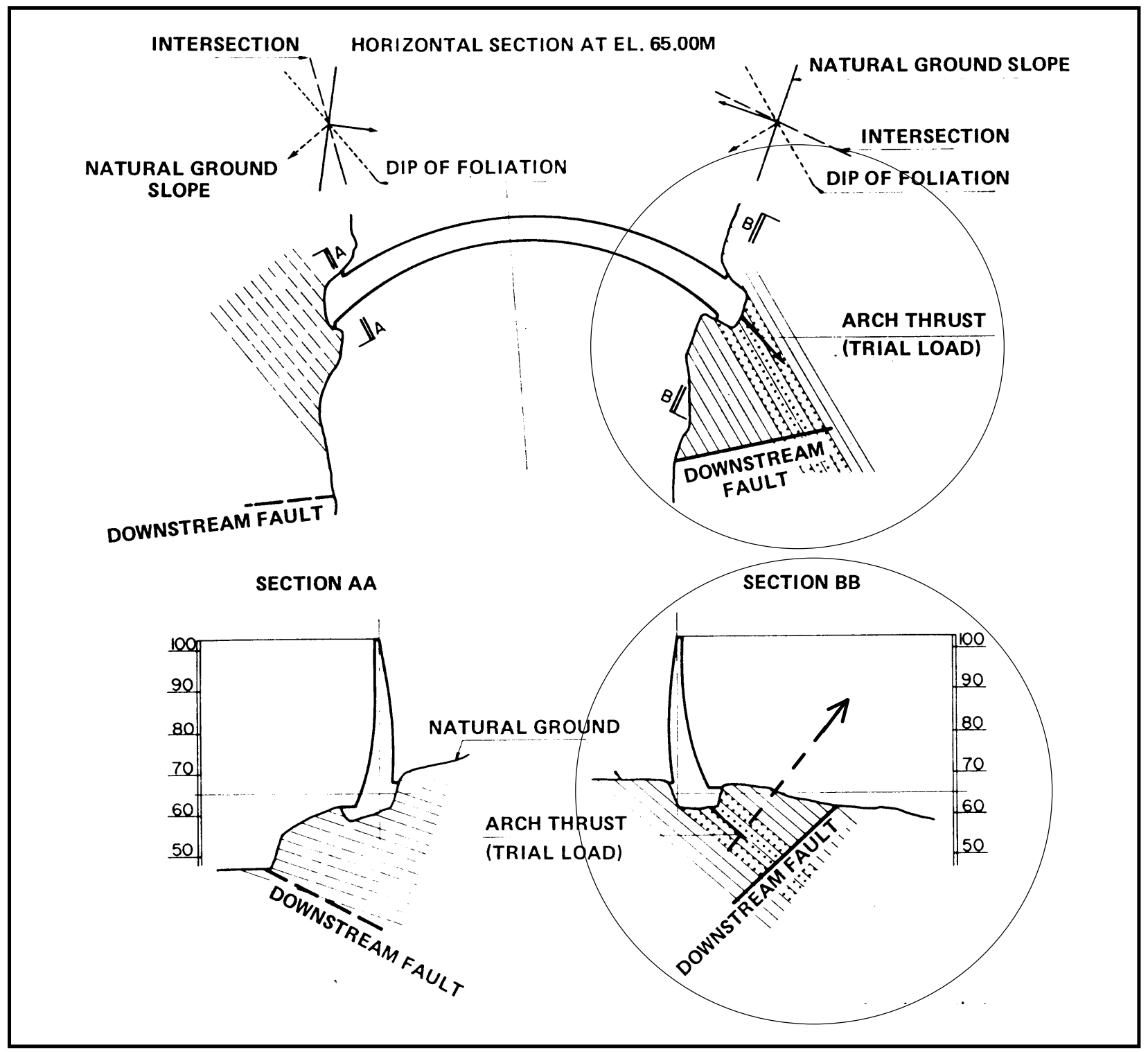

Figure 3.4. Relations between geologic structure in abutment of Malpasset Dam and arch. Circles indicate left abutment conditions. Dashed arrow (added) in Section BB is direction of uplift force. See text for explanation (after Bellier 1977)

broken down by cycles of wetting and drying. Unloading is the release of stresses within the rock mass by erosion of overlying or surrounding materials or glacial melting and retreat, or by blasting or other excavation of the surrounding rock mass. Unloading affects all rocks and causes widening of existing discontinuities such as bedding planes and joints or opening of incipient fractures. Root growth can affect all rocks and causes widening of discontinuities and eventual fragmentation of the rock mass. The actions of animals, especially burrowing animals, are most pronounced in the softer sedimentary rocks.

Chemical weathering occurs by the reaction of water, acids and bases, oxygen, and carbon dioxide with the mineral constituents of the rock. Iron sulfides combine with oxygen to form the commonly occurring red oxides of iron by the 
process of oxidation. Carbon dioxide dissolved in water readily dissolves soluble carbonates such as limestones and dolomites to produce the networks of caves and solution-enlarged discontinuities of karst regions. Many clay minerals, which are significant in the stability of geotechnical structures, form from silicates of the igneous rocks by the addition of water. This process is called hydrolysis, and under certain conditions it forms hydrous compounds. For example, feldspars, the most common igneous minerals, alter in the presence of water to illite or kaolinite, common clay minerals. Oxidation and reduction alter rock minerals to form oxides or hydroxides. Dissolution, or water solubility, occurs in certain sedimentary rocks including evaporites (e.g., gypsum) and limestone. Part of the rock is dissolved and carried away, leaving cavities, a soft residue, or weakened zones within the rock mass.

The absorption of free water into the mineral structure by hydration also produces a kind of mechanical weathering by expansion of the structure when a mineral undergoes growth by recrystallization. For example, the hydration of anhydrite (the "dewatered" form of calcium sulfate) to reform gypsum (hydrous calcium sulfate) produces a volume change of as much as 30 to 60 percent (Robinson 1982). The most significant hydration occurs in the alumino-silicate minerals of igneous rocks (Schultz and Cleaves 1955). The volume increase that accompanies hydration is an important factor in the disintegration of coarsegrained igneous and metamorphic rocks. Clay minerals, such as montmorillonite, that fill the space between discontinuity walls may absorb water and contribute to expansion and mechanical breaking of the rock mass.

The weathering process occurs worldwide. It proceeds faster at the exposed rock surface and along permeable discontinuities, particularly joints and fault zones. It is important to define the depth of the weathered zone and to be prepared to address problems associated with weakened rock and enlarged water passages caused by weathering. The weathering profile from the surface downward is transitional. The degrees of weathering and of deterioration of the rock mass decrease with depth. The transitional zone has been defined by Deere (1981) as the gradational change from residual soil to weathered rock. The depth of the transitional zone varies with rock type, climate, and other factors and proceeds preferentially along planes or zones of discontinuity within the rock mass. In dipping strata, weathering proceeds preferentially and more deeply along beds more susceptible to chemical weathering. Rock mass properties, including strength and hydraulic conductivity, vary extensively within the transition zone. The variation in depth, the irregularity of the weathered zone, and the accompanying range of rock mass properties account for much of the uncertainty in investigating, preparing, and treating excavated foundations for concrete dams.

The weathering of rock is recognized by a decrease in the luster of the rock's minerals, discoloration of the rock, separation of rock crystals or grains along their boundaries, increased friability (crumbling when rubbed between the fingers), and a general decrease in competency and compressive strength. Infiltrating water may stain discontinuity walls or introduce material to fill open discontinuities. The degree of weathering can be classified on the basis of simple qualitative visual and physical inspection. Table 3.2 is a classification developed by Bieniawski (1979) to describe discontinuities in rock masses. 


\begin{tabular}{|c|c|}
\hline \multicolumn{2}{|c|}{$\begin{array}{l}\text { Table } 3.2 \\
\text { Classification of Degree of Weathering of Rocks (after Bieniawski } \\
\text { 1979) }\end{array}$} \\
\hline Classification & Description \\
\hline Unweathered & No visible signs of weathering; rock fresh; crystals bright. \\
\hline Slightly weathered & $\begin{array}{l}\text { Discontinuities are stained or discolored and may contain a thin } \\
\text { filling of altered material. The discoloration may extend into the rock } \\
\text { from the discontinuity surfaces to a distance of up to } 20 \text { percent of } \\
\text { the discontinuity spacing. }\end{array}$ \\
\hline Moderately weathered & $\begin{array}{l}\text { Slight discoloration extends from discontinuity planes for greater } \\
\text { than } 20 \text { percent of the discontinuity spacing. Discontinuities may } \\
\text { contain filling of altered material. Partial opening of grain boundaries } \\
\text { may be observed. }\end{array}$ \\
\hline Highly weathered & $\begin{array}{l}\text { Discoloration extends throughout the rock and the rock material is } \\
\text { friable. The original texture of the rock generally has been } \\
\text { preserved, but separation of the grains or crystals has occurred. }\end{array}$ \\
\hline Completely weathered rock & $\begin{array}{l}\text { The rock is totally discolored and decomposed and friable. The } \\
\text { external appearance of the rock sample is that of soil. Internally, the } \\
\text { rock structure is partially preserved but grains and crystals have } \\
\text { completely separated. }\end{array}$ \\
\hline
\end{tabular}

\subsection{Problems Associated with Stratigraphy}

The overview for this chapter explained that problems with stratigraphy in dam foundations arise primarily from the variation in rock properties across the site and with depth. Sedimentary rocks, in particular, can be stratigraphically diverse. Changes in depositional environments, from deep sea to terrestrial, occur over time, with consequential variations in the types of sediment deposited. Limestones may give way with depth to shales or sandstones, and then the cycle may repeat. In deltaic and near-shore environments, both lateral and vertical changes in sediments occur repeatedly with time as sea level rises and falls and rivers change course as they meander toward the sea. The result is a complex assemblage of sinuous or isolated sand channels, extensive backswamp mud and clay deposits, clay- or silt-filled abandoned channels, overbank deposits, and deltaic fans. These deposits show great variation in shape, size, thickness, and, when converted over time to rock, physical properties. This variation in properties laterally and with depth causes uncertainty in how a foundation will respond to changing stress conditions, how and where it will conduct water, and how and where uplift pressures will develop and be distributed.

Foundation investigations for Red Rock Dam on the Des Moines River in Iowa encountered some of these problems. Red Rock Dam is not a concrete gravity structure, but its foundation stratigraphy exemplifies conditions that could apply in other dam situations. The dam is founded in Mississippian-aged rock of alternating strata of shale, sandstone, and limestone. Figure 3.5 is a geologic section along the dam axis, looking upstream. Alternating sandstone and limestone units, generally 10 to $15 \mathrm{ft}$ thick, persist across the foundation to a depth of about $70 \mathrm{ft}$ below the channel bottom. In some areas, domes of gypsum occur at the base of this sequence (see Figure 3.5). Updoming of the gypsum beds intensely fractured the overlying sandstone and limestone strata. Fracturing allowed river water to seep into the gypsum beds and remove part of the gypsum 


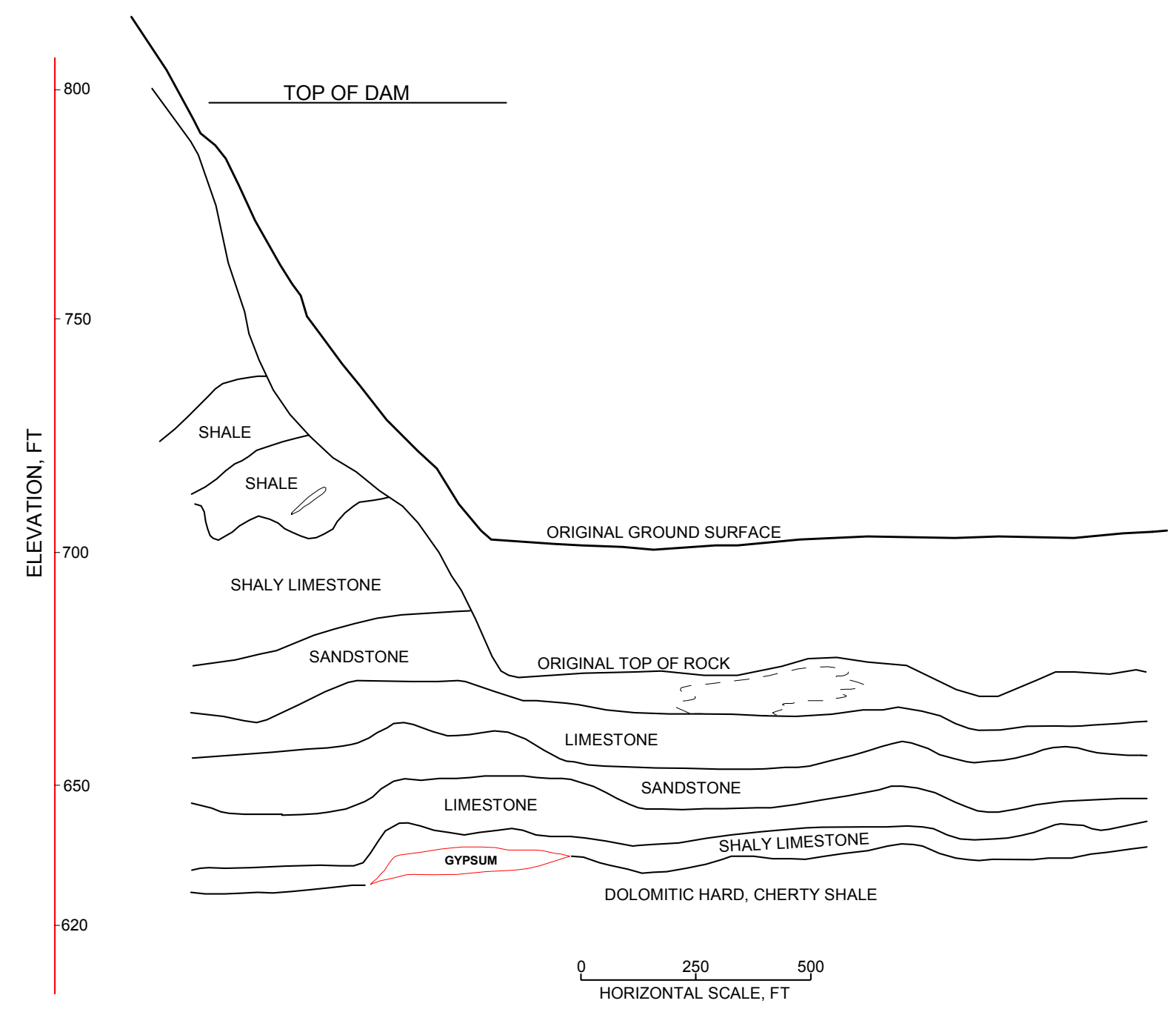

Figure 3.5. Geologic section along axis of Red Rock Dam, looking upstream (after U.S. Army Engineer District, Rock Island, 1965)

by dissolution, resulting in subsidence of the overlying rock into the cavities. Infiltrating water leached the relatively friable sandstone and caused intense weathering along joints. The limestone was affected by dissolution along joints and bedding planes and filling of the dissolution cavities by residue and clay. Hydraulic gradients varied considerably from one side of the foundation to the other. Concerns with excessive seepage and continued dissolution and piping of the limestones and gypsum beds, which could compromise the stability of the dam, required extensive remedial grouting.

\subsection{The Role of Discontinuities}

Dam foundation investigations for uplift prediction should assess those geologic conditions controlling groundwater flow beneath the dam. Among the 
most important geologic factors are the persistence and condition of rock mass discontinuities. Murphy (1985) reviewed descriptive terminology and classification schemes for rock masses, assessed the importance of rock mass descriptors in geotechnical applications, and recommended descriptors for critical rock mass properties and characteristics. The term discontinuity encompasses all natural breaks or planes of separation in a rock mass. Discontinuities include structural features, such as faults, joints, and shears; depositional features, such as bedding planes; post-depositional features, such as schistosity and foliation; and solutionwidened passages that occur in soluble rocks along preexisting discontinuities. Joints, faults, and bedding planes sometimes occur congruently (for example, in bedding joints). Most often, however, a distinction is made in the field between bedding and jointing.

Uncertainty arises in many ways when dealing with discontinuities in a rock mass. All characteristics of discontinuities, including spacing, aperture, persistence, planarity, amount and kind of filling, and the corresponding hydraulic conductivity associated with all of these features, change over distance, both laterally and with depth. Some characteristics also change with time. Stresses imposed by the dam and reservoir deform joints and bedding planes. Filling materials are eroded into and out of joints under changing water pressures and flow velocities. There is uncertainty in extrapolating measurements and descriptions made at one location to the entire foundation rock mass, particularly if observations are made in boreholes, which are essentially one-dimensional. It may also be difficult to confidently extrapolate measurements into the future not knowing precisely what stresses and deformations will occur and what effects they will have on the properties of rock discontinuities. Much of this report, particularly Chapters 2 and 5, addresses the effects of stresses and deformation on the prediction and calculation of foundation uplift pressures.

\subsubsection{Describing and measuring discontinuities in rock}

For engineering purposes, descriptions of discontinuities should be quantitative when possible, should be pertinent to engineering usage, and should include characteristics or properties readily determined in the field. Characteristics of discontinuities that meet these restrictions are joint spacing (joint frequency) and bed thickness, true orientation or attitude within the rock mass (and orientation relative to nonhorizontal excavation surfaces), and condition. Discontinuity condition encompasses surface roughness (asperity), width of opening (aperture), degree of weathering, and type and degree of filling.

Another feature of rock discontinuities, one that leads to perhaps the most uncertainty in evaluating flow through jointed rock, is persistence. Persistence describes the degree to which an individual discontinuity maintains its identity and influence throughout a rock mass or within the boundaries of an excavation or construction site.

Spacing. Ideally, discontinuity spacing applies to the three-dimensional rock mass. Realistically, measurements of spacing are made in the field in one or two dimensions. Borehole core and photolog measurements of spacing are 
one-dimensional (along a line), and most rock exposure measurements are twodimensional (in a plane). Borehole measurements are biased in favor of discontinuities lying at nearly right angles to the borehole axis and against those lying parallel to the borehole axis because more of the former intersect the borehole. A foundation investigation should extrapolate to three-dimensional spacing by analyzing all complementary data from boreholes, trenches, cuts, and other exposures.

Condition. Discontinuity condition, as discussed previously, is an important consideration in classifying rock mass quality for engineering purposes. Shear strength along discontinuities and the stability of the rock mass are affected by the height and strength of surface irregularities (roughness, or asperity); the strength and thickness of joint filling, which is often clayey and considerably weaker than the host rock; and the strength of joint wall rock. Joint aperture controls the secondary permeability or effective porosity of a rock mass.

Orientation. The geometry or orientation of discontinuities is described by measuring their strike and dip. The strike of a joint or bedding plane is the direction of a horizontal line within the plane (the direction of the line of intersection of the plane with the horizontal). Strike may be measured in degrees relative to north, such as "north $50^{\circ}$ west," or degrees of azimuth measured clockwise from north, as " $310^{\circ}$." The dip is the angle between 0 and $90^{\circ}$ that the plane makes with the horizontal, measured perpendicular to the strike. Figure 3.6 illustrates the concepts of strike and dip and joint sets and system. A joint set is a group of more or less parallel joints. A joint system is made up of two or more joint sets with consistent patterns. Joint orientation influences the stability of excavations in rock. Discontinuities that dip into an excavation, or sets of joints that intersect to form a wedge dipping out of the excavation face, may be said to be adversely oriented with respect to the excavation. Joint orientation is perhaps less important than aperture and filling in assessment of uplift pressures. It is the condition of flow within joints that controls the development of uplift pressures in a rock foundation.

Grenoble and Amadei (1990) presented data from a study of uplift pressures in dam foundations. The study used finite element models of the dam and the jointed rock mass to determine the sensitivity of uplift pressures to geological factors. Their data showed that severity of uplift pressure was independent of joint orientation. The finite element model was for a foundation cut by an orthogonal system of joints. Each of ten joint networks was rotated through $360^{\circ}$ in $15^{\circ}$ increments, and the uplift pressure was calculated by the model. Figure 3.7 graphically shows the results of the study. Grenoble and Amadei stated that although the flat, dashed line through the data points of the graph is a representative linear fit of the data, there is considerable scatter in the data points.

Aperture. Engineering classifications of rock mass commonly describe joint aperture as either "tight" or "open" (see Chapter 2 of this report for a quantified definition). Deere (1964) recommended that, in addition to these terms, the magnitude of aperture be recorded for open joints. Effective, or secondary, porosity (fracture porosity of rocks that have little or no primary, or grain, porosity) can be 


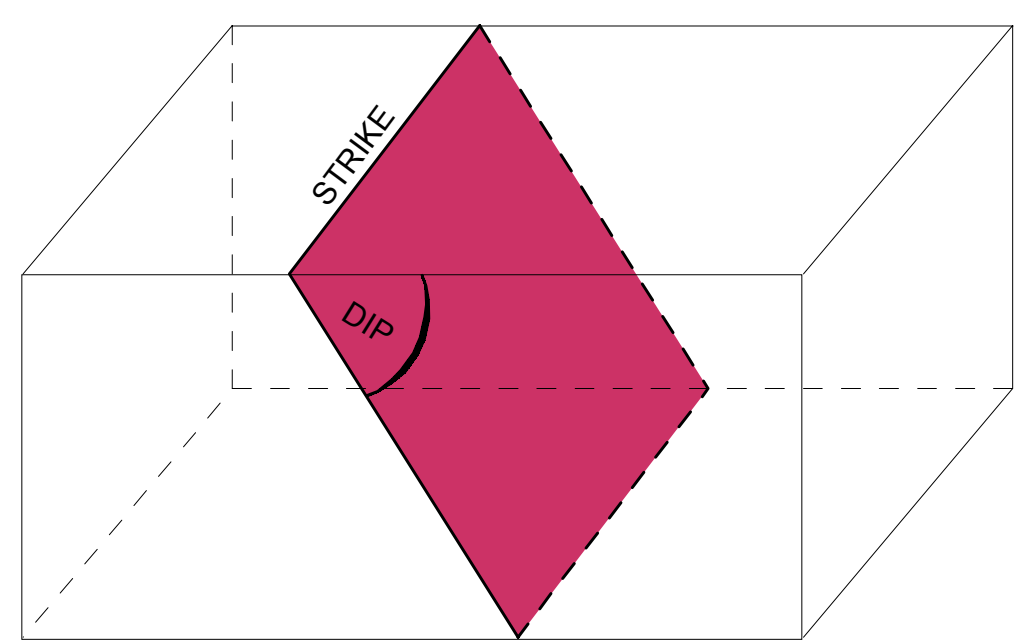

a.

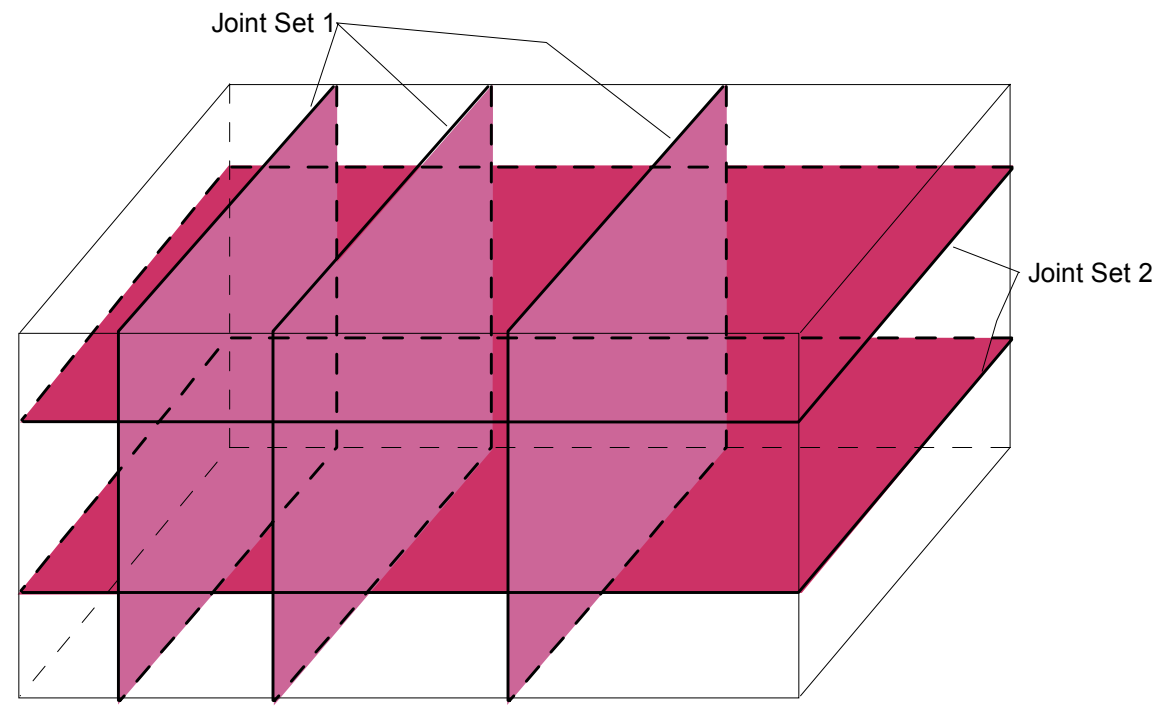

b.

Figure 3.6. (a) Joint orientation or attitude defined by strike and dip of joint plane (shaded). (b) Joint system consisting of joint sets 1 and 2

estimated from analysis of the volume of open joints determined from borehole photographic, borehole television, or other borehole viewer logging.

Borehole photography investigation of jointing in the foundation of Teton Dam defined effective porosity as the total open-joint volume divided by the volume of the boring (Banks 1977). For the Teton Dam analysis, investigators determined joint condition and aperture for every joint visible in the boring walls. 


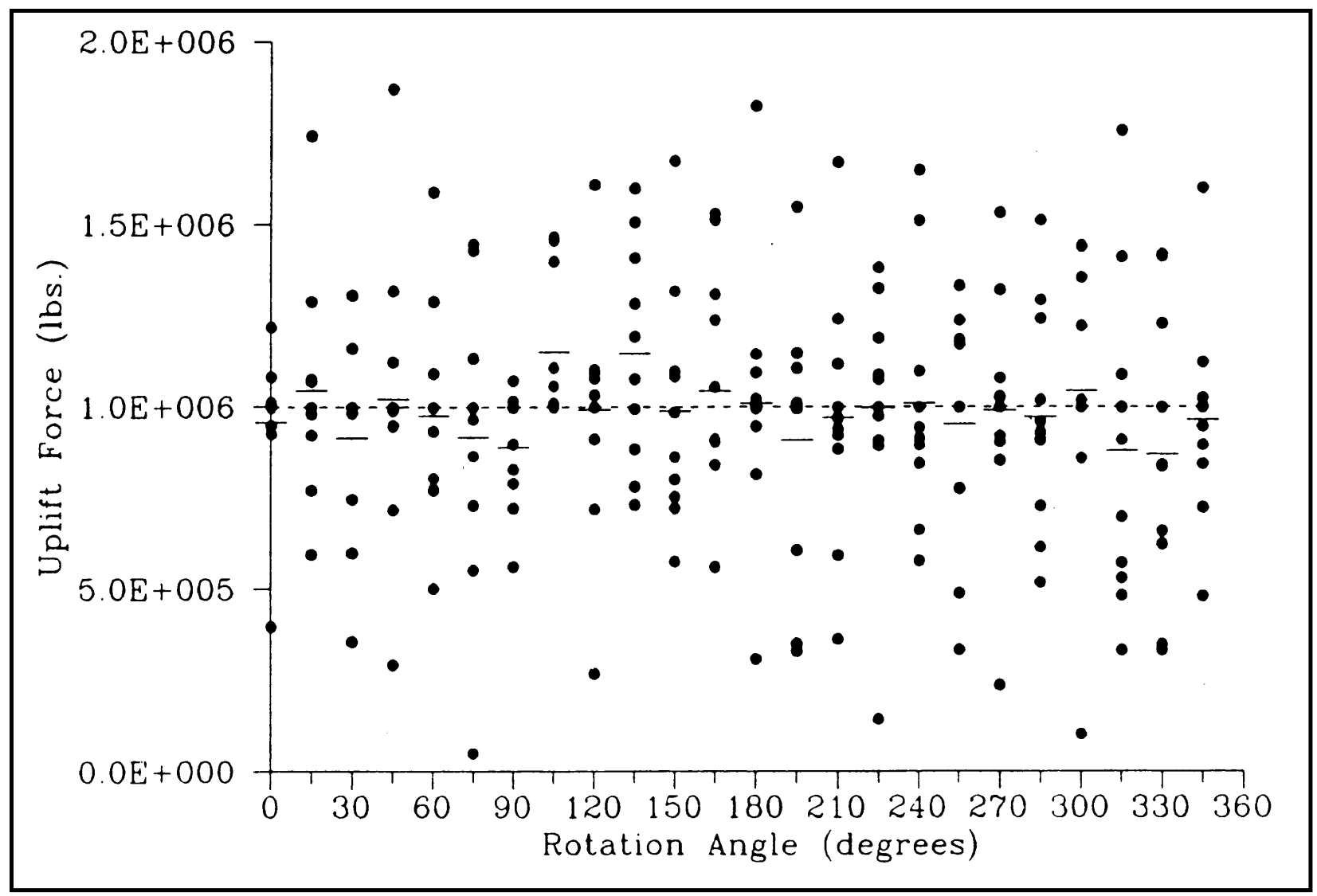

Figure 3.7. Results of finite element joint orientation study. Dashed line indicates uplift force calculated assuming a linear variation in head (after Grenoble and Amadei 1990)

Joint condition was "tight" if no aperture was present, "open" if separation of the joint walls was persistent, and "partially open" if the joint walls did not remain separated throughout the film record. For calculation of effective joint porosity, the volume of open joints was taken at 100 percent; the volume of partially open joints was halved.

Discontinuity surfaces can be examined in rock excavations if the excavation surfaces are fresh (for example, in machine-bored tunnels). Measurements of aperture in boreholes can be made by impression-type packers, which expand against the borehole walls and take an imprint of wall irregularities, such as open joints. However, ISRM (1978) emphasized that measurements of the exposed surfaces of open discontinuities may not be representative of water-conducting potential because wall roughness may reduce flow velocities. In addition, open discontinuities may be filled or closed at some distance from the measured exposure. In situ permeability testing (e.g., pressure testing, pump testing, bailing, and falling head) is a more reliable indicator of flow through apertures.

Filling. Site investigators should describe material within the walls of a discontinuity in terms of its thickness, relative grain size, and, if possible, its composition (mineralogy). Fillings such as calcite and gypsum, which are subject to removal under construction stresses or by solution, may produce greater apertures 
than those initially measured when they are removed. If the thickness and nature of such a filling are recorded, the effects of subsequent widening of the aperture can be predicted or expected.

Fillings of cohesionless materials may flow out when the rock mass is excavated. Fillings of clays with a high activity number (plasticity index divided by percent particles smaller than $0.002 \mathrm{~mm}$ ) can undergo considerable volume change in the presence of varying moisture conditions. In general, the more active a clay soil, the greater will be its volume change under changing moisture conditions. Low-activity or inactive clays are relatively weak and can be washed out from the joints. Table 3.3, from Brekke and Howard (1972), describes materials often filling joints and the potential problems associated with them. Brecciated or gouge fillings may ravel and be easily washed out of joints, resulting in higher hydraulic conductivities.

\begin{tabular}{|c|c|}
\hline $\begin{array}{l}\text { Table } 3.3 \\
\text { Material Filling Discontinuities ar } \\
\text { from Brekke and Howard } 1972\end{array}$ & Associated Problems (modified \\
\hline Material Filling Discontinuity & Potential Problems \\
\hline Swelling clay (montmorillonite, illite, attapulgite) & $\begin{array}{l}\text { Subject to volume change in variable moisture } \\
\text { conditions. May produce swelling conditions } \\
\text { when confined. May cause lifting of excavation } \\
\text { surfaces and foundations. }\end{array}$ \\
\hline Inactive clay & $\begin{array}{l}\text { Represents weak material between discontinuity } \\
\text { walls, with low shear strength if thick enough. } \\
\text { Can be washed out, resulting in open } \\
\text { discontinuity. }\end{array}$ \\
\hline $\begin{array}{l}\text { Low-friction metamorphic minerals (chlorite, } \\
\text { talc, graphite, serpentine) }\end{array}$ & Low resistance to sliding, especially when wet. \\
\hline $\begin{array}{l}\text { Crushed rock fragments or breccia; sand-like } \\
\text { gouge. }\end{array}$ & $\begin{array}{l}\text { May ravel or run out of exposed discontinuity. } \\
\text { Permeability may be high. }\end{array}$ \\
\hline Calcite, gypsum & $\begin{array}{l}\text { Soluble: may later produce larger apertures than } \\
\text { initially measured. May be weaker than wall rock }\end{array}$ \\
\hline
\end{tabular}

Asperity. Roughness, or asperity, of discontinuity walls is manifested in the presence or absence of surface irregularities and their magnitudes. Goodman (1968) showed that roughness and other joint conditions affect peak strength and load deformation curves of laboratory direct shear and in situ block shear tests on discontinuities. In addition to effects on rock shear strength, asperities on a joint surface reduce the aperture of the joint, which directly affects the effective porosity and permeability of the joint, of direct importance to assessment of uplift potential. As discussed in Chapter 2, roughness in a joint lowers the critical Reynolds number, the aperture at which flow becomes nonlaminar.

\subsubsection{Effects of joint condition on groundwater flow}

A study by Pahl, Bräuer, and Liedtke (1995) illustrated the importance of open discontinuities to the fluid conductivity of a rock mass. Salt tracer experiments in a fractured rock mass determined the fluid conductivity between an injection borehole and an observation borehole. Figure 3.8 compares salt tracer 


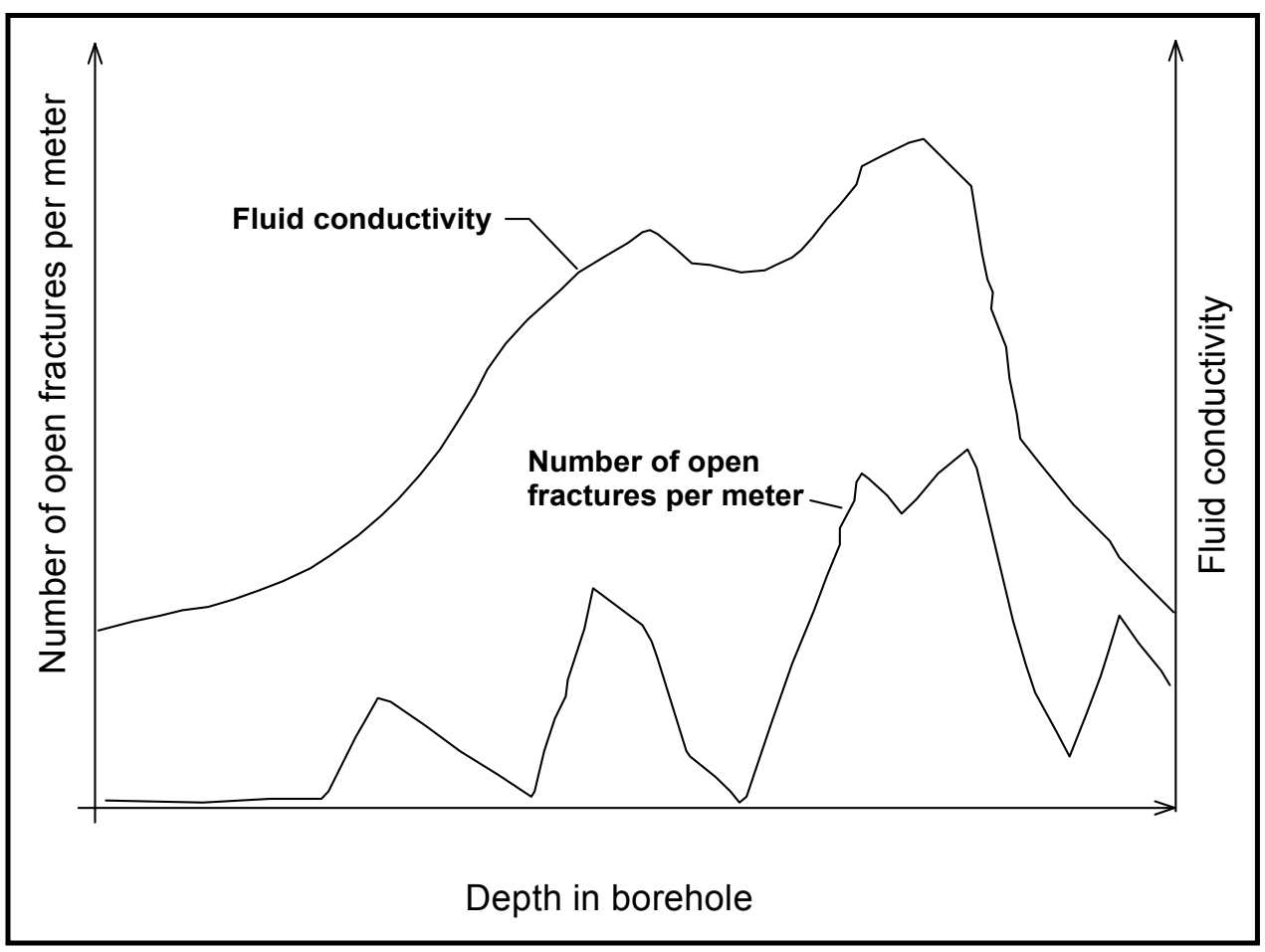

Figure 3.8. Relationship of fluid conductivity to the distribution of open fractures in a rock mass. Conductivity and fracture frequency data are for the same borehole (after Pahl, Bräuer, and Liedtke 1995)

fluid conductivity to the number of open fractures in one tested borehole. Comparison of fluid conductivity and the distribution of open fractures within logged boreholes showed a direct relationship between fluid conductivity and the number and distribution of open fractures. Fluid (hydraulic) conductivity of the rock mass is important to the distribution and magnitude of uplift pressure, as shown previously. Obviously, the number of open fractures, or fracture frequency, which affects the magnitude of fluid conductivity, is an important attribute of rock foundations in uplift prediction. Chapter 5 of this report analyzes the relationship between equivalent hydraulic conductivities and distribution of joints in pressuretested zones in boreholes of the foundation of Libby Dam.

The length of joints and the degree to which joints are interconnected influence the distribution of uplift pressures beneath a structure. Stone and Webster Engineering Corporation (1992) discussed the effects of joint length, degree of interconnectivity, and aperture on uplift pressure distribution. Figure 3.9a shows the distribution of uplift pressure along a smooth joint of constant aperture and length $L$. Figure $3.9 \mathrm{~b}$ shows the distribution of pressure along a longer joint of length $L+\Delta L$. The pressure at the left end of each joint is $P_{1}$ and at the right end is $P_{2}$. The pressure measured at a point, $a$, in the shorter joint is $P_{a}$. The pressure measured at point $a$ in the longer joint is $P_{a}$. Pressure in each joint decreases linearly from $\mathrm{P}_{1}$ to $\mathrm{P}_{2}$, but because the pressure decreases more slowly in the long joint than in the short joint (the slope of the line is lower), the pressure at point $a$ is higher in the long joint. 

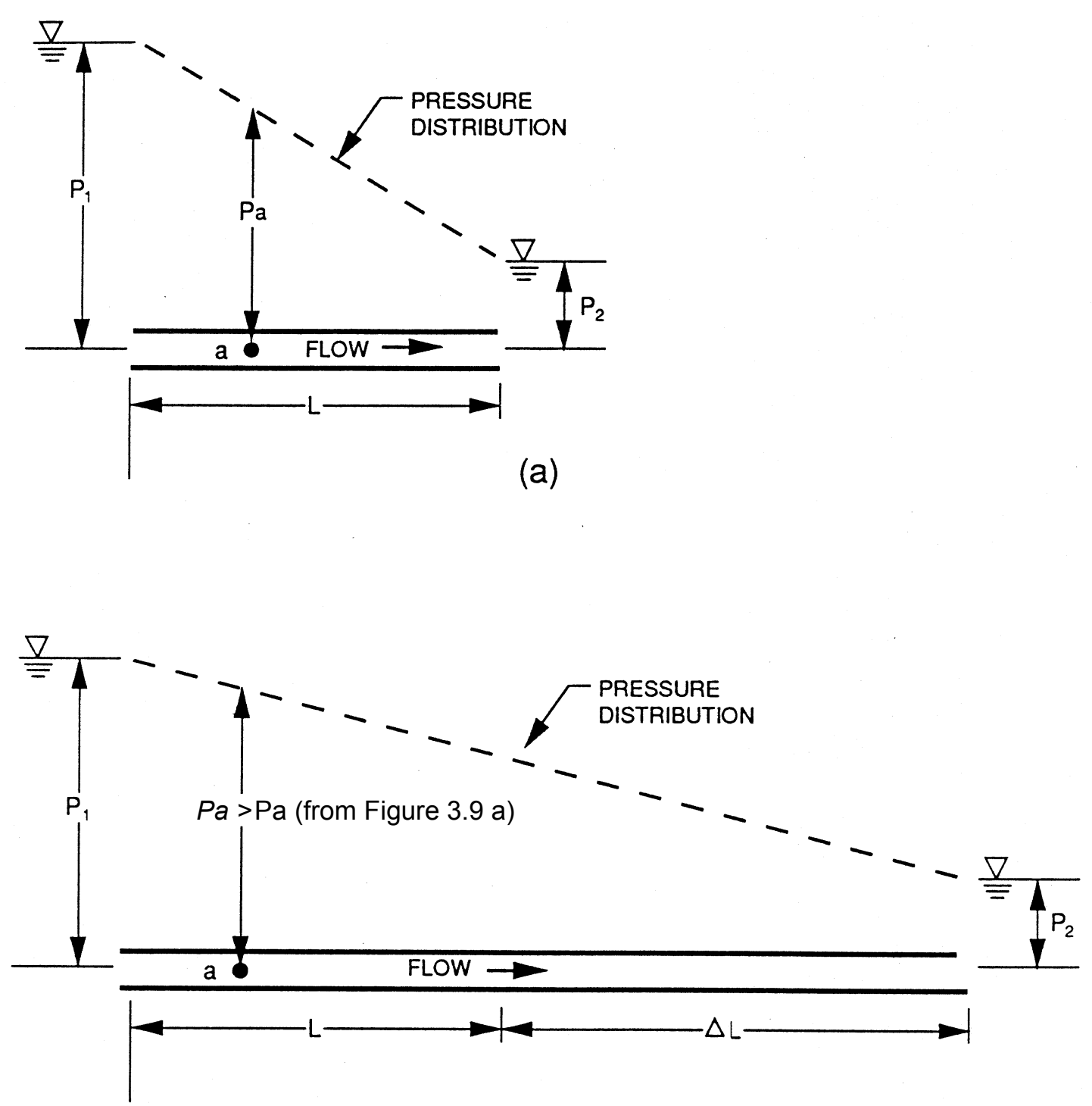

(b)

Figure 3.9. Influence of joint length on uplift pressure distribution (after Stone and Webster Engineering Corporation 1992)

Figure 3.10, also from Stone and Webster Engineering Corporation (1992), illustrates the effects of joint interconnectivity and relative aperture on uplift pressure distribution. In Figure 3.10a, seepage in the foundation is through a set of two joints of different apertures. Most of the pressure dissipation is within the small aperture because of frictional losses, and the pressure distribution is as shown. In Figure 3.10b, the reservoir feeds joints that are not connected to the tailwater of the dam. Water cannot escape through these joints and so the full, undissipated headwater pressure exists over the entire joint area, as shown by the horizontal portion of the dashed line. In a highly interconnected network of joints, the foundation behaves like a porous medium, with diffuse flow, and the pressure distribution approaches a straight line from headwater to tailwater. 


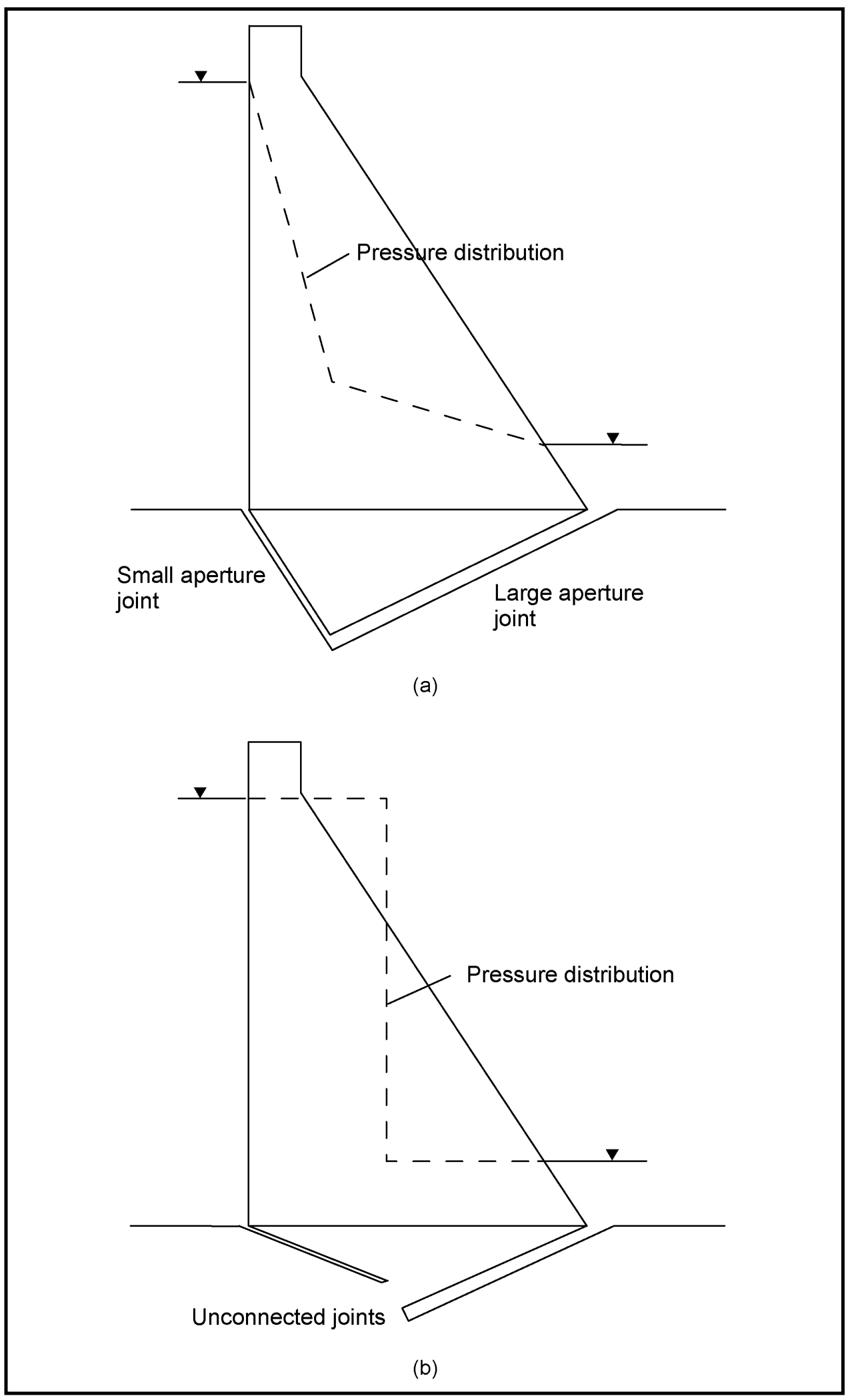

Figure 3.10. Influence of relative joint aperture and joint interconnectivity on uplift pressure distribution (after Stone and Webster Engineering Corporation 1992) 


\subsubsection{The problem with faults}

Deere (1981) discussed the critical role of faults in the design and stability of concrete dam foundations. Faults are similar to shear zones in metamorphic rocks but with additional troublesome characteristics. Unlike shear zones, faults may occur at any orientation, not simply parallel to bedding and foliation. The fault zone may range from centimeters to tens of meters in thickness, but it is typically 1 to $3 \mathrm{~m}$ thick. Because of extensive movement along the fault, the zone usually contains broken and slickensided ${ }^{1}$ rock, fault breccia, and clayey fault gouge. These materials act as zones of either higher or lower hydraulic conductivity. The broken rock on either side of the fault has higher permeability. If the fault zone is oriented so that its upstream end has access to the reservoir and its lower end outcrops below the dam, the fault is a conduit to seepage and can cause leaking and piping of fines. Faults oriented other than parallel to the flow may cause blockage of flow because of the clayey gouge within the fault zone. High piezometric levels, and high uplift pressures, may exist upstream of the fault, and cut off from downstream drains. The high hydraulic gradients upstream of the fault may cause blowouts of fine-grained gouge or soil into open joints or into drainage holes. To accommodate fault zones, deep excavation and concrete backfilling may be necessary. Deere stresses that the engineering geologist should take all steps in the initial site investigation to discover and map fault zones prior to the start of construction. Methods would include the use of aerial and satellite imagery to locate lineations that might signify the presence of faults, mapping of depressions, springs, geologic contacts and geomorphological (landform) indications, and exploratory borings, trenches, adits, test pits, and shafts to characterize the faults adequately.

An example of the impact of faults on dam foundation design and construction activities was provided by the construction of the third dam and power plant for Grand Coulee Dam in central Washington. The forebay dam for the power plant is a gravity-type structure with a maximum height of $200 \mathrm{ft}$ above the foundation. The forebay dam was constructed on the right bank of the Columbia River downstream of the main Grand Coulee Dam. Bock, Harber, and Arai (1974) discussed problems encountered in the initial stages of construction of the forebay dam. The foundation consists of fine- and coarse-grained granite. Geologic investigations of the forebay dam foundation revealed two major faults. One ran parallel to the dam axis and dipped about $60^{\circ}$ downstream, with an apparent width of about $10 \mathrm{ft}$. Officials decided to treat the fault by applying dental concrete to a depth of $25 \mathrm{ft}$. As excavation progressed, however, it was apparent that the fault was considerably wider near the center of the forebay dam. It also contained a distinct zone of gouge on each side, separated by zones of severely jointed rock. The entire 50-ft width of the fault had to be excavated and backfilled to a depth of $25 \mathrm{ft}$. In addition, a set of nearly horizontal drains was drilled upstream at an angle from the toe to intercept the fault. The drains were designed to reduce the pressure against the gouge material and to reduce foundation uplift pressures. It also became apparent that the fault gouge was susceptible to piping. To prevent plugging of the drains by eroded gouge, slotted polyvinyl chloride (PVC) pipe was

\footnotetext{
1 Slickensides are polished and striated surfaces on a fault plane. They are generally aligned
} parallel to the direction of movement along the fault. 
installed in the drain holes where they crossed the fault. This is an example of the variety of problems that faults can cause in evaluating and treating a foundation.

\subsection{Foundation Investigation Methods}

Engineer Manual (EM) 1110-1-2908 (Headquarters, U.S. Army Corps of Engineers, 1994) explains the concept of a guided approach and stepped procedures for the design of rock foundations. Any design that involves rock masses requires a decision-making process in which information and data must be obtained, considered, and addressed before decisions and judgments can be made. A coordinated team of geotechnical and structural engineers and engineering geologists is required to ensure that rock foundation conditions and design are properly integrated into the overall design of the structure and that the compiled final design of the structure is safe, efficient, and economical. Investigations address two usual analytical concerns in the design of dam foundations, bearing capacity and sliding stability. Data that should be obtained in foundation investigations during the design phase include characteristics of discontinuities, depth of overburden, groundwater conditions, depth and degree of weathering, lithology, physical and engineering properties of the rock mass, and loading conditions. The analyses of rock foundations must include an evaluation of the effects of seepage and uplift forces and of the grouting performed to reduce seepage.

Methods of determining the geological and engineering characteristics of a dam foundation include surface geologic mapping, geophysical exploration, boring and sampling, borehole testing, exploratory excavations, in situ testing, laboratory testing, and groundwater pumping and pressure testing. Detailed provisions for foundation investigating procedures, techniques, and methods are provided in EM 1110-1-2908, Rock Foundations (Headquarters, U.S. Army Corps of Engineers, 1994); EM 1110-1804, Geotechnical Investigations (Headquarters, U.S. Army Corps of Engineers, 2001); EM 1110-1-1802, Geophysical Exploration for Engineering and Environmental Investigations (Headquarters, U.S. Army Corps of Engineers, 1995); and EM 1110-2-1901, Seepage Analysis and Control for Dams (Headquarters, U.S. Army Corps of Engineers, 1993). This section summarizes methods commonly used to characterize the rock foundations of large dams.

\subsubsection{Surface mapping}

Geologic mapping of the damsite actually begins long before the start of foundation investigations. Siting of the dam requires extensive areal mapping to develop an accurate picture of the geologic framework of the area for site selection decisions. The amount of areal mapping required depends on the complexity of the regional geology, the size of the project, and the extent to which conditions have previously been described and mapped in existing published geologic reports. Large-scale, detailed geologic maps are prepared for specific sites, particularly the foundation, abutments, and appurtenant areas of the dam. The foundation map is made during excavation and construction. It is a geologic map with details on structural, lithologic, and hydrologic features. It can represent 
structure foundation, cut slopes, and geologic features in tunnels or large chambers. Mapping usually is performed after the foundation has been cleaned just before the placement of concrete or backfill. Surface cleanup at that time usually is sufficient to allow the recording of all geologic details on the foundation surface. The engineering geologist should be familiar with the design memoranda and should discuss the design with design engineers. Foundation geology should be compared with the regional geologic model developed through initial project mapping to determine if there are differences in geologic conditions that require evaluation.

The engineering geologist should look for and map indications of adverse conditions in the foundation rock mass. Adverse conditions affect the stability of cut slopes, foundation settlement and bearing capacity, sliding stability of structures, and water control measures such as grouting, seepage control, and control of uplift forces. Adverse conditions in rock include zones of weathering, soft interbeds in sedimentary and volcanic rocks, lateral changes in rock types and rock properties, presence of materials subject to volume change, adversely oriented discontinuities, highly fractured zones, faults, joints, and shear planes filled with soft or low-resistance materials, and exceptionally hard layers that slow excavation or drilling. Adverse groundwater conditions include high pore pressures and uplift pressures, swelling materials, slaking, and piping.

The field-mapping geologist should start with a geologic interpretation, or conceptual model, of the site, and then refine it as geologic mapping progresses. The scale of the foundation geologic map typically ranges from $1 \mathrm{in} .=5 \mathrm{ft}$ for hard rock with many discontinuities to $1 \mathrm{in}$. $=50 \mathrm{ft}$ for softer sedimentary or less jointed rock. The field base map should have lines of reference for location purposes. Where slopes are nearly vertical or steep and access is difficult, mapping on large-scale photographs may be desirable. Geologic features to be included on the map may include rock type and contacts between rock types; rock structure, including orientation and spacing of bedding planes, joints, faults, shear zones and other discontinuities; the shape of rock blocks (blocky or massive, tabular); and the presence of solution cavities or voids and the materials filling them.

\subsubsection{Geophysical explorations}

Geophysical exploration consists of making indirect measurements from the earth's surface or in boreholes to obtain information about the subsurface. Geophysical measurements, when interpreted, provide information about the geology, structure, and groundwater conditions in the subsurface. Geophysical explorations are most valuable when performed early in the exploration program. They are appropriate for rapid location and correlation of geologic features and the in situ measurement of rock mass elastic moduli and density. The six major geophysical exploration categories are reflection and refraction seismic, electrical resistivity, sonic, magnetic, radar, and gravity. Geophysical explorations are usually calibrated with a limited number of borings. 


\subsubsection{Boring and sampling}

Subsurface investigations are typically invasive and require disturbance of the ground to varying degrees. Most are relatively expensive and should be carefully planned to yield the maximum amount of information. Procedures should be followed carefully to ensure the production of high-quality data. The primary and most versatile means of investigating the interior of the foundation, the subsurface, is the use of borings. Borings are used to define geologic stratigraphy and structure, obtain samples for testing, obtain groundwater data, perform in situ tests, obtain samples to determine engineering properties, and install instrumentation. In rock, borings are classified broadly as rock bit and core.

Rock borings not requiring samples advance using solid bits, including fishtail, drag bits, tri-cone and roller rock bits, or diamond plug bits. Rotary-cored rock samples are commonly retrieved in 5- to 10-ft lengths in hollow-core barrels equipped with diamond- or carbide-impregnated bits. Core hole diameters range from about 1.2 to about $7.75 \mathrm{in}$. The most common hole size used by the Corps for geotechnical investigations is NX size, with a hole diameter of about $3 \mathrm{in}$. The use of wireline drilling, whereby the core barrel is retrieved through the drill rod string, eliminates the need to remove the drill rods for sampling and saves a great deal of time in deep borings. Table 3.4 lists popular core bit core and hole diameters. Core recovery in zones of weak or intensely fractured rock is particularly important because these zones are typically the critical areas in foundation loading and stability considerations. The use of larger diameter core bits ranging from 4 to 6 in. in diameter are frequently required to produce good core in highly fractured rock. Larger diameter core samples are also desirable for rock strength tests, especially for testing discontinuities.

\begin{tabular}{|c|c|c|}
\hline \multicolumn{3}{|c|}{$\begin{array}{l}\text { Table } 3.4 \\
\text { Popular Diamond Core Bit Core and Hole Diameters }\end{array}$} \\
\hline Bit Designation & Core Diameter, in. (mm) & Reaming Shell (Hole) Diameter, in. ( $\mathrm{mm}$ \\
\hline \multicolumn{3}{|c|}{ "W" Group, "G" and "M" design } \\
\hline EWG (EWX), EWM & $0.845(21.5)$ & $1.485(37.7)$ \\
\hline AWG (AWX), AWM & $1.185(30.0)$ & $1.890(48.0)$ \\
\hline BWG (BWX), BWM & $1.655(42.0)$ & $2.360(59.9)$ \\
\hline NWG (NWX), NWM & $2.155(54.7)$ & $2.980(75.7)$ \\
\hline HWG & $3.000(76.2)$ & $3.907(99.2)$ \\
\hline \multicolumn{3}{|c|}{ "Large-diameter } \\
\hline $2-3 / 4 \times 3-7 / 8$ & $2.690(68.3)$ & $3.875(98.4)$ \\
\hline $4 \times 5-1 / 2$ & $3.970(100.8)$ & $5.495(139.6)$ \\
\hline $6 \times 7-3 / 4$ & $5.970(151.6)$ & $7.750(196.8)$ \\
\hline \multicolumn{3}{|c|}{ Wireline } \\
\hline $\mathrm{AQ}$ & $1-1 / 16(27.0)$ & 1-57/64 (48.0) \\
\hline $\mathrm{BQ}$ & $1-7 / 16(36.5)$ & $2-23 / 64(60.0)$ \\
\hline $\mathrm{NQ}$ & $1-7 / 8(47.6)$ & $2-63 / 64(75.8)$ \\
\hline $\mathrm{HQ}$ & $2-1 / 2(63.5)$ & 3-25/32 (96.0) \\
\hline $\mathrm{PQ}$ & $3-11 / 32(85.0)$ & $4-53 / 64(122.6)$ \\
\hline
\end{tabular}


Most rock core borings are drilled vertically. However, inclined and horizontal borings may be required to define stratification, jointing, and other discontinuities adequately, or to install drain or grout holes in critical areas. Oriented core drilling may be required if precise geological structure (orientation of discontinuity planes in the subsurface) is to be evaluated from core samples. In these procedures, the core is scribed or engraved with a special drilling tool so that its orientation is preserved. Borehole viewing equipment, such as cameras, can also be used to determine in situ orientation.

There is always a degree of uncertainty in interpreting subsurface geologic structure from small-diameter boreholes. Core breakage from drill action may mask natural joints and bedding planes. Orientation of discontinuities is obtained somewhat indirectly and may be disturbed during the handling of samples. The persistence of discontinuities within the rock mass is particularly hard to gauge from a borehole. The properties, particularly strength, of cored samples may overestimate the strength of rock mass, because the effects of planes of weakness may be missed in a small sample. Large-diameter borings, or calyx holes, $2 \mathrm{ft}$ or more in diameter, are sometimes used in large or critical structures. Calyx holes permit direct examination of the borehole walls and provide access for performing in situ tests and obtaining high-quality undisturbed samples.

Core logging is usually performed immediately after the core is retrieved from the boring, while natural discontinuities are fresh and the rock has not been exposed to deterioration from stress relief and changing moisture conditions. The core log commonly includes the rock type designation and the name of the geologic unit, if known. The core log provides a field determination of the relative strength of the rock, the degree of weathering, the texture, the structure, and the presence and condition of discontinuities. The latter may include orientation with respect to the core axis, surface roughness, nature of infilling or coating, presence of staining, and tightness or aperture. Other features of the cored rock include color; swelling and slaking properties, if appropriate; inclusions, such as fossils or minerals; and the presence of solution cavities or other voids. Rock quality indexes, such as rock quality designation (RQD), may also be determined during the core logging process.

\subsubsection{Borehole examination and testing}

A wide array of downhole geophysical probes is available to measure geological properties and to supplement core sampling. Borehole electrical probes measure conductivity or resistivity of fluids within the formation and aid in correlating strata between boreholes. Downhole radiation tools measure natural or emitted radiation of formation fluids as an aid to correlation of strata and for determination of type of rock, rock density, and formation hydraulic conductivity. Borehole imagery devices delineate voids and discontinuities in the wall of the borehole using acoustic energy. Mechanical and acoustic calipers measure borehole diameter. 


\subsubsection{Exploratory excavations (tunnels, shafts, drifts, test pits, trenches)}

The complexity, extent, and size of some shear zones and faults in a dam foundation rock mass require a larger surface exposure for adequate examination and testing than is offered by borings. In such cases, the excavation of test pits, trenches, or drifts may be necessary to evaluate the feature. Test pits and trenches can be constructed quickly and economically by bulldozers, backhoes, pans, draglines, or ditching machines in rippable rock and soil. Many test pits and most exploratory tunnels in rock require drilling and blasting and are relatively expensive. Test pits and trenches generally are used only above the groundwater level. Exploratory trench excavations are often used in fault evaluation studies. Largediameter calyx holes have been used successfully on some jobs to provide access for direct observation of critical features in the foundations.

Exploratory tunnels, or drifts, permit detailed examination of the condition and orientation of rock structures. Commonly used in the foundations and abutments of large dams, they are particularly appropriate in defining the extent of marginal strength rock or adverse rock structure detected in surface mapping and borings. For large projects where high loads will be transmitted to the foundation, tunnels and large shafts provide the only practical means for testing in-place rock at locations and in directions corresponding to the structural loading. The geologic information gained from careful mapping of the tunnel provides a critical supplement to interpretations based on data from surface mapping and other sources. Zones of excessive seepage or blockage of groundwater flow in buried shear or fault zones may have a strong effect on the development of uplift pressures following dam construction. Exploratory tunnels offer a means of detecting and examining such zones directly. Exploratory tunnels often serve a multiple purpose by providing access for drainage and grouting holes, for post-construction observations, and for utility conduits.

\subsubsection{In situ testing}

In situ tests are often the best means for determining the engineering properties of subsurface materials and, in some cases, may be the only way to obtain meaningful results. In situ rock tests are performed to determine in situ stresses and deformation properties (elastic moduli) of the jointed rock mass, shear strength of jointed rock masses or critically weak zones, such as shear zones, within the rock mass, and residual stresses along discontinuities or weak zones. Table 3.5 summarizes the types and purposes of in situ tests in rock and soil. Pressure tests, which measure the hydraulic properties of the rock mass or of limited zones of rock, are most applicable to investigations of the potential for uplift pressures. Pressure testing in foundations of gravity dams is discussed at length in Chapters 2 and 5 of this report. 


\begin{tabular}{|c|c|c|c|}
\hline \multicolumn{4}{|c|}{$\begin{array}{l}\text { Table } 3.5 \\
\text { In Situ Tests for Rock and Soil (Headquarters, U.S. Army Corps of } \\
\text { Engineers 2001) }\end{array}$} \\
\hline \multirow[b]{2}{*}{ Purpose of Test } & \multirow[b]{2}{*}{ Type of Test } & \multicolumn{2}{|c|}{ Applicability to } \\
\hline & & Soil & Rock \\
\hline \multirow[t]{4}{*}{ Shear strength } & Plate bearing or jacking & $x$ & $\mathrm{X}^{1}$ \\
\hline & Pressuremeter $^{2}$ & & $x$ \\
\hline & Uniaxial compressive $^{2}$ & & $x$ \\
\hline & Borehole jacking $^{2}$ & & $\mathrm{x}$ \\
\hline Bearing capacity & Plate bearing & $\mathrm{x}$ & $\mathrm{X}^{1}$ \\
\hline \multirow[t]{7}{*}{ Stress conditions } & Hydraulic fracturing & $\mathrm{x}$ & $\mathrm{x}$ \\
\hline & Pressuremeter & $\mathrm{x}$ & $\mathrm{X}^{1}$ \\
\hline & Overcoring & & $x$ \\
\hline & Flatjack & & $x$ \\
\hline & Uniaxial (tunnel) jacking & $\mathrm{x}$ & $x$ \\
\hline & Borehole jacking $^{2}$ & & $x$ \\
\hline & Chamber (gallery) pressure ${ }^{2}$ & & $x$ \\
\hline \multirow[t]{6}{*}{ Mass deformability } & Geophysical (refraction) & $\mathrm{x}$ & $x$ \\
\hline & Pressuremeter or dilatometer & $x$ & $\mathrm{X}^{1}$ \\
\hline & Plate bearing & $x$ & $\mathrm{x}$ \\
\hline & Uniaxial (tunnel) jacking & $\mathrm{x}$ & $\mathrm{x}$ \\
\hline & Borehole jacking $^{2}$ & & $x$ \\
\hline & Chamber (gallery) pressure ${ }^{2}$ & & $x$ \\
\hline
\end{tabular}

\subsubsection{Laboratory testing}

Laboratory tests provide data on physical and hydrological properties of natural materials, determine index values for identification and correlation by means of classification tests, and define the engineering properties in parameters usable for foundation design. A list of references for laboratory tests pertinent to foundation investigations in rock is provided in Table 3.6.

\subsubsection{Groundwater and foundation seepage investigations}

Groundwater investigations for dam foundations in rock provide baseline data on water table and piezometric levels in the vicinity of the dam, areas or zones of pore pressure and potential uplift pressure, and estimates of seepage and the location of sources of seepage. Groundwater studies include observation and measurement of flows from springs and seeps and water levels in existing production wells, exploratory boreholes, observation wells, and piezometers. Foundation investigations include field and laboratory tests for permeability and hydraulic conductivity, pressure testing of rock strata in boreholes, and pumping tests for determination of rock mass hydraulic conductivity. This information is used with site and regional geologic information to determine water table or piezometric elevations, fluctuations in groundwater elevations, direction and rate of seepage flow in the foundation area, and potential for leakage beneath the dam. The most 


\begin{tabular}{|c|c|c|}
\hline \multicolumn{3}{|c|}{$\begin{array}{l}\text { Table } 3.6 \\
\text { Laboratory Classification and Index Tests for Rock (after } \\
\text { Headquarters, U.S. Army Corps of Engineers 2001) } \\
\end{array}$} \\
\hline Test & Test Method & Remarks \\
\hline $\begin{array}{l}\text { Unconfined (uniaxial) } \\
\text { compression }\end{array}$ & $\mathrm{RTH}^{1} 111$ & $\begin{array}{l}\text { Primary index test for strength and deformability of } \\
\text { intact rock }\end{array}$ \\
\hline Water content & RTH 106 & $\begin{array}{l}\text { Indirect indication of porosity of rock or clay content } \\
\text { of sedimentary rock }\end{array}$ \\
\hline $\begin{array}{l}\text { Pulse velocities and elastic } \\
\text { constants }\end{array}$ & RTH 110 & $\begin{array}{l}\text { Index of compressional wave velocity and elastic } \\
\text { constants for correlation with in situ geophysical } \\
\text { test results }\end{array}$ \\
\hline Rebound number & RTH 105 & Index of relative hardness of intact rock cores \\
\hline $\begin{array}{l}\text { Permeability (hydraulic } \\
\text { conductivity) }\end{array}$ & RTH 114 & Intact rock (no joints or other major discontinuities) \\
\hline Petrographic examination & RTH 102 & $\begin{array}{l}\text { Performed on representative cores of each } \\
\text { significant lithologic unit }\end{array}$ \\
\hline $\begin{array}{l}\text { Specific gravity and } \\
\text { absorption }\end{array}$ & RTH 107 & Indirect indication of soundness and deformability \\
\hline $\begin{array}{l}\text { Unit weight and total } \\
\text { porosity }\end{array}$ & RTH 109 & Indirect indication of weathering and soundness \\
\hline $\begin{array}{l}\text { Point load testing (also } \\
\text { performed in field) }\end{array}$ & RTH 325 & $\begin{array}{l}\text { Used to predict other strength parameters with } \\
\text { which it is correlated }\end{array}$ \\
\hline $\begin{array}{l}\text { Elastic moduli from uniaxial } \\
\text { compression test }\end{array}$ & RTH 201 & Intact rock cores \\
\hline $\begin{array}{l}\text { Triaxial compressive } \\
\text { strength }\end{array}$ & RTH 202 & $\begin{array}{l}\text { Deformation and shear strength of core containing } \\
\text { inclined discontinuities }\end{array}$ \\
\hline Direct shear strength & RTH 203 & $\begin{array}{l}\text { Strength along planes of weakness or rock- } \\
\text { concrete contact }\end{array}$ \\
\hline
\end{tabular}

reliable means for determining water levels and monitoring pore pressures is the use of piezometers and observation wells. Piezometers measure pore pressures at a point in the subsurface by means of a porous tip, sealed at a particular depth, and a standpipe or electrical connection to the surface for recording the pressure. Observation wells commonly have a section of open hole or slotted or perforated pipe, 2 or more feet in length, connected to the surface by a standpipe. Observation wells usually measure a composite water level over a considerable length of the aquifer. Table 3.7 describes instruments for measuring piezometric pressure.

Piezometers and observation wells allow measurement of fluctuations in piezometric levels over time. Periodic readings are commonly taken to monitor pressure changes that may develop with reservoir fluctuation and increase or decrease in seepage flows. Locations of piezometers should be selected to provide the data necessary to detect and monitor pore pressure levels and changes and to aid in design of seepage and uplift control measures, such as the installation of drains and grout curtains. The presence of a confined zone or several zones each with a different water level requires the use of piezometers to confine and separate each level. Placing piezometers within key open discontinuities, such as open bedding or shear zones, and monitoring pressures periodically would permit indirect observation and confirmation of deformation within the foundation by reservoir stresses. 


\begin{tabular}{|c|c|c|}
\hline \multicolumn{3}{|c|}{$\begin{array}{l}\text { Table } 3.7 \\
\text { Instruments for Measuring Piezometric Pressure (Headquarters, U.S. Army Corps of } \\
\text { Engineers 1995a) }\end{array}$} \\
\hline Instrument Type & Advantages & Limitations $^{1}$ \\
\hline "Observation well & $\begin{array}{l}\text { Easy installation } \\
\text { Field readable }\end{array}$ & $\begin{array}{l}\text { Provides vertical connection between } \\
\text { strata and should only be used in } \\
\text { continuously permeable strata }\end{array}$ \\
\hline Open standpipe piezometer & $\begin{array}{l}\text { Reliable } \\
\text { Long successful performance record } \\
\text { Self-de-airing if inside diameter of } \\
\text { standpipe is adequate } \\
\text { Integrity of seal can be checked after } \\
\text { installation } \\
\text { Can be used to determine permeability } \\
\text { Readings can be made by installing } \\
\text { pressure transducer or sonic sounder } \\
\text { in standpipe }\end{array}$ & $\begin{array}{l}\text { Time lag can be a factor } \\
\text { Subject to damage by construction } \\
\text { equipment and by vertical } \\
\text { compression of soil around standpipe } \\
\text { Extension of standpipe through } \\
\text { embankment fill interrupts } \\
\text { construction and may cause inferior } \\
\text { compaction } \\
\text { Possible freezing problems } \\
\text { Porous filter can plug owing to repeated } \\
\text { water inflow and outflow }\end{array}$ \\
\hline Twin-tube hydraulic piezometer & $\begin{array}{l}\text { Buried components have no moving } \\
\text { parts } \\
\text { Reliable when maintained } \\
\text { Long successful performance record } \\
\text { When installed in fill, integrity can be } \\
\text { checked after installation } \\
\text { Piezometer cavity can be flushed } \\
\text { Can be used to determine permeability } \\
\text { Short time lag } \\
\text { Can be used to read negative pore water } \\
\text { pressures }\end{array}$ & $\begin{array}{l}\text { Application generally limited to long-term } \\
\text { monitoring of pore water pressure in } \\
\text { embankment dams } \\
\text { Elaborate terminal arrangements needed } \\
\text { Tubing must not be significantly above } \\
\text { minimum piezometric elevation } \\
\text { Periodic flushing is required } \\
\text { Possible freezing problems } \\
\text { Attention to many details is necessary }\end{array}$ \\
\hline Pneumatic piezometer (Embedded) & $\begin{array}{l}\text { Short time lag } \\
\text { Calibrated part of system accessible } \\
\text { Minimum interference to construction; } \\
\quad \text { level of tubes and readout } \\
\text { independent of level of tip } \\
\text { No freezing problems }\end{array}$ & $\begin{array}{l}\text { Requires a gas supply } \\
\text { Installation, calibration, and maintenance } \\
\text { require care }\end{array}$ \\
\hline Vibrating wire piezometer (Embedded) & $\begin{array}{l}\text { Easy to read } \\
\text { Short time lag } \\
\text { Minimum interference to construction; } \\
\quad \text { level of lead wires and readout } \\
\text { independent of level of tip } \\
\text { Lead wire effects minimal } \\
\text { Can be used to read negative pore water } \\
\text { pressures } \\
\text { No freezing problems }\end{array}$ & $\begin{array}{l}\text { Potential for zero drift (Special } \\
\text { manufacturing techniques required to } \\
\text { minimize zero drift }{ }^{2} \text { ) } \\
\text { Need for lightning protection should be } \\
\quad \text { evaluated }\end{array}$ \\
\hline $\begin{array}{l}\text { Electrical resistance piezometer } \\
\text { (Embedded) }\end{array}$ & $\begin{array}{l}\text { Easy to read } \\
\text { Short time lag } \\
\text { Minimum interference to construction; } \\
\quad \text { level of lead wires and readout } \\
\text { independent of level of tip } \\
\text { Can be used to read negative pore water } \\
\quad \text { pressures } \\
\text { No freezing problems } \\
\end{array}$ & $\begin{array}{l}\text { Potential lead wire effects unless } \\
\quad \text { converted to } 4 \text { to } 20 \text { milliamps } \\
\text { Errors caused by moisture and corrosion } \\
\quad \text { are possible } \\
\text { Need for lightning protection should be } \\
\quad \text { evaluated }\end{array}$ \\
\hline \multicolumn{3}{|c|}{$\begin{array}{l}\text { Diaphragm piezometer readings indicate the head above the piezometer, and the elevation of the piezometer must be } \\
\text { measured or estimated if piezometric elevation is required. All diaphragm piezometers, except those provided with a vent to the } \\
\text { atmosphere, are sensitive to barometric pressure changes. If piezometer pipes, tubes, or cables are carried up through fill, there } \\
\text { will be significant interruption to construction and the probability of inferior compaction. } \\
2 \text { See Dunnicliff (1988). } \\
\text { Source: Dunnicliff (1988). }\end{array}$} \\
\hline
\end{tabular}


Hydraulic conductivity of the rock mass or of porous strata can be calculated from pumping test data, slug (single-hole falling head or constant head) tests, or pressure tests. Pumping tests employ a combination of a pumping, or discharge, well and observation wells at variable spacing out from the well. The flow rate of the well and the measured drawdown in the observation wells supply the necessary data to calculate the average hydraulic conductivity of the rock within the zone of influence of the pumping well. A problem with pumping test data in rock in which flow occurs anisotropically within discontinuities, rather than through a pervious rock mass, is that the influence of one or more conductive discontinuities can be overlooked. Pressure tests of specific zones of rock are more useful in delineating zones of hydraulic conductivity in jointed rock. In addition, pressure tests in intervals more accurately define the depth of permeable rock, because rock mass conductivity normally decreases with depth. This kind of information is crucial to designing drainage and grouting curtains to control seepage and uplift in dam foundations. 


\section{Selection of Case History for Uplift Investigation}

This chapter documents the process of selection of a dam for case-history study in the uplift uncertainty investigation. The authors reviewed historical documents and data available for seven U.S. Army Corps of Engineers concrete or concrete and earth-fill dams nationwide. Dams with well-documented foundation geological investigations, particularly with respect to groundwater and joint conditions, and abundant and well-documented uplift pressure monitoring data had the highest potential for selection as a case history.

On recommendation of the Office of the Chief of Engineers, selection of the potential pilot study candidates focused on two geographic areas: the northwestern United States and the Tennessee-Kentucky area, where dams were instrumented by uplift gauges during construction. Dams under consideration were in four Corps Districts: Seattle, Portland, Walla Walla, and Nashville. The dams under consideration spanned a period of 25 to 55 years from completion of construction and were all continuously monitored by instruments for uplift.

Two types of dams were considered: entirely monolithic concrete gravity dams in narrow rocky valleys of the Northwest, and much lower dams consisting of earth-fill-compacted embankments with concrete gravity dams in the center. The latter types were all in the Nashville District.

The following aspects were weighed in consideration of potential candidates for the uplift uncertainty study:

a. Availability of reliable structural and geologic documentation for each dam.

b. Availability and suitability of subsurface exploration performed before, during, and after construction of each dam.

c. Location of instruments in monoliths in proximity to available geologic data.

d. Performance of instrumentation as recorded and published in Periodic Inspection Reports for each dam.

The dams are described in the following paragraphs, with the most suitable dams described first. 


\subsection{Libby Dam}

\subsubsection{Description}

Libby Dam is located in northwest Montana on the Kootenai River 17 miles upstream of Libby, Montana, and 221.9 miles from the confluence of the Kootenai with the Columbia River. Initial geological investigations were conducted between 1951 and 1954. The foundation investigation was completed in 1965, but the final foundation report was not published until 1979. Construction began in 1967 and was completed in July 1973. Figure 4.1 presents a plan and upstream view of the dam.

Libby is a concrete gravity structure, $420 \mathrm{ft}$ high from top of rock and $370 \mathrm{ft}$ above the streambed at its highest monolith. It is $350 \mathrm{ft}$ high from the streambed at monolith 23, where the width of the base is $250 \mathrm{ft}$. Maximum pool elevation of $2,459 \mathrm{ft}$ mean sea level (MSL) was not reached until the summer of 1974 because of operational and safety problems during construction and lack of flow in the river during the period 1972-1973. The minimum regulated pool elevation is $2,287 \mathrm{ft}$. The maximum length of the crest is $3,033 \mathrm{ft}$. The tailwater elevation at Libby Dam varies between 2,198.9 ft and 2,117.3 ft with an average, determined on a frequency basis, of $2,124.7 \mathrm{ft}$.

\subsubsection{Foundation geology}

An initial investigation started in 1961 prior to construction. A total of 225 exploration holes were drilled in the vicinity of the preliminary and final design dam axis. Three test pits excavated in the extensive overburden section, near the right abutment, permitted better sampling of the thick overburden section in this area and more realistic design assumptions for the cut slope in the right abutment.

Four adits were excavated in the abutment areas. One was excavated into rock adjacent to the right abutment. It was $208.3 \mathrm{ft}$ in length at elevation $2,261.7 \mathrm{ft}$, and the portal was a short distance from the toe of the dam. Adit No. 2 was $201 \mathrm{ft}$, and adits No. 3 and No. 4 were $86.5 \mathrm{ft}$ and $85.5 \mathrm{ft}$ long, respectively. Adit No. 1 was left open to provide inspection for possible water seepage on the right abutment. Adit No. 4 was incorporated in the dam as a portion of the downstream drainage gallery. The remaining adits were backfilled with concrete.

Contract specifications called for foundation exploration to confirm the design evaluation of the foundation during construction. Exploration consisted of a minimum of one NX core hole drilled $40 \mathrm{ft}$ into the foundation rock for each abutment monolith founded above elevation 2,300 ft MSL, and $60 \mathrm{ft}$ into the foundation rock for each abutment monolith founded below elevation 2,300 ft MSL. In addition, eight air track probe holes were drilled to establish the extent of the rocksurface low at the downstream toes of the dam in the vicinity of monoliths 17 and 18. Drill action and cuttings were monitored to establish top of rock. Geologic logging of foundation exploration borings for Libby Dam provided more detailed information on discontinuities than that for Dworshak Dam, discussed in the next 


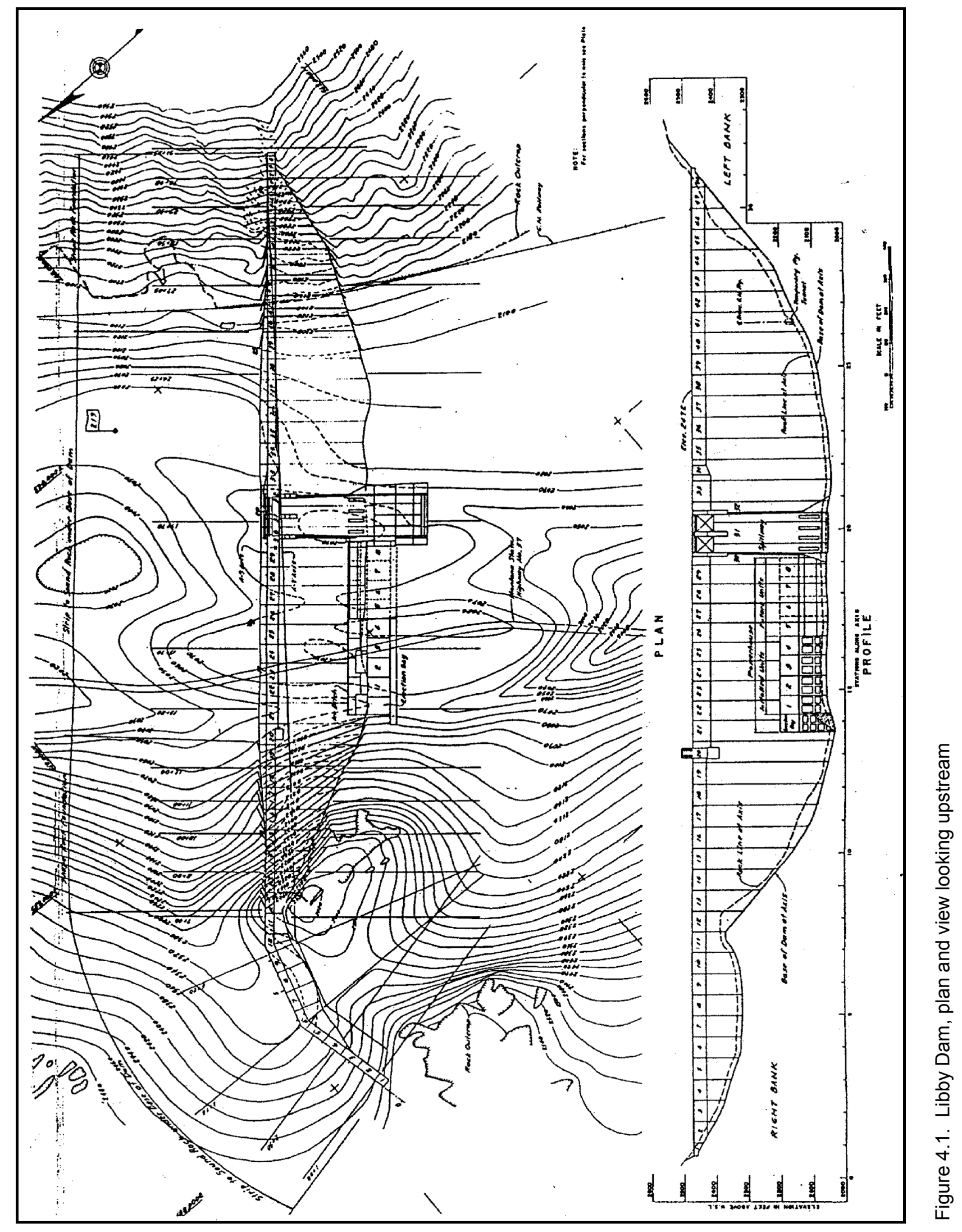


section. In the typical Libby Dam foundation boring log, the column labeled "Graphic Log" apparently identifies every visible joint in the core. Major joints and other discontinuities are described under "Description of Materials" and in the "Remarks" columns of the boring logs.

Rock at the damsite, described in the foundation report (U.S. Army Engineer District, Seattle 1979) consists mainly of quartzite, metasandstone, and siliceous argillite (a weakly metamorphosed mudstone). The foundation has a welldeveloped fracture system consisting of several kinds and sets of joints. Bedding joints strike $330^{\circ}$ (azimuth) and dip $40^{\circ}$ to $45^{\circ}$ west. A prominent set of east-west striking, high-angle shear joints dips $60^{\circ}$ to $80^{\circ}$ north or south. Where shear joints intersect bedding joints, wedges were formed in the valley walls. Generally northsouth striking "relaxation joints" dip $50^{\circ}$ to $80^{\circ}$ east. "Tension" joints strike northeast and dip at moderate to high angles to the southeast. Other tension joints strike parallel to bedding and dip at right angles to bedding, and are probably related to folding. Many low-angle rebound joints (formed during unloading of the rock mass) have random strikes. Some prominent bedding joints are filled with gouge and are slickensided, evidence of movement, and are considered faults. Several episodes of movement were noted along the faults. Intersection of faults with eastwest and north-south trending joints has broken the rock mass into discrete blocks. Certain joints were open to a considerable depth, possibly caused by unloading after glaciation.

The grout curtain is composed of three zones: a tertiary zone $40 \mathrm{ft}$ into rock, a secondary zone $90 \mathrm{ft}$ into rock, and a primary zone $160 \mathrm{ft}$ into rock. In the valley section of the dam (monoliths 18 through 27), the grout holes were inclined $25^{\circ}$ from vertical upstream and $15^{\circ}$ from vertical toward the left abutment. Grouting holes are on 5 -ft centers in monolith 23. Figure 4.2 is a view upstream at the section through the grout drainage gallery along the axis of the dam. Figure 4.3 is a section through monoliths 22,23 , and 24 showing the arrangement of grouting holes.

\subsubsection{Instrumentation}

Two galleries at the lower section of the dam provide access to uplift gauges and tops of drain holes. The galleries run parallel to the axis of the dam and are approximately $100 \mathrm{ft}$ apart and at varying elevations. At monolith 23, the galleries are at elevations $2,078.52 \mathrm{ft}$ and 2,080 ft, respectively. The drains in the two galleries in monolith 23 are between 60 and $150 \mathrm{ft}$ in length. Drain holes were drilled on 10-ft centers through 1/2-in. I.D. galvanized pipes, $5 \mathrm{ft}$ long, embedded in the concrete. All drain holes were 3 in. in diameter and were drilled in a plane parallel to the dam axis. In monoliths 18 through 38, all drain holes were drilled at an angle of $15^{\circ}$ off vertical towards the left abutment.

Uplift pressure cells were installed under six monoliths: two abutment monoliths (14 and 41) and four valley monoliths (18, 23, 29, and 34). Uplift block sensors are in monoliths 18, 19, 23, 34, and 41. Seattle District provided a complete set of gauge readings for these monoliths. The data were also graphically represented in the latest inspection report published by the District. The records 


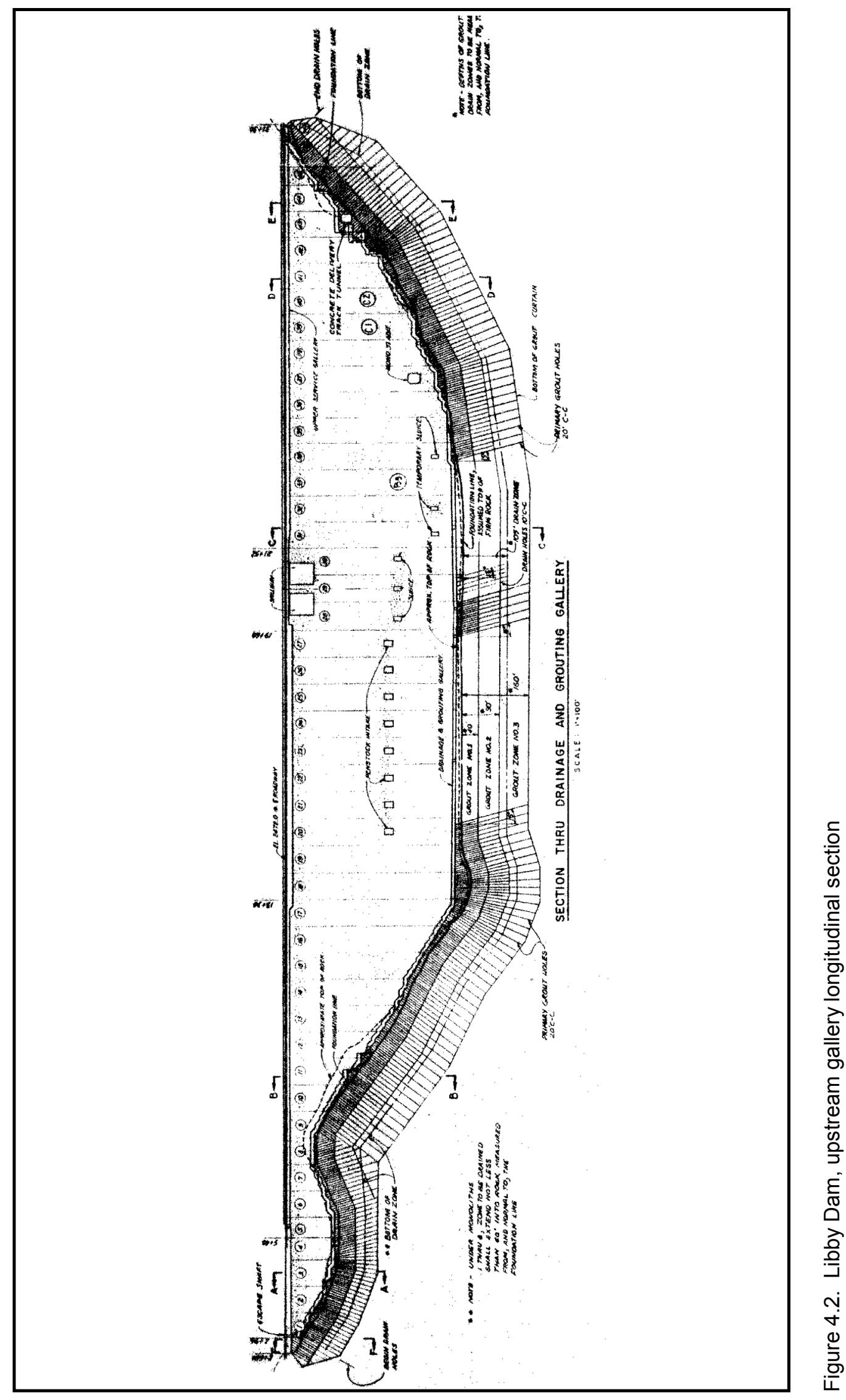




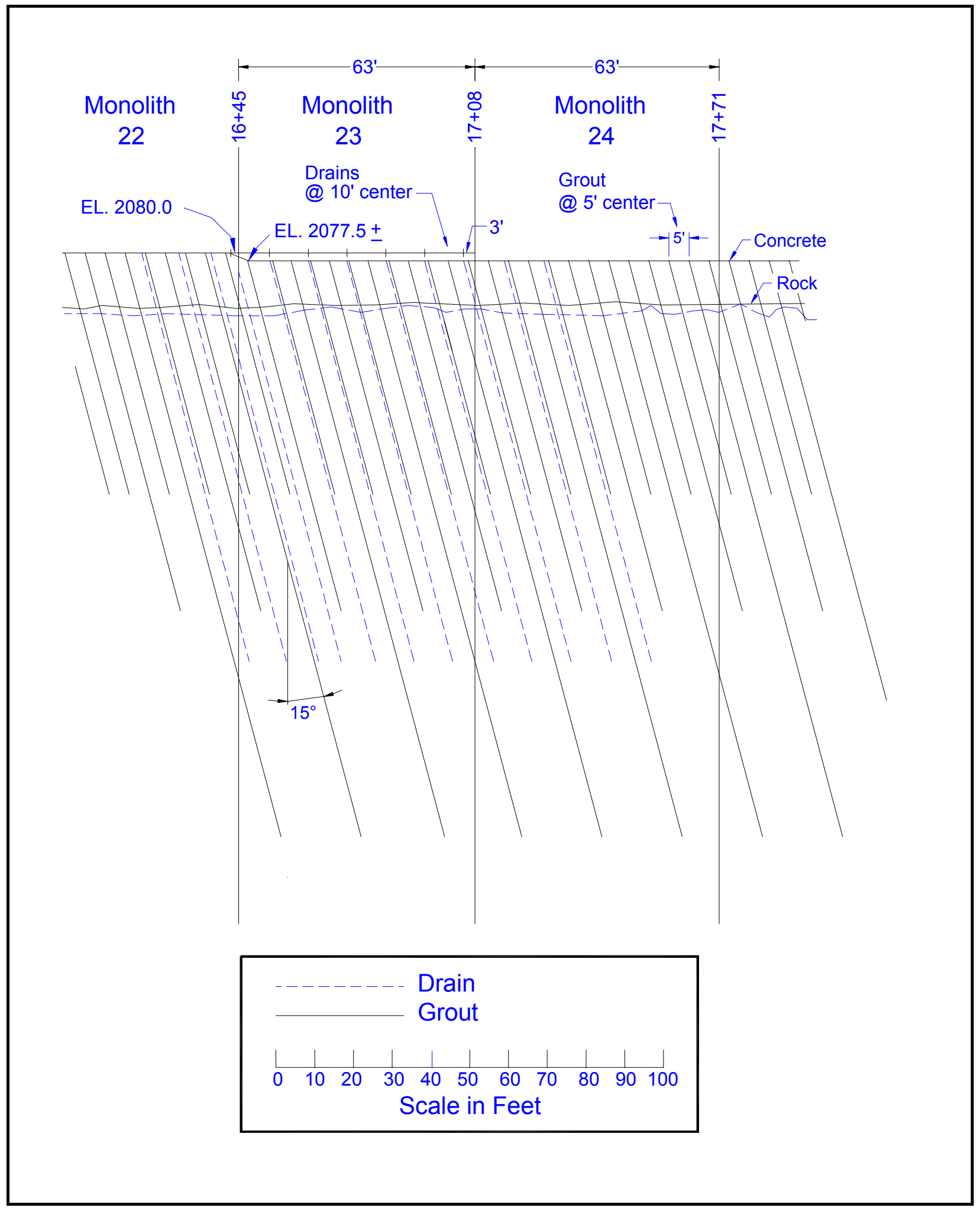

Figure 4.3. View upstream of part of upstream grout/drainage gallery, Libby Dam 
span a period from January 1981 to July 1999. Monolith 23 was selected for further review because it has one of the deepest forebays. To illustrate further the typical behavioral pattern of the gauges, Figure 4.4 shows the relationship between forebay elevation and total head recorded on gauge P23R1 during 1989. There is an almost linear relationship in upward and downward trend during forebay filling and emptying.

Figure 4.5 combines the readings of Gauge $\mathrm{P} 23 \mathrm{C} 1$ for a period of 6 years. There is no longer a single, flat, rising loop but a multitude of pathways. The general trend is still linear. The plots are for monolith 23, first row of gauges, located downstream near the forebay.

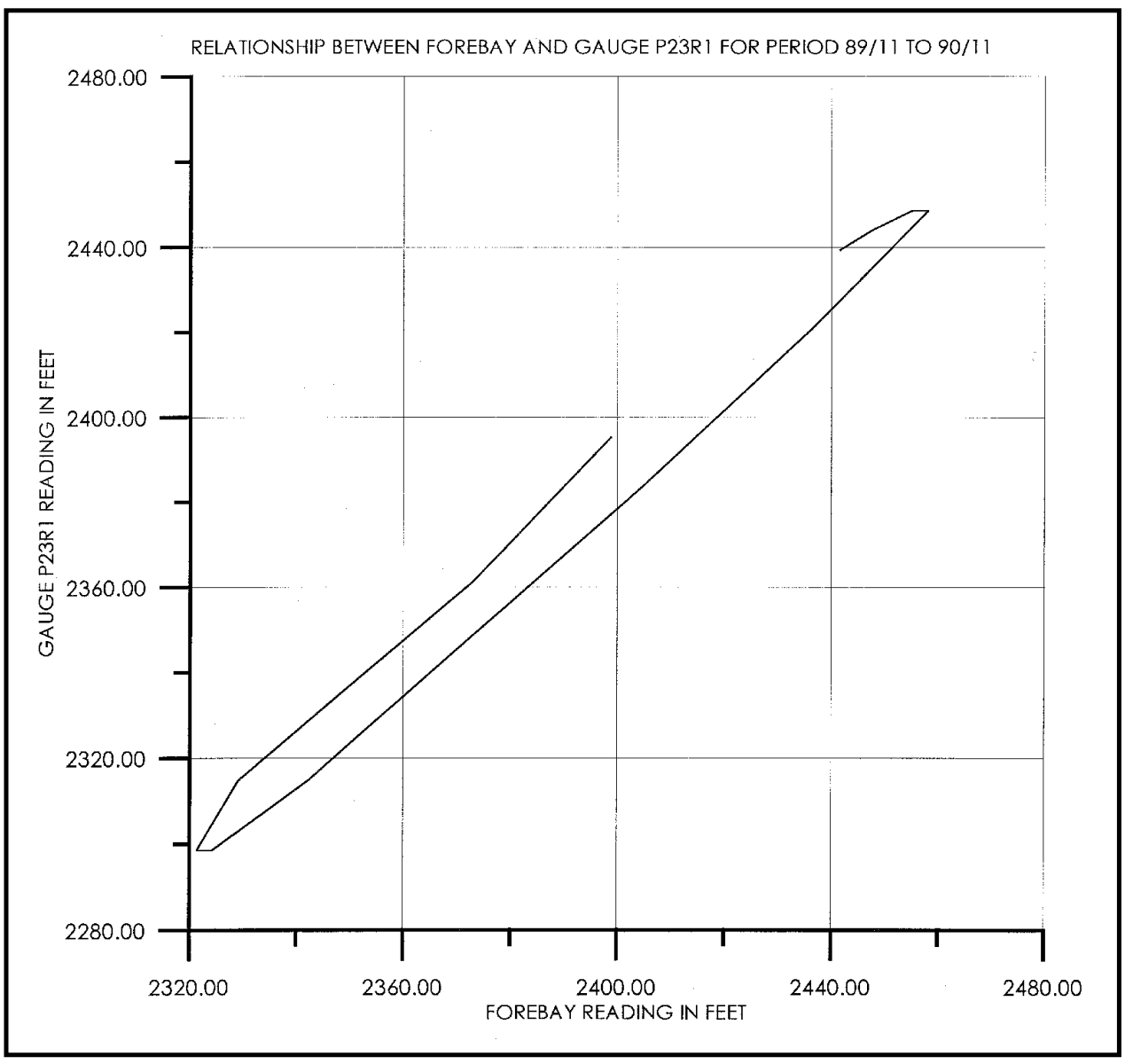

Figure 4.4. Total head recorded on Gauge P23R1 versus forebay reading, 1989, Libby Dam

\subsubsection{Assessment of data quality}

Available Periodic Inspection Reports were studied to identify anomalies occurring during uplift monitoring periods. The gauges were read in all monoliths where uplift pressure gauges were installed: monoliths 14, 18, 23, 29, 34, and 41. The uplift gauges were read on a regular monthly basis to monitor trends in uplift pressure and the effectiveness of the drain system. During all recording periods, 


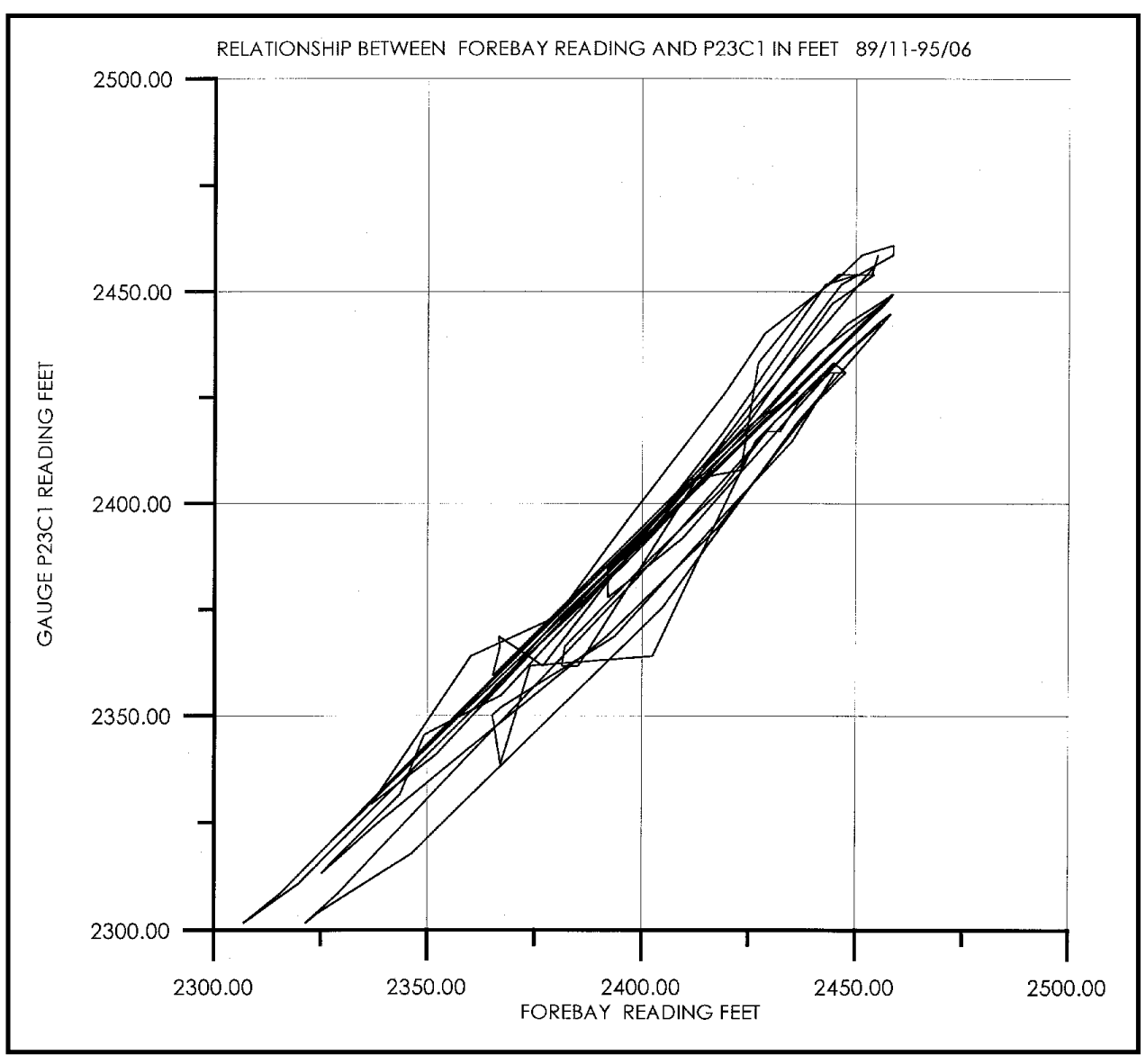

Figure 4.5. Readings for 6 years from Gauge P23C1, Libby Dam

the uplift pressure gradients downstream of the grout curtain were far below the design assumptions. Some of the uplift pressures upstream of the grout curtain were above design assumptions, but the total effect of the actual uplift was below that assumed for maximum in design. Data for the recorded period were consistent. Some uplift pressure cells exhibited upward trends, but further investigation showed the cause to be air trapped in the gauges. When bleeder valves were installed to correct inaccurate readings, the gauges presented actual uplift pressures, expressed as total head.

Total head includes the hydrostatic pressure combined with elevation pressure. A detailed review and preliminary evaluation of the data from the gauges at various monoliths indicated that monolith 23 had consistently reliable readings with respect to forebay fluctuation. A major criterion for the selection of a monolith to be used in the uplift uncertainty study was that the proximity of the gauges to the forebay was sufficient to show the effect of the forebay fluctuation. Readings from gauges located farther from the forebay, especially those beyond the drain holes, did not offer a clear interpretation of the relationship between the forebay and gauge reading. The drain effectiveness, maintenance records, and resulting variable flow could introduce additional variables and thus obscure the nature of the seepage uplift phenomenon. Data for monolith 23 were carefully reviewed. 
Plots of the annual cycle of forebay readings versus gauge readings showed that year 1990 would best merit further study. Gauge readings recorded for the latest available annual cycle should serve as a basis for further assessment of the numerical flow modeling procedure currently under development at the U.S. Army Engineer Research and Development Center (ERDC). Geologic and instrumentation data for Libby Dam were rated "good."

\subsection{Dworshak Dam}

\subsubsection{Description}

Dworshak Dam, originally named Bruces Eddy Dam, is a straight concrete gravity dam located in a narrow canyon of the North Fork Clearwater River, 42 miles east of Lewiston, Idaho. Construction began in July 1966, and the dam was operational for flood control by June 1972. It is 3,287 ft long and $717 \mathrm{ft} \mathrm{high}$ at the lowest point of foundation excavation. The dam is the highest straight-axis concrete dam in the western hemisphere, the $22^{\text {nd }}$ highest dam in the world, and the third highest in the United States. Maximum design pool elevation of the forebay is $1,604.9 \mathrm{ft}$, crest elevation is $1,600 \mathrm{ft}$, and design pool elevation is 1,540 ft. The dam was built between 1967 and 1972. Geological exploration preceded the construction of the dam by almost a decade. Figure 4.6 is a plan view of the dam. The dam is oriented in almost a straight line from northwest to southeast with water impounded to the north. It is accessible by road from the nearby cities of Ashaka, Elk River, and Orofino, Idaho. Figure 4.7 shows the elevation of the dam looking upstream, with a full view of all 58 monoliths. The highest monoliths are (in this view) 23, 24, 25, and 26. Figure 4.8 is section through the dam at station $25+40$. The section shows the general structure, the location of the drains and access galleries, the grout curtain, and contours of the original and excavated ground surface.

\subsubsection{Foundation geology}

The site of the dam was extensively investigated in the mid-1960s (about 1963-1964). A plan of exploration dated March 1971 is included as Figure 4.9. The exploration consisted of NX core drill holes, AX core drill holes, calyx holes, and several adits spread over an area of 2,400 by $1,500 \mathrm{ft}$. A total of 245 borings were drilled in the immediate vicinity of the dam. There are five adits within a distance of $600 \mathrm{ft}$ from the centerline of the dam.

Dworshak was initially considered a good candidate for the uplift uncertainty study. Approximately 13 borings, located within $200 \mathrm{ft}$ of the dam's longitudinal axis, coincided with the highest portion of the dam. Borings vary in depth between 55 and $125 \mathrm{ft}$. Additional exploration was performed as a part of underseepage study for the purpose of grouting in 1989 and 1996. Borings in closest proximity to selected monolith 23 were DH-461, DH-250, DH-252 and DH-90 . 


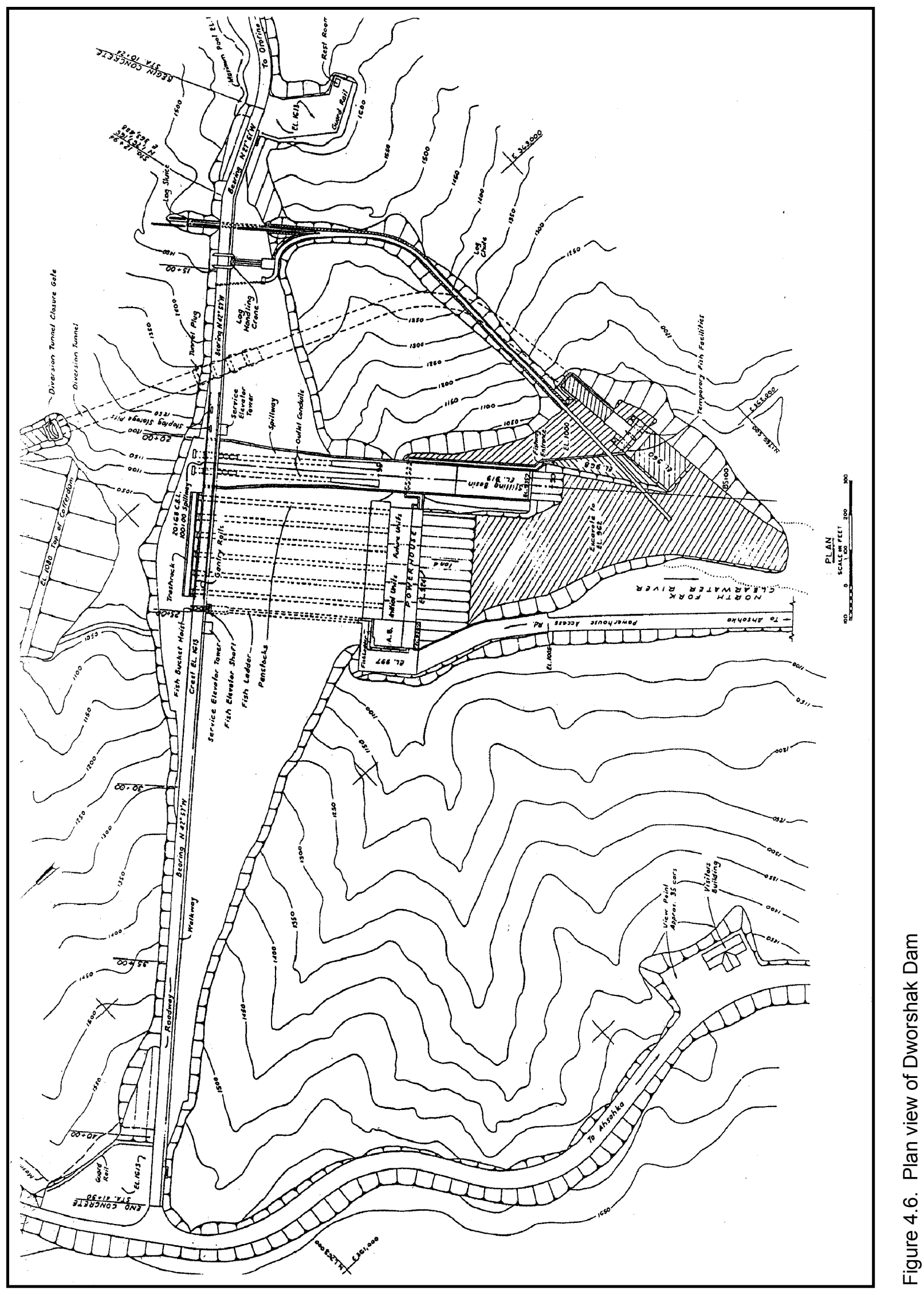




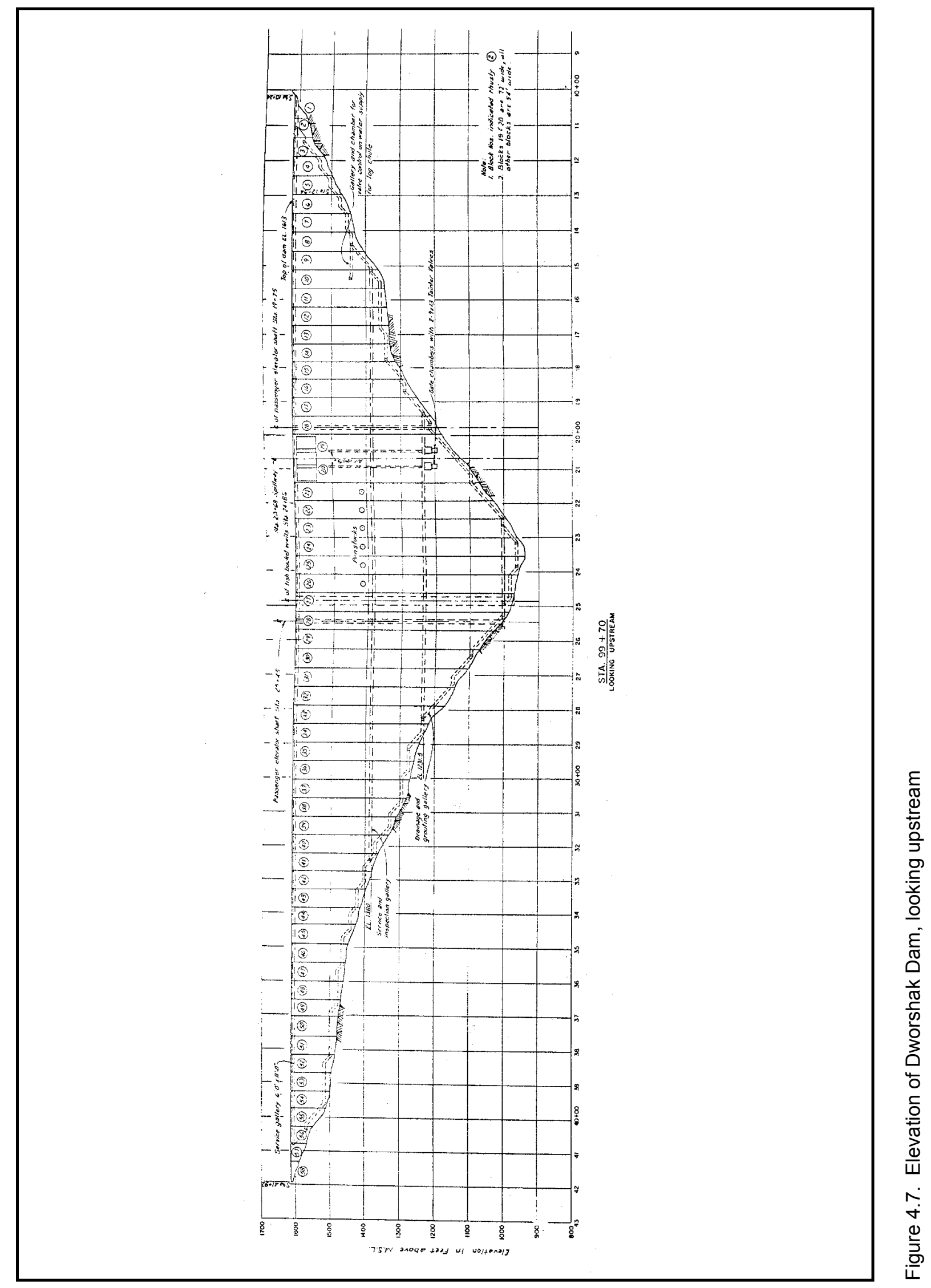




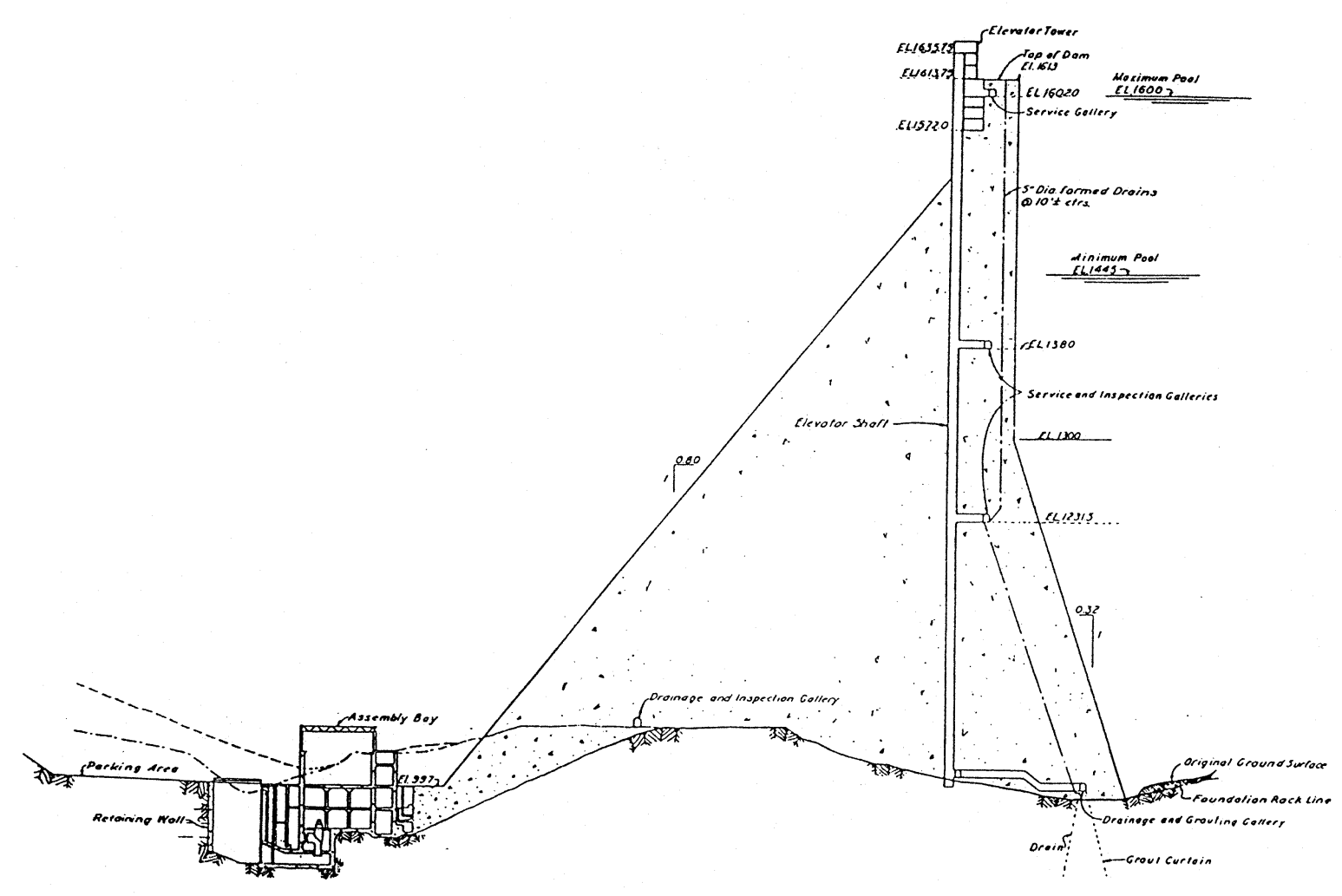

SECTION THROUGH DAM AT STA. $25+40$

Figure 4.8. Section through Dworshak Dam at station 25+40

The foundation report for Dworshak Dam (U.S. Army Engineer District, Walla Walla 1979) reported that the dam is founded on gneiss and amphibolite ${ }^{1}$ of pre-Cambrian aged Orofino metamorphic units. Design Memorandum (DM) No. 6 (U.S. Army Engineer District, Walla Walla, 1964) identifies the rock as a granite gneiss (a footnote on page 3-1 of DM No. 6 states that subsequent geologic investigation by the U.S. Geological Survey (Hietanen 1962) identified the foundation rock as quartz diorite and tonalite). The foundation rock contains discontinuities in the form of joints, shear zones, and porphyritic dikes. DM No. 6 states (p. 3-8) that the predominant joint [set] strikes $5^{\circ}$ (azimuth) and dips $70^{\circ}$ to $90^{\circ}$ east. Less prominent joint sets strike $10^{\circ}$ with dip $80^{\circ}$ to $90^{\circ}$ west, $350^{\circ}$ with $\operatorname{dip} 35^{\circ}$ west, and $340^{\circ}$ with dip $65^{\circ}$ west. Joint attitudes of DM No. 6 were determined in four foundation adits excavated prior to construction of the dam. Shears mapped in the foundation adits were in two sets, a major set striking $4^{\circ}$ to $35^{\circ}$ and dipping $47^{\circ}$ to $80^{\circ}$ east and a minor set striking $275^{\circ}$ to $296^{\circ}$ and dipping $35^{\circ}$ to $80^{\circ}$ south.

The foundation rock is generally massive and contains no distinctive layering, such as marker beds, to permit subdivision of the rock mass. For design purposes, the rock was classified by the degree of weathering and the presence of shears and

1 Amphibolite is a metamorphic rock consisting of the minerals amphibole and dark-colored plagioclase feldspar, with little or no quartz. 


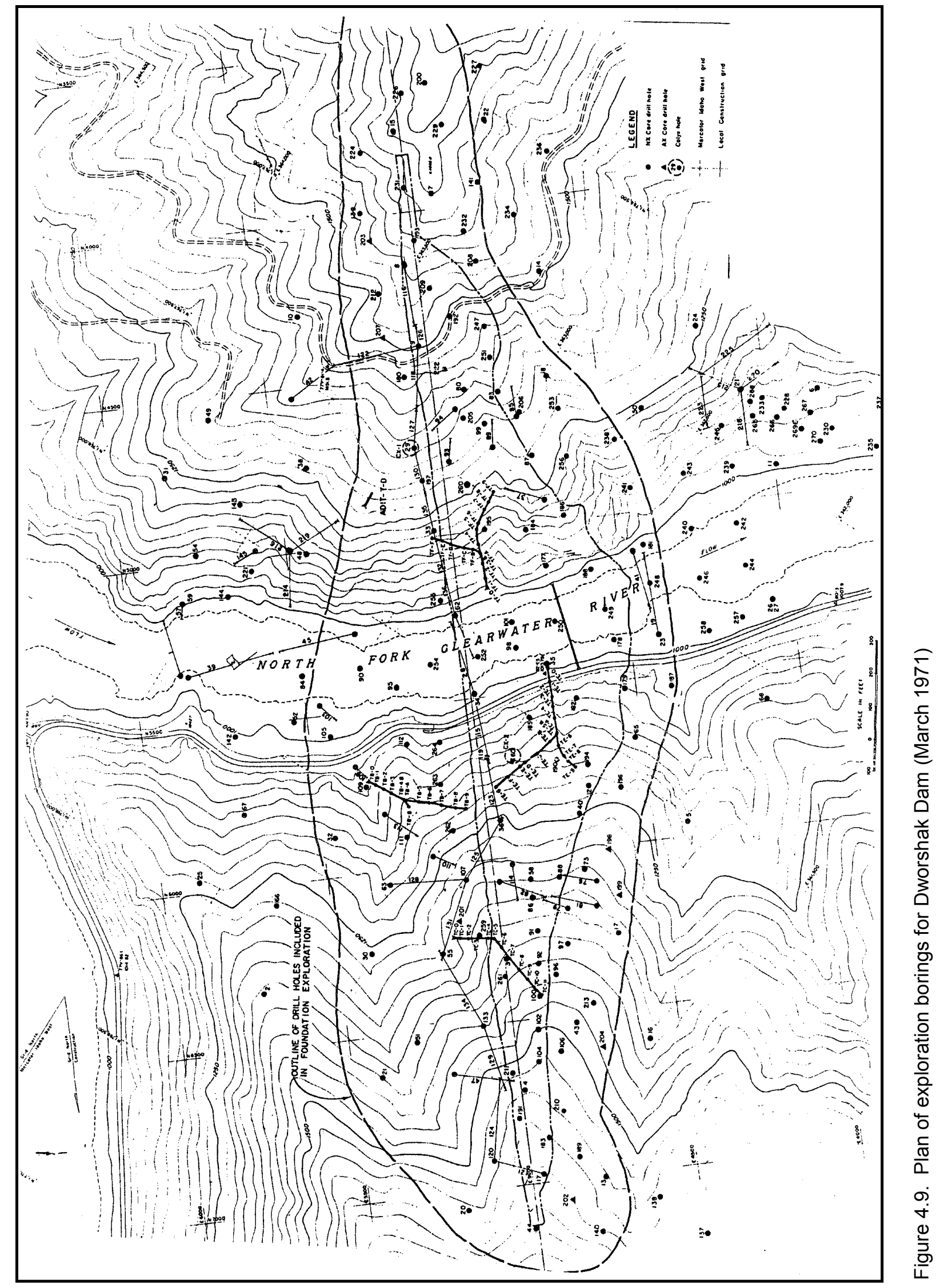


shear zones. Weathering categories were highly weathered, moderately weathered, lightly or slightly weathered, and fresh, or unweathered. Foundation excavation requirements were determined by rock quality, which was defined by degree of weathering. Portions of the dam higher than $150 \mathrm{ft}$ were to be founded on no worse than lightly weathered rock (showing only slight alteration of minerals with no kaolinization of feldspars). Portions less than $150 \mathrm{ft}$ high were to be founded on no worse than moderately weathered rock (showing only partial kaolinization, with some volume change). There were also foundation excavation slope restrictions.

Several shear zones up to several feet wide and persisting for up to several hundred feet across the foundation were mapped in detail and remedied by dental treatment. Shear zones are faults containing slickensides or crushed and clayey gouge, evidence of movement along the faults. Gouge material was removed and the cavities backfilled with concrete. Some of the shear zones and zones of shear intersections were so large and extensive that drilling and blasting were required to remove unacceptable material.

DM No. 6 (U.S. Army Engineer District, Walla Walla, 1964) evaluated the results of 1,234 pressure tests conducted in 139 drill holes in the foundation of Dworshak Dam. Data from water pressure tests indicated that the rock "tightened" with depth. A scatter diagram provided in DM No. 6 (p. 5-3) was interpreted as showing "a progressive decrease in maximum observed permeability with depth...." The DM stated that because many pressure tests showed no water take, the rock matrix was impermeable. By default, permeability of the rock mass was attributed to the presence of fracturing. The scatter diagram showed higher permeability near the top of the rock mass in lightly weathered rock, indicating a decrease in fracture frequency with depth. Observations in the test adits showed that water from the rock mass was insufficient to cause observable flow from the adits, a further indication of the tightness of the rock and independent confirmation of the pressure test interpretations.

Hydraulic tests performed on foundation rock during the exploration phase reported a rock permeability varying between $10^{-5}$ and $10^{-3} \mathrm{ft} / \mathrm{min}$, depending on the depth from the excavated rock surface and the location. U.S. Army Engineer District, Walla Walla (1979), offered a wealth of documentation about borings and size and location of rock fractures.

\subsubsection{Instrumentation}

Dworshak Dam consists of 58 monoliths. Uplift gauges are located in monoliths 13 through 36 . A total of 65 uplift pressure measuring devices were installed during dam construction to monitor grout curtain effectiveness and foundation drainage system performance. The highest concentration of the gauges is in monoliths $21,23,24,25,28$, and 31 . The highest monolith, monolith 22, is not the best instrumented one. Refer to Figure 4.10 for locations of the uplift gauges. Figure 4.11 is a detail of the centrally located monoliths 23 and 25, the best instrumented of all the monoliths. All gauges consist of perforated pipes drilled $4 \mathrm{ft}$ into the rock. Gauges in the second row, designated $\mathrm{P}^{* * 2}$, were drilled $6 \mathrm{ft}$ into rock 


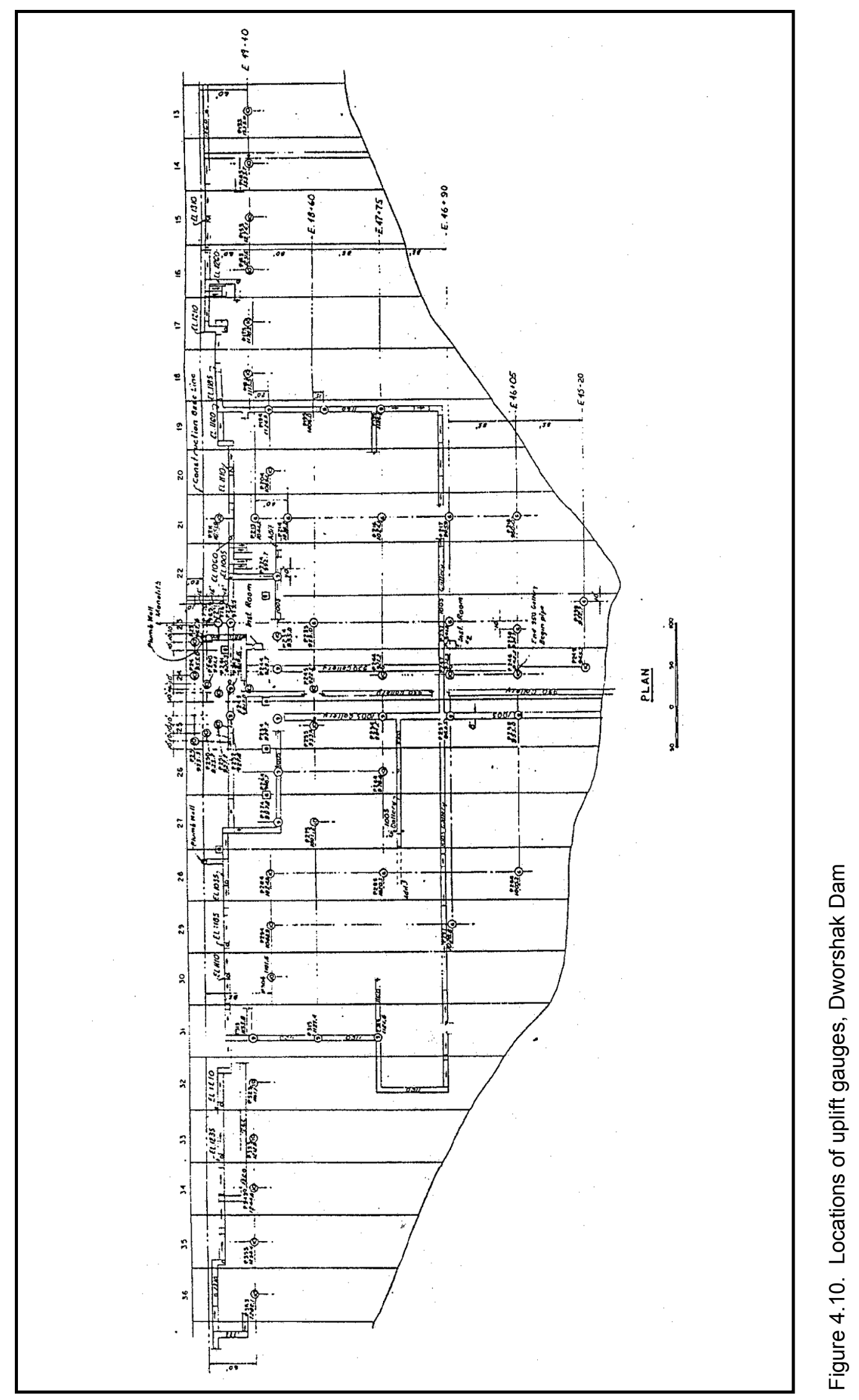




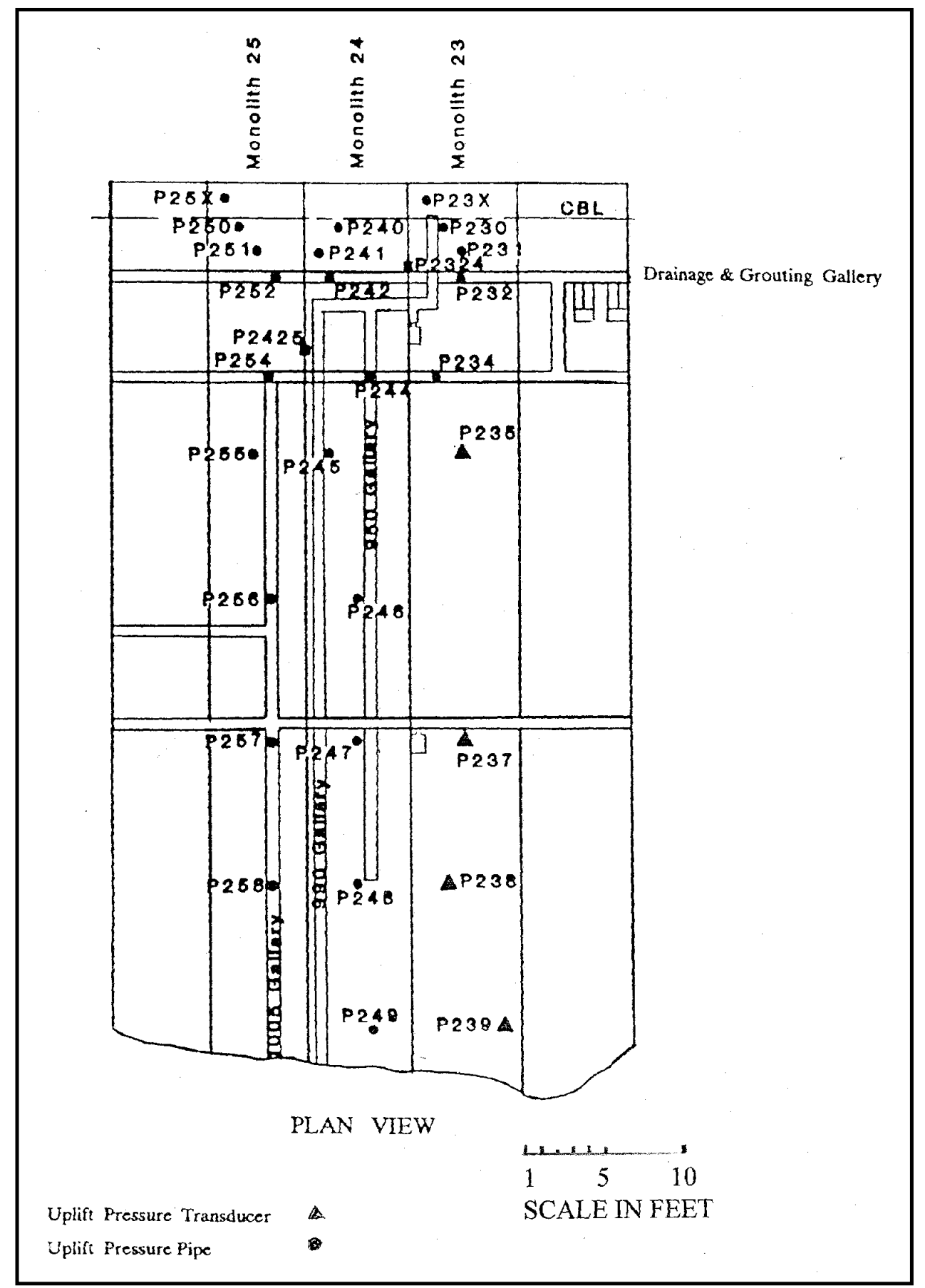

Figure 4.11. Detail of instrumentation, monoliths 23 and 25, Dworshak Dam

because they coincided with the drains. Monolith 23 is approximately in the middle of the dam and corresponds to the second highest forebay water elevation. The dam has several access galleries at different elevations mutually connected for maintenance and monitoring of instruments. Extensive instrumentation monitors internal stresses and concrete temperature in addition to uplift pressures. 
Monolith 23 was chosen for more detailed study in the uplift uncertainty project after examination of data quality of periodic inspection reports. Nine of a total of 65 uplift measuring gauges are located in monolith 23. The uplift pressure monitoring gauges in monolith 23 consist of five pipe piezometers and four transducers. Three piezometers are located between the drainage gallery and forebay, and one piezometer is located in the gallery itself. One piezometer is located $111 \mathrm{ft}$ downstream.

\subsubsection{Assessment of data quality}

Inspection of Dworshak Dam began in 1972 when the dam was still under construction. No gauges were read at that time. Reporting of uplift pressures started in 1975. Inspection Brochure No. 4, dated April 1975, recorded readings for some gauges in monoliths 21 and 24 . The brochure indicated that gauges in the first row downstream of the forebay exceeded design uplift pressure during periods of high pool elevations. Inspection Brochure No. 5, June 1975, confirmed this situation. Inspection Brochure No. 7, 1981, listed only gauges for monolith 21. Gauges close to the forebay reflected the fluctuation of the forebay, with an unusually steady rising trend over the recorded time span for both peak and bottom readings. The remaining gauges stagnated at the same reading with no response to forebay changes. A possible explanation for this behavior is that the readings in those gauges could be triggered only at uplift pressures that were never reached during the recording period. Design pressures were thus grossly overestimated, while uplift pressures next to the forebay were slightly underestimated. The effectiveness of the grouting curtain and drains in connection with this behavior suggested a strong influence downstream from the drains and grouting curtain. Inspection Brochure No. 9, June 1989, reported on 30 gauges in monoliths 23, 24, and 25. Gauges in monolith 25, closer to the forebay, exceeded design pressures during the period 1980 to 1993. The remaining gauges had readings much under design pressures. Some gauges indicated pressures well under tailwater elevation.

The authors concentrated efforts on monolith 23, which showed a greater consistency in data over a longer period of recording than other monoliths. Gauges P23X, P230, and P231 are located upstream of the drain holes. Gauge P232 coincided with a drain hole, and Gauges P234, P235, P237, P238, and P239 are located downstream behind drains. Gauges P23X, P230, P240, P241, and P242 consistently exceeded design uplift pressures for stages of the forebay above elevation 1,600 ft. Plots relating forebay readings to gauge readings for selected periods of time were fit to evaluate the behavioral pattern of the gauges and the quality of the data. Figure 4.12 is one such plot. In spite of considerable scatter, there is a distinct linearity in hysteresis of the rising and falling of the forebay in the response for Gauge P23X. Contrary to readings of Gauge P23X, Gauge P230 (Figure 4.13) shows a distinctly two-pronged trend in the plot. The upper portion of the plot is for the initial period after dam filling. The lower branch of the plot is for the latter decade of recording. The significance is that the latter behavior suggests a nonlinear relationship between the forebay elevation and the gauge reading. For the nonlinear behavior, an appropriate explanation would be that the rock 


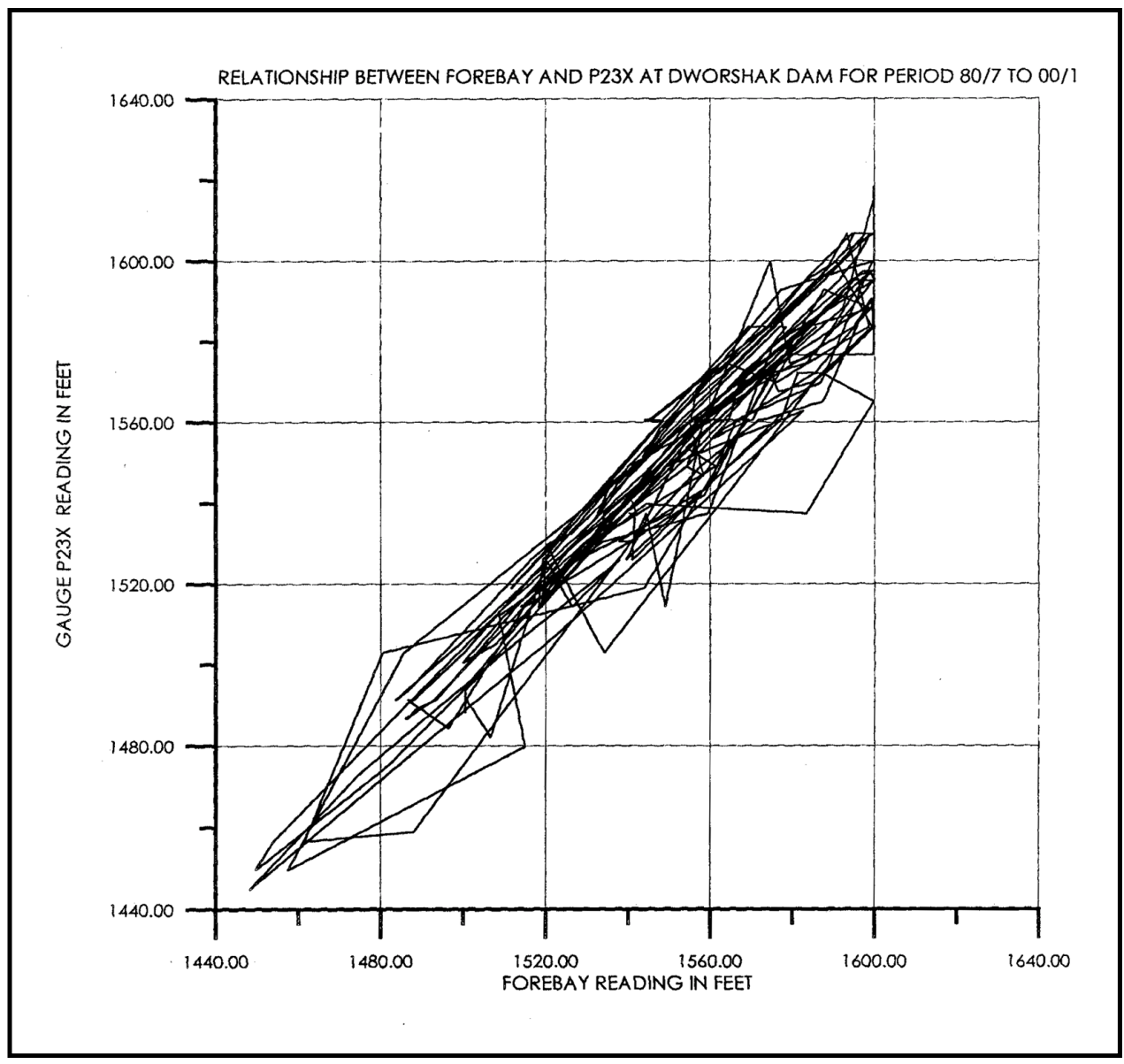

Figure 4.12. Forebay level versus Gauge P23X reading, Dworshak Dam

fracture system underlying the dam may be opening and closing, creating nonconstant flow conditions.

Modeling of this situation would be very complicated. Figure 4.14 is a plot of the relationship between forebay changes and gauge readings in feet of total head. Although there is a hysteresis, it forms an oddly shaped loop.

Geologic data for Dworshak were rated "good," and instrumentation data were rated "sufficient."

\subsection{Green Peter Dam}

\subsubsection{Description}

Green Peter Dam is located on the Middle Santiam River, 4.7 miles above its confluence with the South Santiam River and approximately 30 miles southeast of Albany, Oregon. Construction of the dam began in 1963, and the dam was dedicated in June 1967. Green Peter is a 330-ft-high concrete monolith structure, $1,455 \mathrm{ft}$ long at the crest and $260 \mathrm{ft}$ wide at the foundation-rock interface. Design 


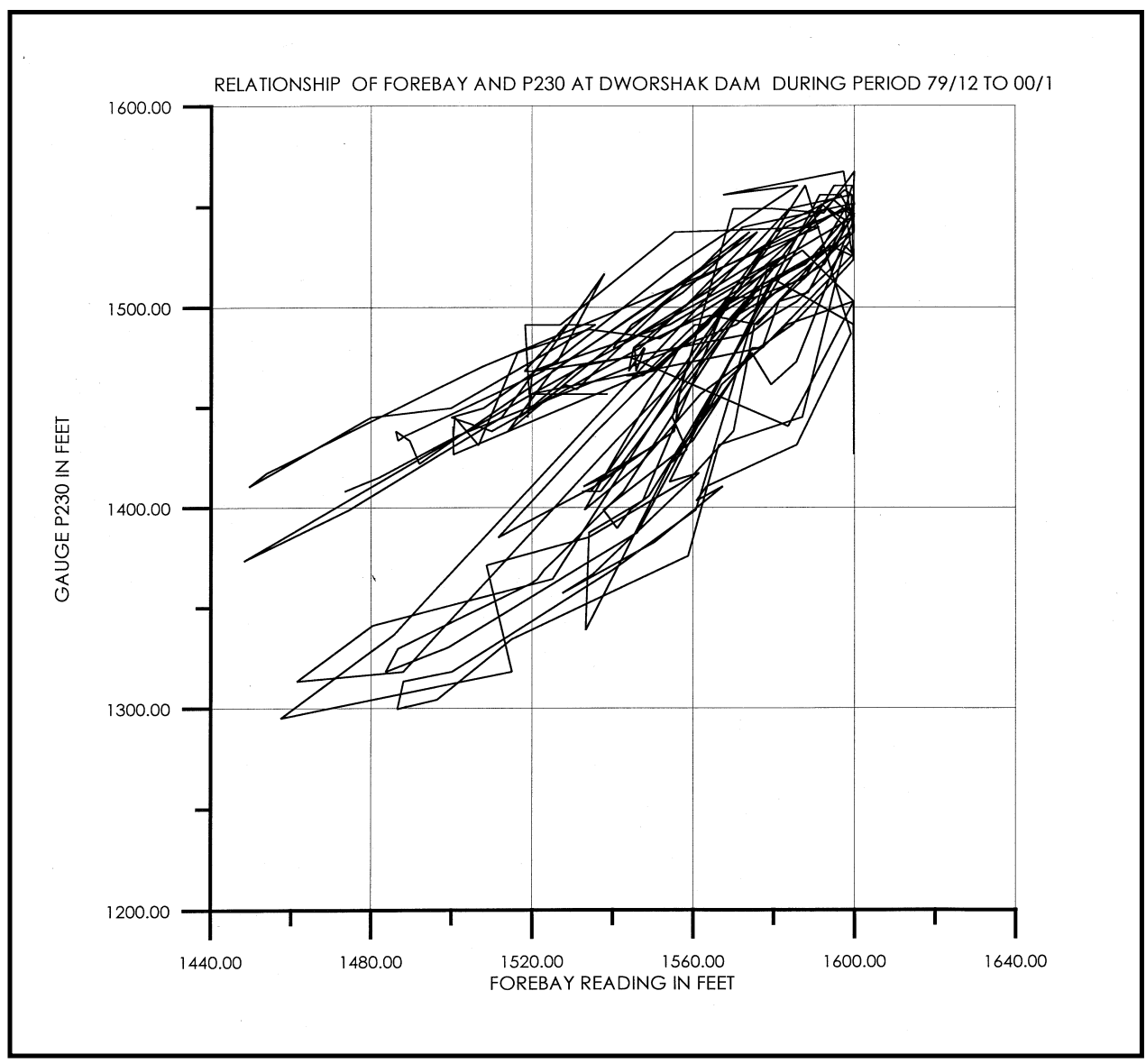

Figure 4.13. Forebay level versus Gauge P230 reading, Dworshak Dam

maximum pool elevation is $1,015 \mathrm{ft}$. The dam is divided into 29 monoliths varying in width from 90 to $120 \mathrm{ft}$. The highest monoliths are 12 through 21, in the center of the structure (Figure 4.15). Green Peter Dam is oriented west-northwest to east-southeast. Water is impounded from the north. Two sections through the dam are shown in Figure 4.16: one through the spillway and the other through the powerhouse and penstock.

\subsubsection{Foundation geology}

Geological exploration occurred in several stages. Most borings were emplaced between 1959 and 1962. A total of 297 borings and calyx holes were drilled in the immediate vicinity of the dam. Borings consist of core borings, churn holes, and 36-in. and 42-in. calyx holes. In addition, 12 exploration drifts and cross cuts were cut (Figure 4.17). Some drill holes were equipped with piezometers. Approximately 40 borings drilled in the highest portion of the dam were suitable for this study.

The dam lies in the Western Cascades geologic province and is characterized by the presence of volcanically derived sediments, lava flows, and pyroclastic materials with local intrusives. The foundation report (U.S. Army Engineer 


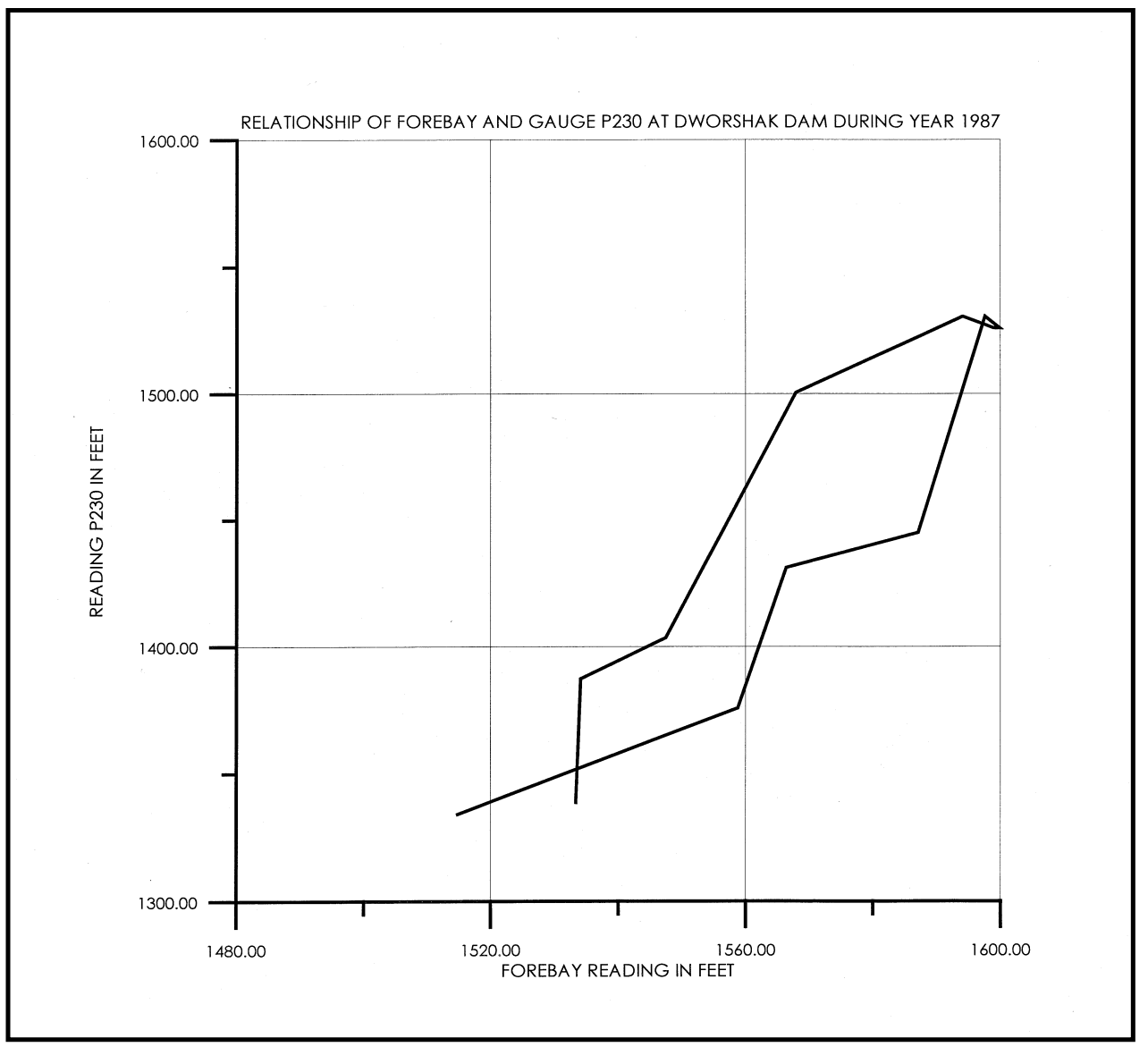

Figure 4.14. Forebay level versus Gauge P230 reading, 1987, Dworshak Dam

District, Portland, 1969) stated that the foundation geology is complex, with major lava flows separated by four interbeds of pyroclastics (Figure 3.3). A number of shear zones, some containing clay or gouge, cut the foundation. Rocks have been folded, jointed, and faulted by regional uplift. Groundwater occupies closely jointed rock in semiconfined conditions. Most of the groundwater flows were identified in open joints, where the flows were not entirely laminar. With increased hydrostatic head, some clay materials were expected to migrate downgradient, thus gradually changing the flow pattern. Two drainage systems were installed in the dam in addition to the grout curtain. Of several hundred borings drilled for this dam, about 47 coincided with the actual dam, some exceeding a depth of $100 \mathrm{ft}$. Figure 4-18 is a geologic section through the foundation along the dam base line. The foundation report for Green Peter Dam (U.S. Army Engineer District, Portland, 1969) provides much information on stratigraphy, geologic structure, and lithology through detailed boring logs and cross sections.

\subsubsection{Instrumentation}

A total of 35 uplift gauges were monitored at this dam in monoliths 7 through 26. Initially, Gauges 14A, PU-14-2, PU-20-2, PU-20-1, and PU-14-2A provided useful information. The latest periodic inspection brochures available indicated 


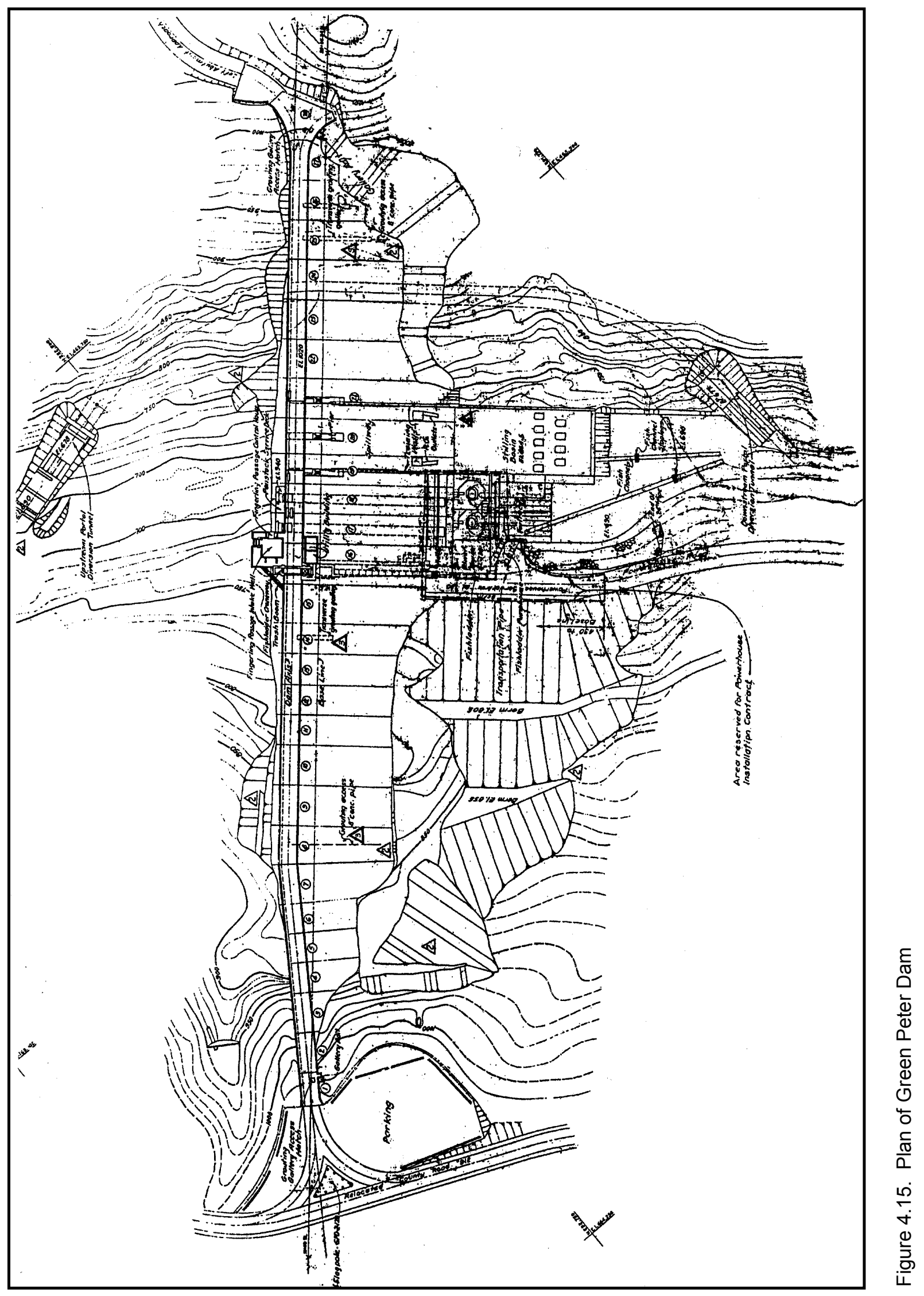




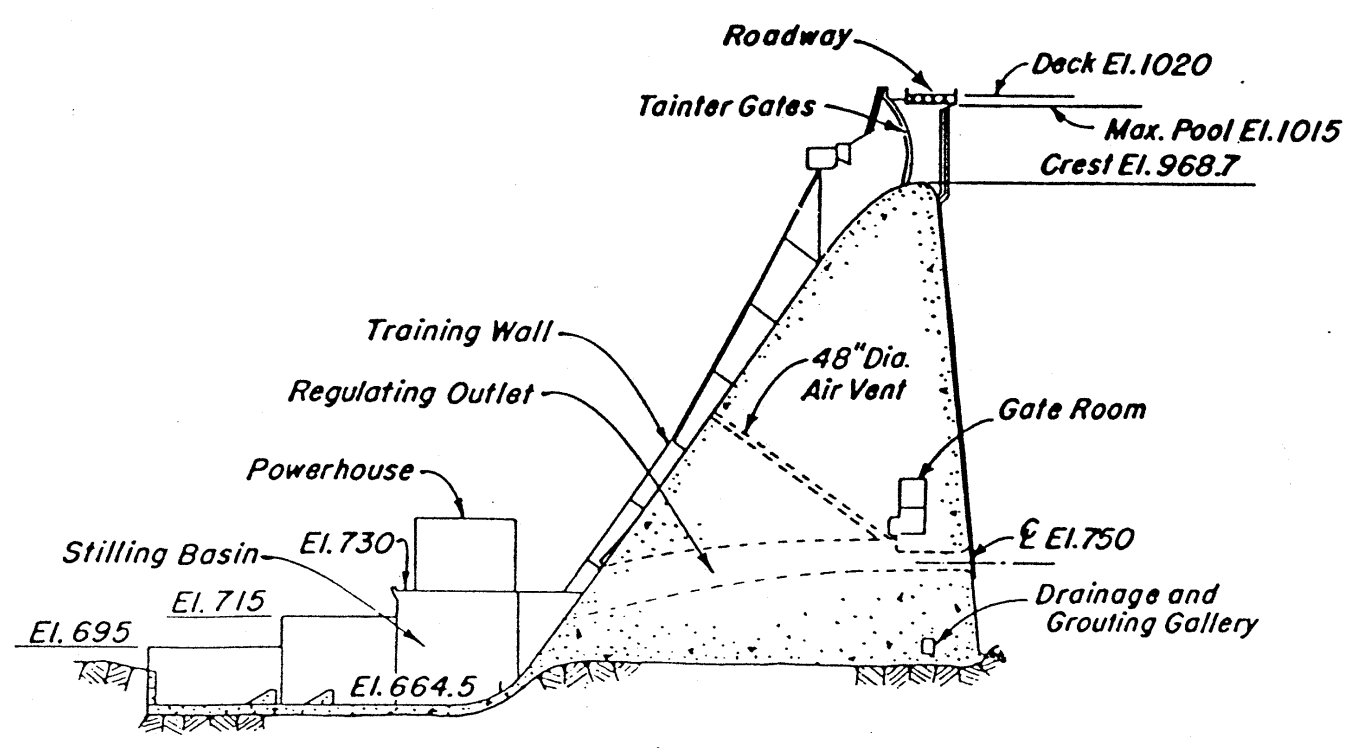

SECTION THRU SPILLWAY

SCALE IN FEET
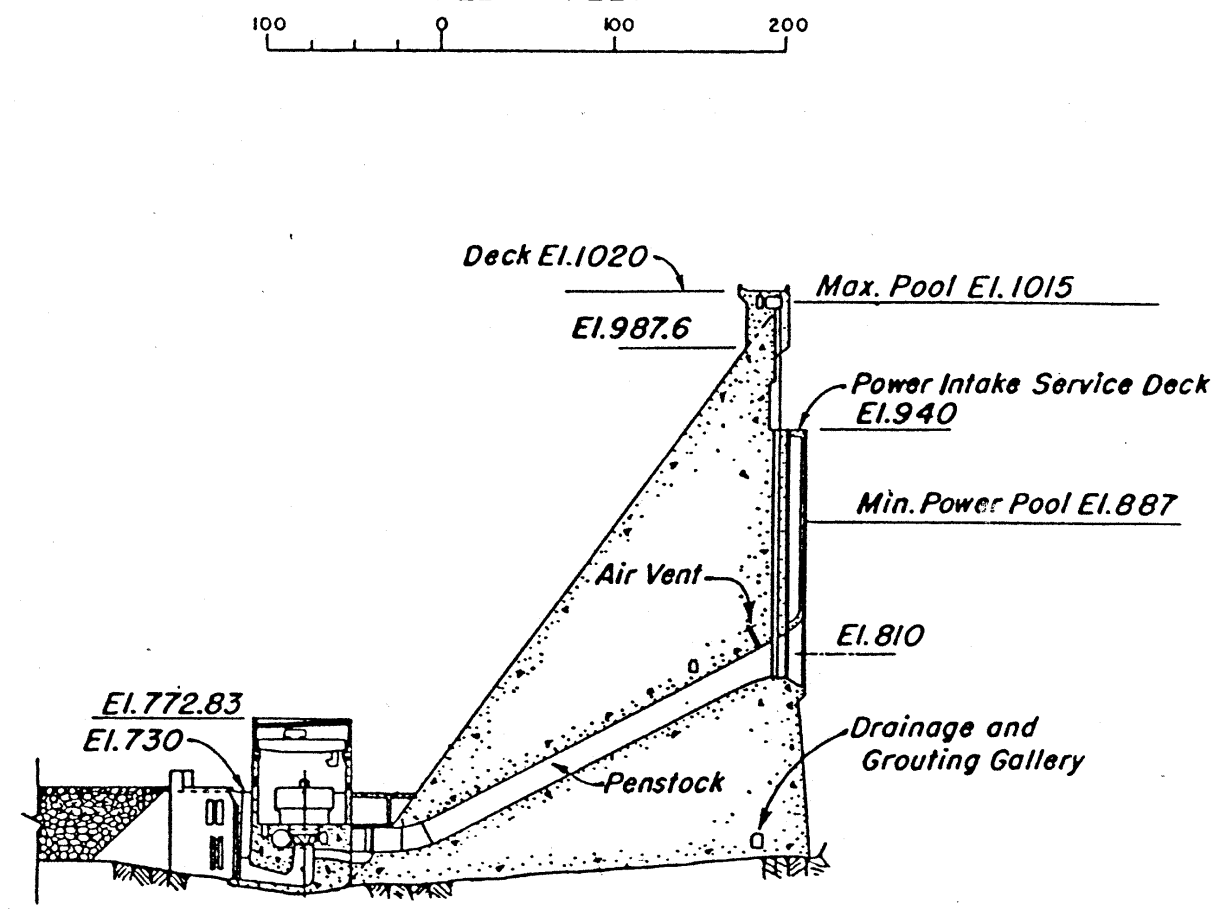

SECTION THRU POWERHOUSE AND PENSTOCK SCALE IN FEET

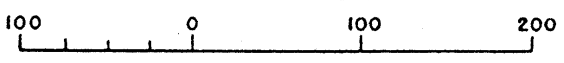

Figure 4.16. Sections through Green Peter Dam 


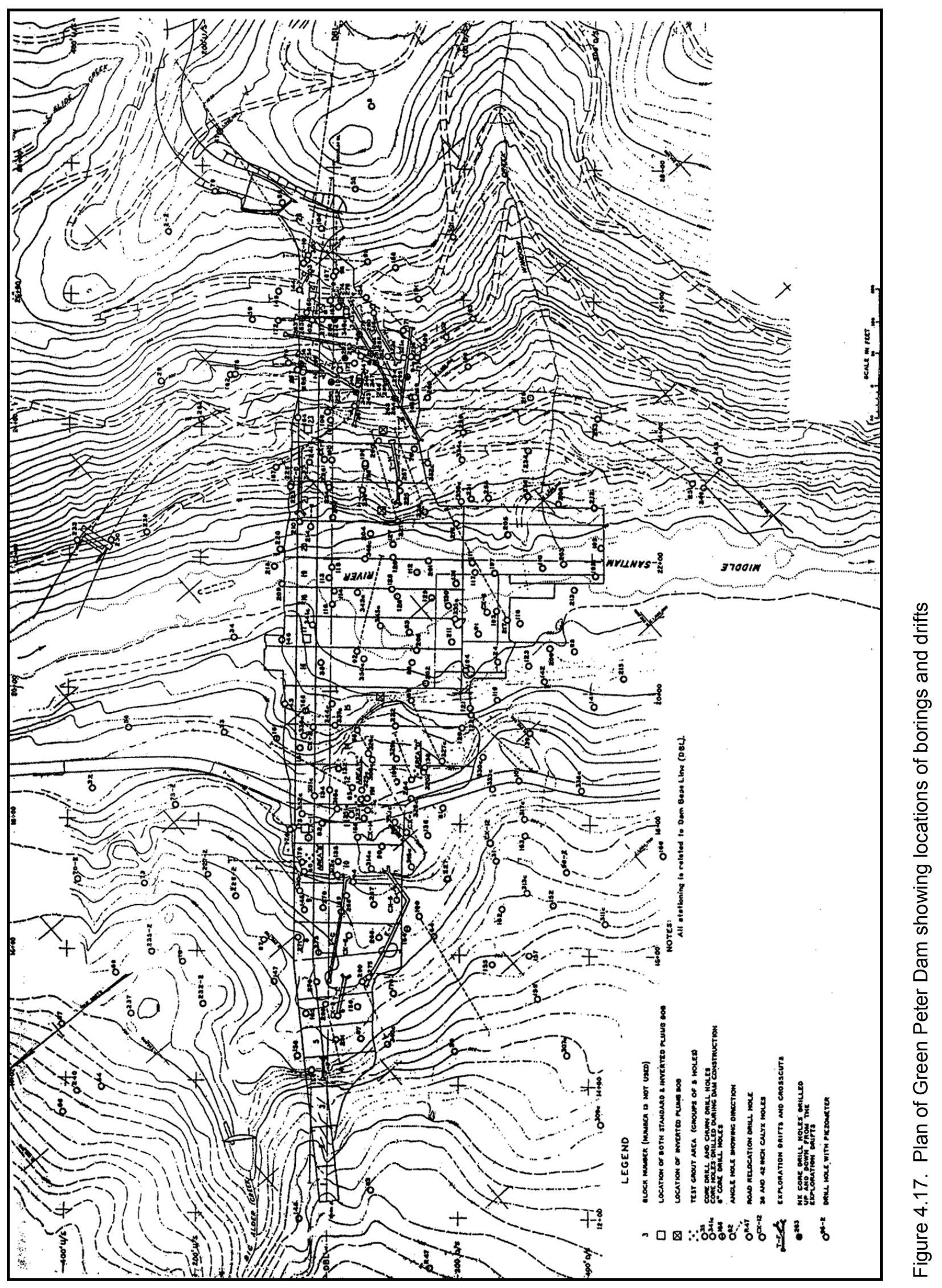




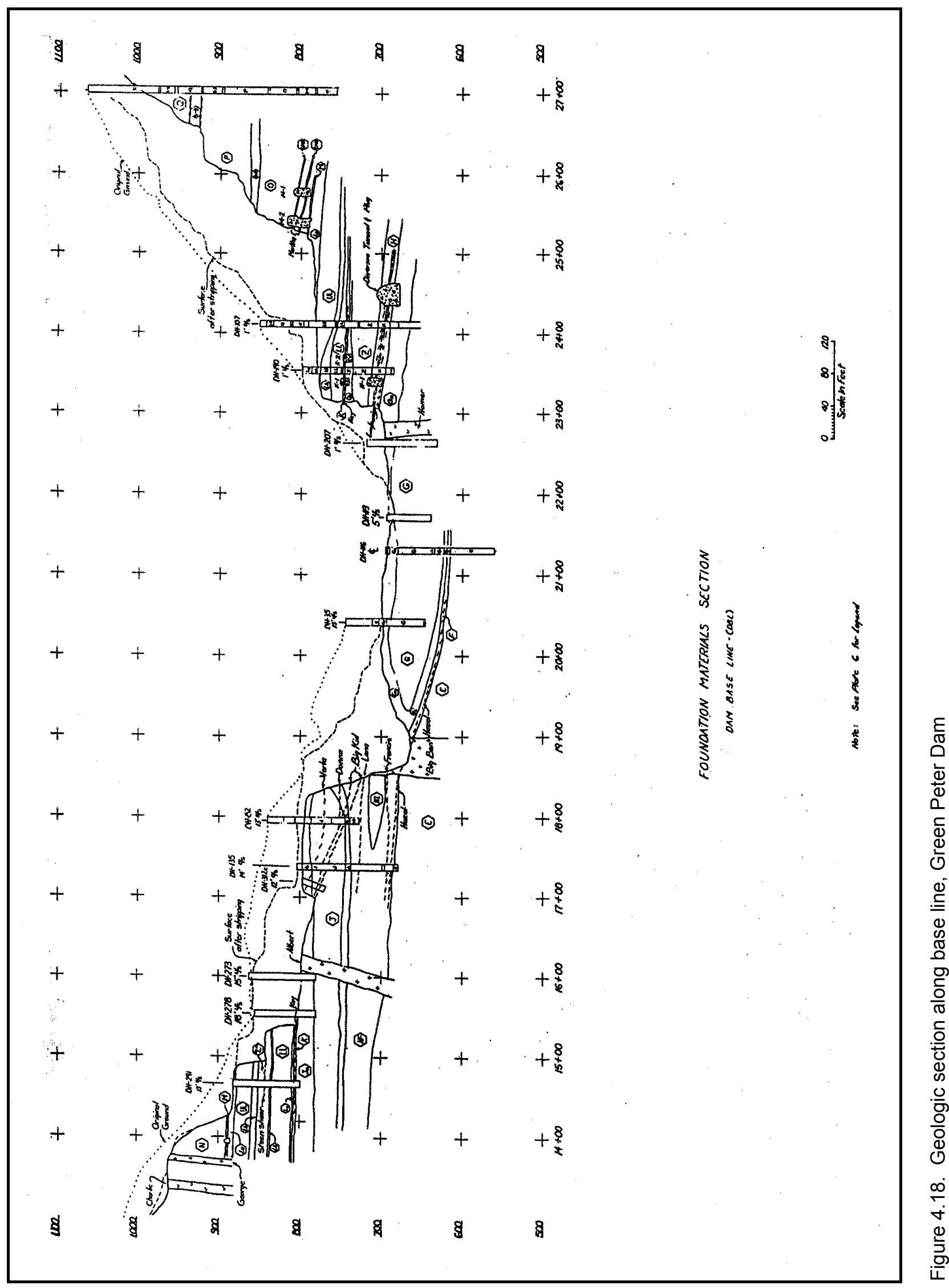


that six gauges may have records correlated to the fluctuation of the forebay: Gauges 14-2, 14-1B, 18A, 18-1A, 19-1B, and 20-1. Locations of the instruments related to uplift pressure measurement and geology are shown in plan view and longitudinal section in Figure 4.19. Gauges marked as "U" designate uplift gauges. Piezometers are designated as "P." The most useful gauges for this project would be those in monoliths 12,16, and perhaps 21 . Gauges in these high monoliths are distributed through the foundation in a line from upstream to downstream. Unfortunately, gauges in these monoliths did not provide much useful information.

\subsubsection{Assessment of data quality}

A substantial number of gauges clustered together is necessary to evaluate the behavioral pattern of subsurface seepage flow that is inducing uplift. One or two gauges in a monolith are not sufficient for a reliable model of the uplift pattern. Instrumentation data of this kind at Green Peter was insufficient. The geological information available is applicable to the uplift study.

\subsection{Detroit Dam}

\subsubsection{Description}

Detroit Dam is located on the North Santiam River 6 miles west and downstream of Detroit, Oregon, and about 75 miles southeast of Portland. The structure was built in the early 1950s and consists of a concrete gravity dam and spillway $376 \mathrm{ft}$ high above the controlled minimum tailwater, with a crest length of $1,579 \mathrm{ft}$. The highest monoliths are 15 through 21 in the center of the dam. Monolith 19 is the highest.

Figure 4.20 is a plan of Detroit Dam. The dam is oriented northeast to southwest with the forebay on the south side of the structure. An elevation of the dam, looking downstream, is shown in Figure 4.21. Two sections through the dam are presented in Figure 4.22. Section A-A is through the spillway, and Section B-B is through the penstock. Both sections show locations of the grouting and drainage gallery, where the instruments are accessible for monitoring. The dam is $450 \mathrm{ft}$ high from the top of excavated rock, forming a maximum crest elevation at $1,541 \mathrm{ft}$. The maximum width of the dam is $321 \mathrm{ft}$ at the foundation-rock contact.

\subsubsection{Foundation geology}

Foundation exploration began in June 1951. A total of 119 borings were drilled and an exploration tunnel was driven. No boring logs or other critical information was available for this dam. The foundation report, dated December 1952, described the geology but did not contain the boring logs that were referenced in the report. A personal sketch provided by the Portland District contained a section through the rock fracture system between monoliths 15 and 23 but did not provide any other detailed information or dimensions. Portland District 


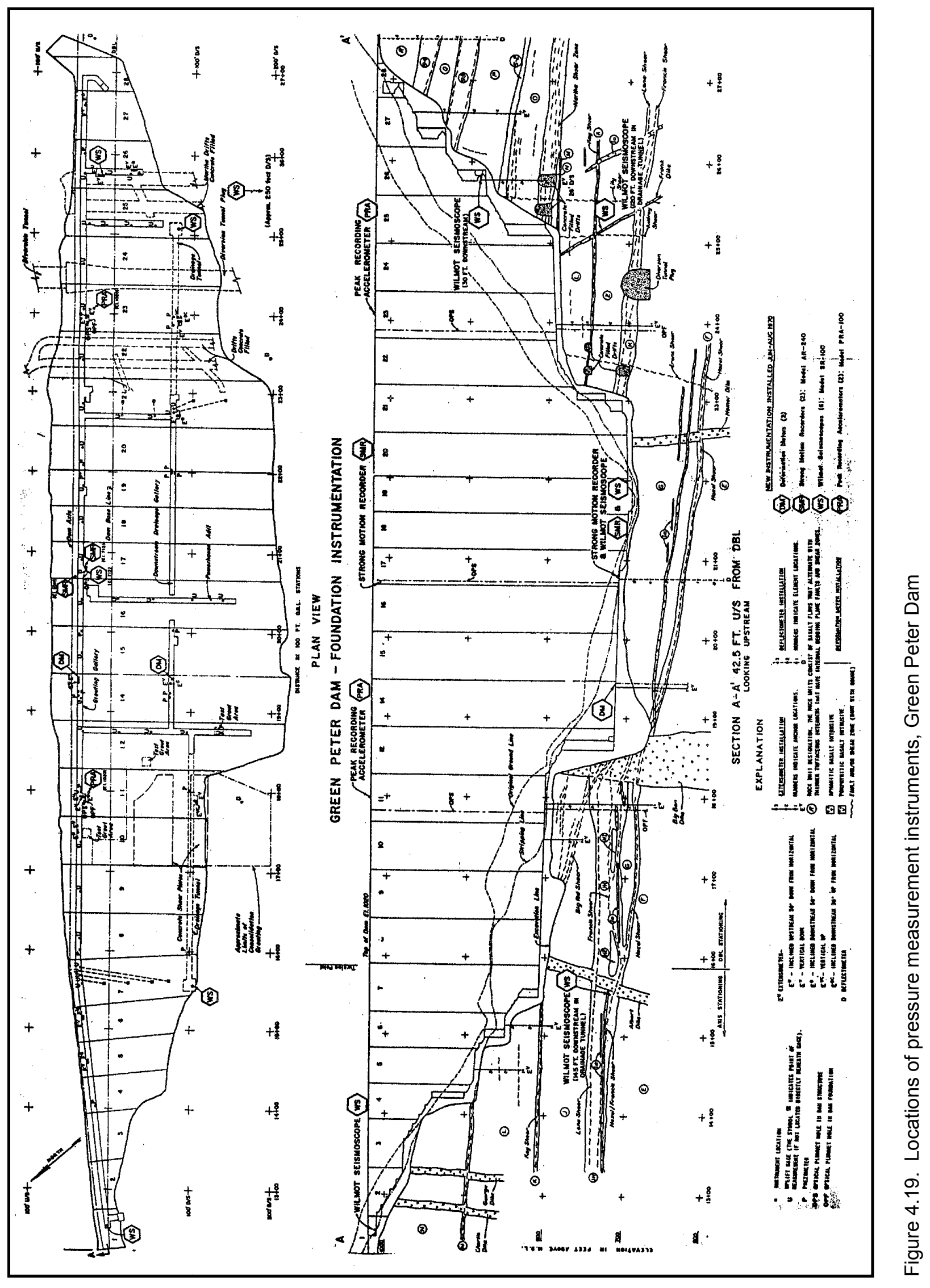




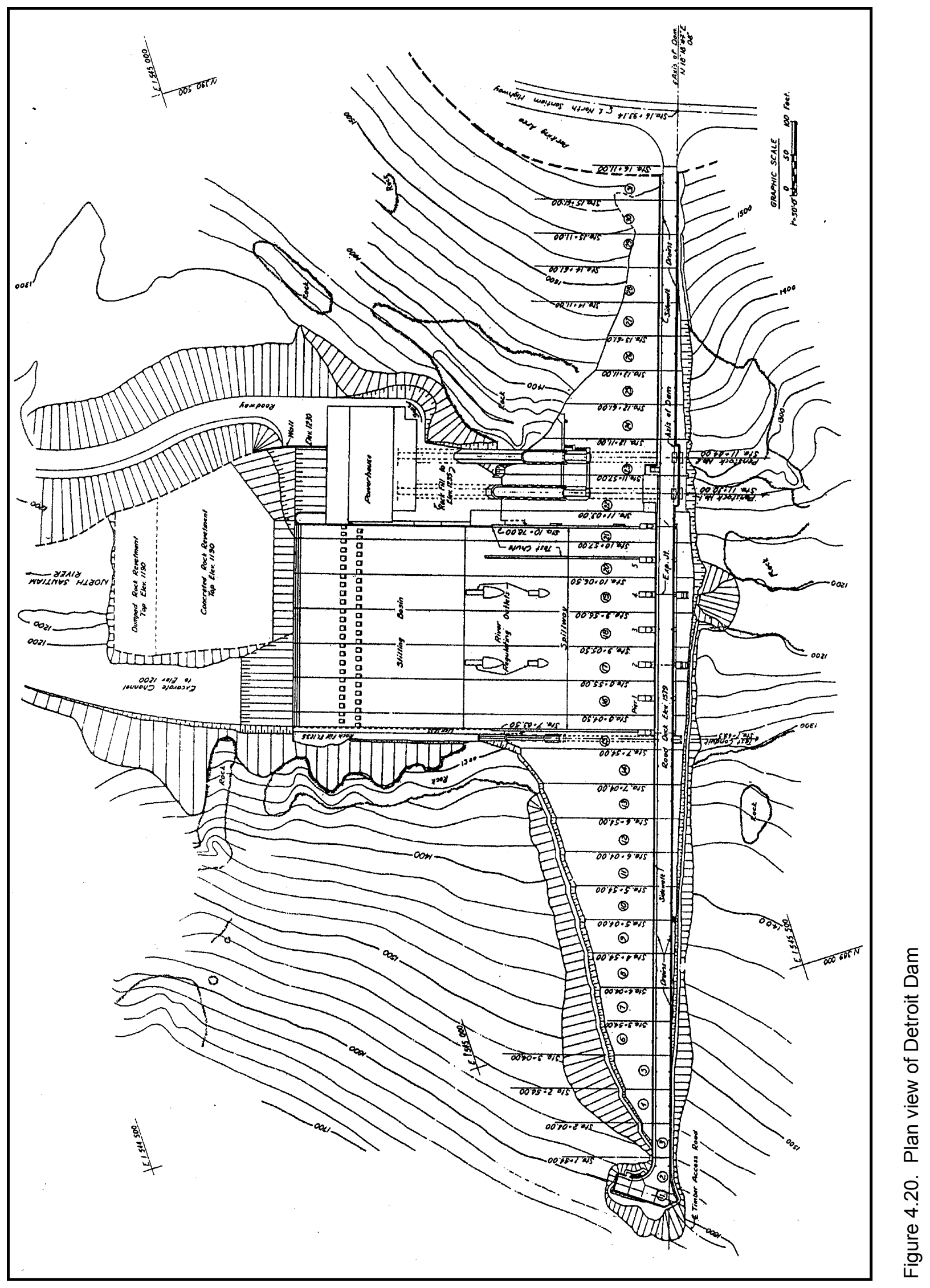




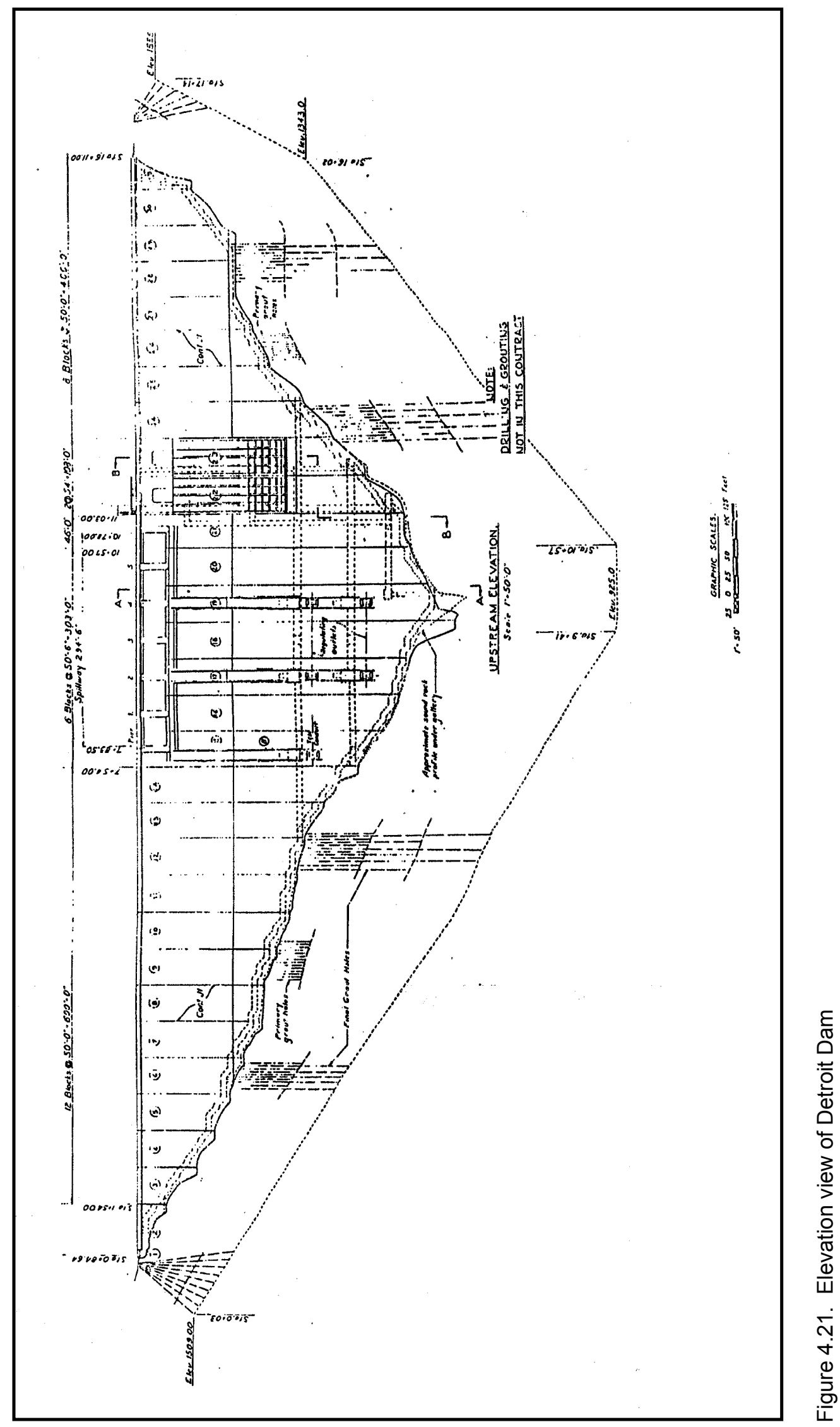




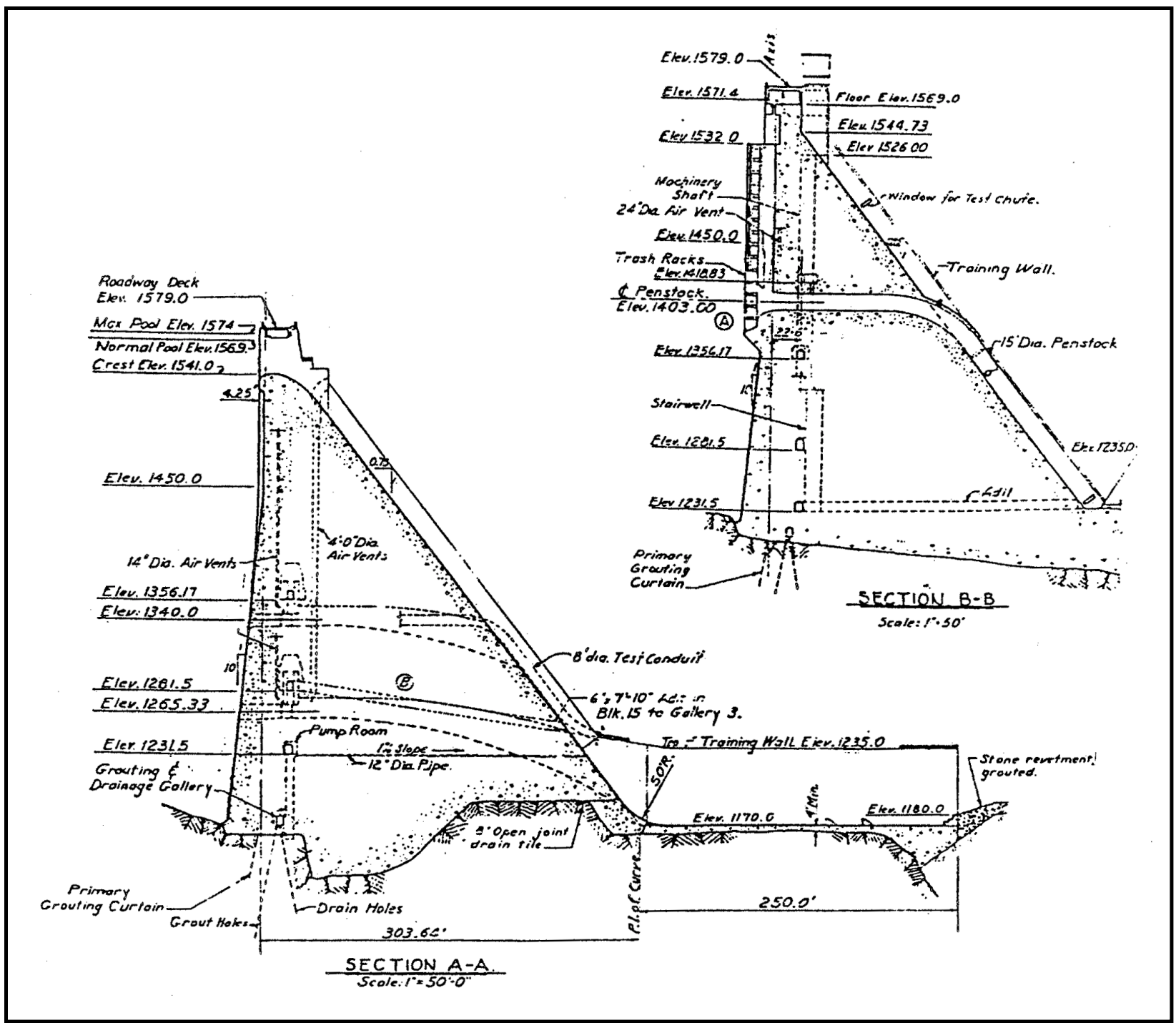

Figure 4.22. Sections through Detroit Dam

reported that the foundation rock consisted of andesite breccia, diorite, aplite, andesite porphyry, and hydrothermally altered phases of these rocks. The degree of fracturing rather than the hardness of the rock was the basis for determining its adequacy for foundation purposes. Andesite breccia and diorite dominated, cut by fissures and joints trending generally $\mathrm{N} 45^{\circ} \mathrm{W}\left(315^{\circ}\right)$. The fissures were narrow and tight.

\subsubsection{Instrumentation}

Thirty-six uplift gauges were installed during construction; they have been monitored continuously to the present. Piezometers are located in monoliths 9 through 24 and are concentrated mainly in monoliths 15 and 21 (Figure 4.23). Of a total of 36 gauges, 23 piezometers are located coincidentally with the maximum height of the dam. Dam periodic inspection brochures indicated that 


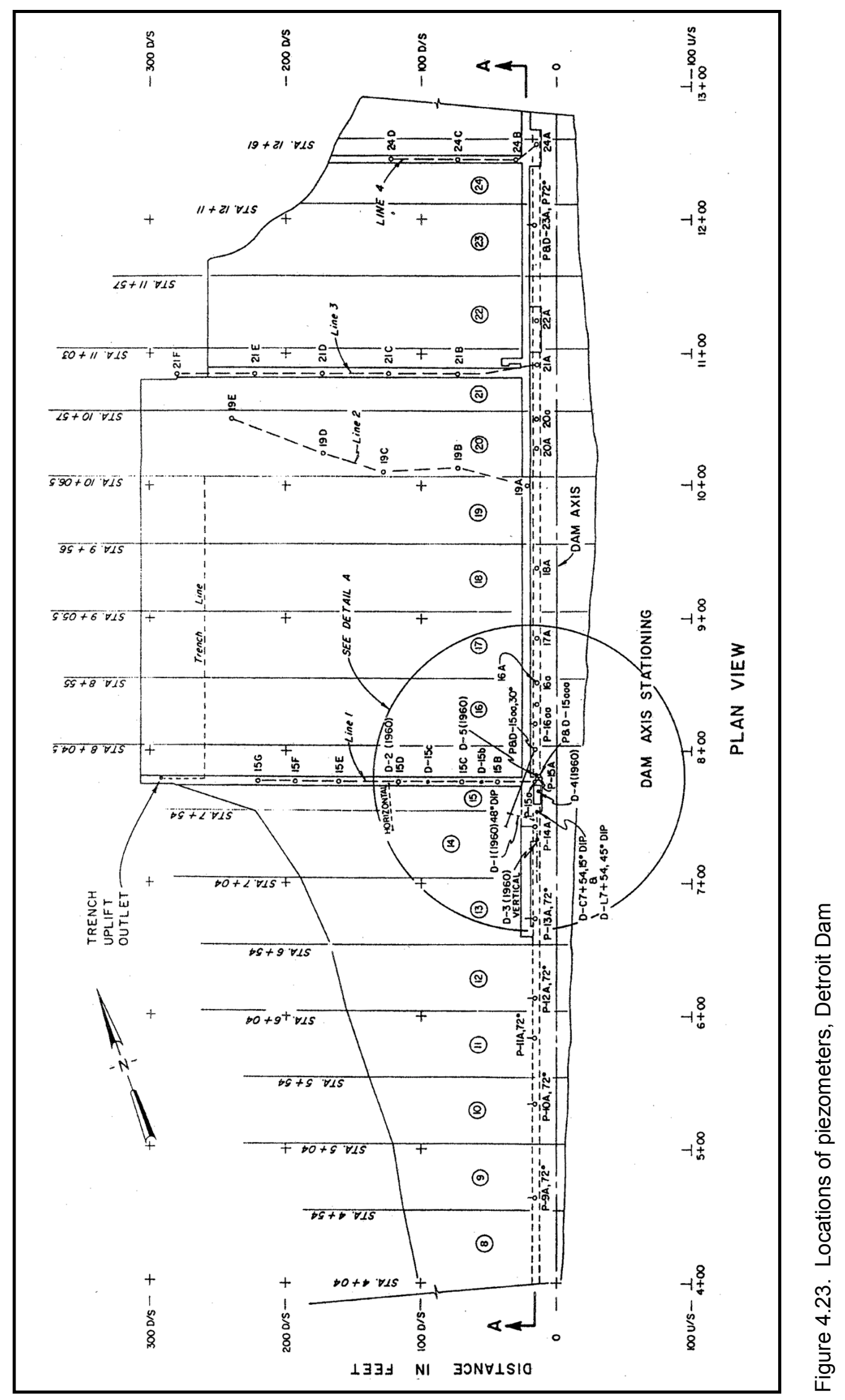


19 piezometers had no change in readings with time. An additional 11 piezometers responded very irregularly and had no apparent relationship to fluctuation of forebay levels. Seven piezometers provide useful data. Piezometers 15XXX, 16A, 16XX, 20A, and 20X showed a good response to forebay levels. Piezometer $17 \mathrm{~A}$ was not very sensitive to fluctuations, but provided a good response. Piezometer 15XXX exceeded the forebay at high pool. Piezometer 15A responded in a way that could be tied to forebay fluctuation but had some unusual peaks.

\subsubsection{Assessment of data quality}

Seven of the 36 gauges showed potential for consideration in the uplift uncertainty study. Those piezometers, which provided consistently good readings, were located in monolith 16 and possibly monolith 20 . Because there were only two piezometers in a cluster, there was no information on uplift through the cross section of the dam, since the piezometers farther away from the forebay had no readings. Instrumentation and geologic data were rated "insufficient." Figure 4.24 shows instrumentation details.

\subsection{Wolf Creek Dam}

\subsubsection{Description}

Wolf Creek Dam is a combination earth-fill and concrete gravity dam. It is located in Kentucky on the Cumberland River, 461 miles above the Ohio River. Construction of Wolf Creek Dam began in August 1941, but it was discontinued in August 1943 because of World War II. Construction of the dam and powerhouse was resumed in September 1946, and the dam was completed in August 1951. The dam became operational in August 1952. It consists of a homogeneous rolled-fill embankment 3,940 ft long and a concrete portion 1,796 ft long forming an east wing of the project. The maximum pool is $158 \mathrm{ft}$ (depth), and extreme maximum pool is $195 \mathrm{ft}$. The estimated average pool is $152 \mathrm{ft}$. The normal design pool is $135 \mathrm{ft}$. The spillway crest is at elevation $760 \mathrm{ft}$, and the minimum design tailwater is at elevation $550 \mathrm{ft}$. The width of the dam at the concrete portion is approximately $120 \mathrm{ft}$ (varies with foundation rock elevation) at the highest monolith. Figures 4.25 and Figure 4.26 are a plan and section of Wolf Creek Dam, respectively.

\subsubsection{Foundation geology}

The initial geological exploration predates World War II. Because of leakage problems encountered after reservoir filling, more fundamental exploration and mapping followed in the early 1960's before remedial work was undertaken in 1968-1970. A wealth of borings resulting from extensive exploration was available for this dam. Borings adjacent or related to monolith 11 (which had potential for the study) consisted of at least five borings: 2-RB at $90 \mathrm{ft}$ upstream, 3-RB coinciding with the monolith, 4-RB at $100 \mathrm{ft}$ downstream, and 2- and 3-RV at 


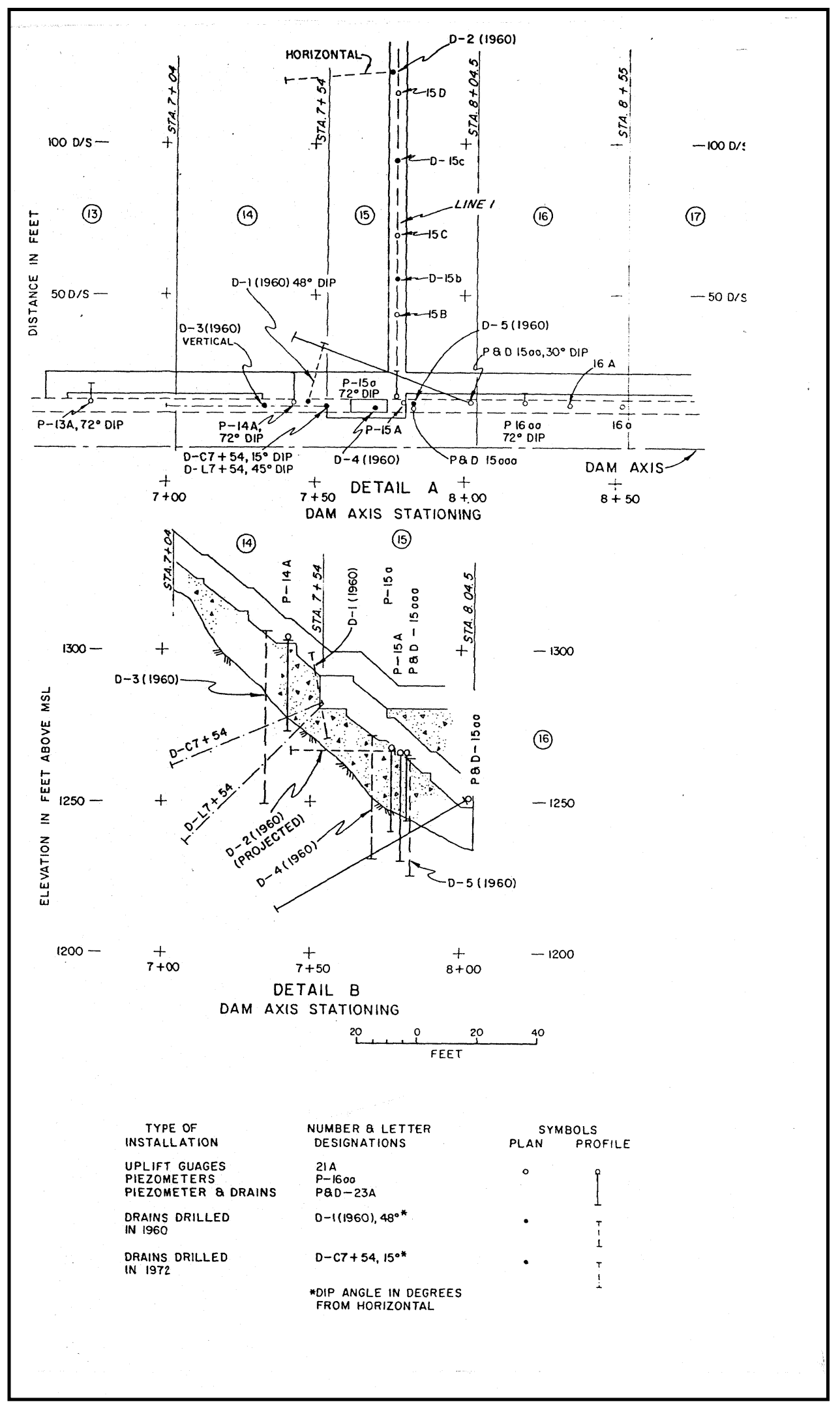

Figure 4.24. Details of instrumentation at Detroit Dam 


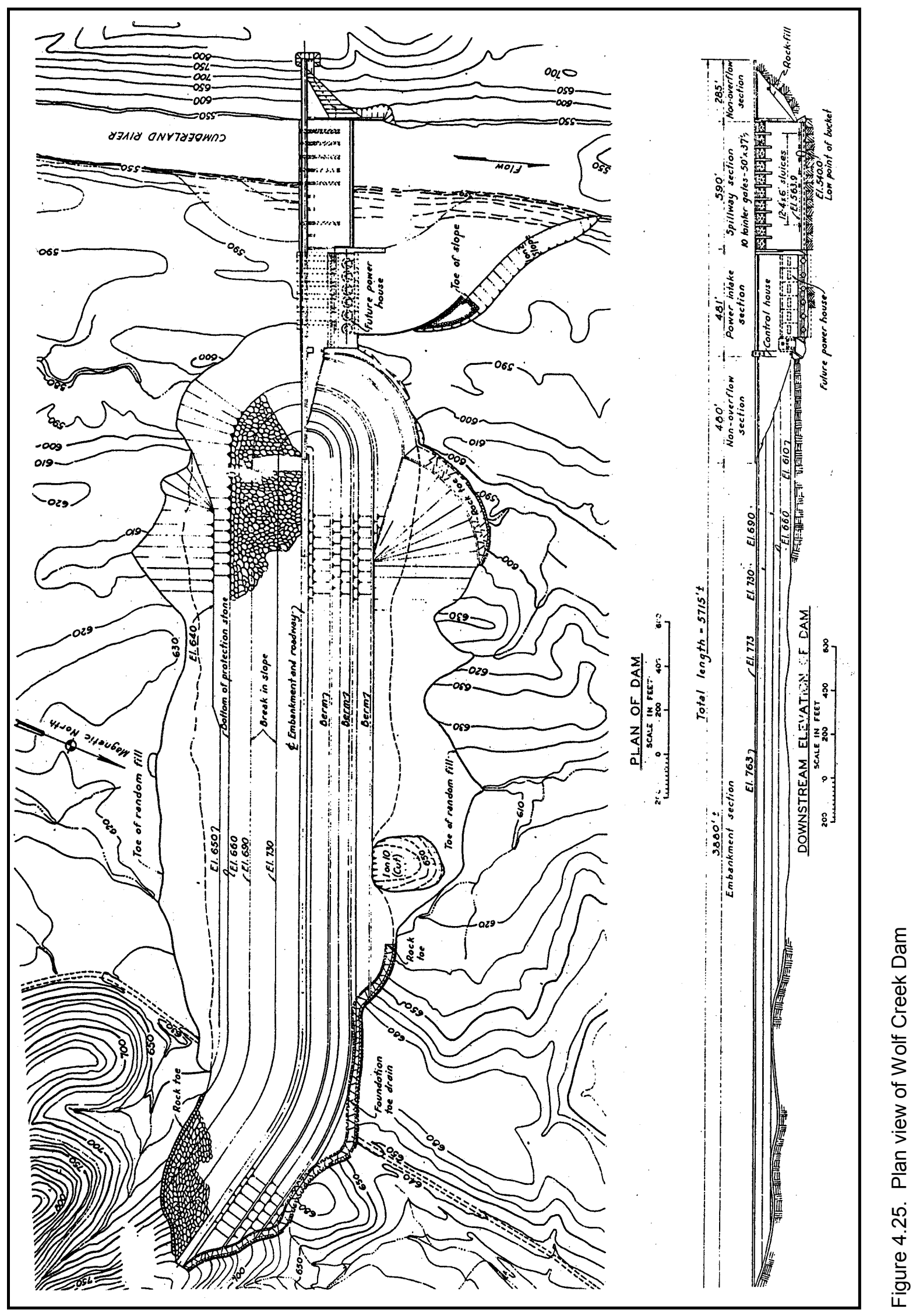




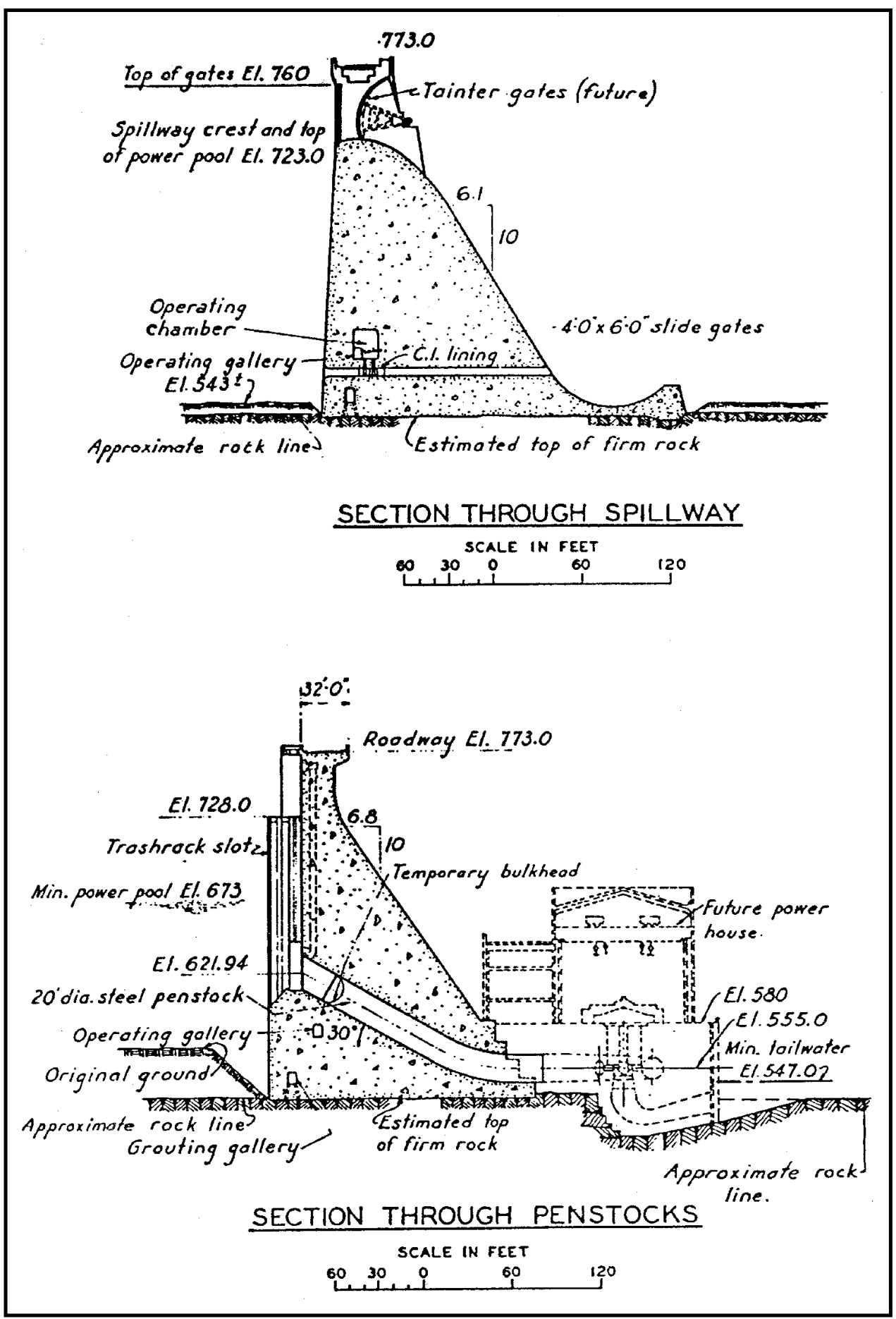

Figure 4.26. Sections through Wolf Creek Dam

60 and $170 \mathrm{ft}$ upstream, respectively. Locations and types of borings are presented in Figure 4.27.

Foundation rock consists of argillaceous or shaly limestone and calcareous shale. Initial geological exploration indicated that jointing controlled rock leakage. 


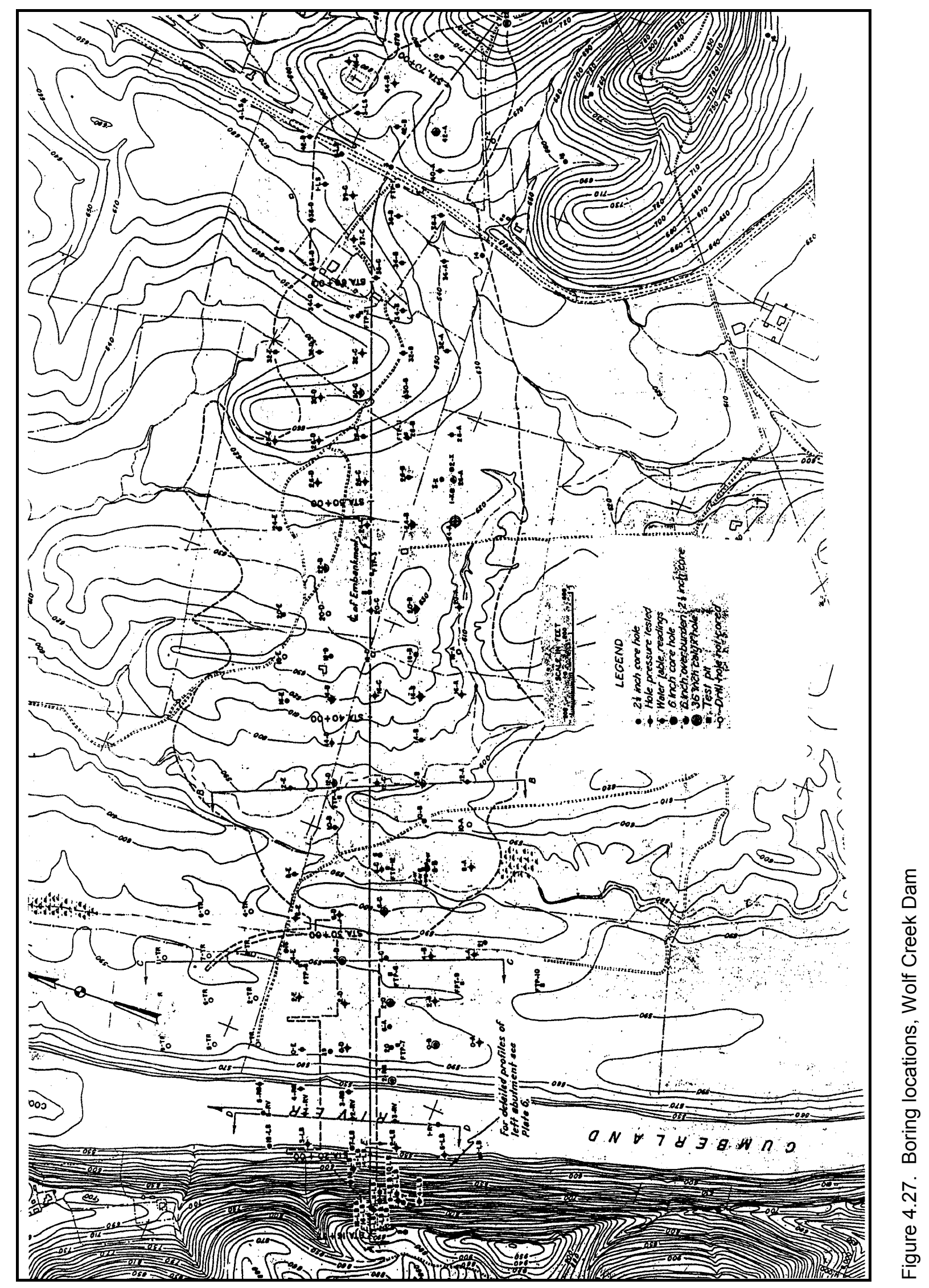


Numerous solution channels, caves, and small tunnels were uncovered during excavation of the cutoff trench and were confirmed during additional exploration in the 1960's. The foundation of the concrete monoliths was grouted in three stages: the first-stage grout holes reached to a depth of approximately $25 \mathrm{ft}$, the second stage to a depth of $50 \mathrm{ft}$, and the third stage to a depth of approximately $75 \mathrm{ft}$ into the foundation. The grout holes are on 5-ft centers along the dam's longitudinal axis. A system of drain holes on 10-ft centers parallel to the line of the grouting holes was drilled $6 \mathrm{ft}$ downstream of the line of grouting holes after completion of grouting.

\subsubsection{Instrumentation}

Geological information for Wolf Creek Dam was excellent, but instrumentation was lacking. Most piezometers are located under the fill embankment portion. An additional grout curtain was installed diagonally in the downstream embankment adjacent to the concrete portion of the dam. Periodic inspection reports documented leakage through the grout curtain. Remedial work was undertaken on several occasions.

In 1972, six uplift cells were installed in Wolf Creek Dam's grouting and drainage gallery (Figure 4.28). Three cells were located upstream and three were located downstream of the grout curtain. Only readings from Gauge M-11U fluctuated with changes in the forebay until 1984, when the reading dropped to tailwater level. Before the quick-release coupling method, coinciding with the sudden drop of the gauge reading, was modified, no true readings were obtained at this or any other gauge. The gauges probably were not connected long enough to reflect true pressures in the instruments. In 1994, 14 additional piezometers were installed to supplement existing cells. Like the original cells, they are angled $30^{\circ}$ upstream and downstream from the vertical axis of the dam. Only gauge M-11U can be linked to variations in the forebay level. The remaining original gauges follow tailwater trends. The newly installed additional gauges provide a flat plot and do not follow fluctuations in either the forebay or the tailwater.

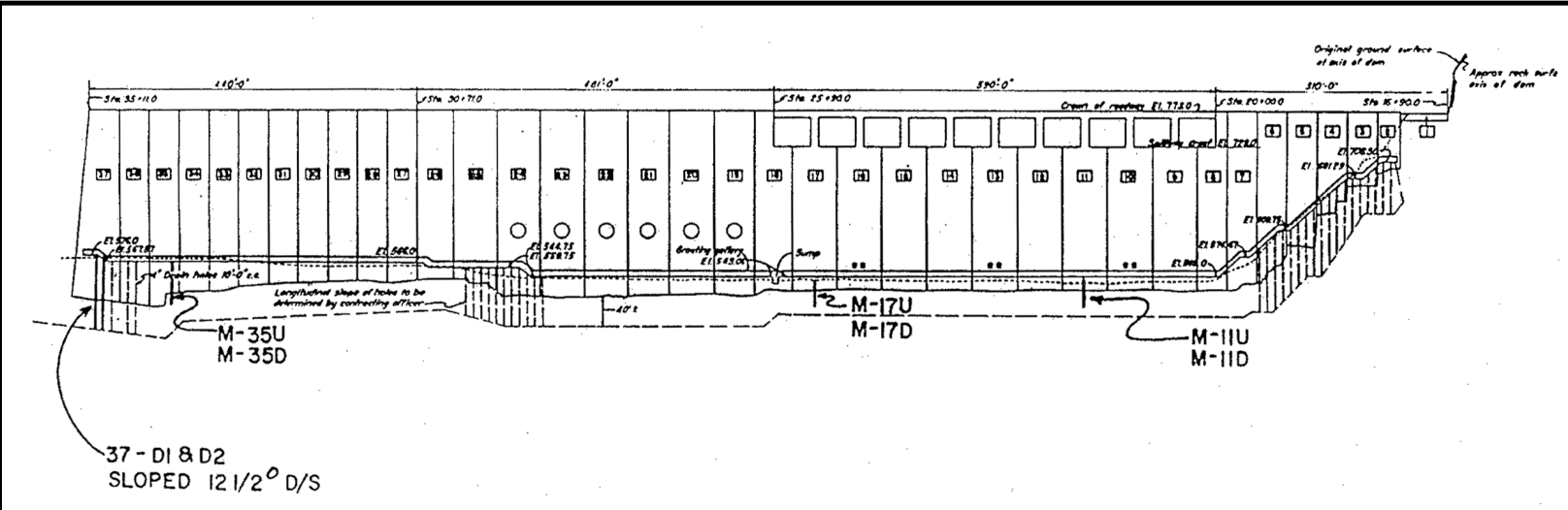

PROFILE OF FOUNDATION DRAINAGE LINE NEAR AXIS OF DAM

Figure 4.28. Uplift cells in Wolf Creek Dam 


\subsubsection{Assessment of data quality}

A single gauge record is considered a poor and insufficient data source for uplift evaluation and made this dam a poor candidate for the uplift uncertainty study. Geologic information for Wolf Creek Dam was rated "very good." Instrumentation data were rated "very sparse."

\subsection{Old Hickory Dam}

\subsubsection{Description}

Old Hickory Dam is in Sumner and Davidson Counties at mile 216.2 on the Cumberland River, approximately 10 miles northeast of Nashville, Tennessee. Old Hickory Dam is a combination concrete gravity and rolled earth-fill structure. It was built between 1952 and 1954. The earth embankment section is about $2,800 \mathrm{ft}$ long. The dam is about $50 \mathrm{ft}$ high, and its concrete portion is $30 \mathrm{ft}$ wide at the foundation base. Pool elevation fluctuates little (between 442 and $445 \mathrm{ft}$ ). The highest pool elevation ever recorded was $450 \mathrm{ft}$. Figure 4.29 is a plan and one embankment section of the dam. No cross section at the gravity part of the dam was available.

\subsubsection{Foundation geology}

The dam is within the regional upwarp of the Nashville Dome. A geological investigation was undertaken in 1951 by drilling a total of 100 holes, and an additional two holes in 1952. The deepest boring was $88 \mathrm{ft}$ deep. There are approximately 44 borings coinciding with the concrete portion of the dam, spillway, and lock (Figure 4.30). The deepest boring reaches about $40 \mathrm{ft}$ into the rock. At the dam site, drilling identified interbedded argillaceous and relatively pure limestones. Some cavernous conditions were uncovered at the site of the spillway. The upper $40 \mathrm{ft}$ of rock was excavated for construction of the concrete portion of the dam. Available boring logs did not provide information on rock fractures. Only 12 borings coincided with locations of the uplift gauges. Constructing a suitable geologic profile would be difficult.

\subsubsection{Instrumentation}

Ten uplift gauges were installed in monoliths on the spillway during construction. Refer to Figure 4.31 for locations of the uplift instruments. All ten gauges are read regularly. Periodic inspections reported that flow from most of the uplift cells is very slow, requiring the measuring gauges to be left connected for a long time. Of the ten uplift cells, readings for three cells did not change in 5 years, one cell read pressure lower than the downstream water level, and the remaining cells were constant. Piezometer O-13 reflects fluctuations of the tailwater. Piezometer O-14 responds only to the tailwater. Piezometer O-7 shows some dependence on tailwater and is reportedly strongly influenced by the upstream grout curtain. 


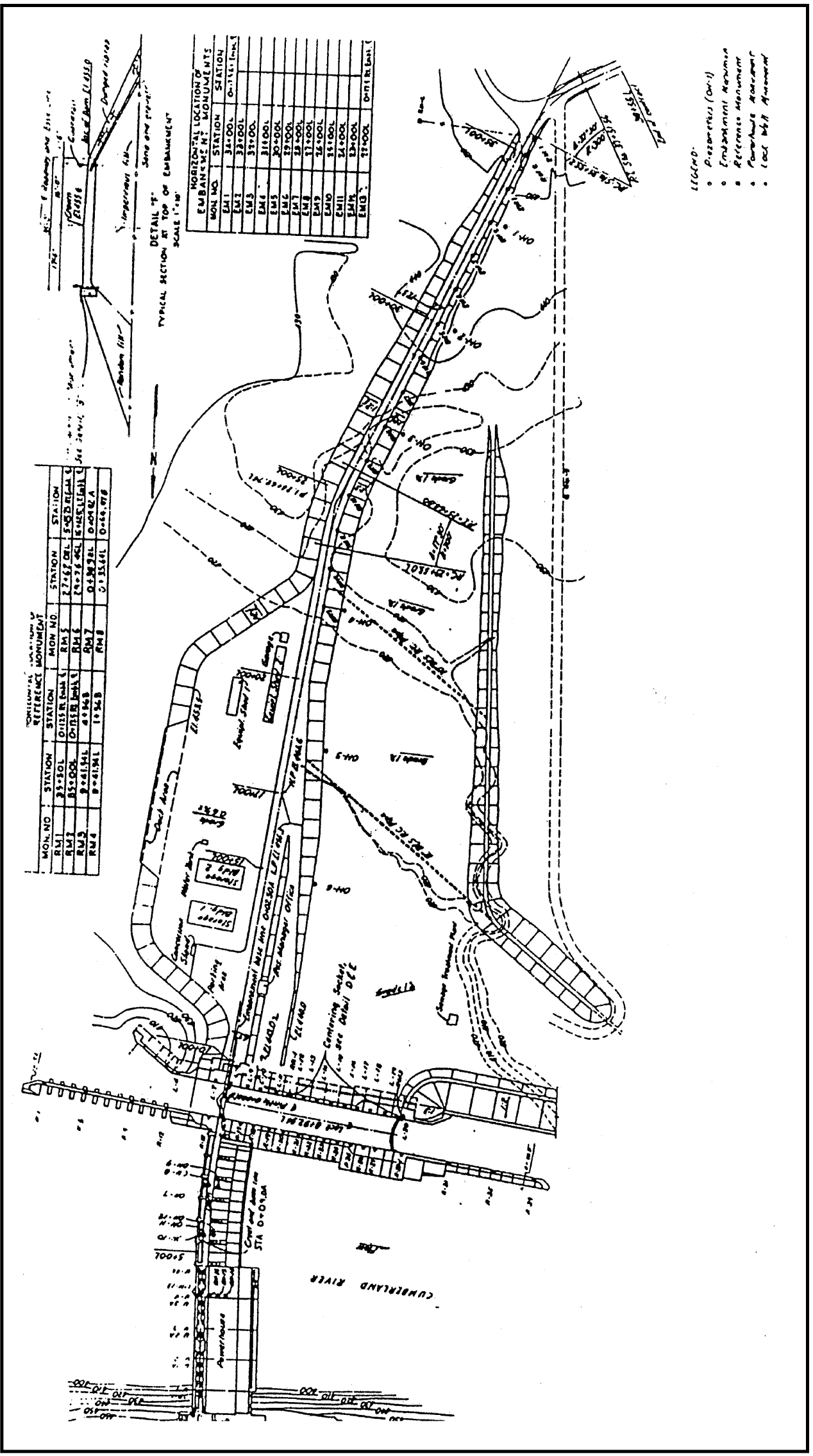

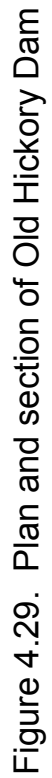




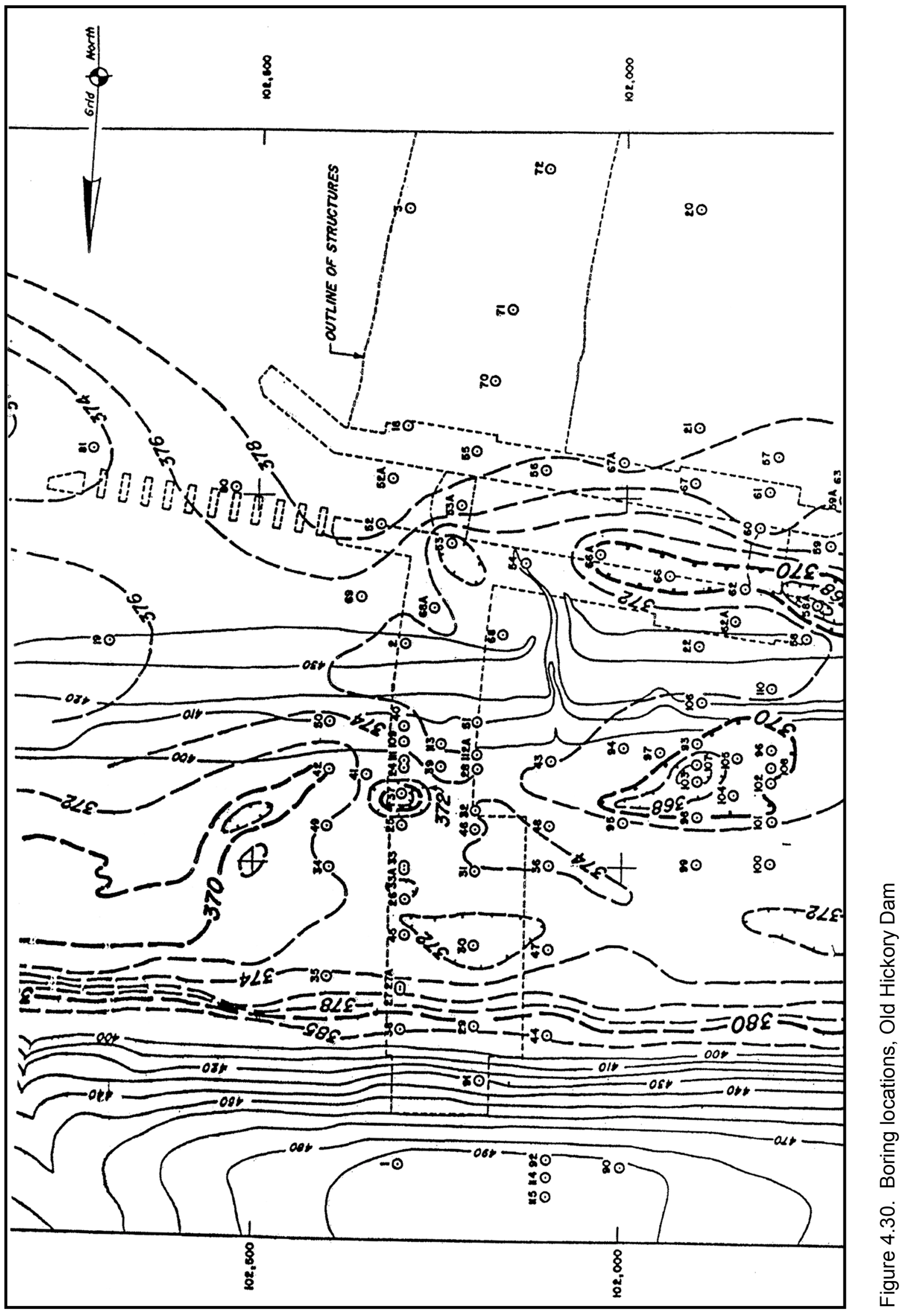




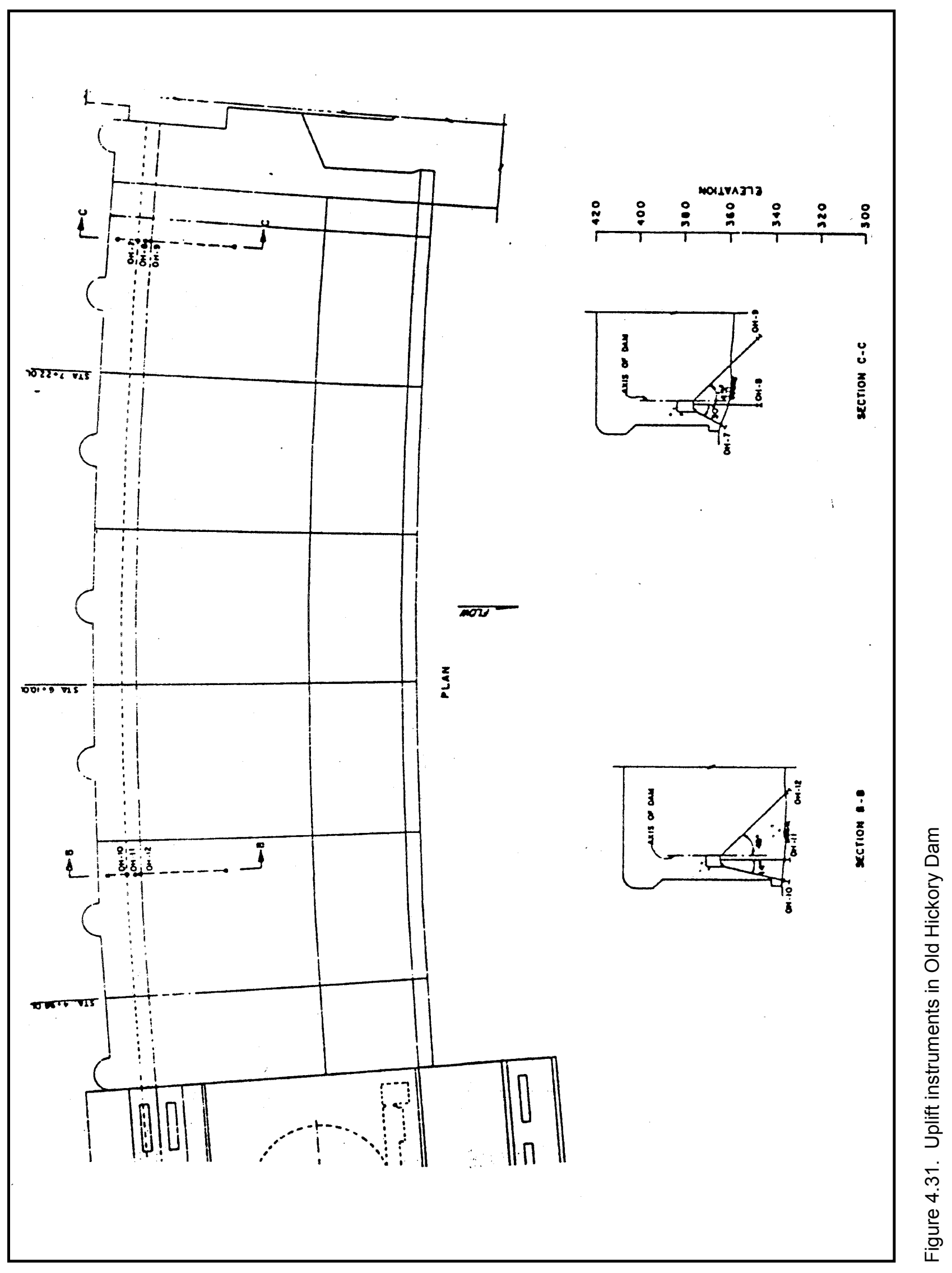




\subsubsection{Assessment of data quality}

Detailed drawings showing installation and exact locations of uplift cells were not found in any available report or documentation. The uplift data history did not indicate that any information consistent with the goals of the uplift study was available. The dependence of gauge readings on the tailwater would obscure rather than elucidate relationships of the forebay control mechanism on uplift pressure effects induced by underseepage. Instrumentation was rated "insufficient." The grouting curtain is located in such way that the uplift pressures and direction of seepage through the substratum would be difficult to determine. Geologic data for Old Hickory Lock and Dam were rated "insufficient" because the essential parameters would be impossible to find or derive. Instrumentation data for Old Hickory Lock and Dam were unsuitable for any serious modeling effort.

\subsection{J. Percy Priest Dam}

\subsubsection{Description}

J. Percy Priest Dam was built between 1963 and 1968 on Stone River east of Nashville Municipal Airport, Tennessee. Figure 4.32 is a plan and elevation upstream of the dam with water impounded from the south. The dam is a combination earth-fill and concrete gravity dam. Only the central portion of the dam is a concrete gravity structure. Two sections through the concrete gravity dam are shown in Figure 4.33. The western part of the earth embankment is 1,340 ft long; the eastern part is $622 \mathrm{ft}$ long. The concrete gravity dam in the middle is $753 \mathrm{ft}$ long at the crest, $130 \mathrm{ft}$ high, and about $80 \mathrm{ft}$ wide at the foundation-rock interface. The concrete portion of the dam consists of 15 monoliths varying in width along the dam axis between 34 and $59 \mathrm{ft}$.

\subsubsection{Foundation geology}

Geological exploration was performed extensively during 1929 and 1930. Drilling continued in 1941, again from 1943 to 1944 and 1947 to 1948, with additional drilling in 1962. Figure 4.34 shows locations of borings. A total of 109 borings, some inclined $45^{\circ}$, were emplaced during the three periods of exploration. A detail of the geologic section at monoliths 4 and 5 is provided in Figure 4.35. Relatively flat-lying, thin-bedded limestone with shale layers, some very soft, was encountered. Drilling crews reported cavitation and water leakage from neighboring borings under pressure during drilling. This required construction of a grout curtain, although no major caverns were uncovered during construction.

Borings of importance to the uplift study are located near monoliths 5, 11, and 15. Exploration done in proximity of monolith 5 included borings $20-\mathrm{I}$ and P-4. Boring 6X-9 is downstream from the axis of the dam in monolith 5. Boring 6X-4 is about $60 \mathrm{ft}$ from monolith 11. Monolith 15 has a larger number of borings: calyx hole No. 1 and borings P-1, 6X-1, and 6X-2. Monolith 15 is adjacent to the 


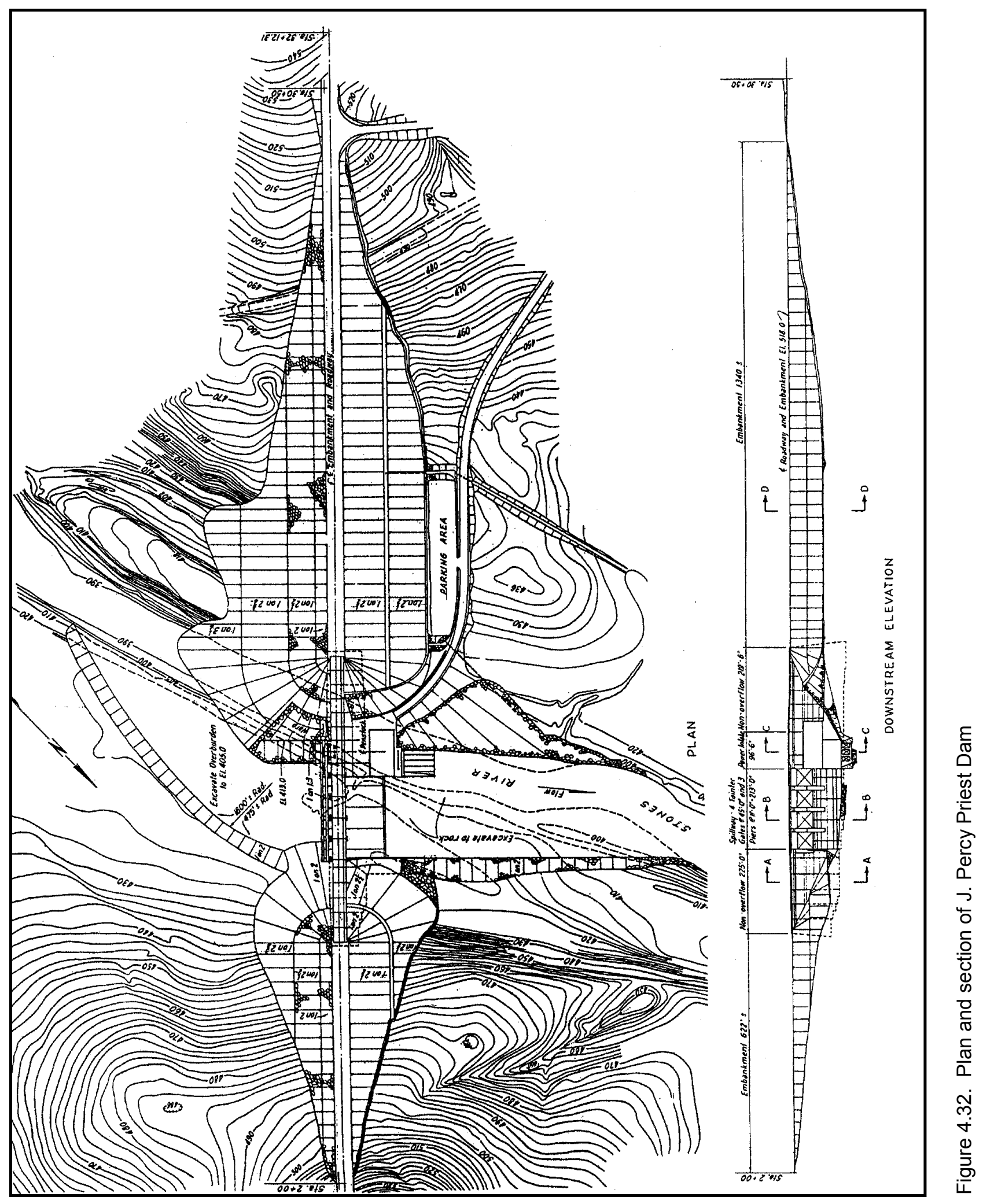




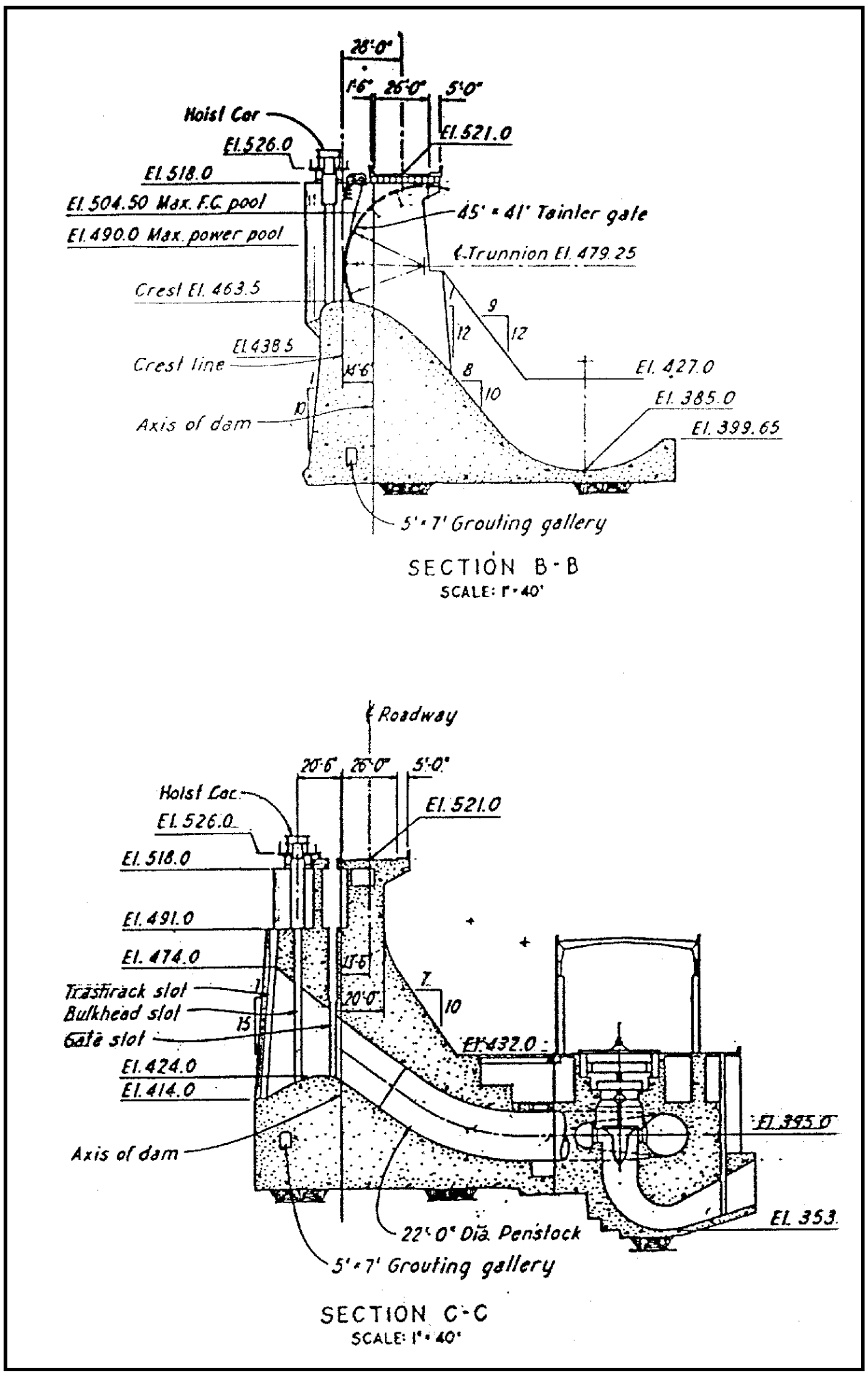

Figure 4.33. Sections through concrete portion of J. Percy Priest Dam 


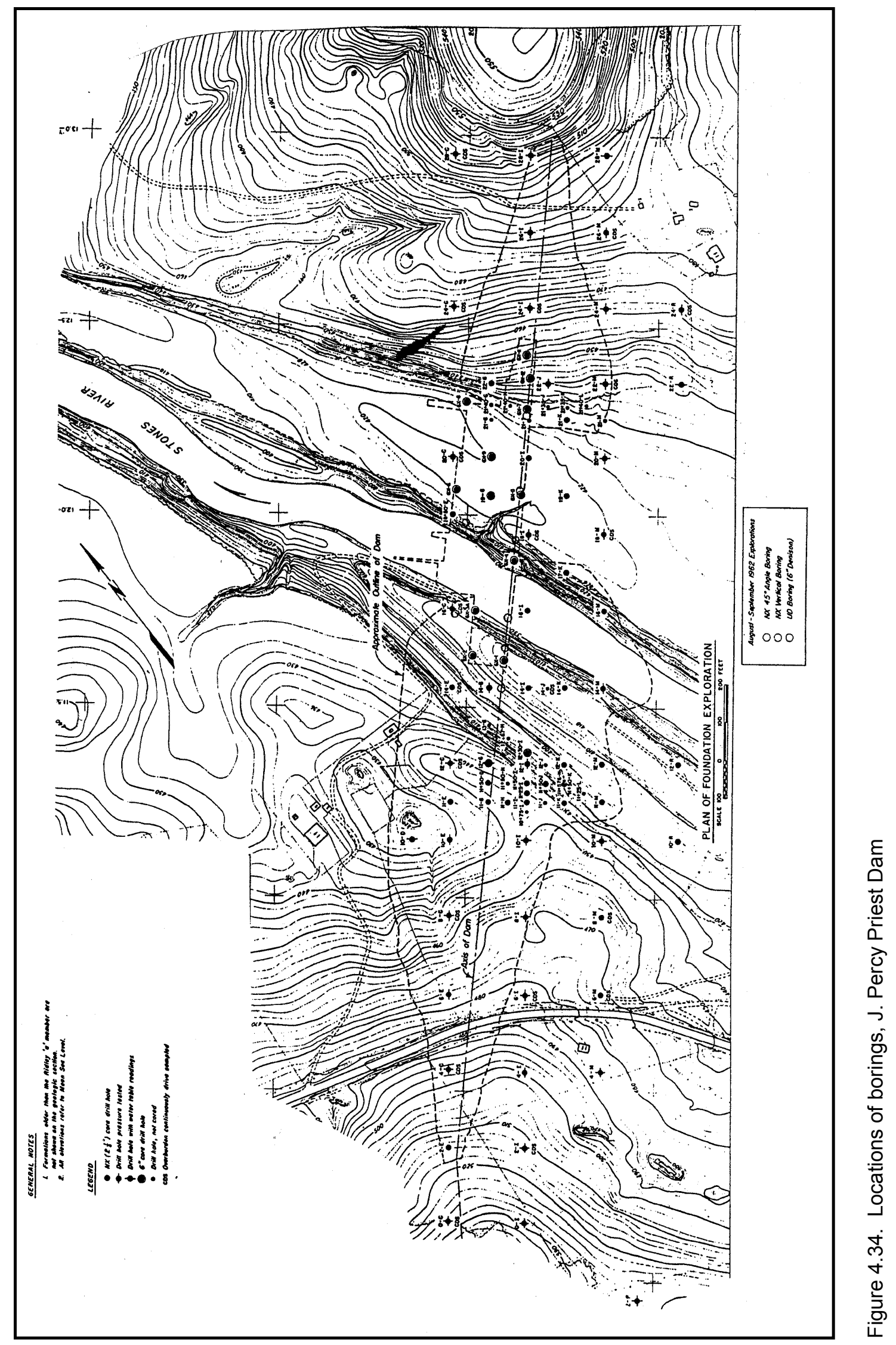




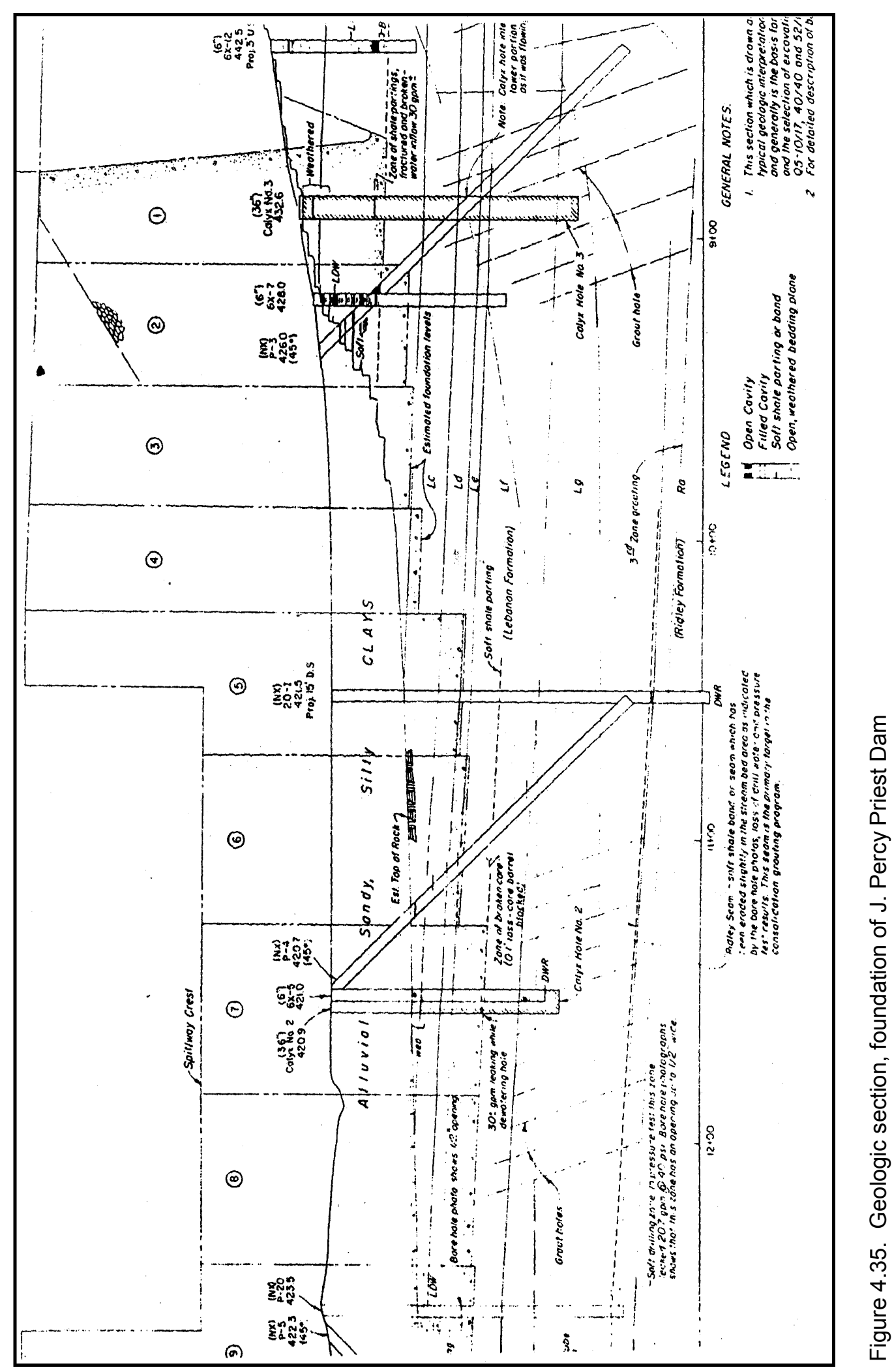


embankment and is less suitable for uplift modeling. Flow through the embankment portion near monolith 15 would make modeling of flow very complex. Figure 4.36 shows a geologic section along the axis of the dam, the Lower Carters, Lebanon, and Ridley formations in relation to the locations of the embankments and concrete gravity structure in the center.

\subsubsection{Instrumentation}

During construction of the dam, six piezometers were initially installed in the gallery: U-1, U-7, U-15, D-1, D-7, and D-15. The letters U and D designate the locations of the piezometers within the monolith upstream or downstream of the grout curtain. In 1983, an additional nine uplift cells were installed in a line perpendicular to the axis of the dam at monoliths 4, 5, and 11. Piezometers (uplift cells) P-56 through P-59 are located in monoliths 4 and 5. P-60 through P-64 were installed in monolith 11. All other piezometers in this dam, including four rock piezometers, are located in the embankment near the trace of a fault. The embankment piezometers have no relevance to the uplift study. All piezometers (uplift cells) are inclined away from the grout curtain.

Initially, piezometer D-7 fluctuated closely with the tailwater reading. The remaining piezometers did not fluctuate either with the forebay or the tailwater. In November 1978, instruments in monolith 7 were damaged by a bomb explosion and repaired. Readings taken since the repair do not indicate any changes at all, plotting with a flat response. The piezometers installed in 1983 continue to show a reasonable correlation with tailwater fluctuations, except for piezometers P-60 and P-64, which show little or no response to either the forebay or the tailwater, and plot a straight line. Figure 4.37 is a longitudinal section along the dam axis showing the location of piezometers in the embankments and uplift gauges, shown as $\mathrm{U}$ - and D- numbered devices, in the concrete portion. Figure 4.38 is a plan view corresponding to the section in Figure 4.37. Locations of only four gauges are shown in this figure, since some uplift gauges were added later and information on those locations was not available.

\subsubsection{Assessment of data quality}

For the purposes of the uplift study, uplift pressures related to tailwater fluctuation have little value. Instrument readings depending on both the forebay and tailwater would be too complex for interpretation. It would be difficult to evaluate the effects of the various responses. The instrumentation was judged unusable and insufficient. Geologic information also was insufficient.

\subsection{Selection of a Case History}

Documentation to support the selection process varied significantly among the dams. In the process of consolidation of the Corps of Engineers District libraries, many dam records related to dam construction have been transferred to the ERDC technical library. Because of the disparity in age of the dams, records varied 


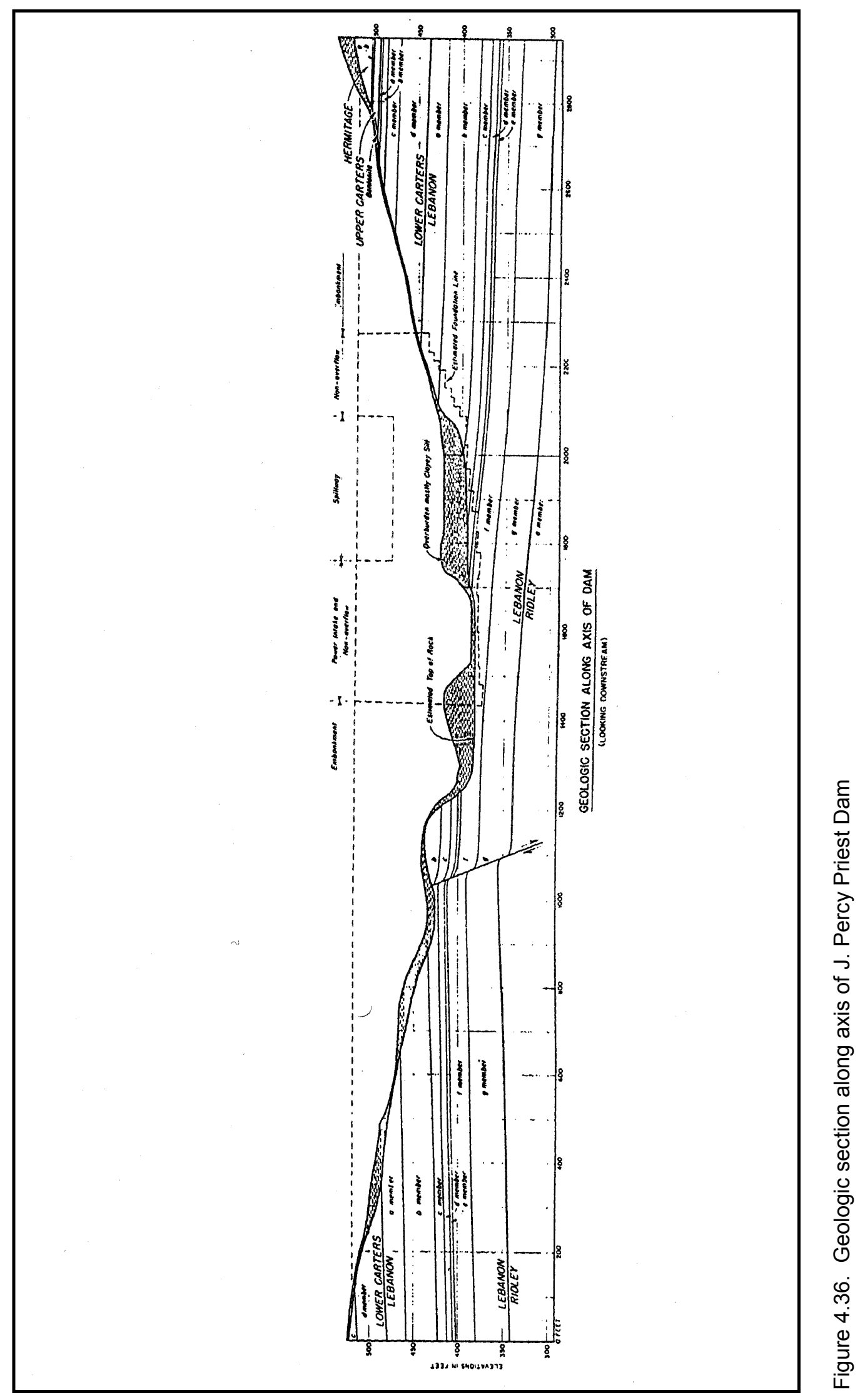




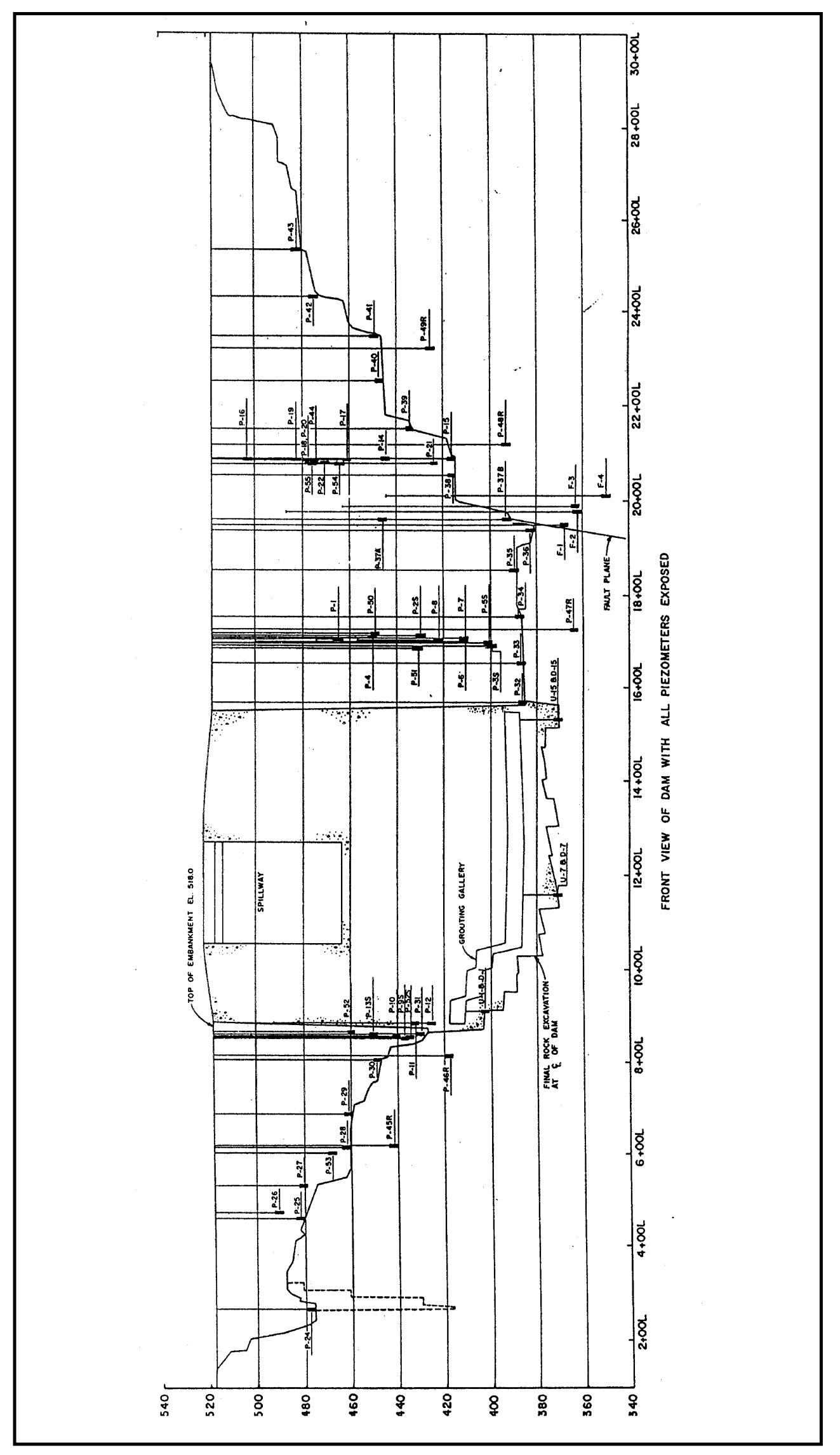

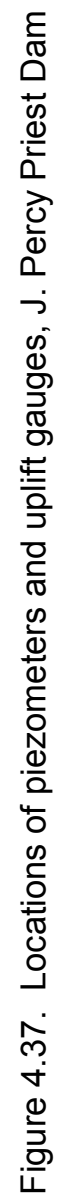




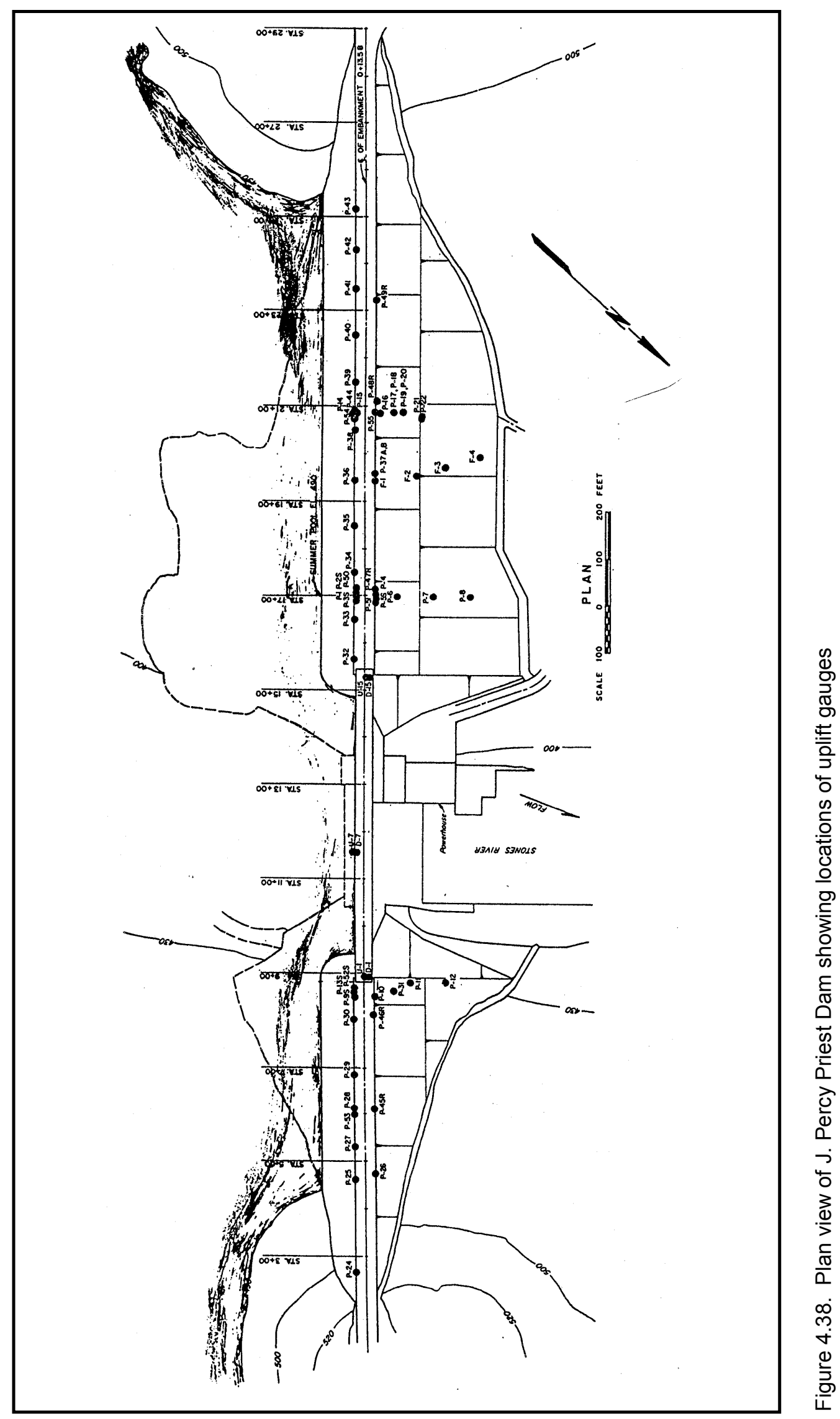


greatly in quality. Historically, older dams have less supporting technical documentation than newer dams. Many project documents were not furnished to the ERDC library, and under additional inquiry with the Districts, were not available in the Districts' libraries, nor in geology or foundation and materials branches of the respective Districts. Full-scale copies of the borings (boring logs) were often replaced in the foundation reports and other design memoranda by sketchy geological profiles. Fracture systems and sizes of fractures could not be evaluated, in most instances, from available documentation.

Table 4.1 rates the evaluated dams for documentation essential to an uplift study. They are listed in descending order of their potential evaluated by the preceding criteria. In the final stage of selection, the decision narrowed between Libby Dam and Dworshak Dam. Both dams had suitable geologic information and functioning uplift pressure monitoring instrumentation and data. Libby Dam was selected for its greater magnitude of data recorded in the cluster of gauges within a single monolith. Gauge readings at Libby Dam appeared more consistent and linear for all gauges at all distances from the forebay to the toe. Repeated grouting and extensive remedial work at Dworshak Dam relegated it to second choice.

\begin{tabular}{|c|c|c|c|c|}
\hline Dam & District & State & Geology & Instrumentation \\
\hline Libby & Seattle & Montana & Good & Good \\
\hline Dworshak & Walla Walla & Idaho & Good & Sufficient \\
\hline Detroit & Portland & Oregon & Insufficient & Insufficient \\
\hline Green Peter & Portland & Oregon & Not determined & Possible \\
\hline Wolf Creek & Nashville & Tennessee & Very good & Very sparse \\
\hline Old Hickory & Nashville & Tennessee & Insufficient & Insufficient \\
\hline J. Percy Priest & Nashville & Tennessee & Insufficient & Insufficient \\
\hline
\end{tabular}

\subsection{Other Observations}

Uplift pressure gauges installed in the foundations of the dams evaluated and documented in this chapter were generally placed in the upper few feet of the foundation rock, near the monolith-rock interface. Uplift pressure measurements thus reflected pressures only in the upper part of the rock mass, and not necessarily pressures in discontinuities at depth. Grout and drain holes were extended to depths sufficient to intercept a number of potentially permeable discontinuities, but uplift pressures that were monitored by gauges are not necessarily representative of pressures in those discontinuities. There is the potential for development of unexpected uplift pressures in discontinuities deeper than the pressure gauges. Sliding instability might then occur along the deep discontinuity rather than along the concrete-rock interface.

Design engineers usually assume a linear, non-site-specific drained uplift pressure distribution in the foundation (for example, Ebeling et al. 2000). Uplift pressure gauges presumably monitor actual pressures developed in the foundation 
following reservoir filling, but the preceding paragraph explained that critical pressures in uninstrumented rock mass discontinuities may go undetected and unheeded because of the shallow placement of uplift gauges. Assessments of uplift pressure distribution and prediction in rock-founded concrete dams should consider the possibility that existing pressure gauge systems may not monitor critical pressures. 


\section{Hydraulic Properties of Jointed Rock from Pressure Tests at Libby Dam}

\subsection{Background}

Ebeling, Pace, and Morrison (1997) discussed procedures for predicting uplift pressures beneath concrete dams founded on rock. Four procedures widely used to predict uplift were (a) use of prescribed non-site-specific uplift distributions, (b) computation from confined, one-dimensional (1-D) steady-state flow within a rock joint, (c) computation of flow in a 1-D tapered rock joint, and (d) flow-netcomputed uplift pressures. They cited studies of existing dams (Stone and Webster Engineering Corporation 1992) suggesting that foundation geology, particularly the condition of rock joints, strongly influences the development and distribution of uplift pressures beneath large gravity dams. Ebeling and Pace (1996a) and Pace and Ebeling (1998) studied the effects of joint geometry and aperture on the flow of water through the foundation and on the development of uplift pressures. They used a 1-D steady-state laminar flow analysis and twodimensional finite element model to investigate the effects of joint aperture on computed uplift pressures. These models incorporate estimates of joint aperture and joint hydraulic conductivity in computing developed uplift pressures. In assessing uncertainties in predicting uplift pressures, it is useful to attempt to derive joint hydraulic properties from commonly available test data. This chapter documents computations of hydraulic properties from borehole pressure test data and borehole log information at Libby Dam obtained prior to dam construction.

The authors derived values of equivalent hydraulic conductivity ${ }^{1}$ of pressuretested zones of rock in the foundation of Libby Dam. The coefficient of equivalent hydraulic conductivity is the hydraulic conductivity of a zone of jointed rock in which flow is assumed to occur uniformly throughout the rock mass rather than

\footnotetext{
1 As explained in Chapter 2, the term hydraulic conductivity is used in this report in keeping with recent usage. The terms permeability and coefficient of permeability are restricted to describing the intrinsic property of a medium to transmit fluid independent of the fluid properties.
} 
through individual joints ${ }^{1}$ (Bennett and Anderson 1982). Although flow actually occurs through one or more joints in otherwise impermeable rock, treating the rock as a uniform mass allows the use of Darcy's law of diffuse flow in calculating an equivalent hydraulic conductivity for a given zone of rock in which pressure tests have been conducted.

Foundation investigation borings placed in 1962 and 1963, prior to construction of Libby Dam, penetrated up to $120 \mathrm{ft}$ of jointed argillite (a metamorphosed claystone). About $60 \mathrm{ft}$ of sand and gravel overlay the rock in most of the foundation boreholes at the time of drilling. Seattle District pressure-tested many of the boreholes by inflating packers to seal off approximately $10-\mathrm{ft}$ zones of rock either as the borehole progressed or after completion of a borehole. To conduct the tests, District personnel pumped water into the test zones at pressures ranging from 30 to $100 \mathrm{psi}$ and measured inflow in gallons per minute, converting to cubic feet per minute. Pressure was measured at a surface gauge and inflow in a surface flowmeter. For selected boreholes within monolith 23 of Libby Dam, the authors applied Hvorslev's equation for radial flow to a well through a permeable layer between impervious strata to derive the equivalent hydraulic conductivity of each pressure-tested zone.

From computed values of equivalent hydraulic conductivity and a count of the number of joints in each test interval, equivalent joint aperture (also called equivalent parallel plate or conducting aperture) and equivalent joint hydraulic conductivities were derived for each test zone using procedures suggested in the Rock Testing Handbook (Geotechnical Laboratory 1993). Line graph plots of depth versus derivative properties show the distribution of hydraulic properties within the foundation of monolith 23 .

\subsection{Geological Conditions at Libby Dam}

Libby Dam is located in northwest Montana on mile 221.9 of the Kootenai River, 17 miles from its confluence with the Columbia River (Figure 5.1). It is a concrete gravity dam $420 \mathrm{ft}$ high and 3,055 ft long at its crest, impounding a reservoir 90 miles in length that extends into Canada. Initial geological investigations were conducted between 1951 and 1954; detailed foundation investigations were completed in 1966. The dam was completed in July 1973. The maximum reservoir pool is elevation 2,459 ft. Libby Dam and its reservoir are in the northern Rocky Mountains, a region characterized by rugged mountains and linear valleys trending north to northwest. Maximum relief in the area is about $5,000 \mathrm{ft}$. The region is underlain by thick pre-Cambrian metasediments known as the Belt Series, consisting of argillite, quartzite, metasandstone, and limestone.

As stated in Chapter 4, rock at the dam site, described in the foundation report (U.S. Army Engineer District, Seattle, 1979), consists mainly of quartzite, metasandstone, and siliceous argillite (a weakly metamorphosed mudstone). Rock

\footnotetext{
1 The term joint is used in this discussion to describe rock mass discontinuities in the foundation
} of Libby Dam. It is understood that many of the "joints" are actually bedding plane separations. 


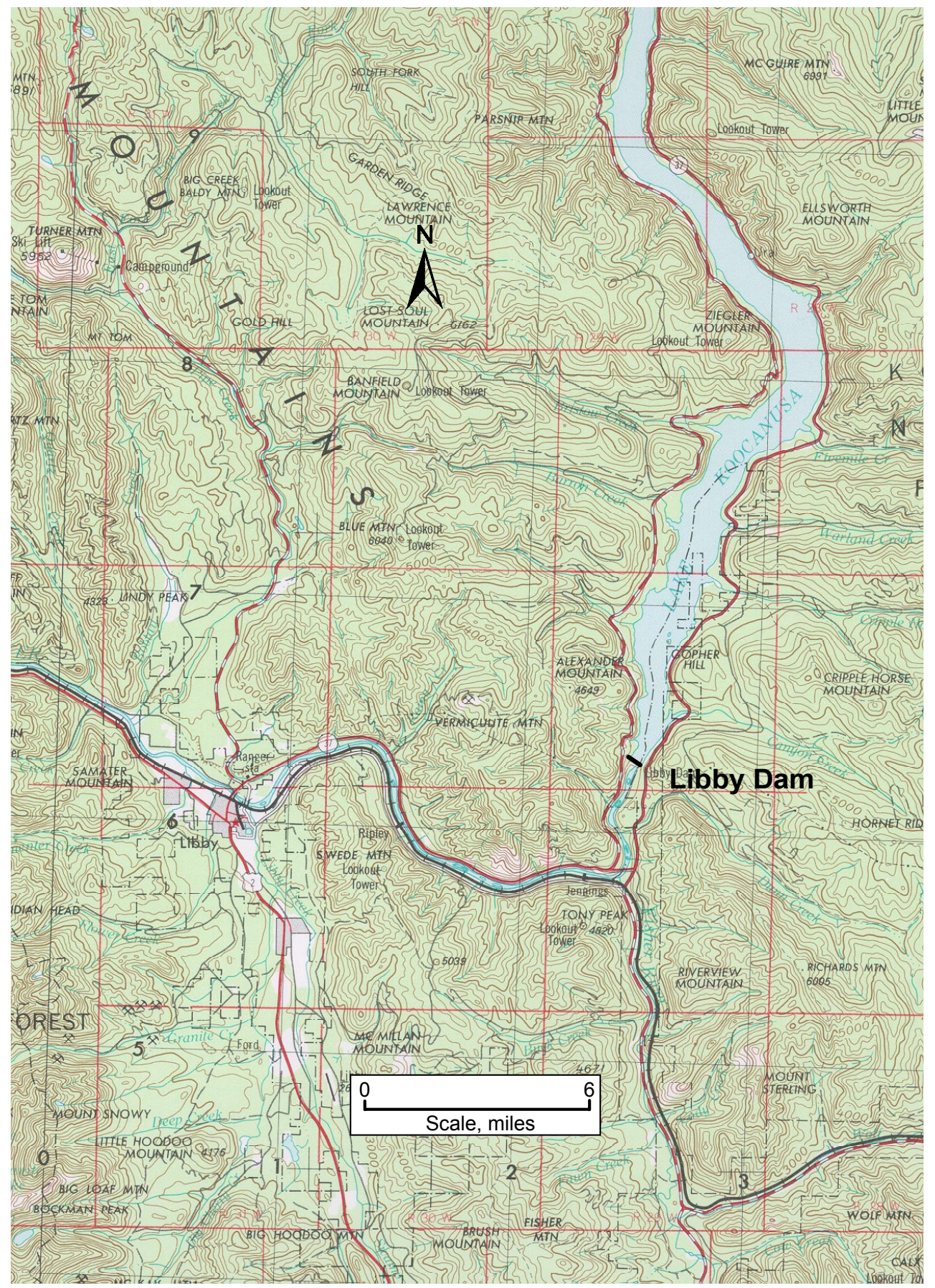

Figure 5.1. Location of Libby Dam, Kootenai River, Montana

in the foundation of Libby Dam was described as hard, thin-bedded argillite with sandy and calcareous zones. The foundation has a well-developed fracture system consisting of several kinds and sets of joints, as described in the foundation report. Figure 5.2 shows detailed mapping of discontinuities in the vicinity of monolith 23. Bedding joints (congruent with the attitude of the bedded argillite) are 


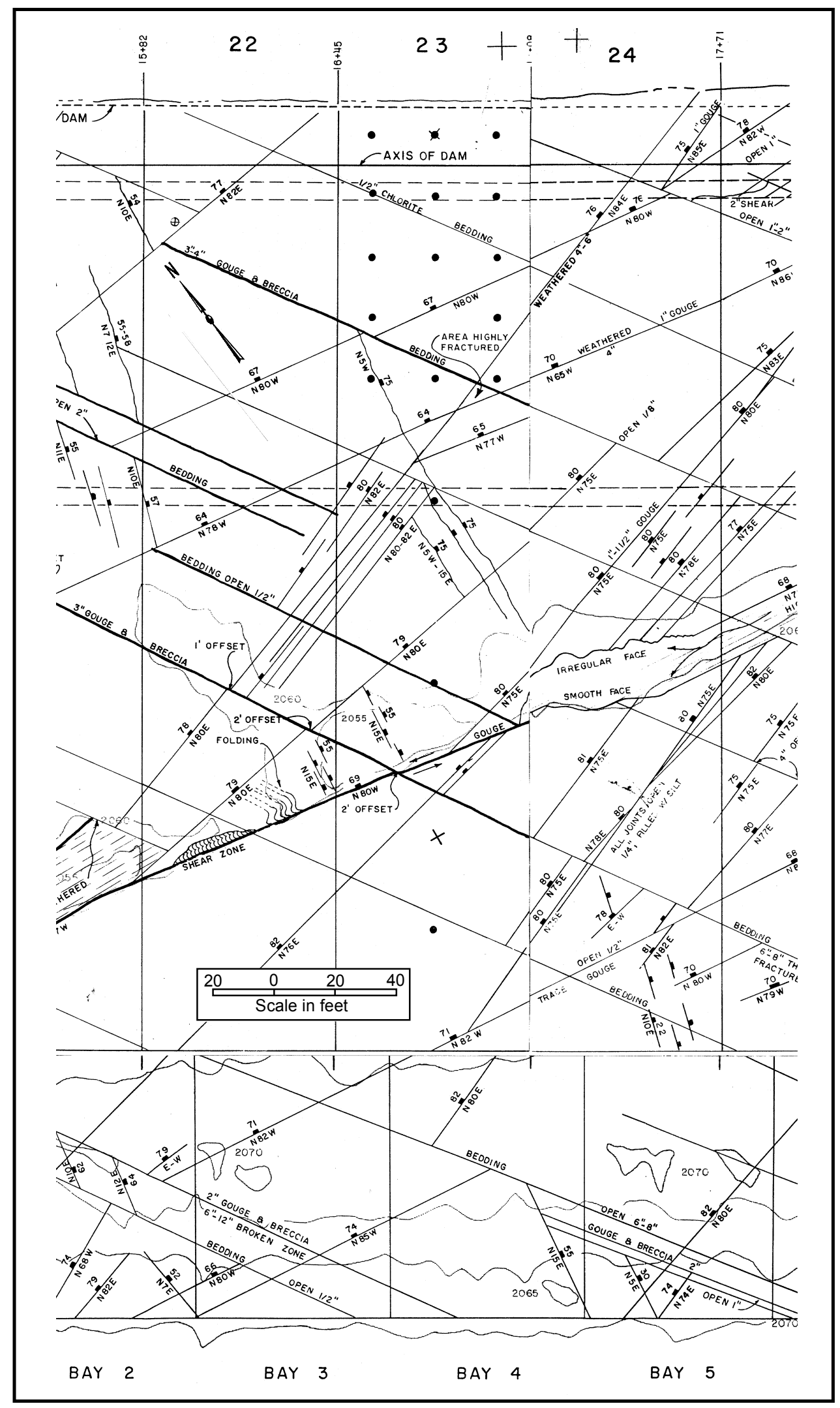

Figure 5.2. Mapped discontinuities on foundation floor, monoliths 22,23 , and 24 , Libby Dam 
common and strike $330^{\circ}$ and dip $40^{\circ}$ to $45^{\circ}$ west. A prominent set of generally east-west, high-angle shear joints dips $60^{\circ}$ to $80^{\circ}$ north or south. Where shear joints intersect bedding joints, wedges were formed in the valley walls. Generally north-south "relaxation joints" dip $50^{\circ}$ to $80^{\circ}$ east. Transverse "tension" joints strike northeast and dip at moderate to high angles to the southeast. Other tension joints strike parallel to bedding and dip at right angles to bedding and are probably related to folding. Many low-angle rebound joints (formed during unloading of the rock mass) have random strikes. Some prominent bedding joints are filled with gouge and are slickensided, evidence of movement, and are considered faults. Several episodes of movement were noted along the faults. Intersection of faults with east-west and north-south trending joints has broken the rock mass into discrete blocks. Certain joints were open to a considerable depth, possibly caused by unloading after glaciation.

Two impervious cutoff trenches were built for Libby Dam (U.S. Army Engineer District, Seattle, 1979). The trenches did not reach the top of rock through the full length of the cofferdam. To provide additional stability, the dam foundation was excavated with a slightly lower elevation at the axis than at the downstream toe. Grout holes are inclined $25^{\circ}$ upstream and $15^{\circ}$ into the left abutment. The primary grouting zone was $40 \mathrm{ft}$ deep, the secondary zone $90 \mathrm{ft}$, and some locations $160 \mathrm{ft}$ deep.

Two drainage curtains assist the operation of the grout curtain: one $5 \mathrm{ft}$ downstream and one $105 \mathrm{ft}$ downstream of the grout curtain. The foundation report stated that two lines of drains were considered necessary because of the 290-ft base width of the dam. Drain holes varied from 60 to $105 \mathrm{ft}$ in depth (U.S. Army Engineer District, Seattle, 1979). An exploration adit was incorporated into the drainage gallery.

Uplift pressure monitoring cells were installed under six monoliths: two abutment monoliths, 14 and 41, and four valley monoliths, 18, 23, 29, and 34 .

\subsection{Computation of Equivalent Hydraulic Conductivity}

\subsubsection{Principles and assumptions}

Bennett and Anderson (1982) reviewed methods of determining flow properties in bored rock masses. They stated that an equivalent hydraulic conductivity (they used the term equivalent coefficient of permeability) can be estimated using data from constant head pressure tests if certain assumptions of groundwater flow are satisfied:

a. The rock mass is homogeneous, isotropic, and saturated.

$b$. All flow is radial and axisymmetric about the borehole.

c. The borehole is vertical.

1 Structural attitudes are given in azimuth degrees, 0 to 360, clockwise from north. 
d. Flow is steady state (at equilibrium, or constant head).

e. Flow is laminar.

f. A linear relationship exists between pressure and flow rate (i.e., Darcy's law is valid).

g. There is no leakage around the packer(s).

$h$. The change in pressure caused by acceleration of flow into the rock mass is negligible.

When these conditions are met, the equivalent hydraulic conductivity $K_{e}$ may be calculated from results of constant-pressure tests using the equation derived by Hvorslev (1951, his Figure 12, Case 9). ${ }^{1}$ Bennett and Anderson rearranged Hvorslev's equation to solve for $K_{e}$ :

$$
K_{e}=(Q / 2 \pi l H) \ln \left(R / r_{o}\right)
$$

where

$K_{e}=$ equivalent hydraulic conductivity (units of $L / T$ )

$Q=$ volume flow rate at equilibrium $\left(L^{3} / T\right)$

$l=$ length of test section $(\mathrm{L})$

$H=$ excess pressure head $(L)$ at center of test section $=P_{t} / \gamma_{w}+H_{g}$, where $P_{t}$ is the pressure measured at the surface gauge and $H_{g}$ is the head produced by the height of water in the flow pipe (depth to the water table for a submerged test section). Calculation of $H$ neglects head losses between the surface gauge and the test section and head due to flow velocity at the gauge because these parameters were unknown or unrecorded

$R=$ radius of influence of the pressure test $(L)$

$r_{o}=$ borehole radius $(L)$

The authors also reviewed the suggested method for pressure testing for the determination of rock mass hydraulic conductivity, method RTH 381-80 in the Rock Testing Handbook (Geotechnical Laboratory 1993). RTH 381-80 also provided relationships for determining equivalent parallel plate aperture $(e)$ and joint hydraulic conductivity $\left(K_{j}\right)$. Zeigler (1976) provides a thorough review of procedures for determining rock mass hydraulic conductivity from pressure tests.

\subsubsection{Libby Dam model}

Borehole logs from the foundation report for Libby Dam (U.S. Army Engineer District, Seattle, 1979) provided data for the pressure tests. Pressure-test

1 Hvorslev's Case 9 is actually for a confined aquifer bounded above and below by impermeable soil or rock. The Libby Dam foundation pressure tests were in zones confined only in the borehole by inflatable packers, or by the bottom of the hole and a packer at the top of the zone. Flow within the foundation rock could thus occur from or into rock above and below the sealed zone, unlike flow in a permeable zone modeled by Hvorslev's Case 9. 
sections were nominally $10 \mathrm{ft}$ long, the length of a typical drilling run. Some tests were conducted as boring progressed, using a single inflatable packer in combination with the bottom of the hole to define each section. Other tests were conducted after completion of a borehole, using a pair of packers to define a test zone, starting at the bottom of the hole and progressing upwards. Pressure readings were recorded on a gauge at the ground surface as \#, presumably pounds per square inch. Excess pressure heads ( $H$, Equation 5.1) were therefore corrected for height above the test section. Figure 5.3a illustrates the physical model describing the case of the Libby Dam pressure tests. Figure 5.3b illustrates Hvorslev's analytical model applied to the pressure test data to derive rock mass hydraulic properties. Most tests were run for 10 minutes with the flow $(Q)$ measured for each 1-minute interval. The value of $Q$ used to calculate the hydraulic properties discussed in the following paragraphs was the mean of the ten 1-minute measurements.

Zeigler (1976) reviewed Corps procedures for conducting pressure testing in jointed rock masses. He stated that in most pressure tests the water injection pressure is limited to a value that is not expected to increase the joint aperture (by hydrofracturing). An increase in aperture would cause erroneously high flow rates, resulting in higher and unrepresentative permeabilities than actually exist in the rock mass. Common practice is to limit the water injection pressure to $1 \mathrm{psi} / \mathrm{ft}$ of borehole depth above the water table and $0.5 \mathrm{psi} / \mathrm{ft}$ of borehole depth below the water table. This criterion results in a maximum injection pressure less than the effective overburden pressure if the overburden has a unit weight greater than $144 \mathrm{lbf} / \mathrm{ft}^{3}$ (overburden pressure $144 \mathrm{lbf} / \mathrm{ft}^{3}=1 \mathrm{psi} / \mathrm{ft}$ dry, and $1 \mathrm{psi}$ minus $0.43 \mathrm{psi} / \mathrm{ft}=0.57 \mathrm{psi} / \mathrm{ft}$ submerged). Seattle District adjusted gauge pressures for shallow test zones to maintain safe pressures in some of the pressure tests conducted at Libby (roughly 0.5 to 1 psi per $\mathrm{ft}$ of depth: see column B in Table 5.1). In others, however, no adjustment was made. For example, in borehole D-125, gauge pressures were maintained at $100 \mathrm{psi}$ in all 12 tested zones, including zones as shallow as $66 \mathrm{ft}$ depth.

Referring to Equation 5.1, $Q$ is in $\mathrm{cfm} ; l, H, H_{g}, R$, and $r_{o}$ are in $\mathrm{ft}, P_{t}$ is in psi, and $K_{e}$ is calculated in $\mathrm{ft} / \mathrm{min}$. The pressure $P_{t}$ is converted to $\mathrm{ft}$ of head by multiplying by $2.31 \mathrm{ft} / \mathrm{psi}^{1}{ }^{1} . H_{g}$ is taken to be the depth from the ground surface to the water table as recorded on the borehole $\log$ (all test sections were below the water table). The borehole radius, $r_{o}$, is $(2.98 \mathrm{in} . / 2) / 12=0.124 \mathrm{ft}$ (from the NX drill bit). $R$, the radius of influence, is unknown; but because the quotient $R / r_{o}$ is a function of the natural logarithm $(\ln )$, the value of $\ln \left(R / r_{o}\right)$ does not vary significantly with large changes in $R\left(\ln \left(R / r_{o}\right)=4.38,6.69\right.$, and 8.99 for values of $R=10,100$, and 1,000 , respectively). The effect on $K_{e}$ of assuming an incorrect radius of influence is not significant (Bennett and Anderson 1982; Zeigler 1976, p. 43). Because there were many uncertainties associated with estimating equivalent hydraulic conductivities for the Libby Dam foundation boreholes, including sparse data on geometry and spacing of individual joints, the possibility of leakage through the packers, distribution of flow within individual joints of a tested zone, and magnitude of flow velocities within individual joints, the importance of obtaining a precise value for $R$ was further reduced. Following Bennett and Anderson (1982),

$\overline{{ }^{1} P_{t} / \gamma_{w}=P_{t} /\left(62.4 \mathrm{lbf} / \mathrm{ft}^{3}\right) /\left(144 \mathrm{in}^{2} / \mathrm{ft}^{2}\right)}=P_{t} * 2.31 \mathrm{ft} /\left(\mathrm{lbf} / \mathrm{in} .{ }^{2}\right)=P_{t} * 2.31 \mathrm{ft} / \mathrm{psi}$. 


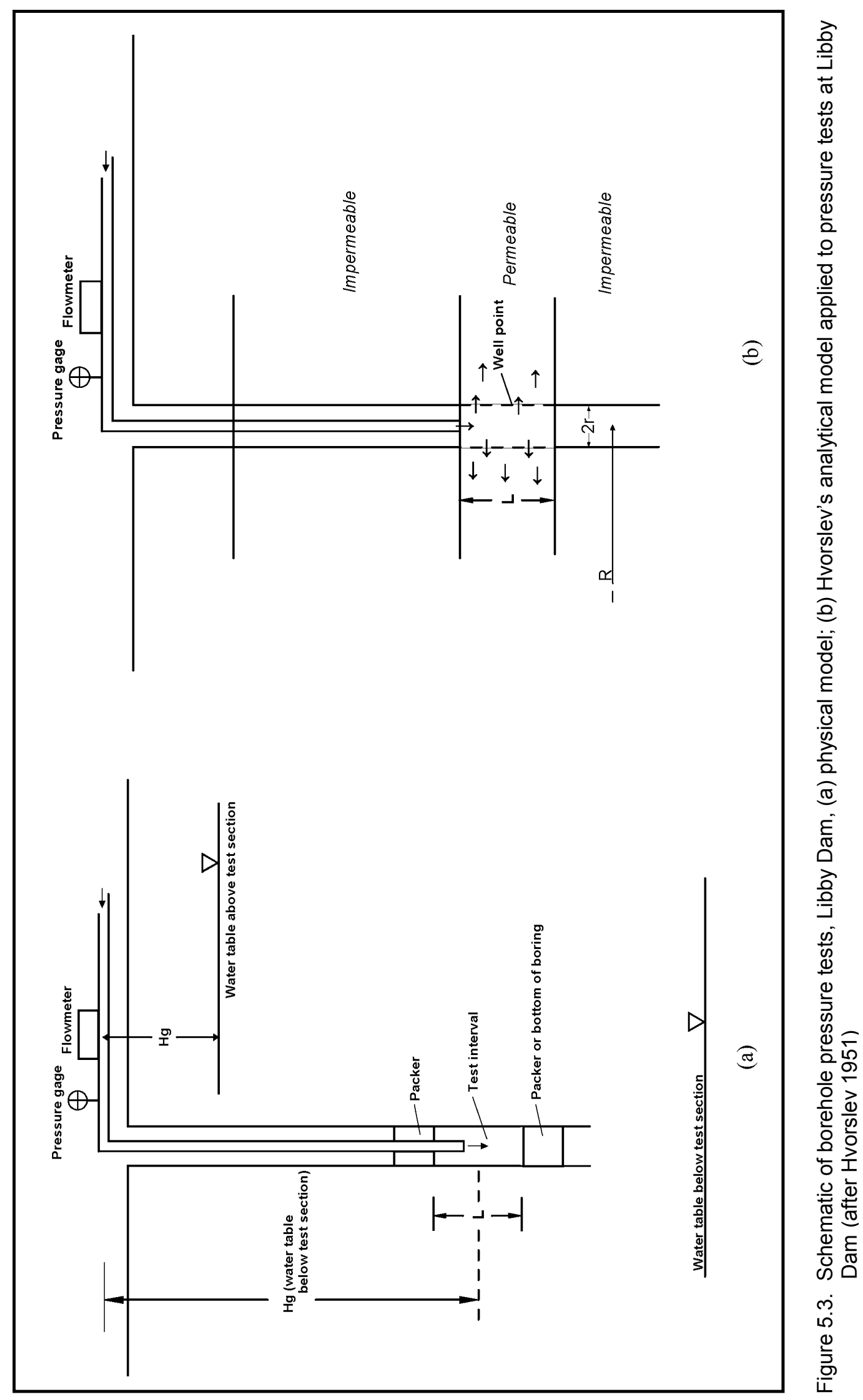




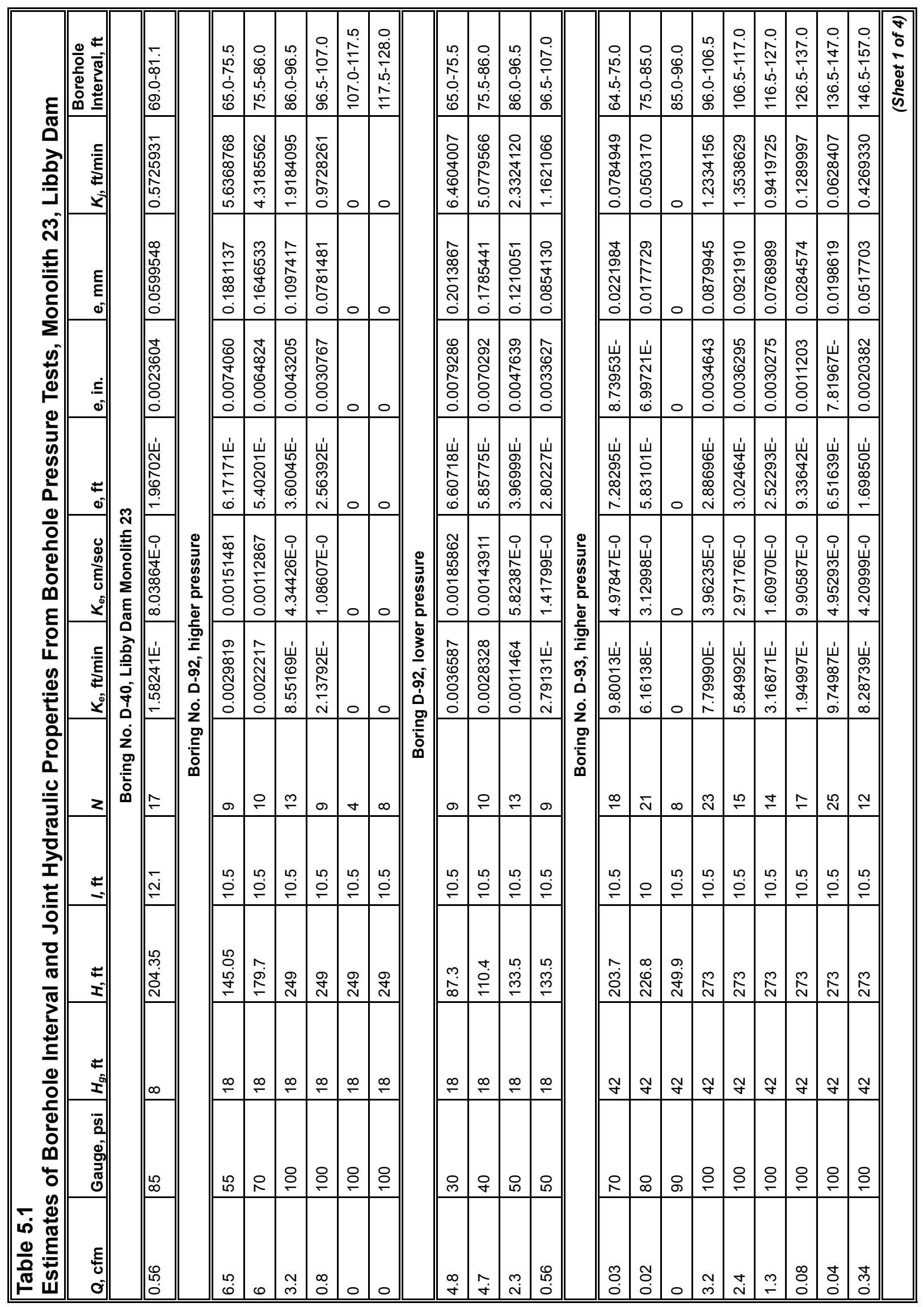




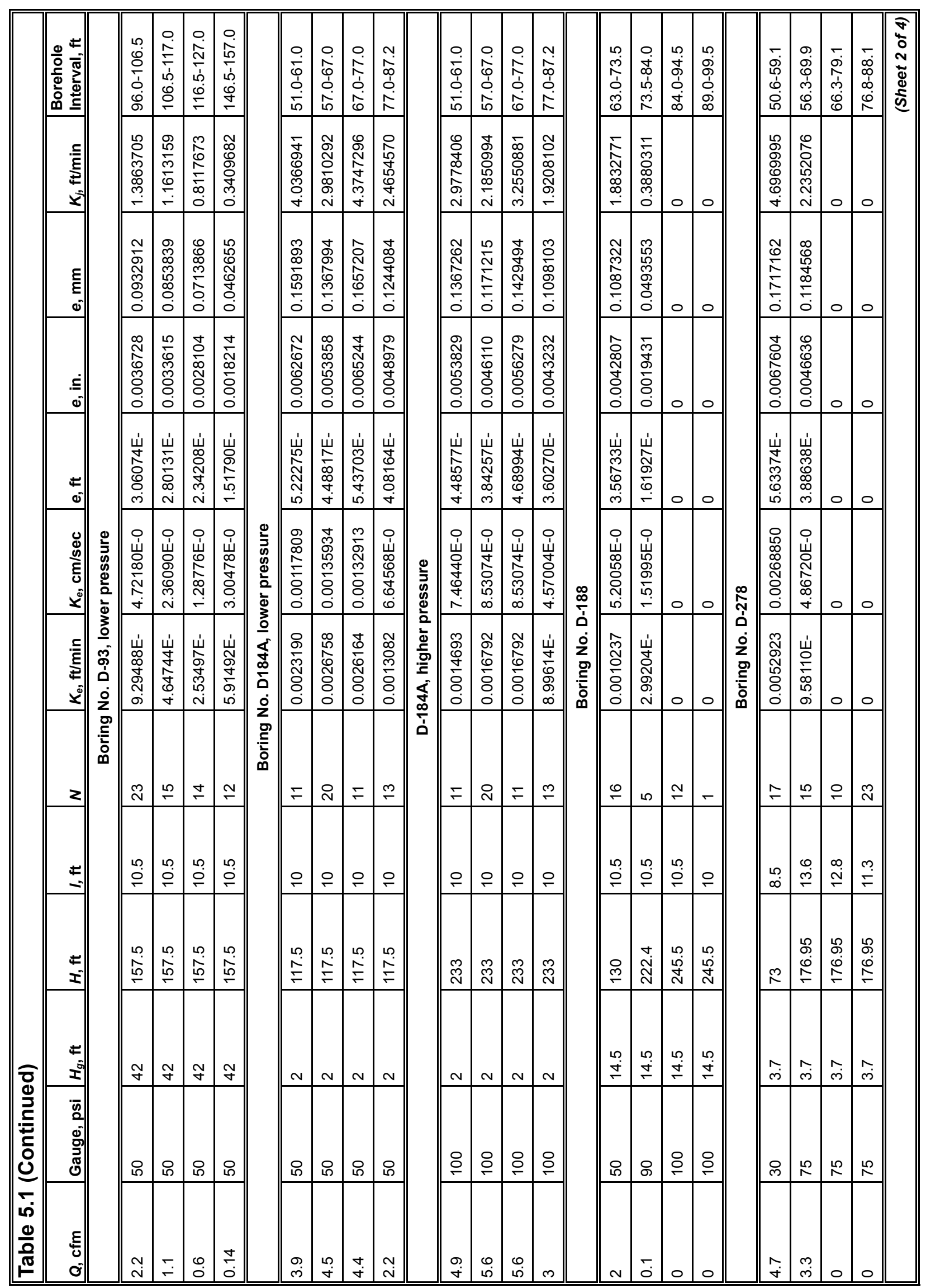




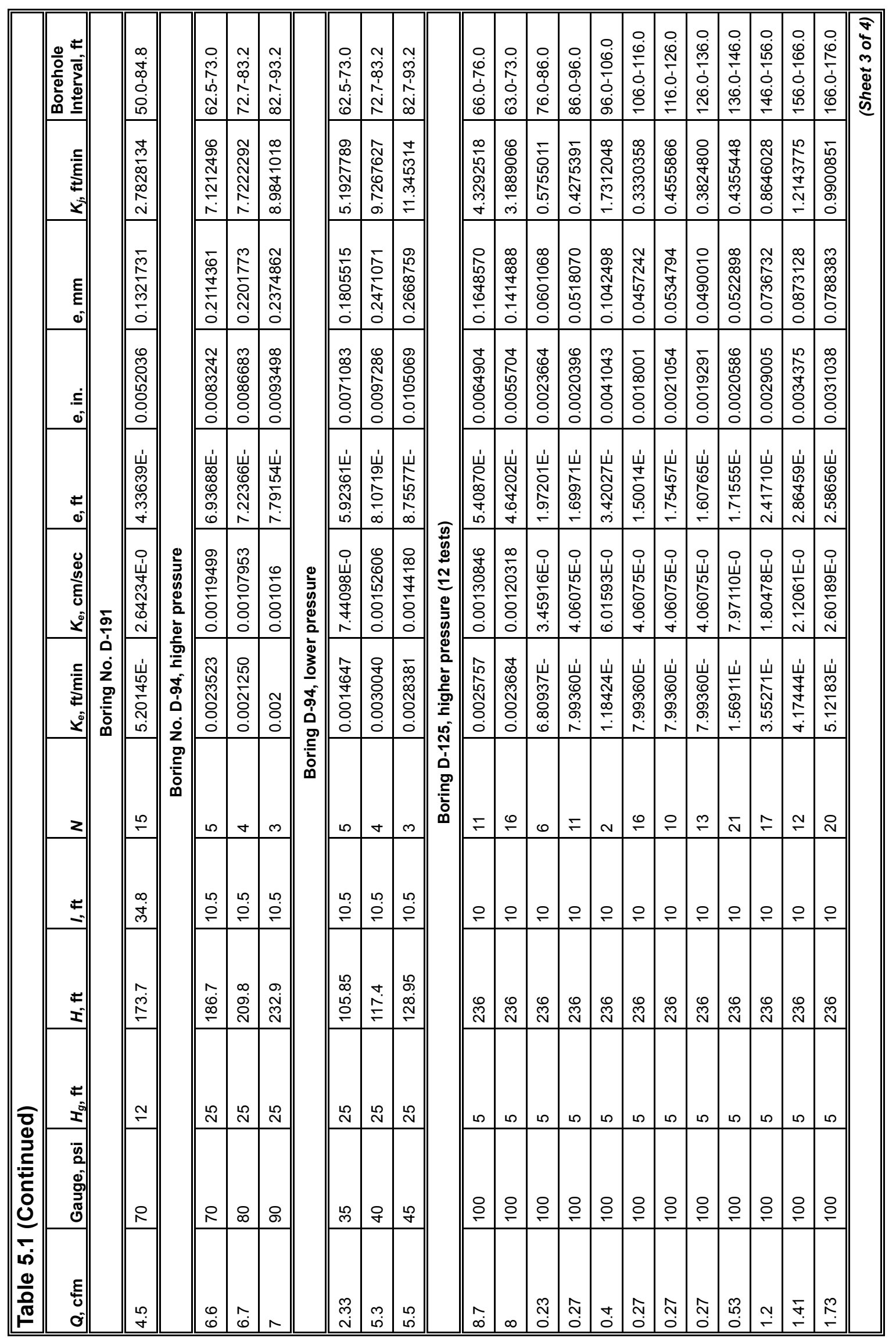




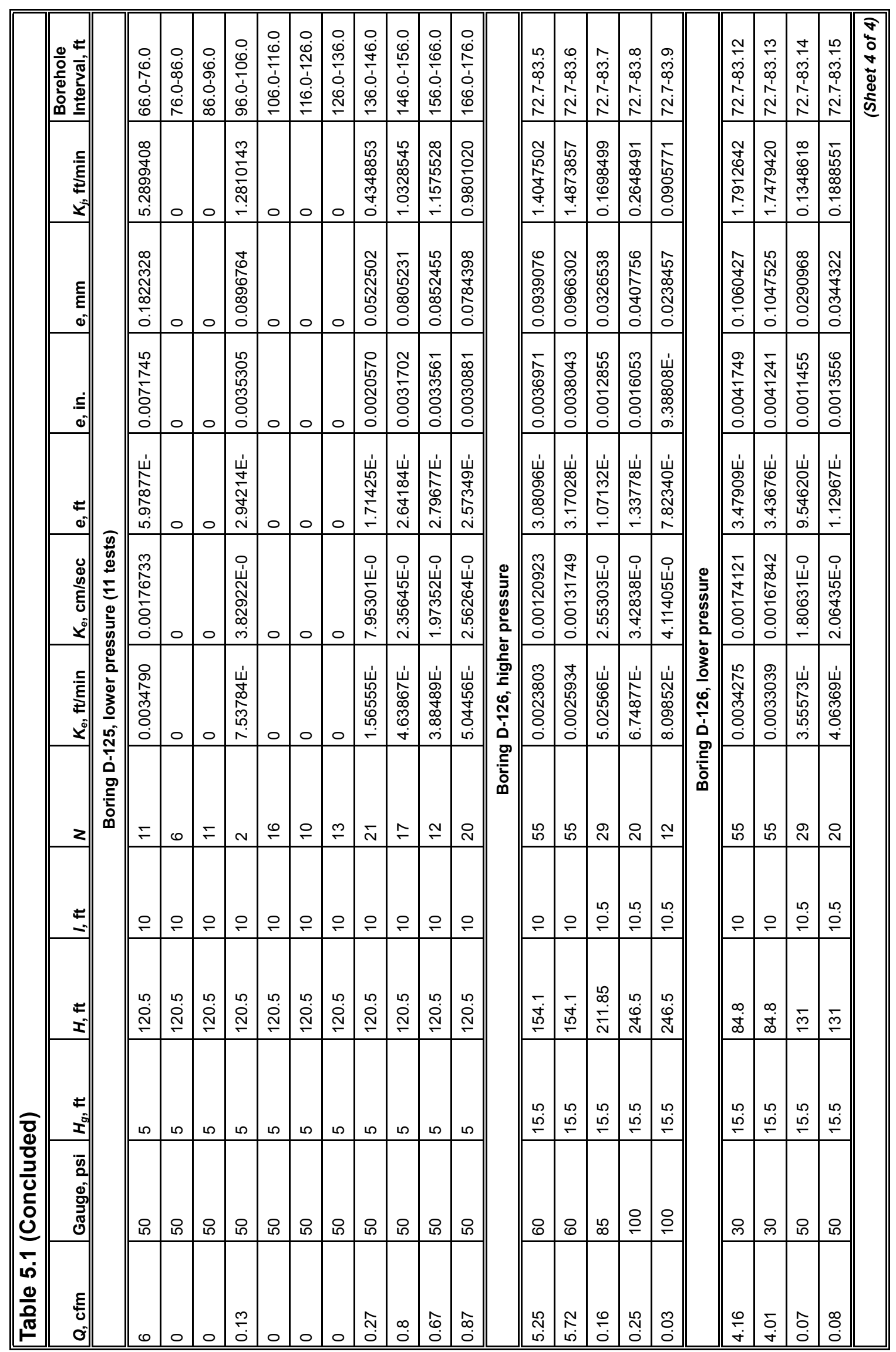


suggesting a value for $R$ of between $l$ and $l / 2$, a value of $10 \mathrm{ft}$ for $R$ was selected, and the resulting value for $\ln \left(R / r_{o}\right)$ of 4.390059 was used in the computation of $K_{e}$.

Zeigler (1976) evaluated the "zone of influence" around a borehole during pressure testing. He calculated the drop in pressure head at distance from the borehole during radial flow and showed that a 50 percent head loss occurs within a radial distance of about 3 to $4 \mathrm{ft}$ from the borehole. Citing theoretical and laboratory studies, he also showed that large changes in the radius of influence, $R$, do not greatly affect the rate of head drop. During a pressure test there is a severe drop in pressure near the borehole. The area over which a pressure test is effective is unknown but may well be within only a few feet of the test section. Consequently, only those joints intersecting the borehole will materially influence the test results (Zeigler 1976, p 50).

\subsubsection{Pressure tests versus pumping tests}

Pressure tests in rock differ from pumping tests in that pressure tests are of short duration and affect a much smaller volume of the rock mass than do pumping tests (Headquarters, U.S. Army Corps of Engineers, 1993, pp 3-10 and 3-11). A pumping test injects water into or withdraws water from a well at a constant or variable rate for a considerable period of time and measures the drawdown of the piezometric surface in observation wells within the aquifer. Pumping tests involve large volumes of the rock mass and tend to average the effects of discontinuities within the rock mass. A pressure test, which pumps water into a well under constant pressure and measures the resulting flow rate, is of short duration and affects only a small volume of the rock mass because frictional losses in the immediate vicinity of the test section are commonly large. Pressure tests therefore provide more accurate information on the effects of discontinuities near the borehole.

\subsubsection{Pressure testing at Libby Dam}

Figure 5.4 shows the locations of foundation boreholes in the vicinity of monolith 23, Libby Dam. Summary logs for boreholes are presented as Figures 5.5 through 5.12. The author reviewed archived files at the Seattle District office to obtain original or facsimile copies of the full-sized borehole logs, pressure test data, and other field documents. Pressure-test data provided in the "Remarks" column of each summary log were augmented by the field logs. In many cases, additional pressure-test information, including tests at lower or higher pressures, was available in the field logs.

Pressure tests were generally 10 minutes in duration. Some boreholes were tested at two pressures that differed by a factor of approximately two. Usually, but not always, tests at the higher pressures were conducted first. Water inflow from the boreholes into the rock mass during the pressure tests (in the monolith 23 area) ranged from 0 to $8.7 \mathrm{cfm}$. Gauge pressures ranged from 30 to 100 psi. Pressures were not always the same for different test intervals within a borehole. 


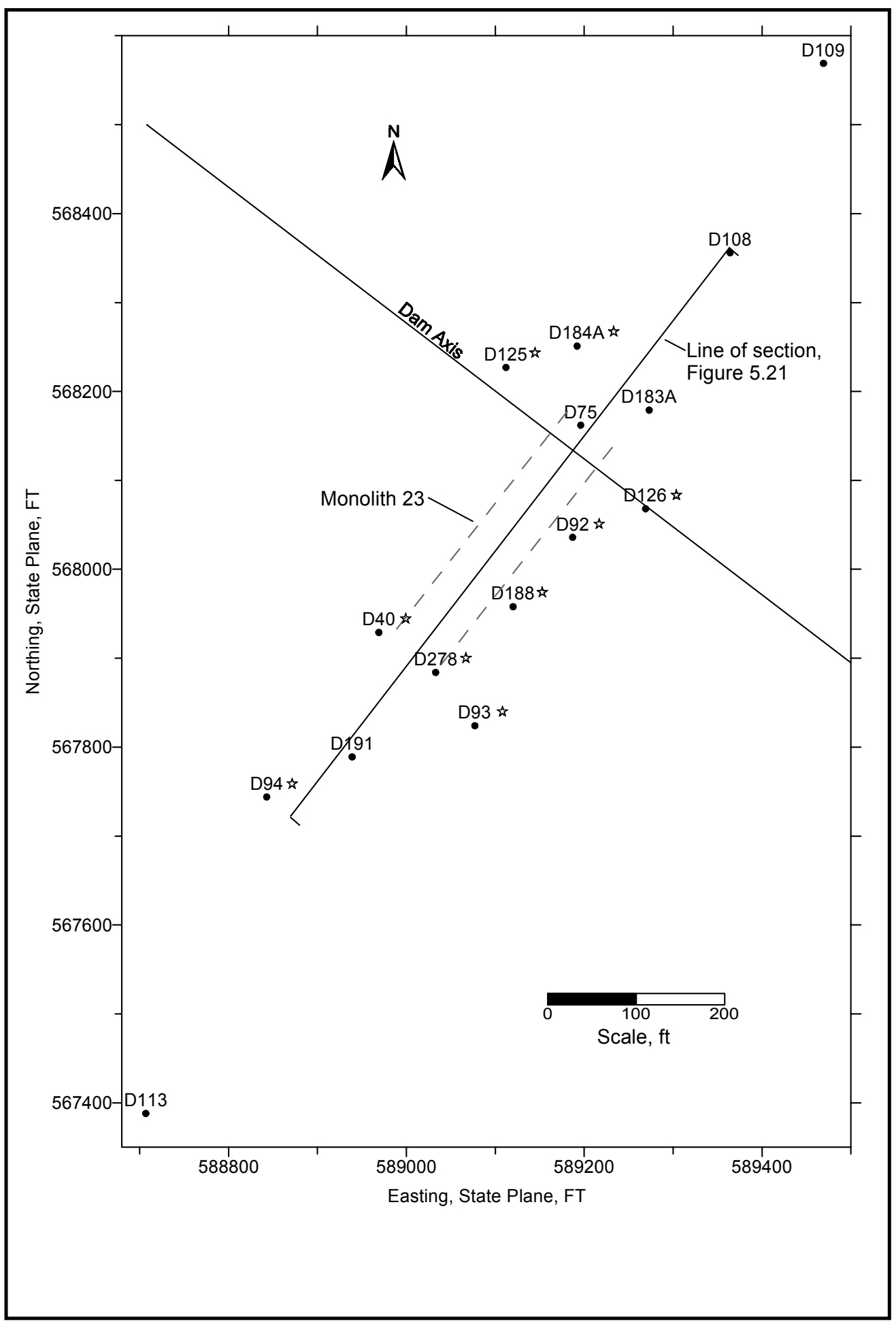

Figure 5.4. Locations of boreholes, monolith 23 area, Libby Dam. Star denotes borehole was pressure-tested 

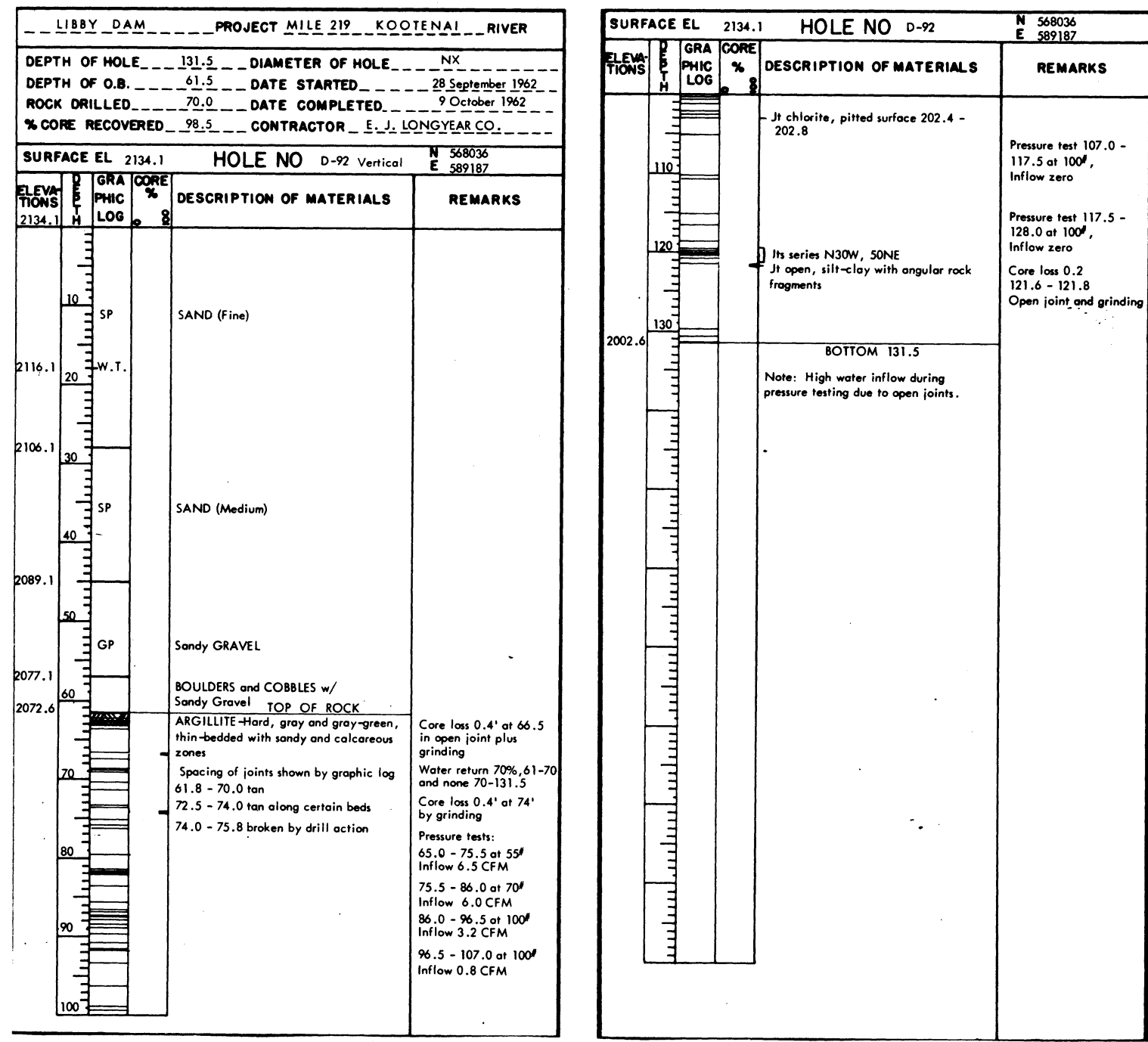

Figure 5.5. Summary log of boring D-92, monolith 23 area, Libby Dam

\subsubsection{Results for Libby Dam model}

Data required for Equation 5.1 and for Equations 2.13 and 2.5 and calculations of joint and rock mass hydraulic properties for eight boreholes were compiled in an Excel ${ }^{\mathrm{TM}}$ spreadsheet, a printout of which is presented as Table 5.1. $K_{e}$ is tabulated in $\mathrm{ft} / \mathrm{min}$ and $\mathrm{cm} / \mathrm{sec}, e$ in $\mathrm{ft}$, in., and $\mathrm{mm}$, and $K_{j}$ in $\mathrm{ft} / \mathrm{min}$. Graphs of $K_{e}, N$ (number of joints intersecting the test section), $e$, and $K_{j}$ versus depth were then plotted. The graphs are presented as Figures 5.13 through 5.20. Where pressure tests at two pressure ranges were conducted for a borehole, the graphs show $K_{e}$ versus depth for both pressures. Computations of $e$ are presented in the next section. 

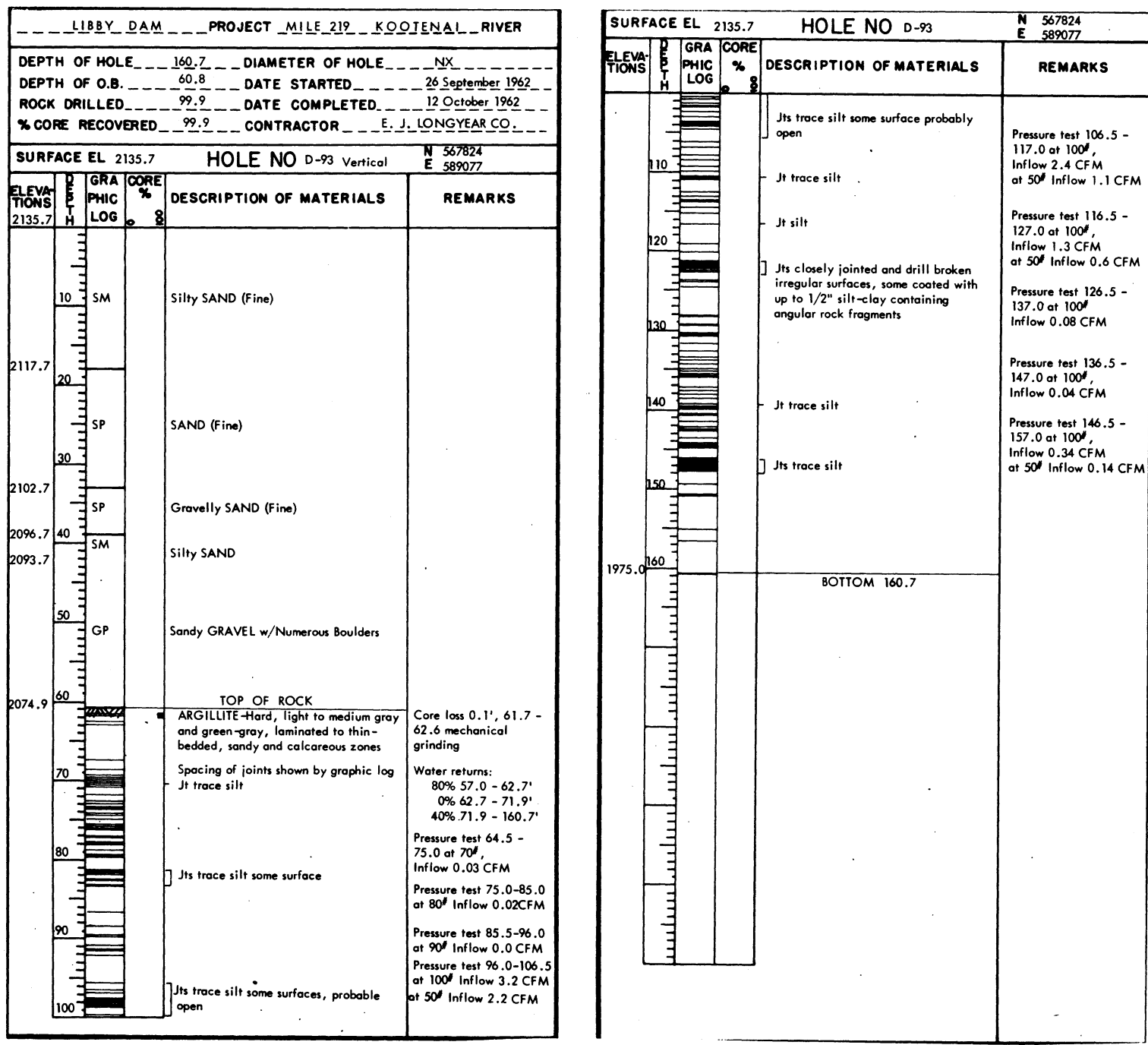

Figure 5.6. Summary log of boring D-93, monolith 23 area, Libby Dam

\subsection{Computation of Parallel Plate Aperture and Joint Hydraulic Conductivity}

Studies of the effects of uplift on sliding stability at Bluestone Dam, West Virginia (Fuller, Mossbarger, Scott, and May 2000), suggested that examination of mechanical apertures was not sufficient to predict flow into and through a fracture. Investigators relied instead on packer (pressure) tests and laboratory tests of conducting aperture for estimates of conducting aperture, $e$. For the Libby Dam exercise, hydraulic conductivities of equivalent individual joints were estimated using the procedure suggested in RTH 381-80 (Geotechnical Laboratory 1993) and in Zeigler (1976) whereby pressure test data are first used to compute a parallel plate aperture, $e$. The test section is assumed to be intersected by a group of parallel and identical joints. Each joint is assumed to be an equivalent parallel 


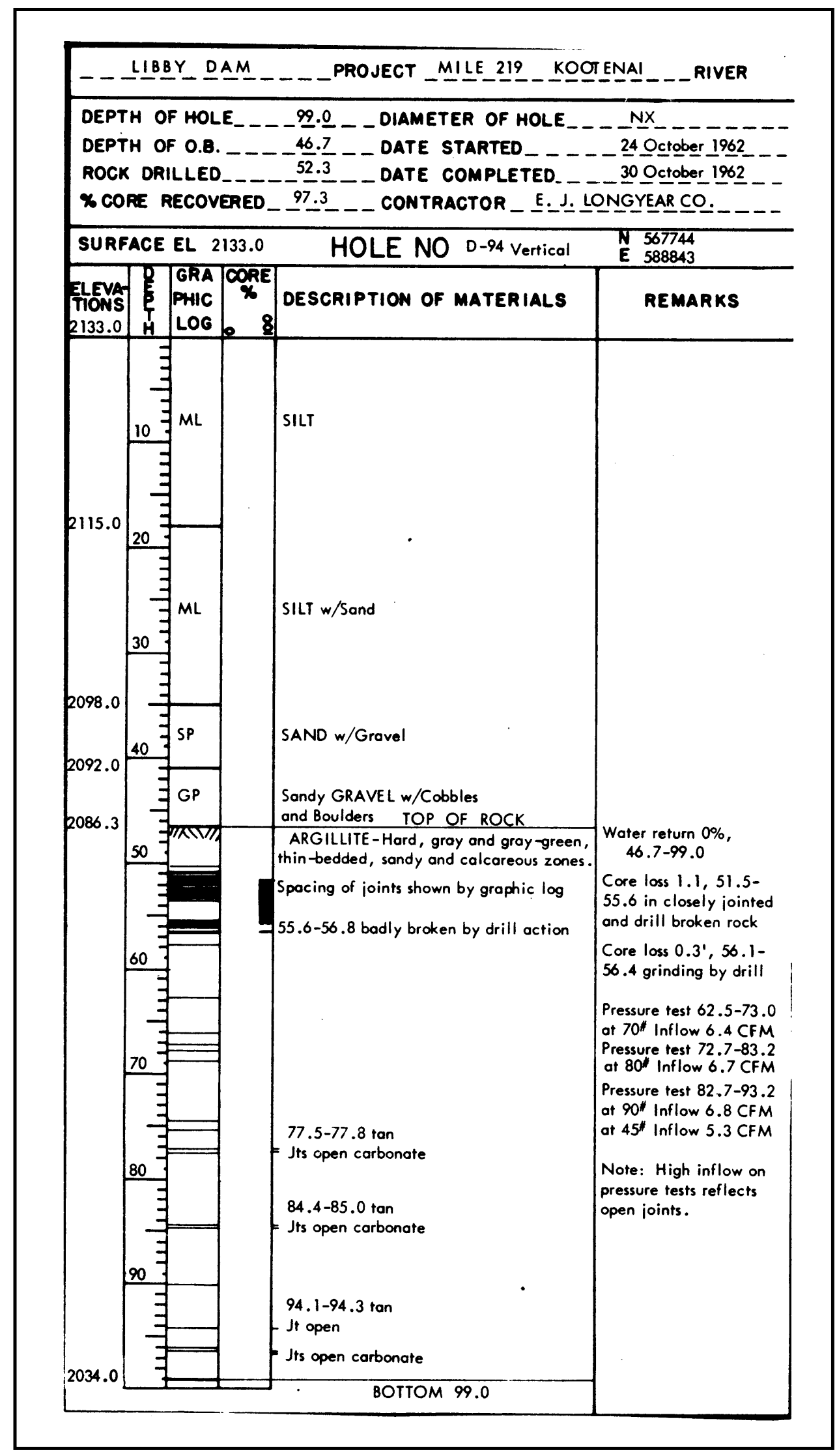

Figure 5.7. Summary log of boring D-94, monolith 23 area, Libby Dam 


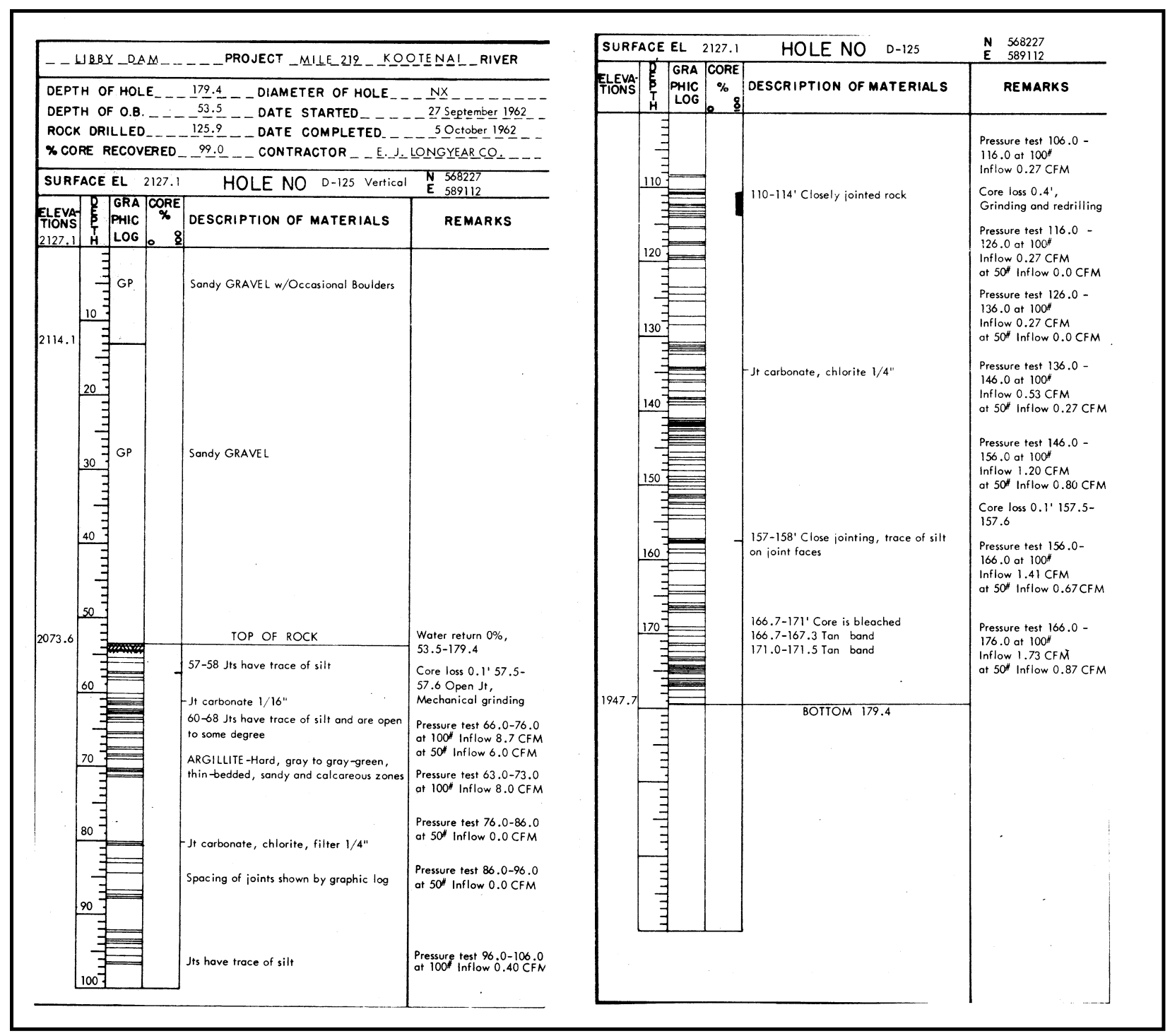

Figure 5.8. Summary log of boring D-125, monolith 23 area, Libby Dam

(smooth-walled) plate. Flow to the borehole is assumed to be radial and to occur only within the joints. The rock mass between the joints is assumed impermeable. Joint hydraulic conductivity, $K_{j}$, is then estimated using $e$ and physical properties of the fluid. Equations 2.13 and 2.5 (rearranged) are applicable (see Chapter 2 for discussion):

$$
K_{j}=\left(e^{2} \gamma_{w}\right) / 12 \mu_{w}
$$

The number of joints, $N$, for a test interval was determined by counting the joints in the graphic borehole log. Applying Equations 2.13 and 2.5, $e$ and $K_{j}$ were estimated for each pressure-tested zone in the ten boreholes analyzed for monolith 23. Using Equation 2.13, an estimate of conducting aperture $e$ was computed. 


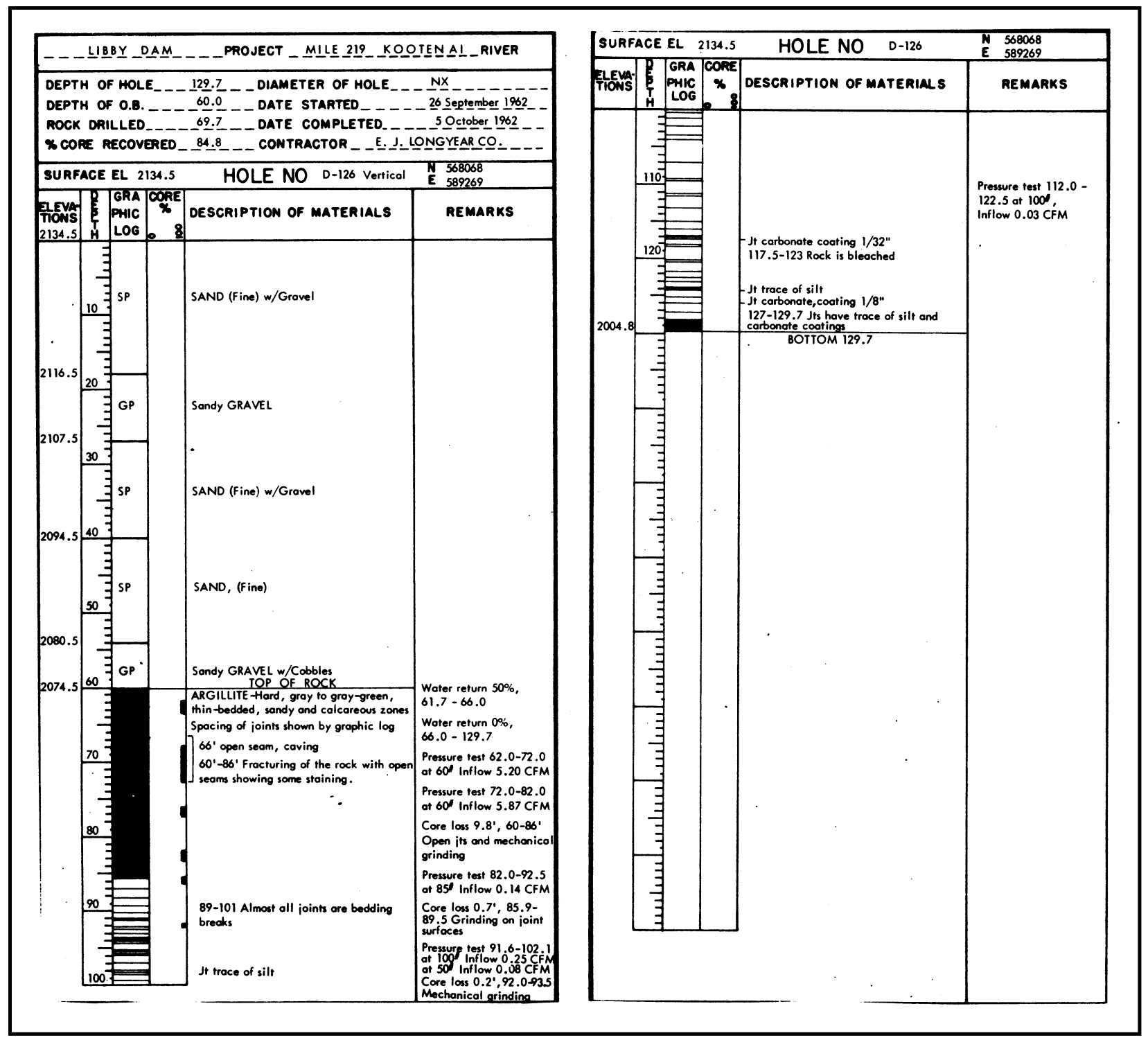

Figure 5.9. Summary log of boring D-126, monolith 23 area, Libby Dam

The value of $\mu_{w}$ in Equation 2.13 is $3.479 E^{-5} \mathrm{lbf} \mathrm{min} / \mathrm{ft}^{2} \times 0.0101=3.5138$ $\mathrm{E}^{-7} \mathrm{lbf} \mathrm{min} / \mathrm{ft}^{2} .{ }^{1}$ The value of $12 \mu_{w} / \gamma_{w}$ is $12\left(3.5138 E^{-7}\right) / 62.4 \mathrm{lb} / \mathrm{ft}^{3}=6.7573$ $E^{-8} \min \mathrm{ft}$.

With Equation 2.5, the equivalent individual joint hydraulic conductivity $K_{j}$ was calculated by squaring the value of $e$ derived by Equation 2.13 and multiplying it by the reciprocal of $12 \mu_{w} / \gamma_{w}$. The results of applying Equations 2.13 and 2.5 are presented in Table 5.1, columns I, J, and $\mathrm{K}(e$ in ft, in., and $\mathrm{mm}$, respectively) and $L\left(K_{j}\right.$ in $\left.\mathrm{ft} / \mathrm{min}\right)$. See Figures 5.13 through 5.20 for plots of $e$ versus depth for eight of the ten boreholes.

1 Dynamic viscosity of water at $20^{\circ} \mathrm{C}=0.0101$ poise. 1 poise $=1 \mathrm{dyne} \mathrm{sec} / \mathrm{cm}^{2} .1$ dyne $=2.247$ $E^{-6} \mathrm{lbf}$. So 1 poise $=2.247 E^{-6} \mathrm{lbf}, \mathrm{X}(1 / 60) \mathrm{min} /\left[1 /\left(30.48^{2}\right)\right] \mathrm{ft}^{2}=3.479 E^{-5} \mathrm{lbf} \mathrm{min} / \mathrm{ft}^{2}$. Dynamic viscosity of water $=3.5138 \mathrm{E}^{-7} \mathrm{lbf} \mathrm{min} / \mathrm{ft}^{2}$. 


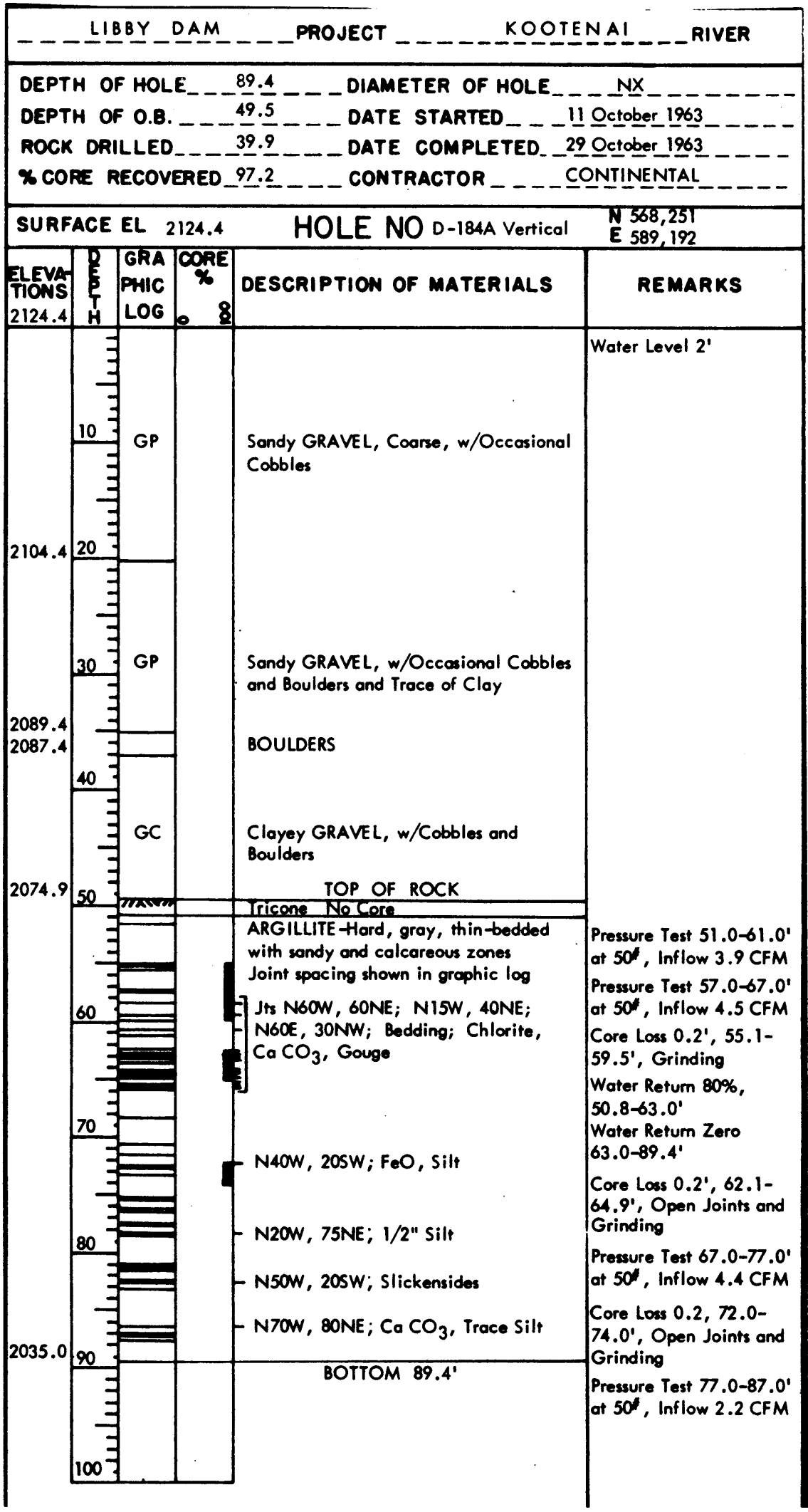

Figure 5.10. Summary log of boring D-184A, monolith 23 area, Libby Dam 


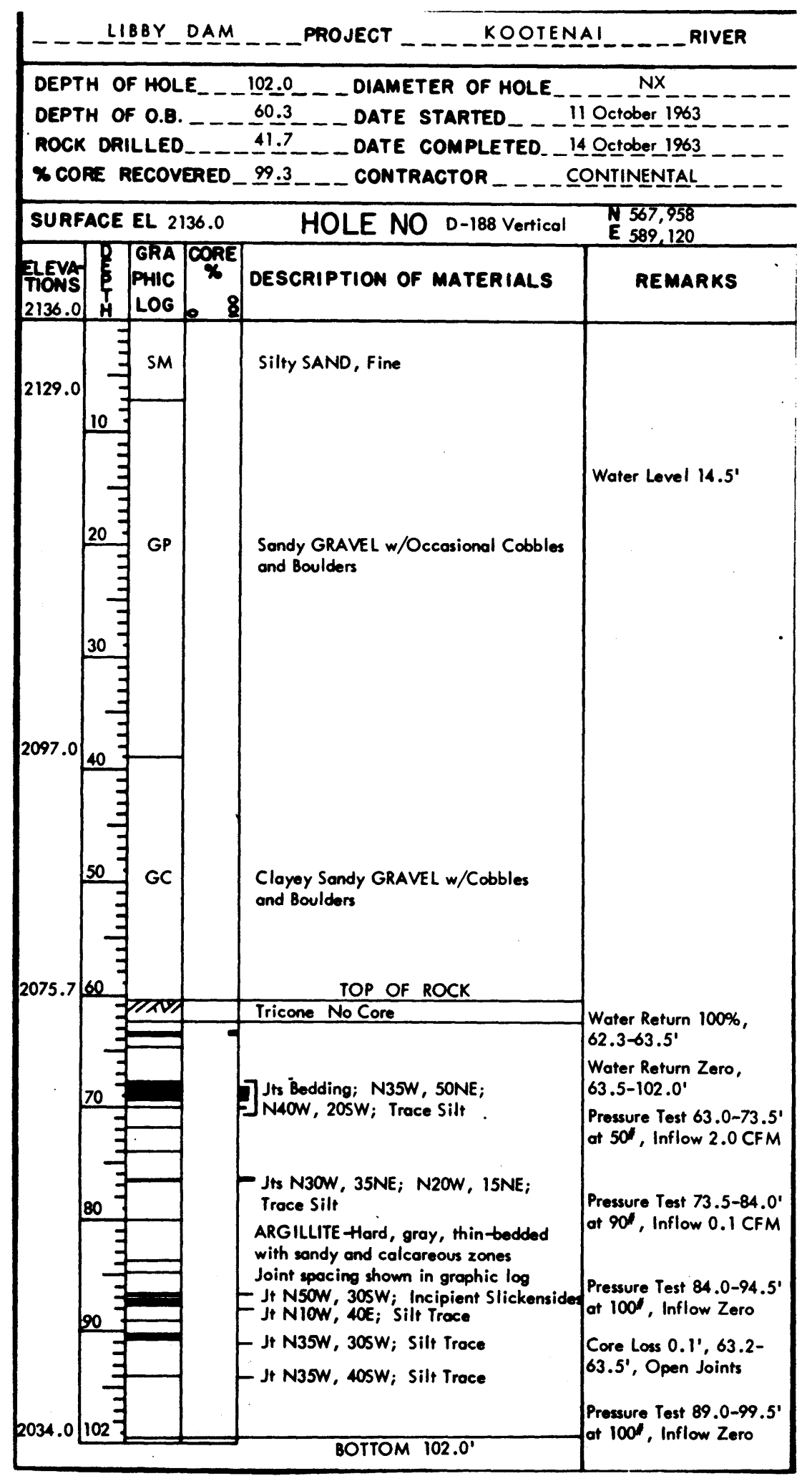

Figure 5.11. Summary log of boring D-188, monolith 23 area, Libby Dam 


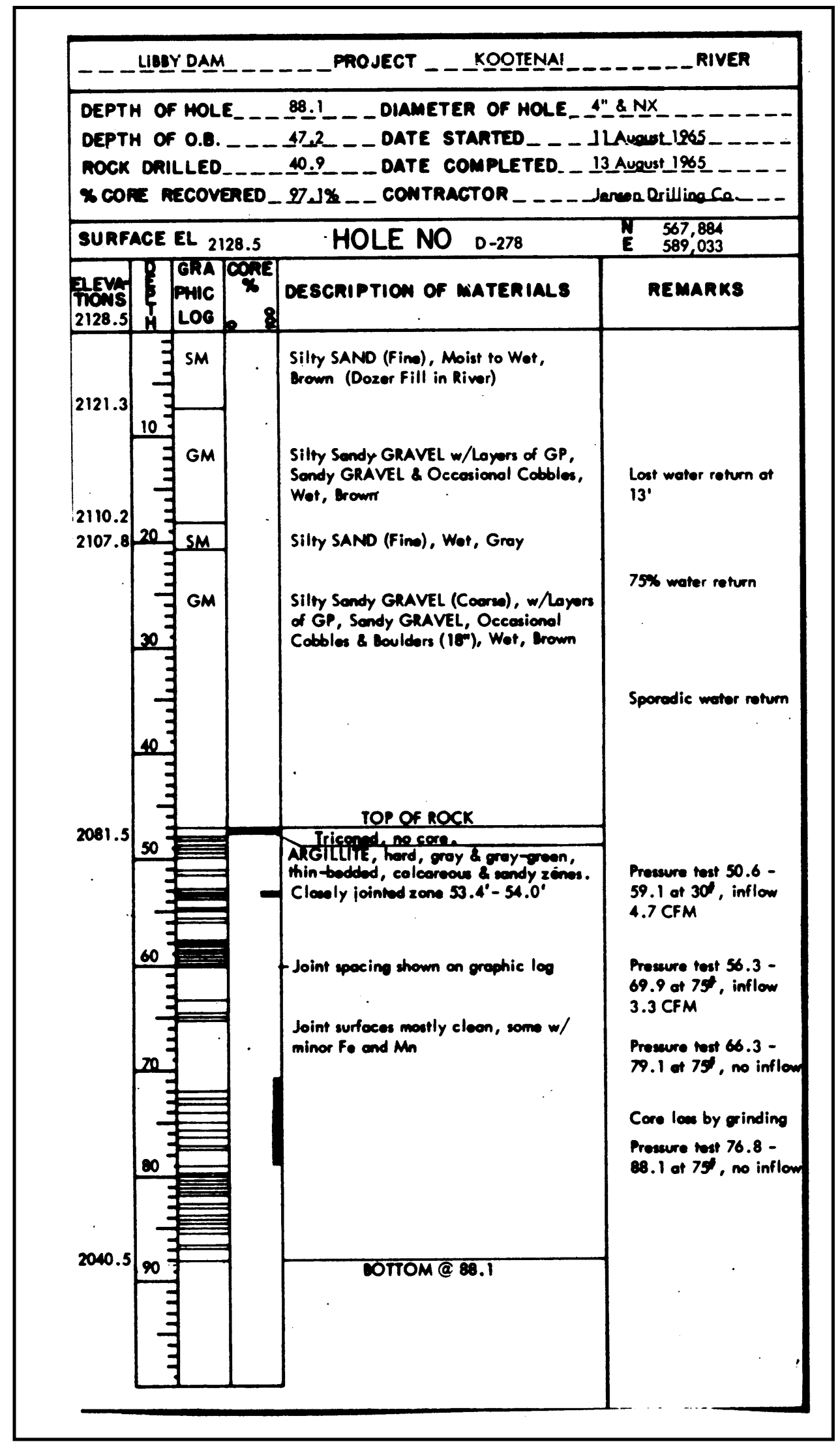

Figure 5.12. Summary log of boring D-278, monolith 23 area, Libby Dam 

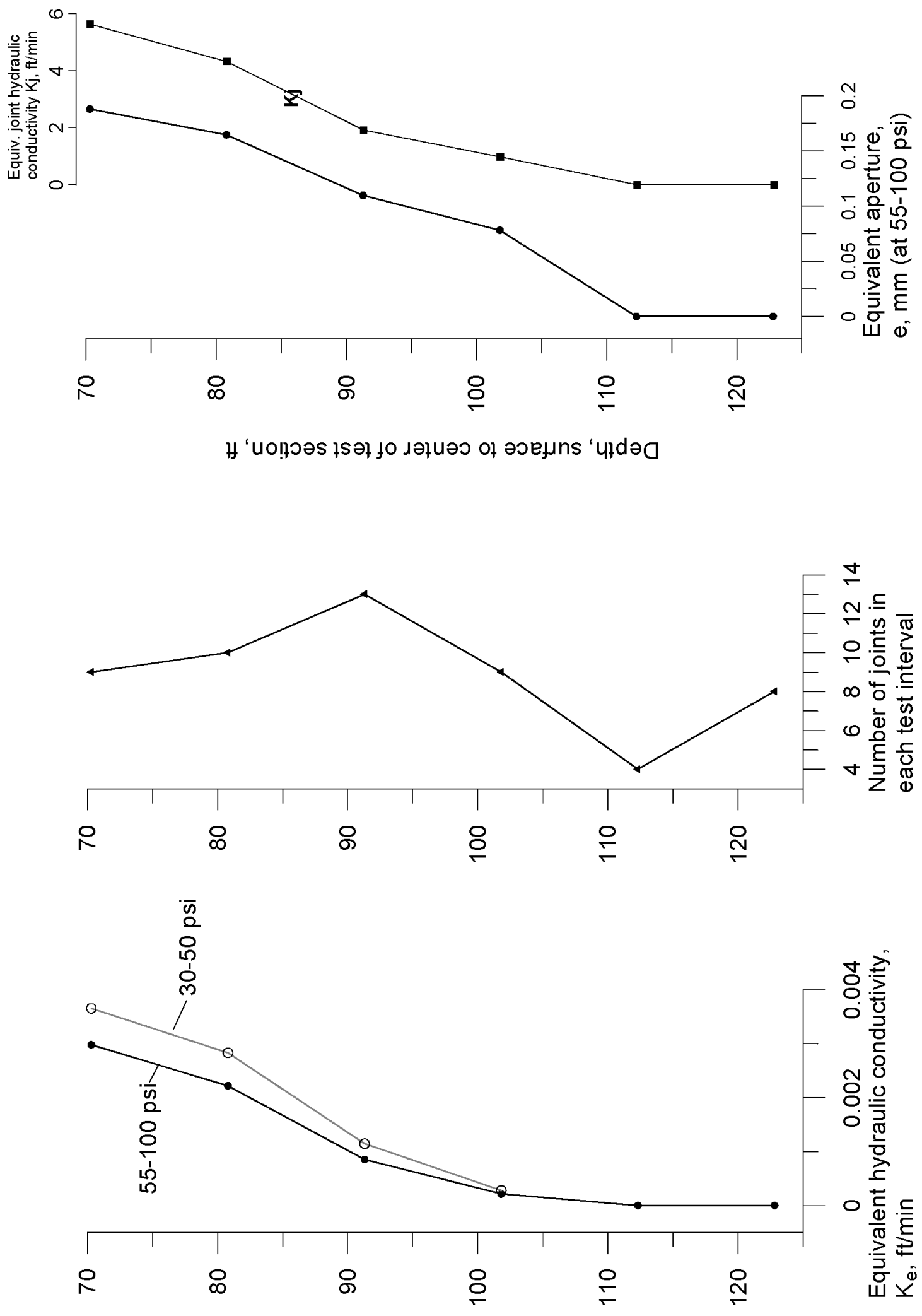

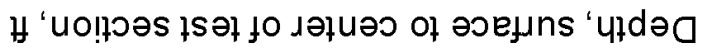




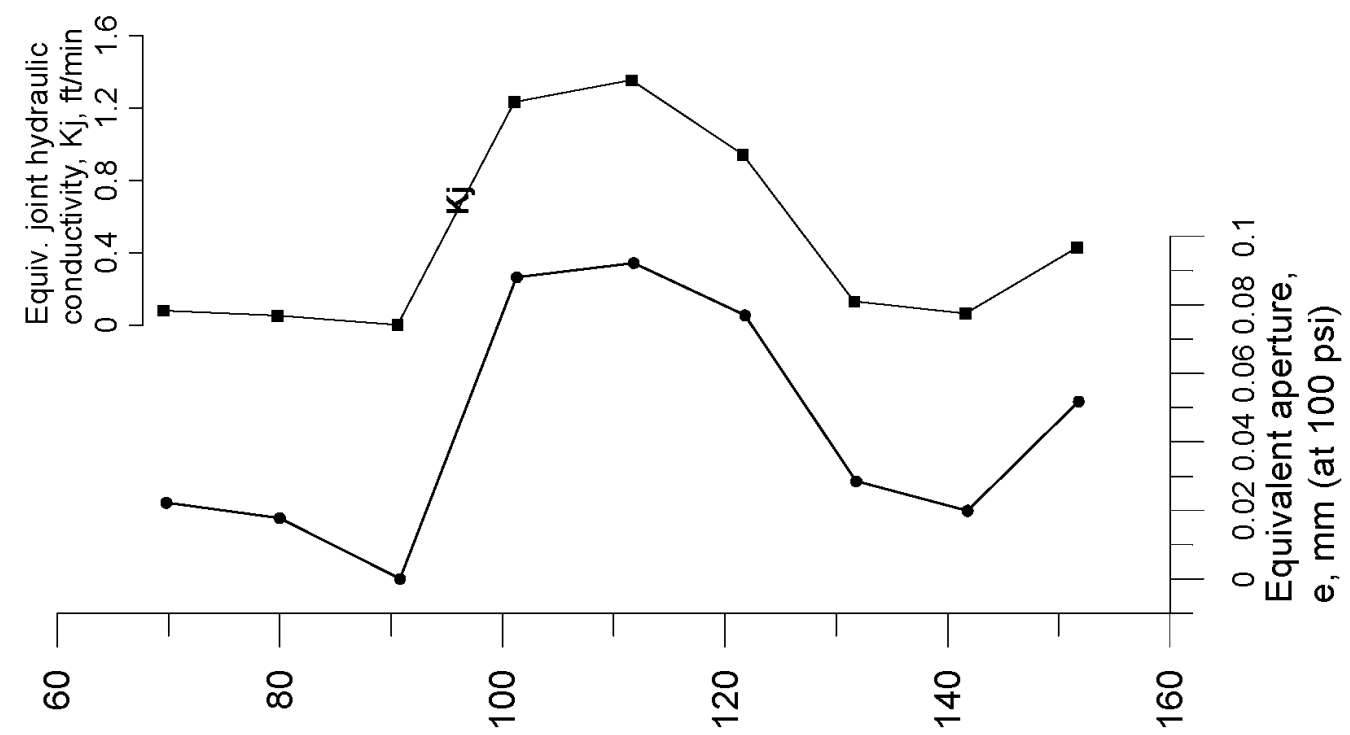

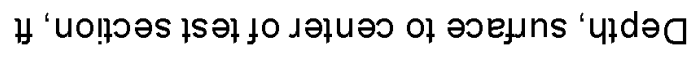
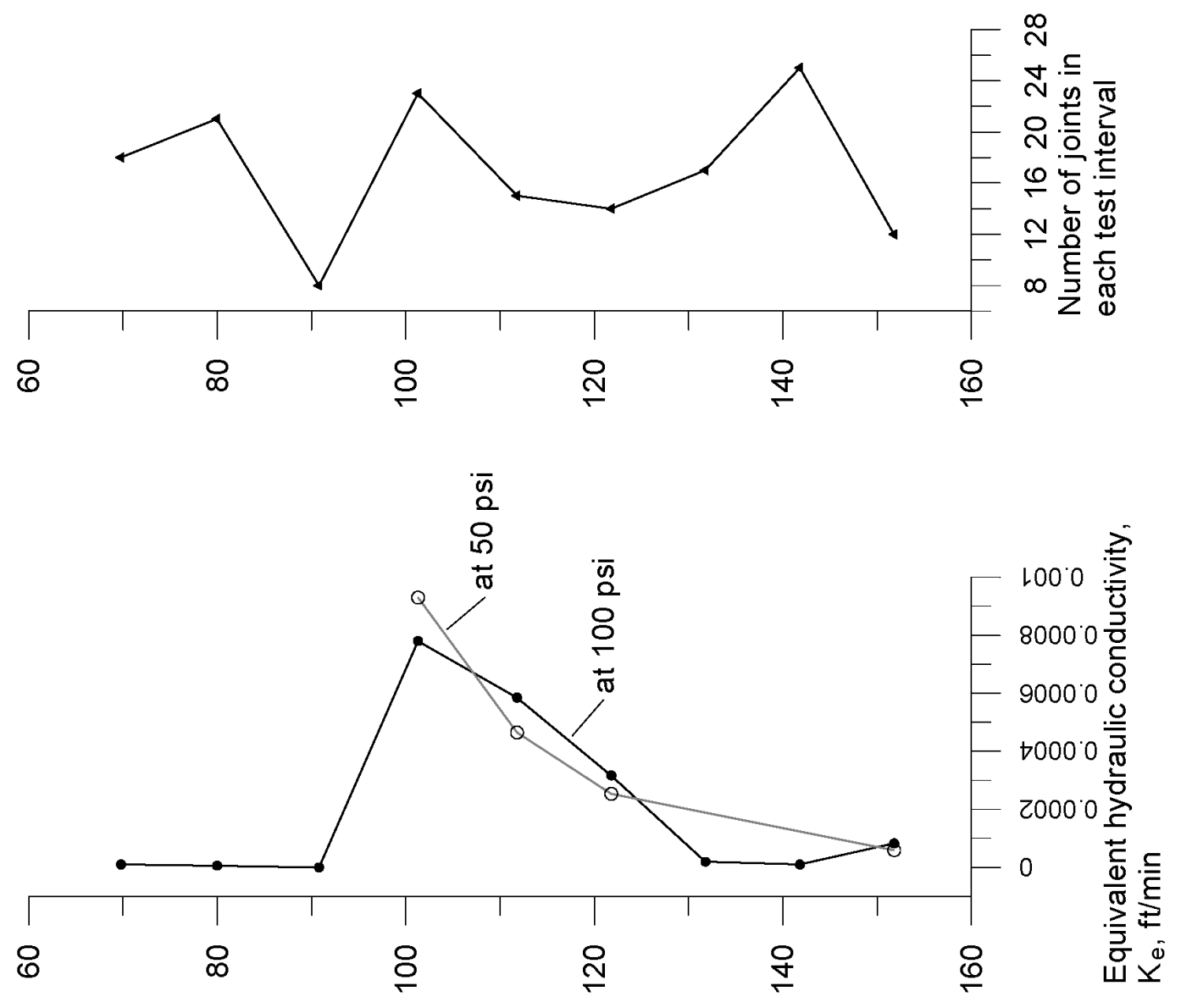

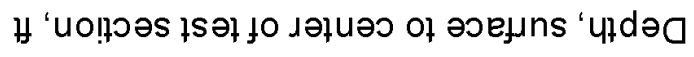




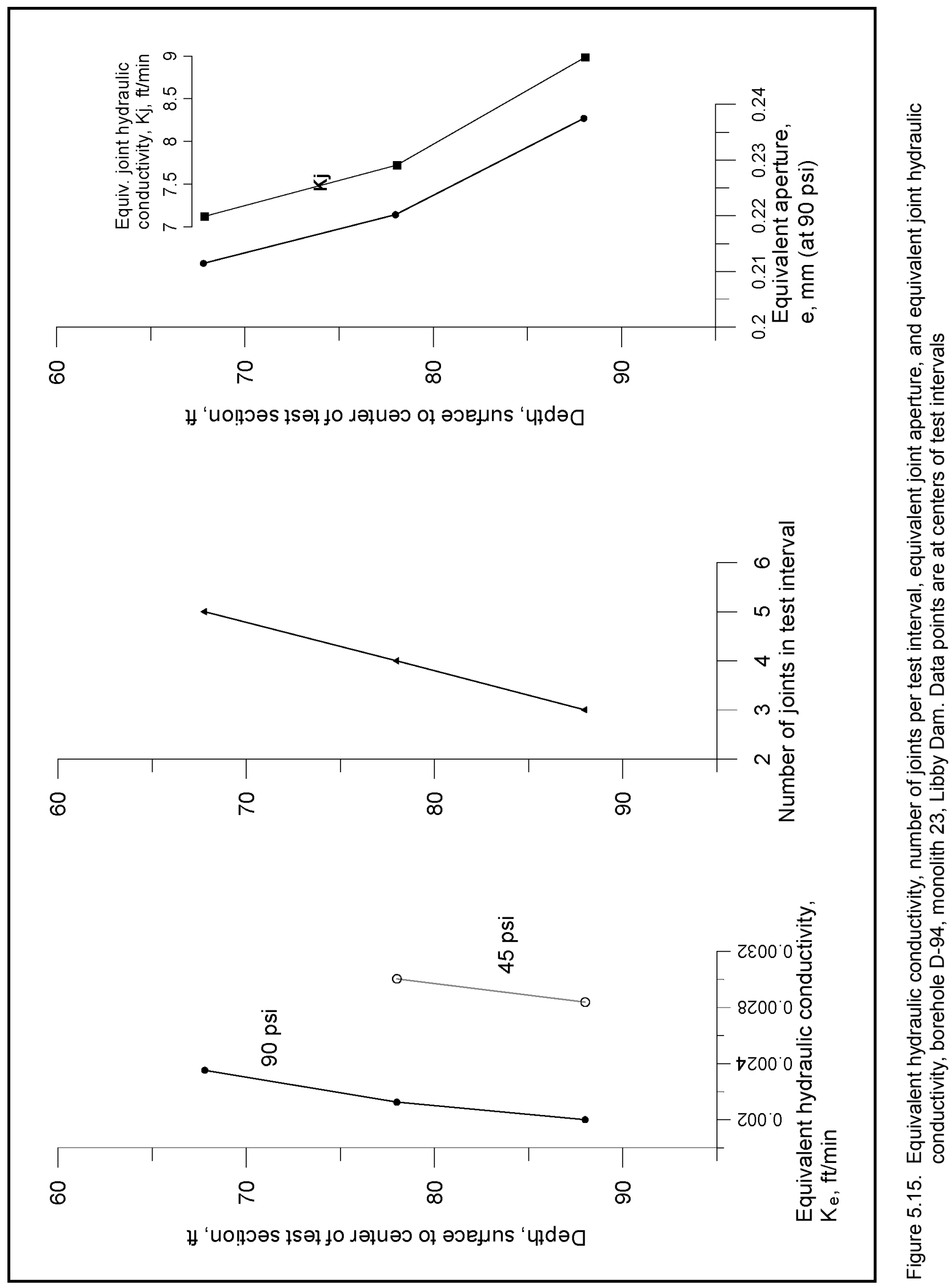




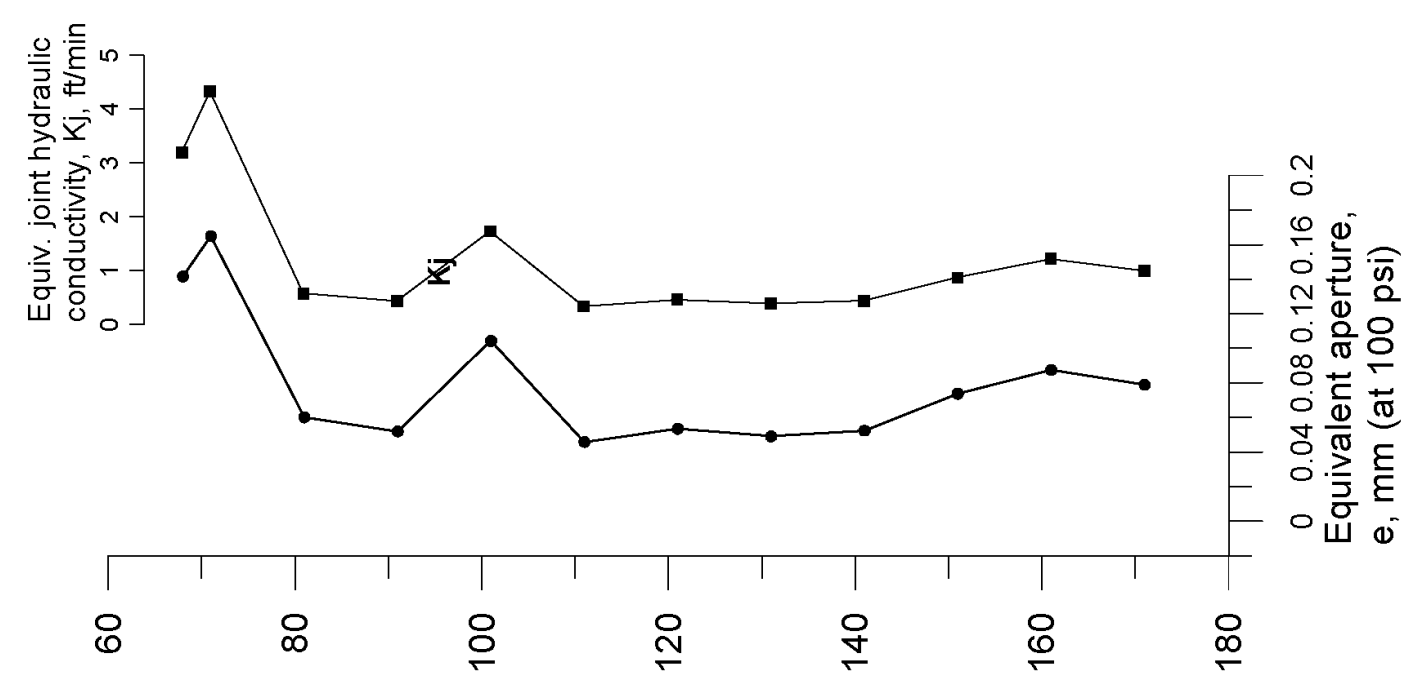

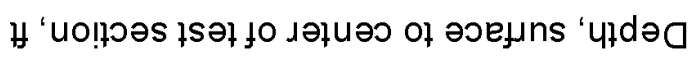
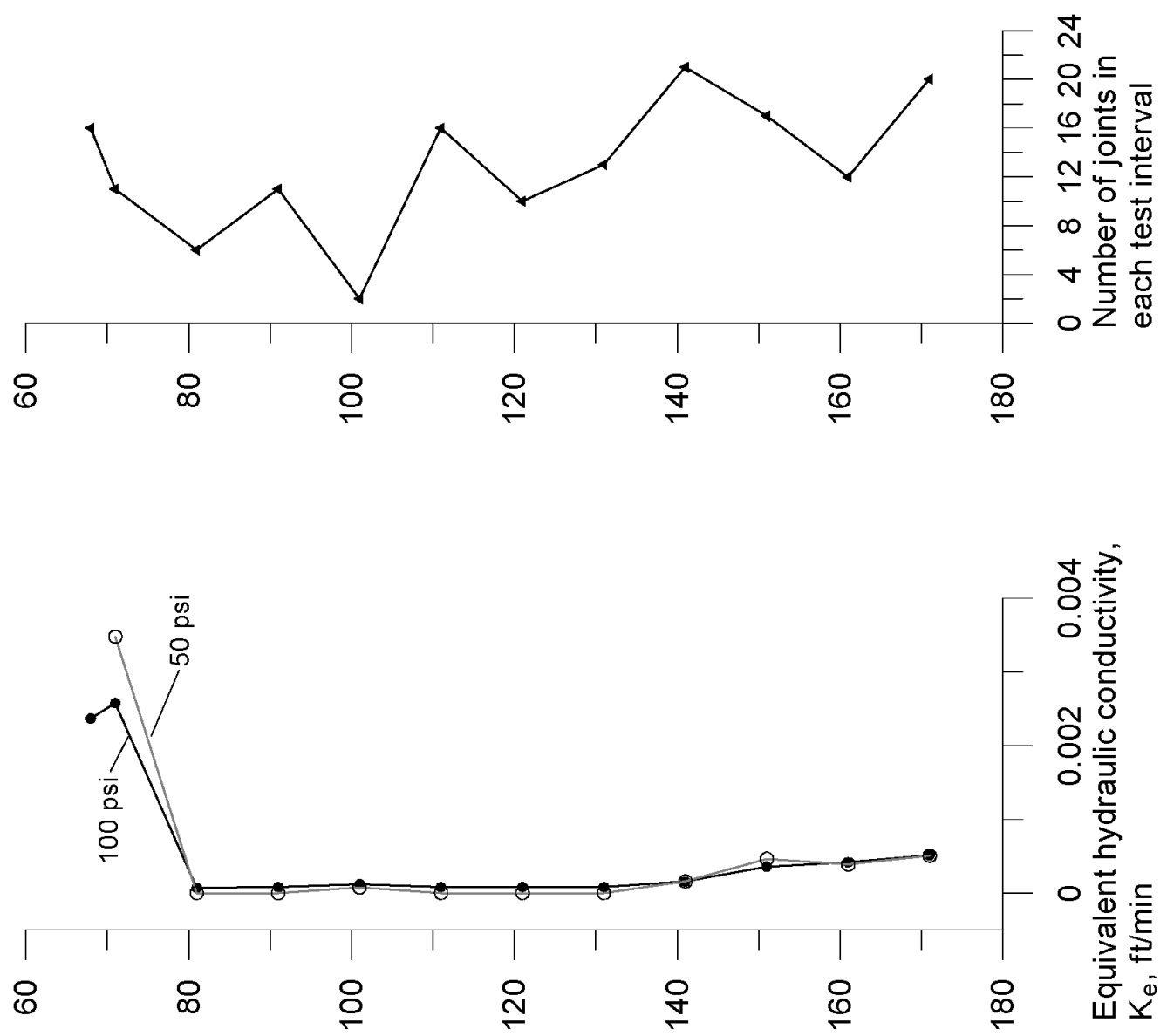

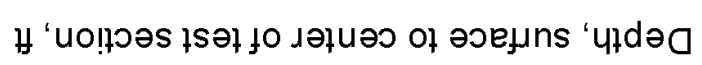




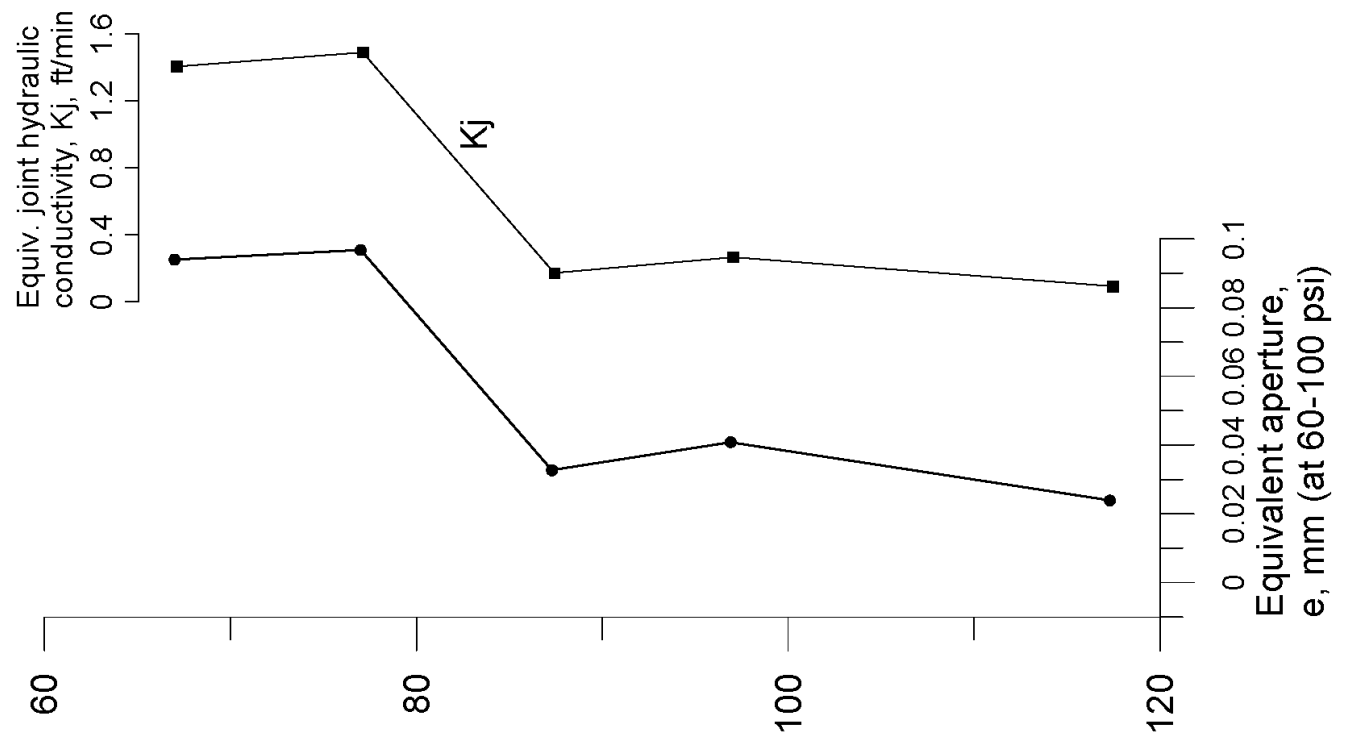

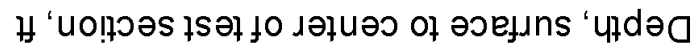
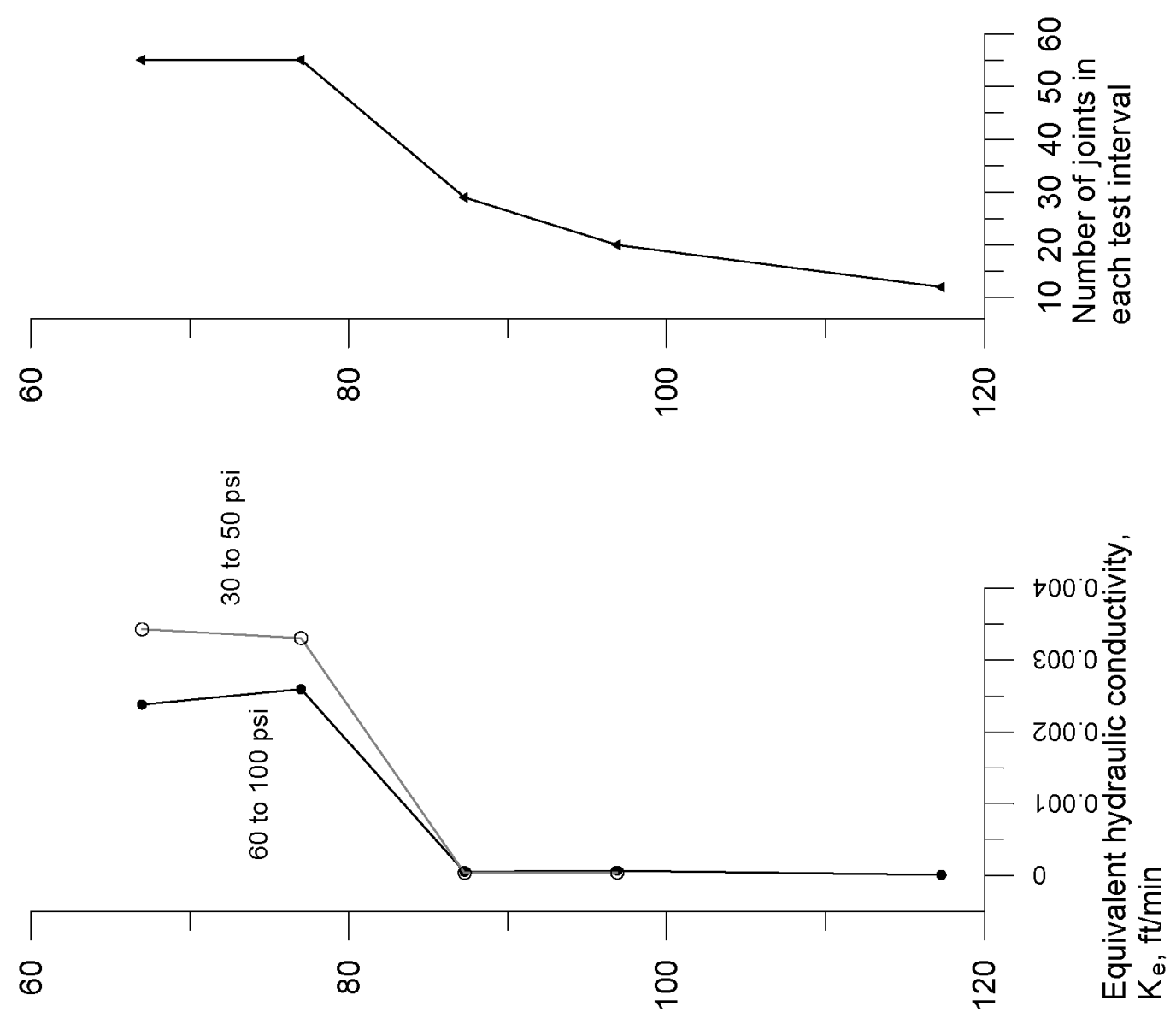

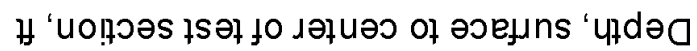




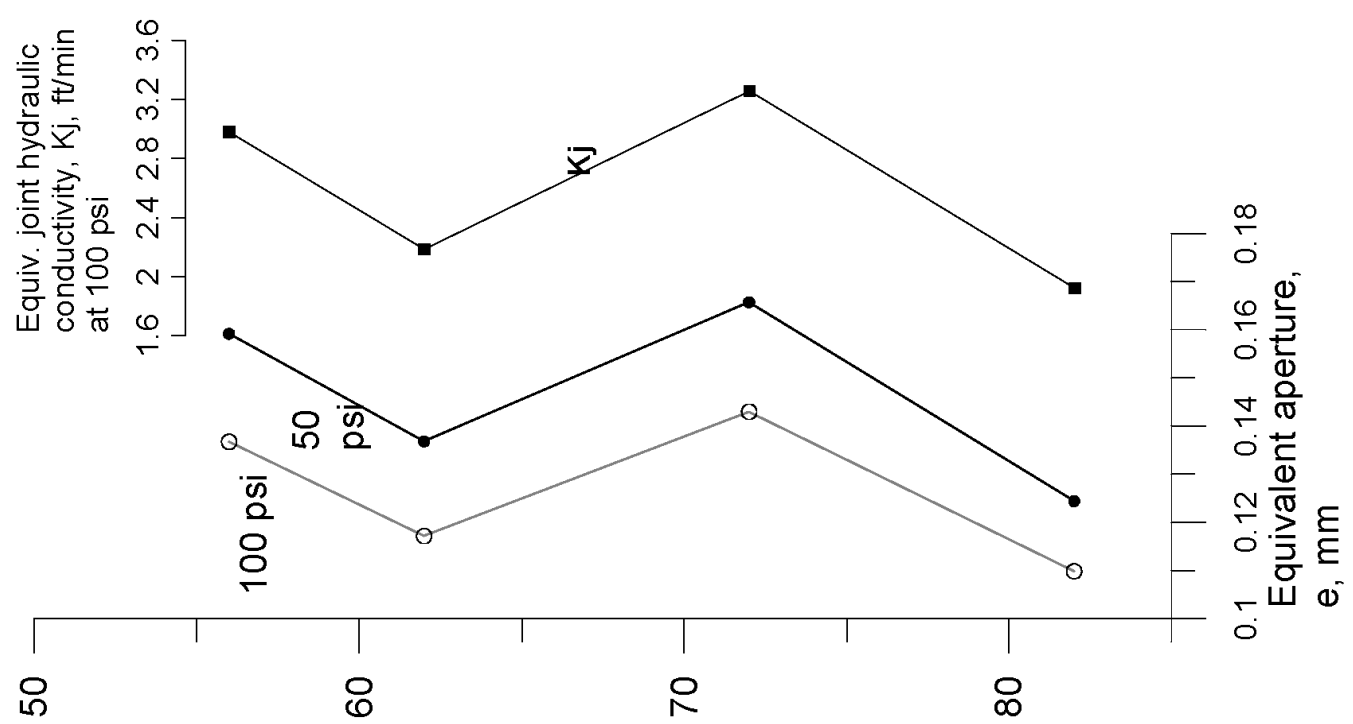

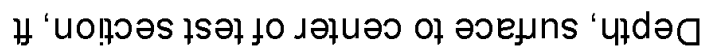
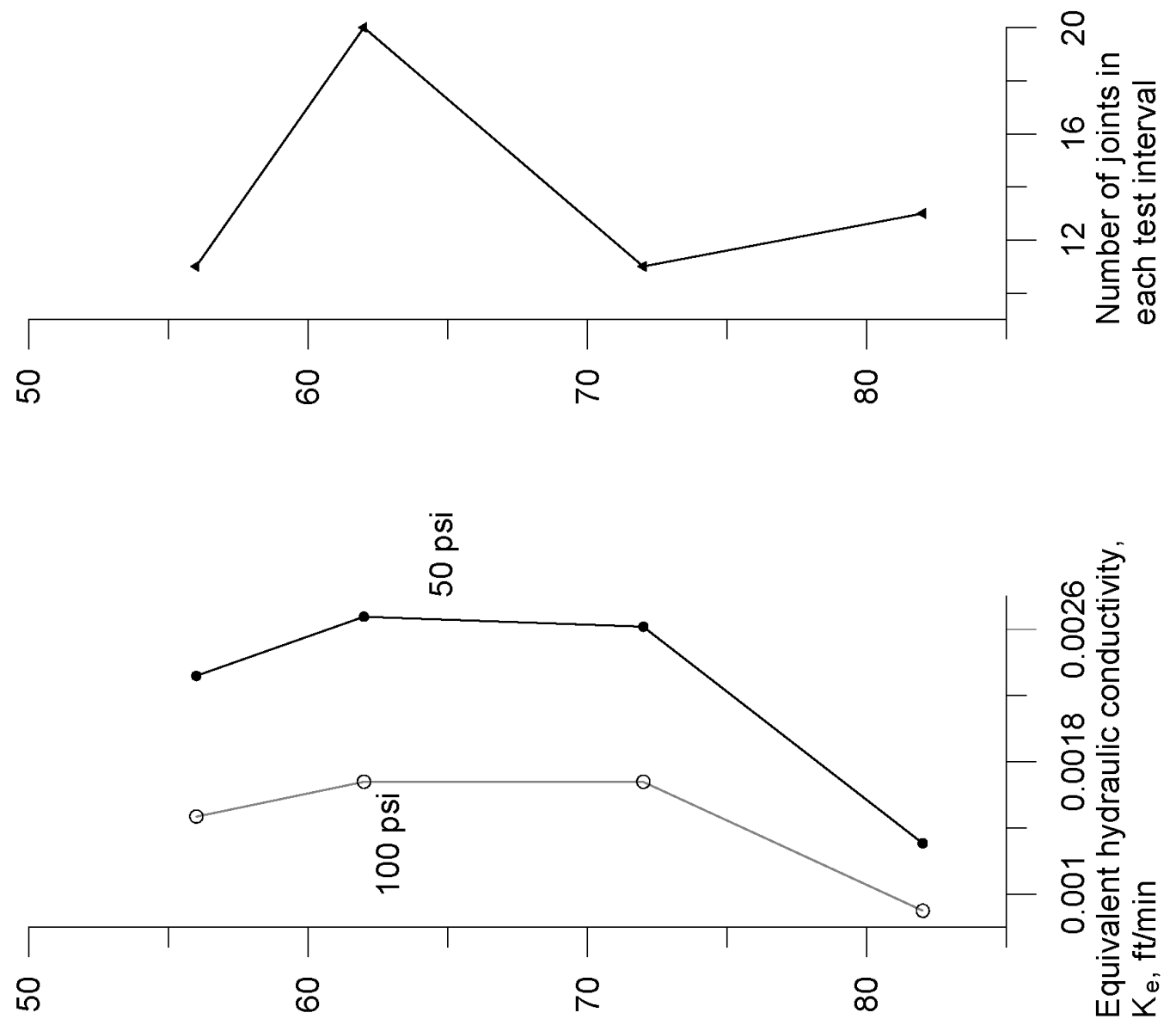

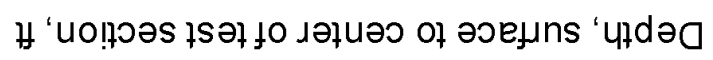




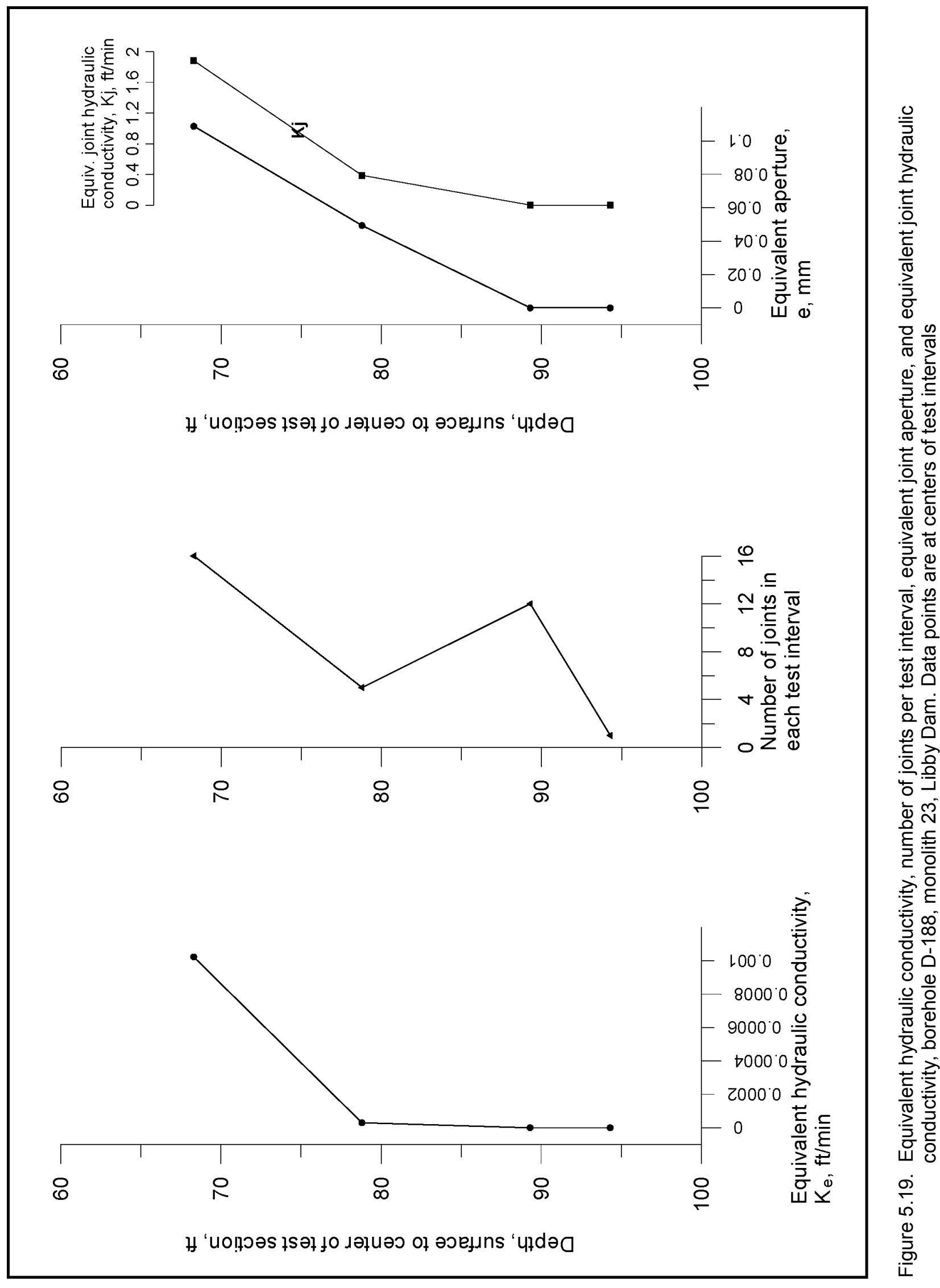




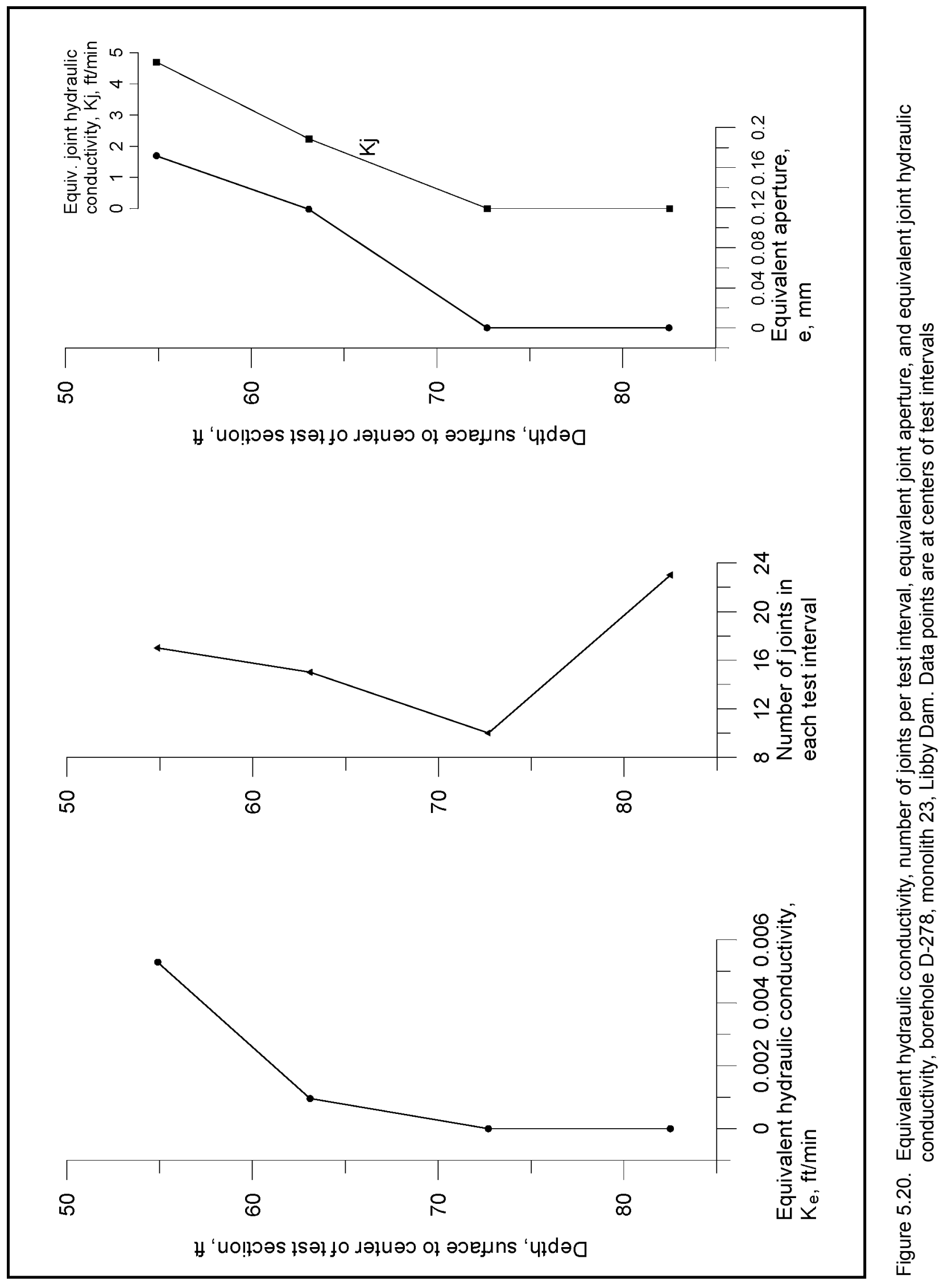




\subsection{Discussion of Results}

\subsubsection{Equivalent hydraulic conductivity, $K_{e}$}

Cursory examination of the plots of $K_{e}$ versus depth (Figures 5.13-5.20), suggests a general decrease in equivalent hydraulic conductivity of the rock mass with increasing depth. Next, depths were converted to elevations for comparison of $K_{e}$ with increasing depth (decreasing elevation) in all boreholes. Figure 5.21, a composite plot of all values of $K_{e}$ versus elevation (all boreholes), confirms that the higher equivalent hydraulic conductivities occur near the top of the rock mass. The top of rock in the vicinity of the boreholes ranged from about 2,072 to 2,086 ft MSL. Data for Figure 5.21 are for tests in each of nine boreholes in which pressure tests were conducted (data are for only the highest pressure range in boreholes in which two tests were conducted). In a rock mass in which groundwater flow is through discrete discontinuities, higher hydraulic conductivities are expected in the upper portion of the rock mass where weathering and stress relief of joints have created greater apertures. Equivalent hydraulic conductivities decrease rapidly below about elevation 2,045 ft MSL. Some tight joints (near-zero $K_{e}$ ) occur throughout the rock mass. The cluster of four data points showing a slight increase in $K_{e}$ with increasing depth from elevations 1,986 to $1,956 \mathrm{ft}$ are for a single borehole (borehole D-125). Plots of conducting aperture, $e$, versus elevation and versus depth are presented later in this section.

The central plot of Figures 5.13 through 5.20 shows the number of joints (joint frequency) logged in each borehole at depths representing the centers of the pressure test intervals. The distribution of joints with depth appears to be random. That is, there is no apparent correlation of joint frequency with depth below top of rock. In most boreholes, there is little correlation between joint frequency and equivalent hydraulic conductivity $K_{e}$. The rightmost plot of Figures 5.13 through 5.20 shows the distribution of equivalent joint apertures computed for each pressure test interval. There is a reasonably good correlation between $e$ and $K_{e}$ in the plots, but little or no correlation between $e$ and the number of joints. For example, Figure 5.13, borehole D-92, shows a wide variation in joint counts between $80 \mathrm{ft}$ and the bottom of the borehole, but a relatively constant decrease in aperture $e$ and conductivity $K_{e}$ with increasing depth. Figure 5.14, borehole D-93, shows a dramatic increase in joint aperture accompanying a sharp rise in $K_{e}$ between 90and 120-ft depth, but with a lower joint count in the same interval. Recall that equivalent aperture $e$ is derived from $K_{e}$ using the cubic law and the joint count, $N$ (see Equations 5.1 and 2.11). The implication is that joint aperture, not joint frequency, is the dominant factor in determining zones of high flow in jointed rock masses. Of course, joints must also be persistent enough or sufficiently interconnected that a flow path is sustained to the tailwater. That is, joints must not "dead-end" short of the outlet.

Borehole data for the vicinity of monolith 23 were used to construct a cross section through the monolith foundation (Figure 5.22). Borehole data are projected into the section (note that boreholes do not necessarily lie within monolith 23, as shown in Figure 5.4). The cross section shows selected logged features in those portions of the boreholes below top of rock (as defined by exploratory 


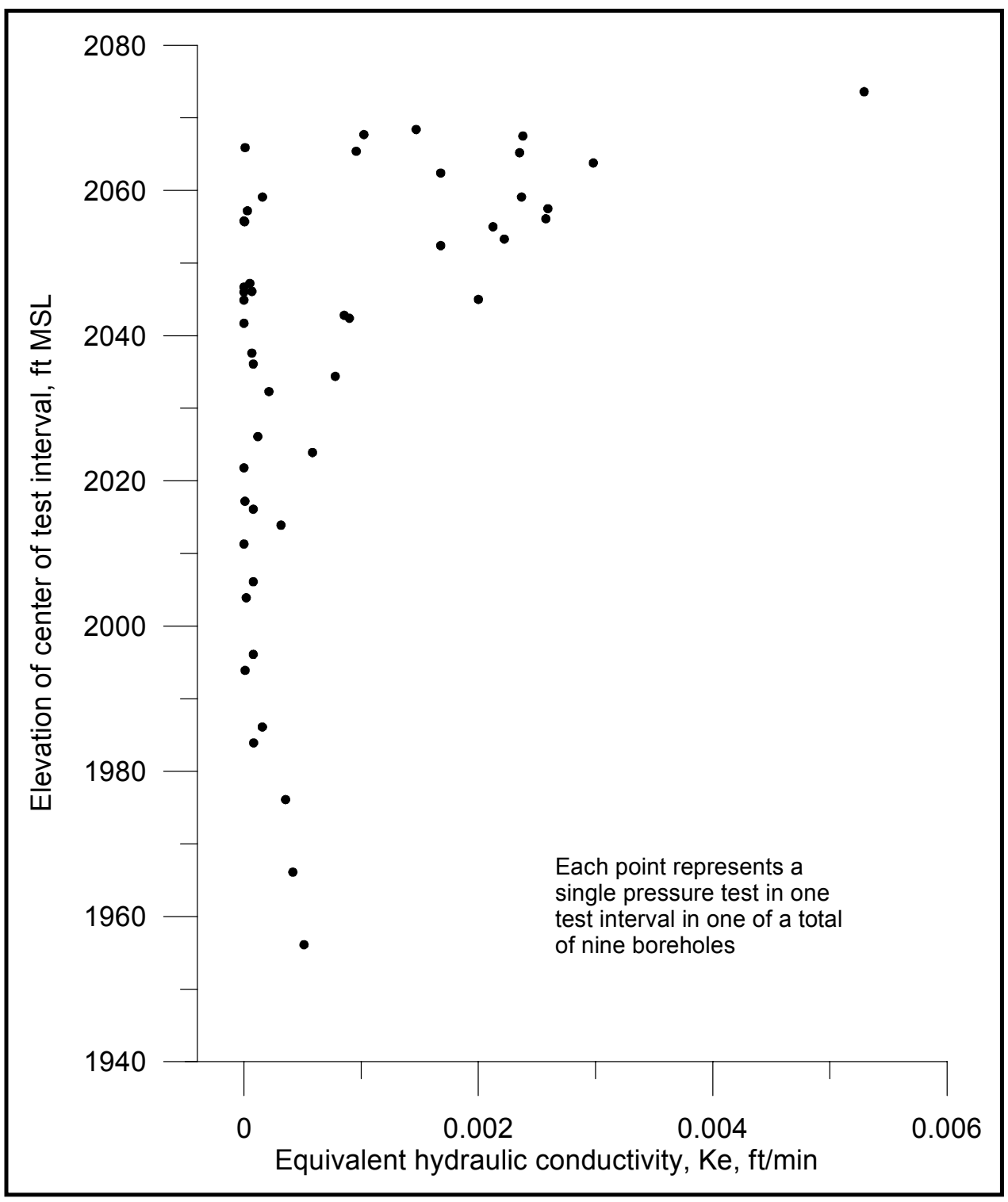

Figure 5.21. Variation in equivalent hydraulic conductivity with elevation in nine boreholes near monolith 23. From foundation pressure tests, Libby Dam

boreholes). The bold line near the center of the section is the profile of the dam (monolith 23). Vertical enhancement of the section is 5 to 1 . Graphs of $K_{e}$ beside each borehole log show the distribution of computed hydraulic conductivities in pressure-tested boreholes within the foundation. The dashed line delimits the base of a zone of relatively high hydraulic conductivity as defined by the pressure test data and subsequent calculations. The base of the conductive zone is essentially the elevation at which the computed conductivities dropped below about $10^{-3} \mathrm{ft} / \mathrm{min}$. The zone coincides generally with regions of "open" joints or "shattered" rock in boreholes. The zone of higher conductivity is thicker upstream and in the upstream portion of monolith 23 than in the downstream portion. Excavation of the foundation removed up to about $18 \mathrm{ft}$ of weathered and more permeable rock prior to pouring of the monolith (see the bold line of the monolith in 


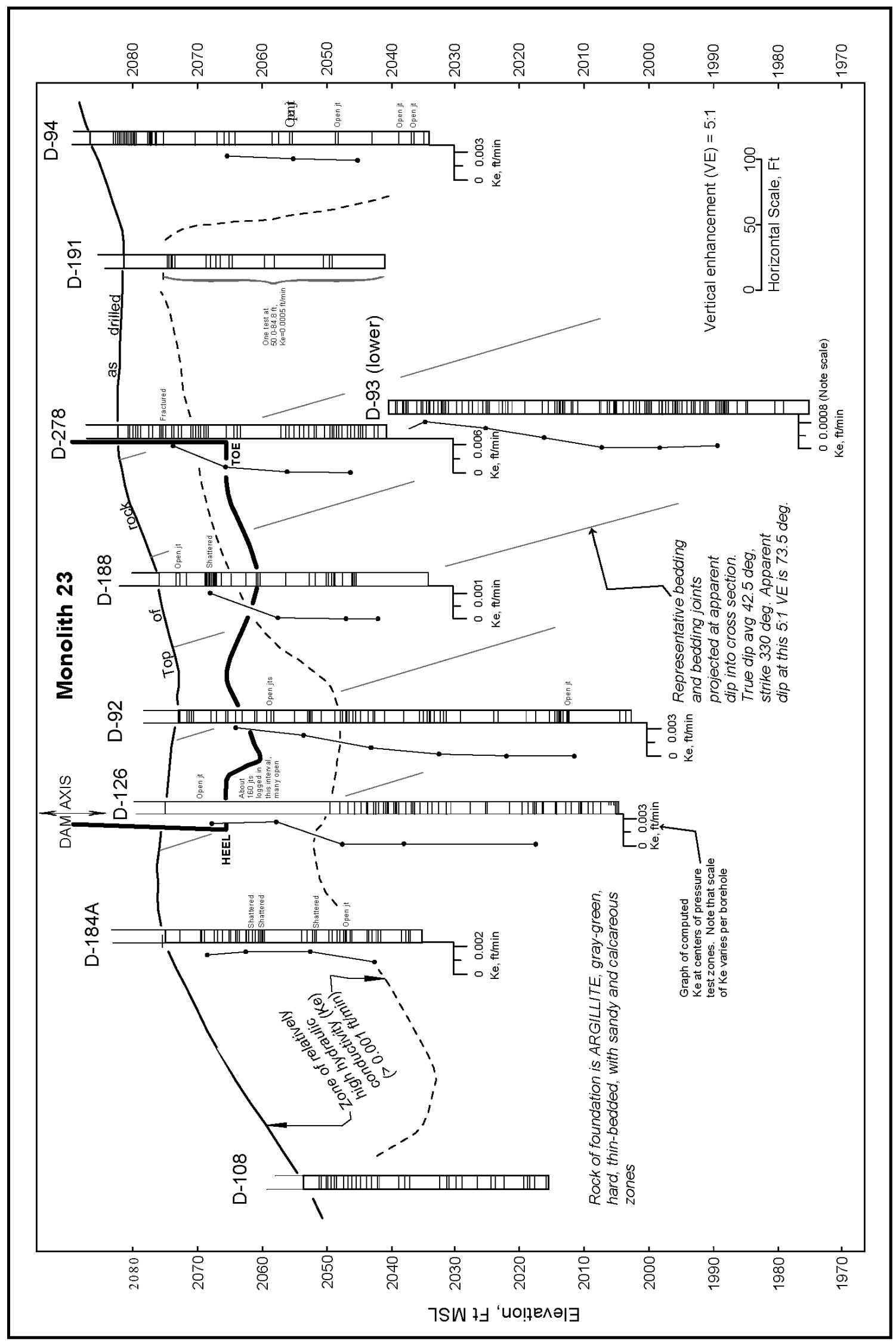

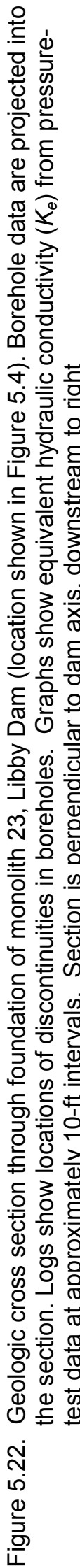

ฟิ



몬 
Figure 5.22). The cross section indicates that permeable rock extends another $15 \mathrm{ft}$ or so deeper than the base of the excavation in the vicinity of the heel of the dam and upstream.

An anomaly became apparent when values of $K_{e}$ were computed for boreholes in which pressure tests were conducted at two distinct pressures. Equivalent hydraulic conductivities from tests at high pressures were consistently lower than conductivities computed from tests at the lower pressures. The difference was greatest at higher values of $K_{e}$. Figure 5.13, the plot of $K_{e}$ versus depth for borehole D-92, illustrates the phenomenon. Computed values of $K_{e}$ for the 55- to 100-psi tests were consistently lower than values computed for the 30- to 50-psi tests, and the difference was consistently greater with increasing $K_{e}$. The difference is most prominent for values of $K_{e}$ greater than $10^{-3} \mathrm{ft} / \mathrm{min}$. Figure 5.23 shows that a relationship exists between the difference in $K_{e}$ and the magnitude of $K_{e}$. The plot has two implications. First, the range in the difference in computed $K_{e}$ at two pressures is linearly related to the magnitude of the computed $K_{e}$. Second, there is more scatter in the range in computed values of $K_{e}$ between the test pairs at higher magnitudes of $K_{e}$. This plot may signify that there is simply more error inherent in computations of equivalent hydraulic conductivity at higher flow rates and in larger aperture joints than in less permeable joints.

What is more difficult to explain is the tendency for the higher pressures to consistently result in lower computed $K_{e}$ than the lower pressures. Referring to Table 5.1 (Borehole D-92, higher pressure and lower pressure), higher pressures (gauge psi, column B) produced, as expected, mean higher flow rates $(Q, \mathrm{cfm}$, column A) at equivalent borehole intervals (column M) in the pair of tests (about 33 percent higher than in the low-pressure tests). Gauge pressures in the highpressure tests were about double that of the low-pressure tests (mean 91 percent higher). $H$, the excess head (column $\mathrm{D}$, Table 5.1) consists of gauge pressure, in $\mathrm{ft}$, plus gravity head $H_{g} . H$ was a mean 77 percent higher in the high-pressure tests than in the low-pressure tests. Computed $K_{e}$, however, was lower at the higher pressures than at the lower pressures by a mean 26 percent. Equation 5.1 shows that $K_{e}$ is directly proportional to flow rate $Q$ and inversely proportional to excess pressure head $H$. If $Q$ and $H$ change proportionally from one test to another, $K_{e}$ changes proportionally. In the monolith 23 pressure-test pairs, $Q$ (the numerator in Equation 5.1) changed much less than $H$ (the denominator) from high-pressure to low-pressure tests. The result was that high-pressure tests produced lower values of computed $K_{e}$ than low-pressure tests, which intuitively should not be the case if the relationship between hydraulic conductivity, $Q$, and $H$ is linear (i.e., $K_{e}$ computed from high-pressure tests should be the same as that computed from lowpressure tests). In other words, high-pressure tests produced a lower inflow $(Q)$ than low-pressure tests (in open joints).

These results may signify that turbulent, or nonlinear, flow is occurring in the joints at higher pressures. Equation 5.1 implies that $K_{e}$ is linearly proportional to flow rate $Q$. Zeigler (1976) and Headquarters, U.S. Army Corps of Engineers (2001) state that flow rates that are not proportional to pressure in a test zone may indicate turbulent flow. It is possible that turbulent flow at the higher pressure impedes the flow of water through the test interval and results in a lower $Q$ and lower computed $K_{e}$. Nonlinear flow at higher test pressures is a source of potential 


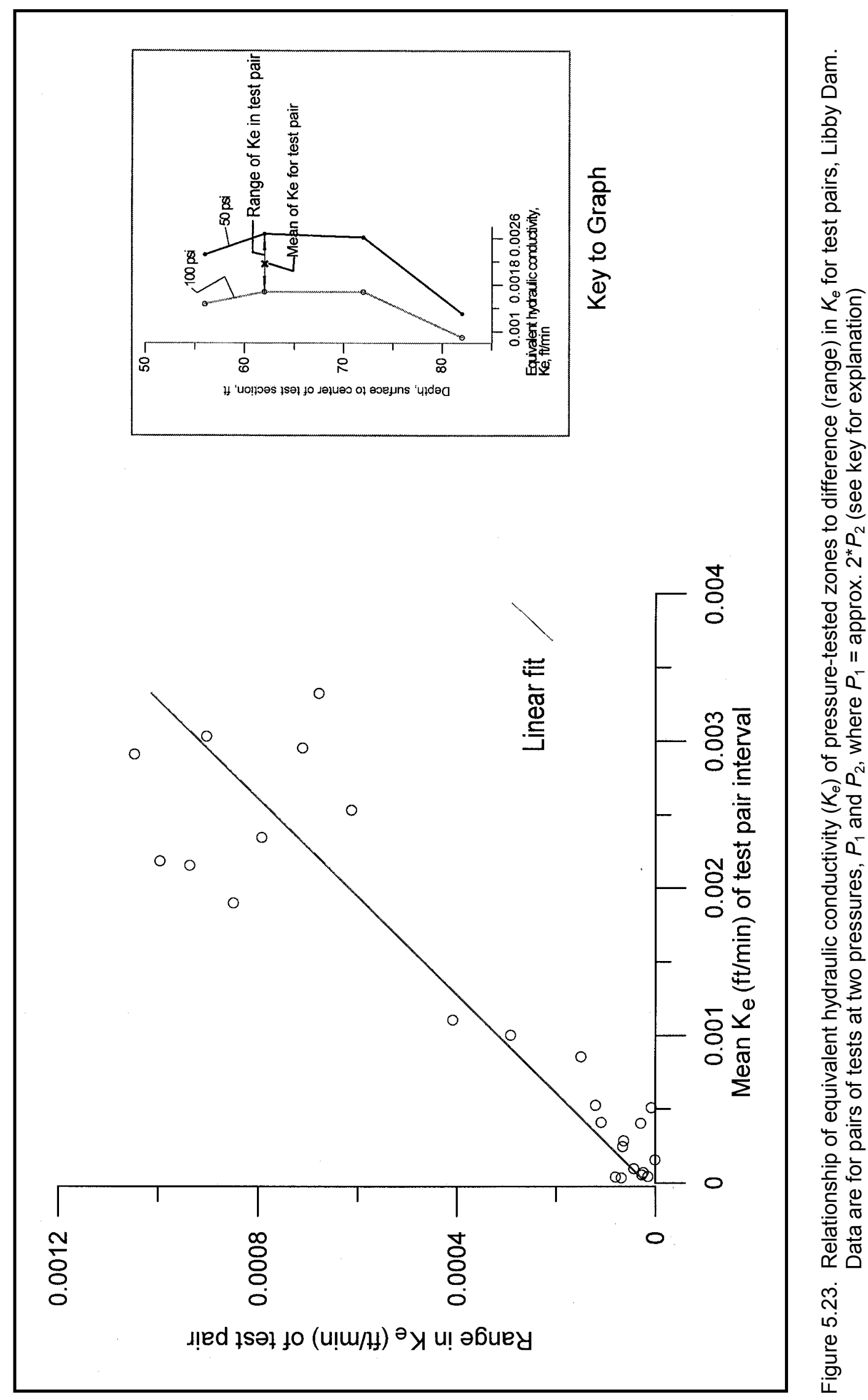


error in computations of $K_{e}$ and conducting aperture $e$ and leads to uncertainty in predicting corresponding uplift pressures in numerical models.

\subsubsection{Conducting aperture, e}

Although the graphs in Figures 5.13 through 5.20 show a clear tendency toward decreasing $e$ with depth, a simple statistical report was made of all apertures treated independently of depth (see Table 5.2). Equivalent parallel plate apertures $e$ computed with Equation 2.11 from the higher pressure test data ranged from 0 to $0.2375 \mathrm{~mm}$. Maximum computed $e$ was $0.2375 \mathrm{~mm}$ (238 microns $(\mu \mathrm{m}))$. Mean computed $e$ was $0.0817 \mathrm{~mm}(82 \mu \mathrm{m})$. The standard deviation, an indication of the spread of the $e$ values about the mean, was 0.0769 . Perhaps a better measure of the spread of values is the coefficient of variation (the standard deviation divided by the mean), which expresses the standard deviation as a percentage of what is being measured. The coefficient of variation was 0.7673 , a high number that indicates that the standard deviation is almost as high as the mean and implying a wide variation in computed values of $e$.

The computed parallel plate aperture, $e$, is not the true joint aperture but the conducting aperture. As explained in Chapter 2, the conducting aperture $e$ is the distance between two smooth parallel plates that would allow the same flow as a mechanical aperture $(E)$ with rough walls. Conducting aperture is always less than or equal to mechanical aperture (Ebeling, Wahl, and Pace 1997). Computed values of $e$ at Libby Dam are in the same range as apertures computed for dams by other investigators (Barton, Bandis, and Bakhtar 1985; Snow 1965).

\begin{tabular}{|c|c|}
\hline \multicolumn{2}{|c|}{$\begin{array}{l}\text { Table } 5.2 \\
\text { Statistical Information on } \\
\text { Computed Values of Equivalent } \\
\text { Aperture, e }\end{array}$} \\
\hline Number of values & 49 \\
\hline Minimum e, mm & 0 \\
\hline Maximum $e, \mathrm{~mm}$ & 0.2375 \\
\hline Range in $e, \mathrm{~mm}$ & 0.2375 \\
\hline Mean $e, \mathrm{~mm}$ & 0.0817 \\
\hline Median $e, \mathrm{~mm}$ & 0.0769 \\
\hline Standard deviation, $\mathrm{mm}$ & 0.0627 \\
\hline Coefficient of variation & 0.7673 \\
\hline
\end{tabular}

The relationship of conducting aperture, $e$, and depth is shown in Figures 5.24 through 5.26. Figure 5.24 shows the variation in $e$ with elevation in the foundation of Libby Dam. A relationship similar to that between $K_{e}$ and elevation is apparent (higher apertures at higher elevations). Snow (1968) investigated rock fracture openings (conducting apertures computed from pressure tests) at several dam sites. He plotted apertures against the depth at which they occurred below the top of rock or below the base of the

overburden. Snow presumably believed that joint and bedding planes opened following erosion of the rock (denudation and subsequent stress release) and that apertures should therefore be adjusted for depth below top of rock rather than for depth from ground surface or for elevation. Apertures computed for Libby Dam were adjusted for depth below top of rock for comparison with Snow's results for other dams. Figure 5.25 is a plot of computed apertures beneath monolith 23 versus depth below top of rock. The scale in Figure 5.25 is identical to that of 


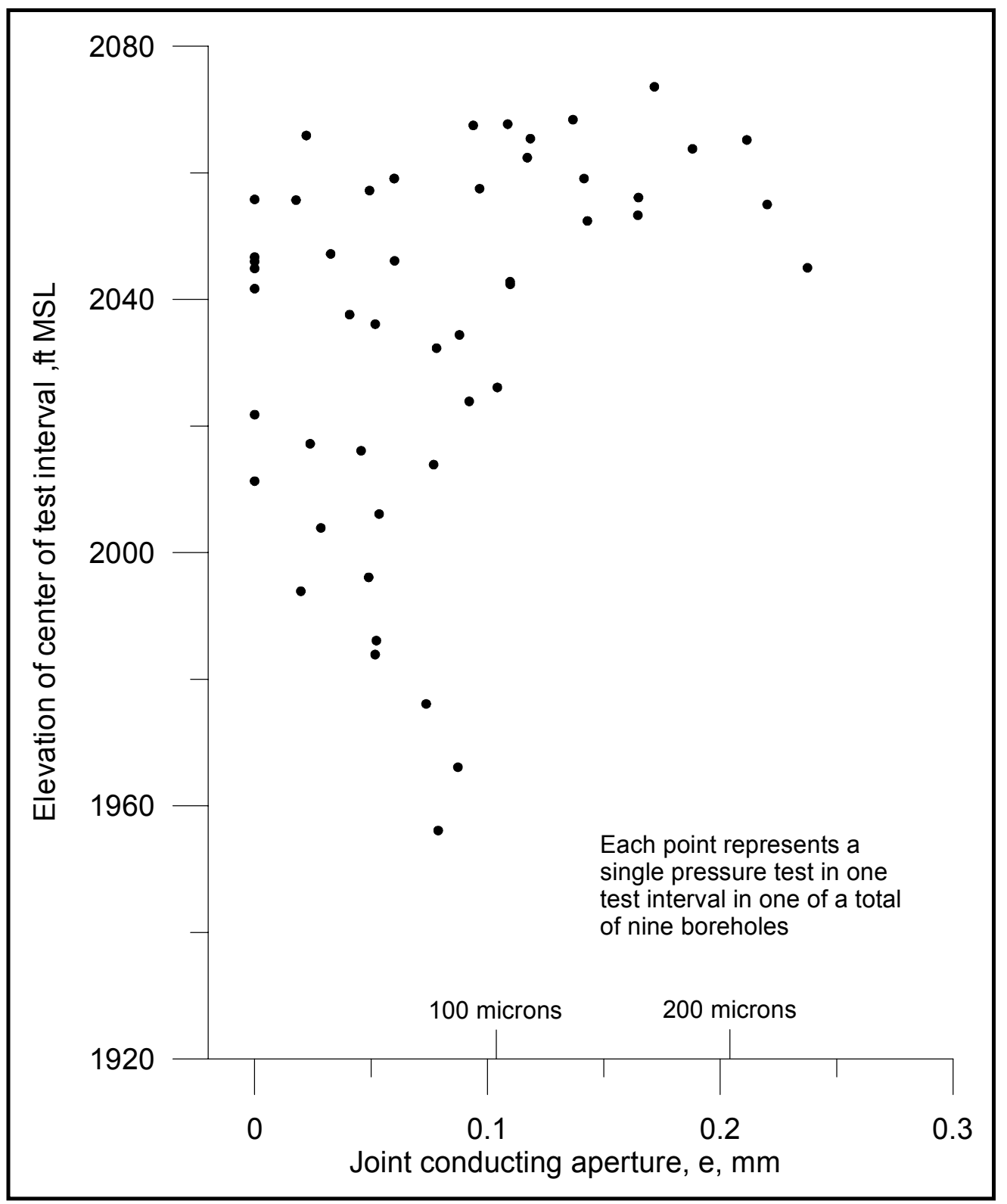

Figure 5.24. Joint conducting aperture, e, versus elevation, Libby Dam monolith 23

Figure 5.24 (the plot of $e$ versus elevation). Figure 5.26 is a plot of Snow's (1968) data. Data for Libby Dam and for Snow's dams are strikingly similar. Snow's conclusion that joint "...openings [aperture] decrease with depth..." and that "...the marked decrease of openings with depth is most responsible for decreases in permeability..." is consistent with the Libby Dam data. Note that the computed conducting apertures for Snow's discontinuities and for the Libby Dam joints are also very similar, ranging from near zero to 200 or $300 \mu \mathrm{m}$. A marked decrease in aperture occurs at about 40 to $50 \mathrm{ft}$ in depth in both Snow's and the Libby Dam data. Apertures generally are less than $100 \mu \mathrm{m}$ below that depth. 


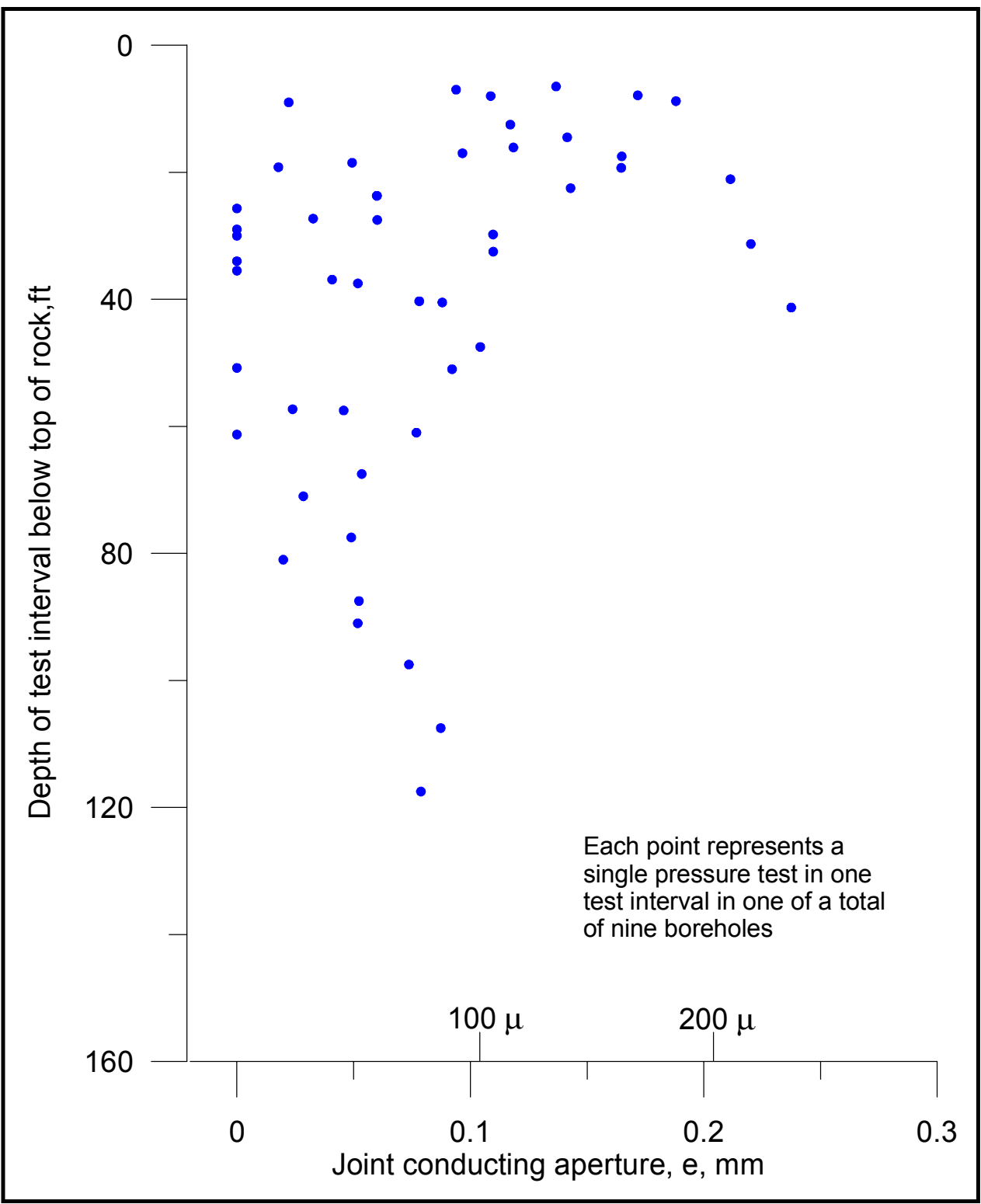

Figure 5.25. Joint conducting aperture, e, versus depth below top of rock, Libby Dam monolith 23

In the case of the Libby Dam data, there is little difference in the shape of the plots of $e$ versus elevation and $e$ versus depth below top of rock (Figures 5.24 and 5.25 , respectively). Snow's presumed concern about the need to reference aperture to top of rock rather than ground surface is less a factor for the Libby Dam monolith 23 area because the total relief on the original rock surface is only $14 \mathrm{ft}$ and on the original ground surface only $12 \mathrm{ft}$.

Using the relationship of Barton, Bandis, and Bakhtar (1985), Figure 2.8, an expected equivalent mechanical aperture, $E$, for a conducting aperture, $e$, of $100 \mu \mathrm{m}$ and greater would be 2 to 3 times the value of $e$ (i.e., $E / e=2$ to 4 ), assuming a roughness (JRC) of 15 (typical value cited in Ebeling, Wahl, and Pace 1997). Maximum computed mechanical, or actual, apertures for monolith 23 


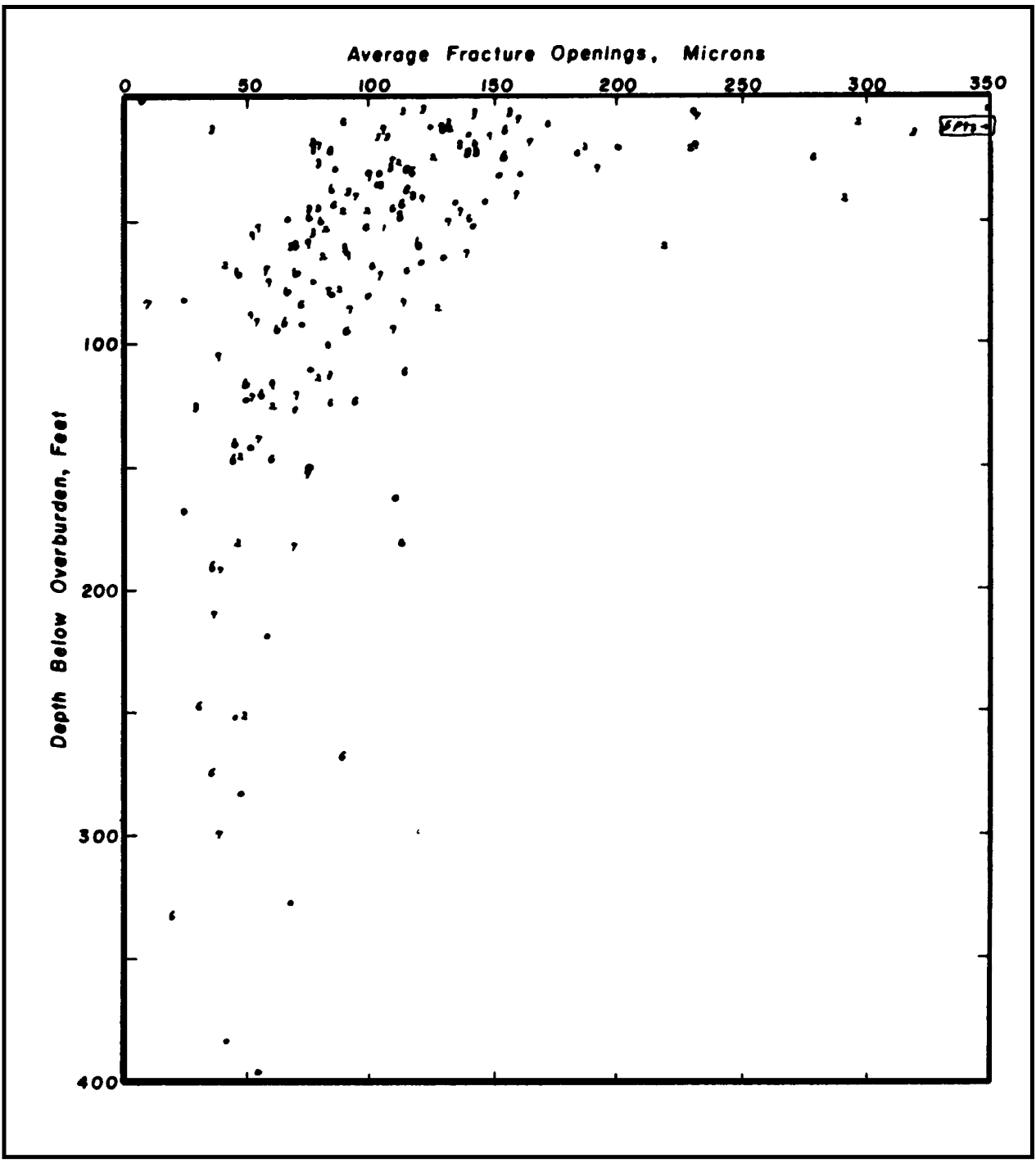

Figure 5.26. Average rock fracture openings (in microns) versus depth below overburden (top of rock) at dam sites (after Snow 1968, Figure 7)

joints would thus be in the range of 500 to $700 \mu \mathrm{m}(0.5$ to $0.7 \mathrm{~mm})$. Following work by Barton (1982, pp. 65-68), $E$ could also be calculated from Equations 2.9 or 2.10 if measurements of JRC (from tilt tests, for example) were available $\{E=$ $\left.\left[e /(\mathrm{JRC})^{2.5}\right]^{0.5}\right\}$. Examples of apertures describing open joints were presented in Chapter 2. A joint was generally described as open if its mechanical aperture was equal to or greater than 250 to $500 \mu \mathrm{m}$ (see Table 2.1). Snow (1968) used a conducting aperture as low as $35 \mathrm{~mm}$ to describe an open joint. Under those precedents, most of the joints in the upper 25 to $50 \mathrm{ft}$ of foundation rock in monolith 23 are open joints.

Barton (1982) suggested the use of borehole pressure tests to estimate conducting and real apertures to predict joint deformation from future stress perturbation of foundations and excavations. He advised using low injection pressures to avoid reducing levels of existing effective stress and subsequent enlarging of 
joint apertures (hydrofracturing). Barton stated that calculations of $e$ from pressure tests, and $E$ from estimates of JRC, could be the starting point for estimations of mechanical and hydraulic response of joints to further stress. His considerations emphasize the need to define the uncertainties inherent in deriving discontinuity characteristics from field tests that are not carefully controlled. Pressure testing in some of the monolith 23 boreholes at Libby Dam was not limited to the suggested $0.57 \mathrm{psi} / \mathrm{ft}$ (discussed earlier in this chapter), and slight widening of existing joints may have occurred in the upper portions of the rock mass. 


\section{Analysis of Uplift Pressures at Libby Dam}

Libby Dam is a concrete gravity dam. It consists of 47 monoliths, each between 59 and $66 \mathrm{ft}$ wide as measured along the longitudinal dam axis. The uplift pressure gauges were installed in six monoliths: 14, 18, 23, 29, 34, and 41 . Monoliths 23 and 29 were considered for the dam uplift study because they are centrally located and the hydrostatic pressure on the reservoir base is at its maximum in these monoliths. The basis for the selection of the monolith 23 uplift pressure gauges was the quality and higher number of useful readings in its available 20-year monitoring history.

The uplift pressure gauges are located at the two lowest galleries, mutually parallel at elevations varying between $2,177.5 \mathrm{ft}$ and 2,197.75 ft. These are the "drainage and grouting gallery" located $5 \mathrm{ft}$ downstream from the dam axis, and "downstream drainage gallery," $105 \mathrm{ft}$ downstream from the dam axis (Figure 6.1).

The grouting curtain incorporated into the dam foundation is composed of three zones: a tertiary zone $40 \mathrm{ft}$ into rock, a secondary zone $90 \mathrm{ft}$ into rock, and a primary zone $160 \mathrm{ft}$ into rock. The grout holes top at the floor of the upstream drainage and grout gallery. A section and plan of the grout holes and drains and locations of uplift pressure instruments (gauges) are shown in Figure 6.1. The grout holes are, as in all other valley monoliths, inclined $25^{\circ}$ upstream and $15^{\circ}$ toward the left abutment as measured from vertical. The grout holes are on $5-\mathrm{ft}$ centers along the longitudinal axis of the dam.

The dam has a system of drains organized in two rows. The drains at the upstream grout and drainage gallery are spaced evenly $10 \mathrm{ft}$ apart parallel to the dam axis in a row $10 \mathrm{ft}$ downstream from the dam axis. All drains in monolith 23 at the upstream grout and drainage gallery are $105 \mathrm{ft}$ deep. Drains outlet at the level of the grout and drainage gallery. A profile view of this gallery is provided in Figure 6.2.

A second row of drain holes is $95 \mathrm{ft}$ downstream from the front row of the drains. These drains are $60 \mathrm{ft}$ deep. They outlet at the downstream drainage gallery. All drain holes in both the upstream grout and drainage gallery and downstream drainage gallery were drilled on 10-ft centers through 3.5-in. I.D. galvanized pipes, each $5 \mathrm{ft}$ long and embedded in concrete prior to construction. 

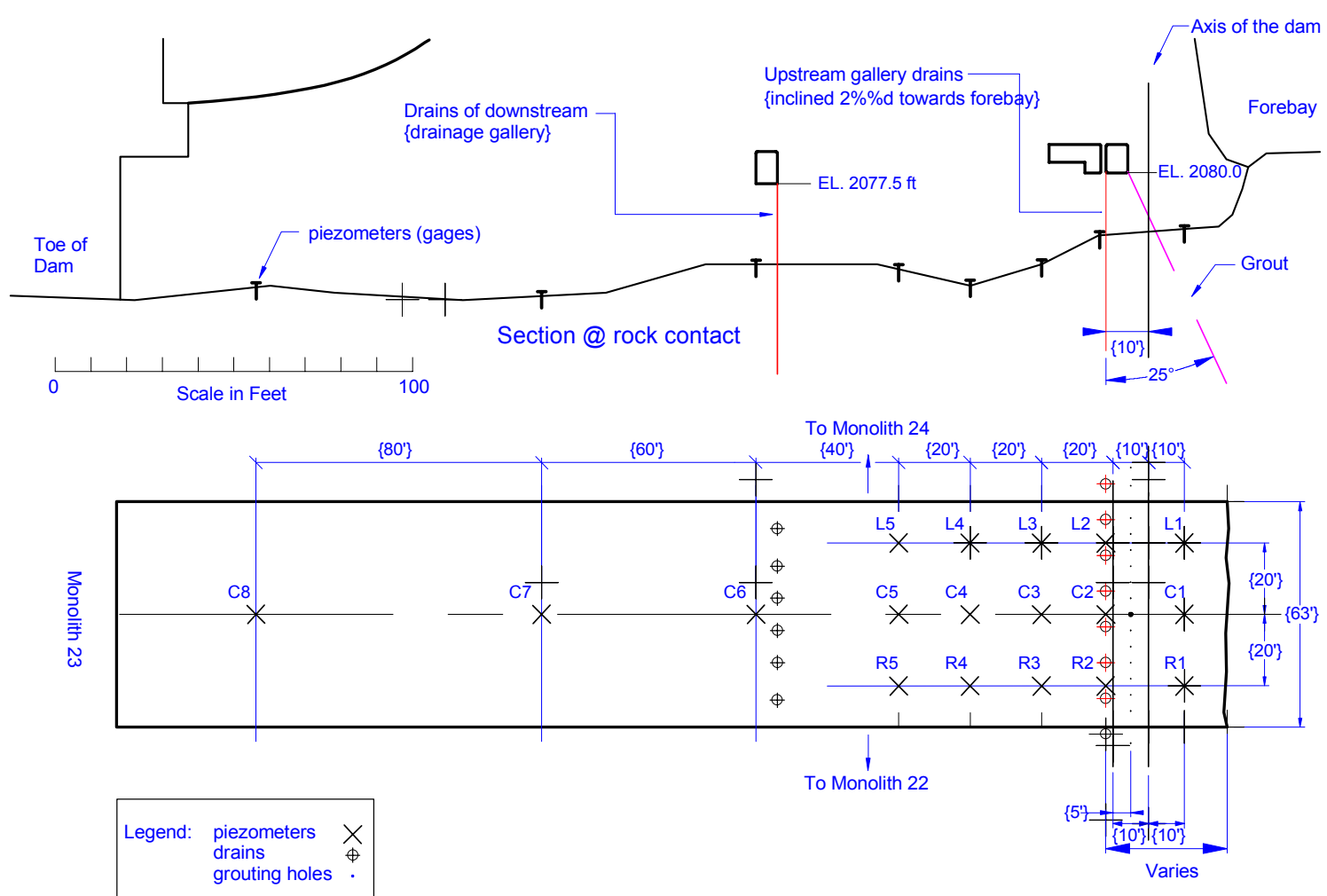

PLAN AT EL. 2077.5

Instrument and Drain Locations at Monolith 23

Figure 6.1

Figure 6.1. Instrument and drain locations, monolith 23, Libby Dam

All drain holes in both galleries are 3 in. in diameter and inclined on an angle $15^{\circ}$ off the vertical toward the left abutment and $2^{\circ}$ off the vertical toward the forebay. A profile view of the downstream drainage gallery is provided as Figure 6.3.

A total of 18 pressure cells (gauges) were installed in monolith 23. The pressure cells are organized in groups of three gauges in five rows spaced in equal 20$\mathrm{ft}$ intervals, with three additional pressure cells centered in unequal distances downstream from the forebay group. The first row of gauges is $10 \mathrm{ft}$ upstream of the dam axis, the second row is $10 \mathrm{ft}$ downstream of the dam axis, the third row is $30 \mathrm{ft}$ downstream of the dam axis, the fourth row is $50 \mathrm{ft}$ downstream of the dam axis, and the fifth row is $70 \mathrm{ft}$ downstream of the dam axis.

The gauges in this main group are designated $\mathrm{L}$ for gauges $20 \mathrm{ft}$ left of the center of the monolith, $\mathrm{C}$ for the center monolith gauges, and $\mathrm{R}$ for gauges $20 \mathrm{ft}$ to the right of the centerline of the monolith, facing the forebay. Three additional pressure gauges are in the center of the monolith: gauge C6 is $110 \mathrm{ft}$ downstream from the axis, and gauges $\mathrm{C} 7$ and $\mathrm{C} 8$ are $170 \mathrm{ft}$ and $250 \mathrm{ft}$, respectively, downstream of the axis of the dam. Refer to the plan in Figure 6.1 for respective 


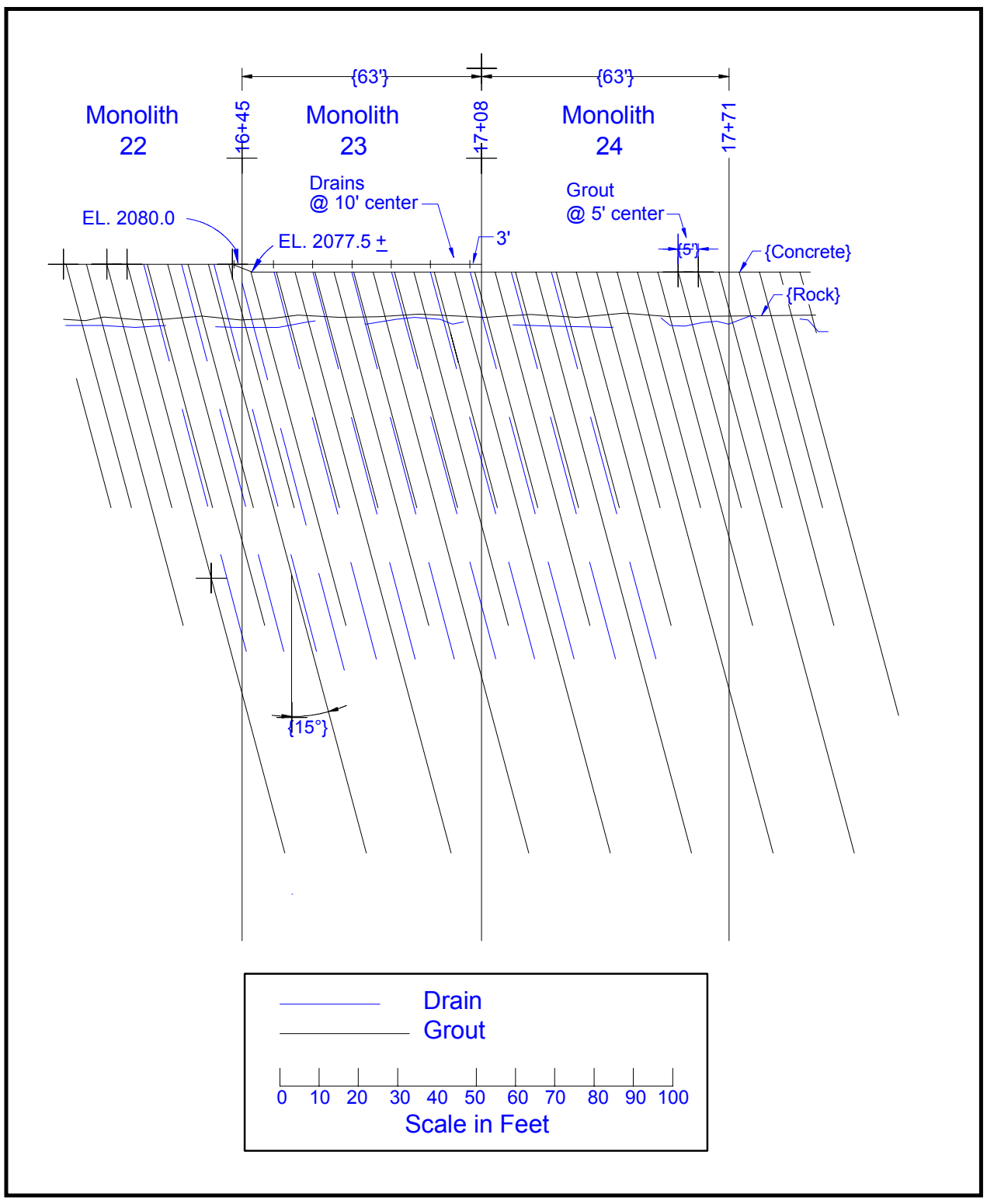

Figure 6.2. Upstream grout and drainage gallery, monolith 23, Libby Dam, looking upstream

locations of the pressure gauges. A detail of the gauge installation at the rock/ monolith interface is shown in Figure 6.4.

\subsection{Calculation of Uplift Pressures from Gauge Readings}

The Geology Section of the Seattle District furnished a complete set of data files containing uplift pressure gauge readings, recorded forebay elevations in feet, volume discharge, recorded tailwater elevations in feet, and ambient forebay 


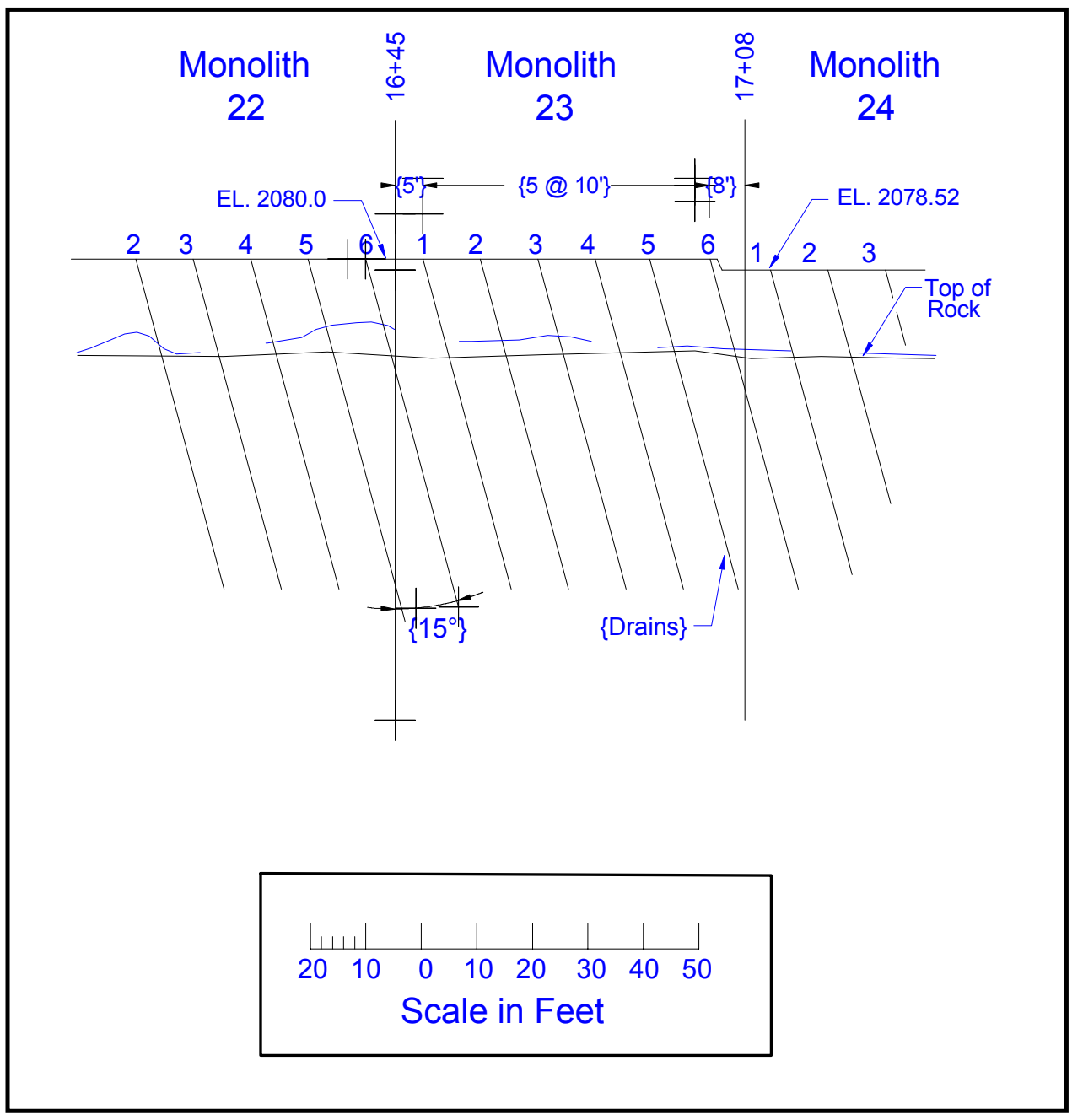

Figure 6.3. Downstream drainage gallery, monolith 23, Libby Dam, looking upstream

temperature. The hydraulic readings of forebay elevation were recorded on a daily basis for all dates since November 1979. The uplift pressure gauge readings were taken continuously on a monthly basis from October 1979 until the present. For peak forebay elevations, the uplift pressure (gauge) readings were taken twice a month.

The readings of the gauges represent total head in feet, which includes pressure head and elevation head. The readings do not include velocity head, which is considered negligible for this study. No conversion factor was indicated for the data files obtained from Seattle District.

\subsection{Variation of Uplift Pressure with Time}

Two periodic inspection reports were available for this report: Periodic Inspection Report No. 10 (1987) and Periodic Inspection Report No. 13 (1993). 


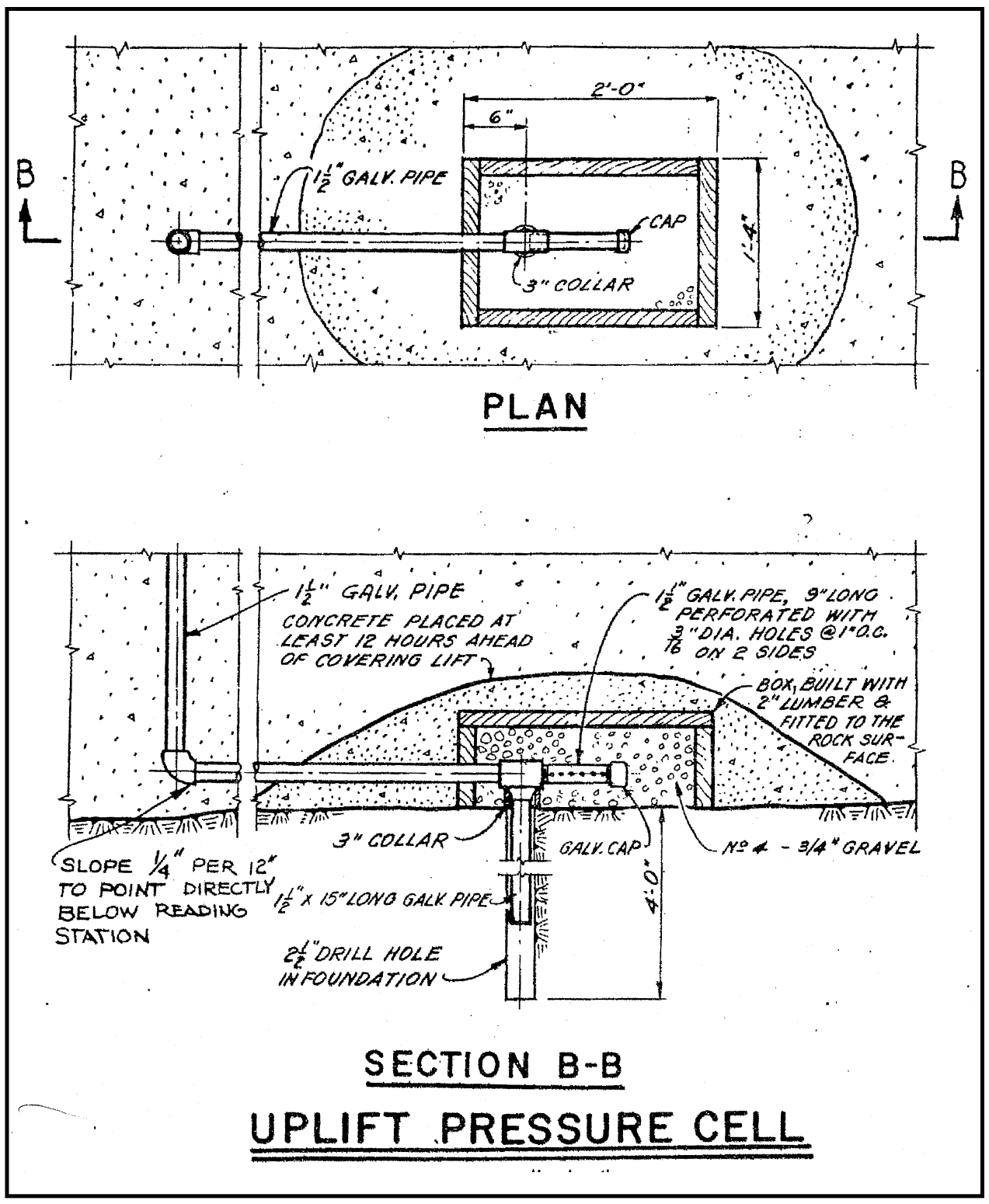

Figure 6.4. Detail of uplift cell and installation, Libby Dam

The Seattle District provided a complete plot of gauges for the interval 1981-1999 for each monolith equipped with pressure gauges at Libby Dam. Plots for monolith 23 gauges are included as Figures 6.5 through 6.12. Gauge $\mathrm{C} 1$ was replaced in May 1995 and in December 1997. Gauges C2, C3, and C4 were replaced in May 1993. All gauges were bled in March 1993, September 1995, April 1996, July 1996, March 1997, and April 1998. A C1 bleeder valve was installed in May 1995. Gauges C5, C6, C7, and C8 were replaced in May 1993, and the gauges were bled in March 1995, September 1995, April 1996, July 1996, March 1997, August 1997, and April 1998. Gauges R1, R3, R4, and R5 were replaced and gauge R2 bled in May 1993, and gauge R5 was replaced in September 1995. Gauge R1 bleeder valve was installed in May 1995 and R3 gauge was replaced in July 1996 and March 1997. All R gauges were bled in March and September 1995, in April 1996, in March and August 1997, and finally in April 1998. 


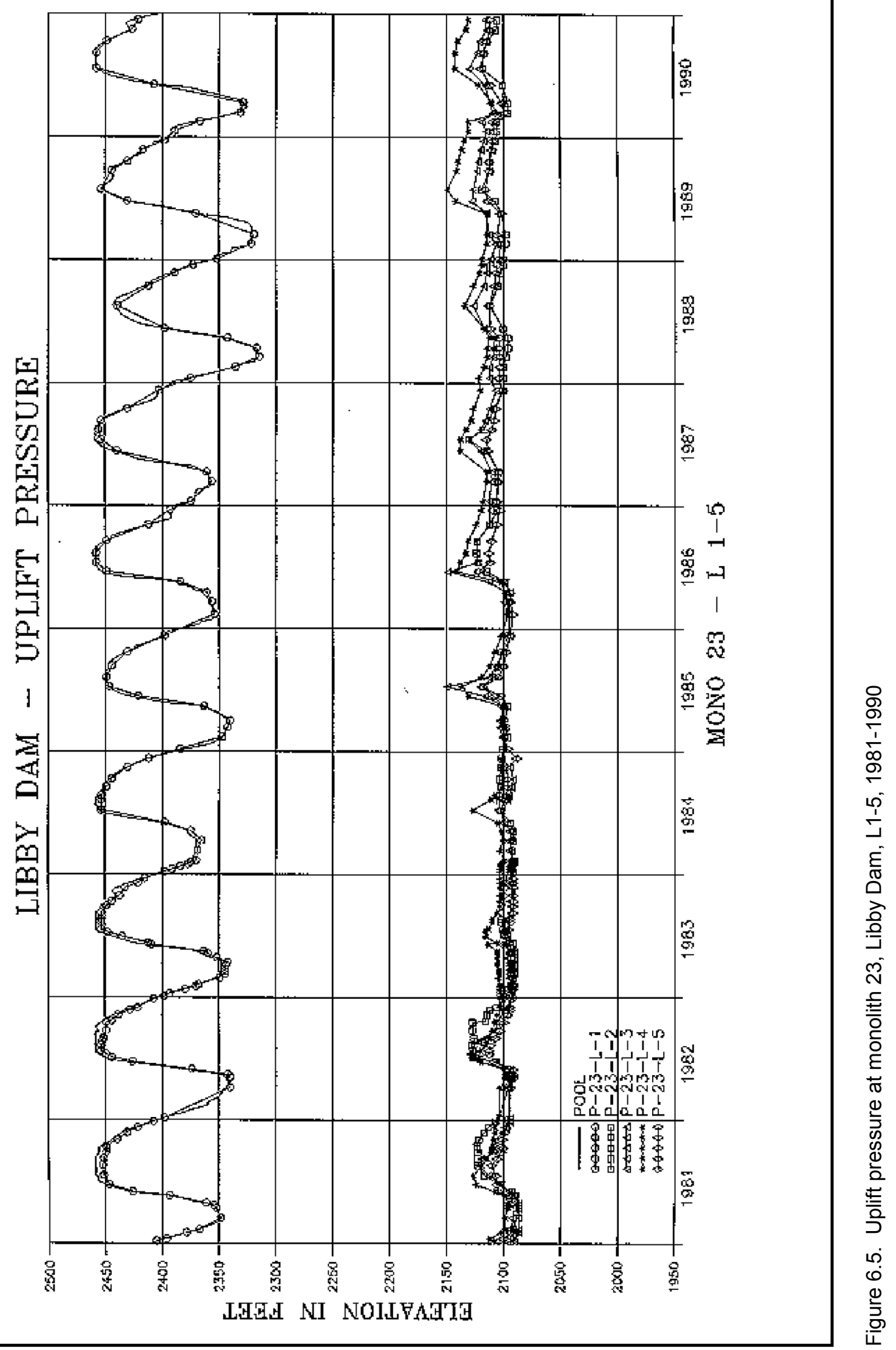




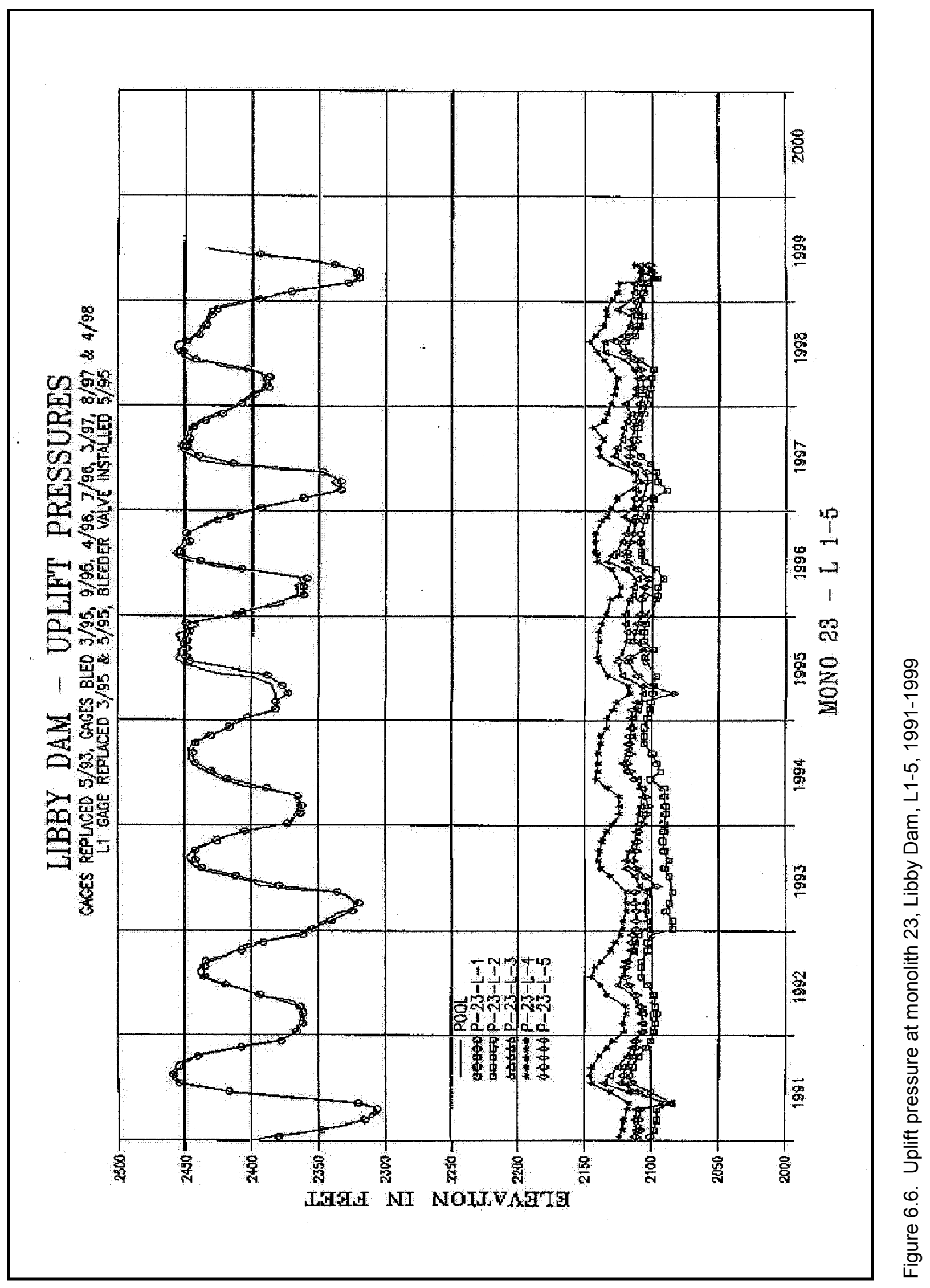




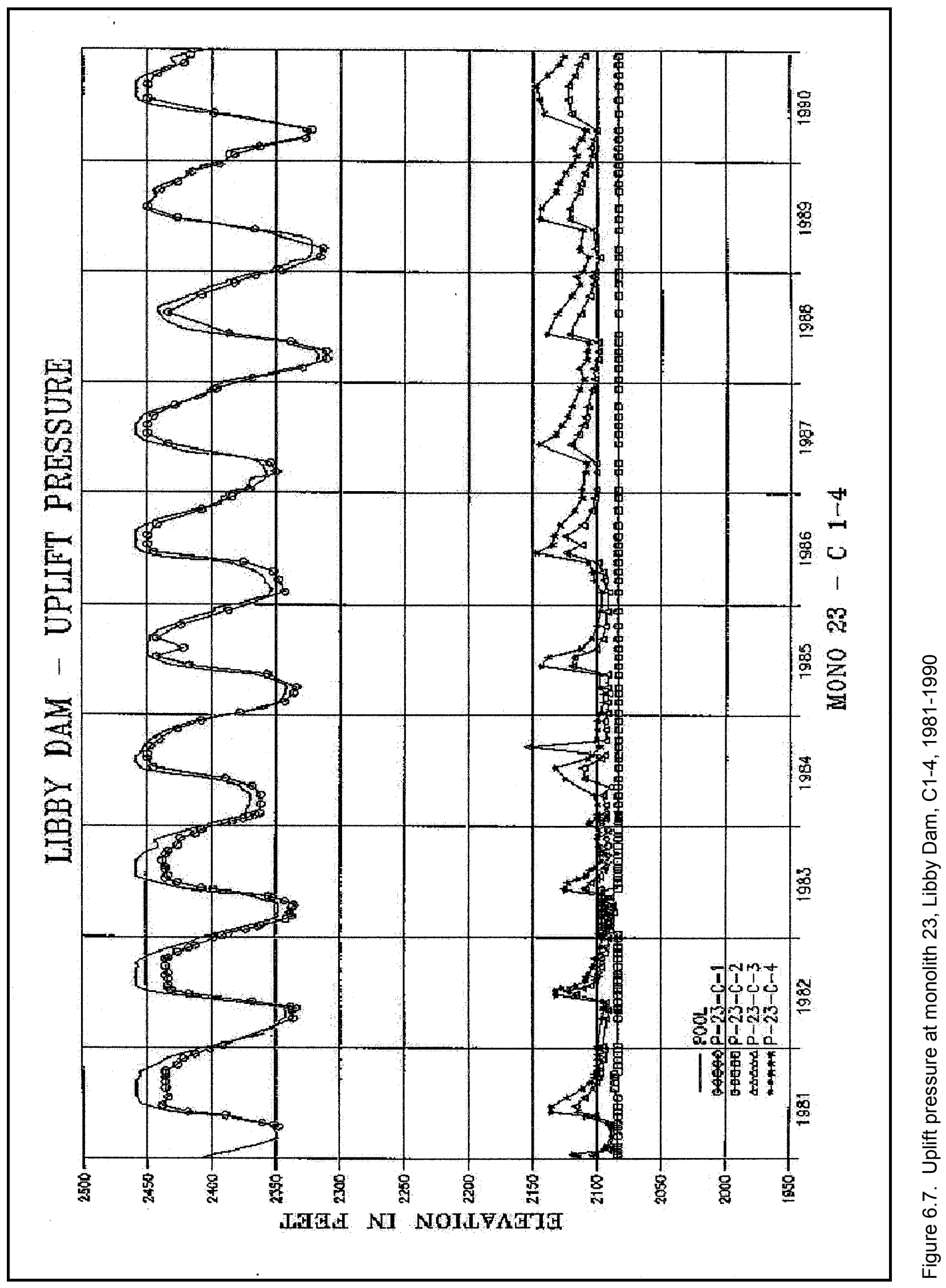




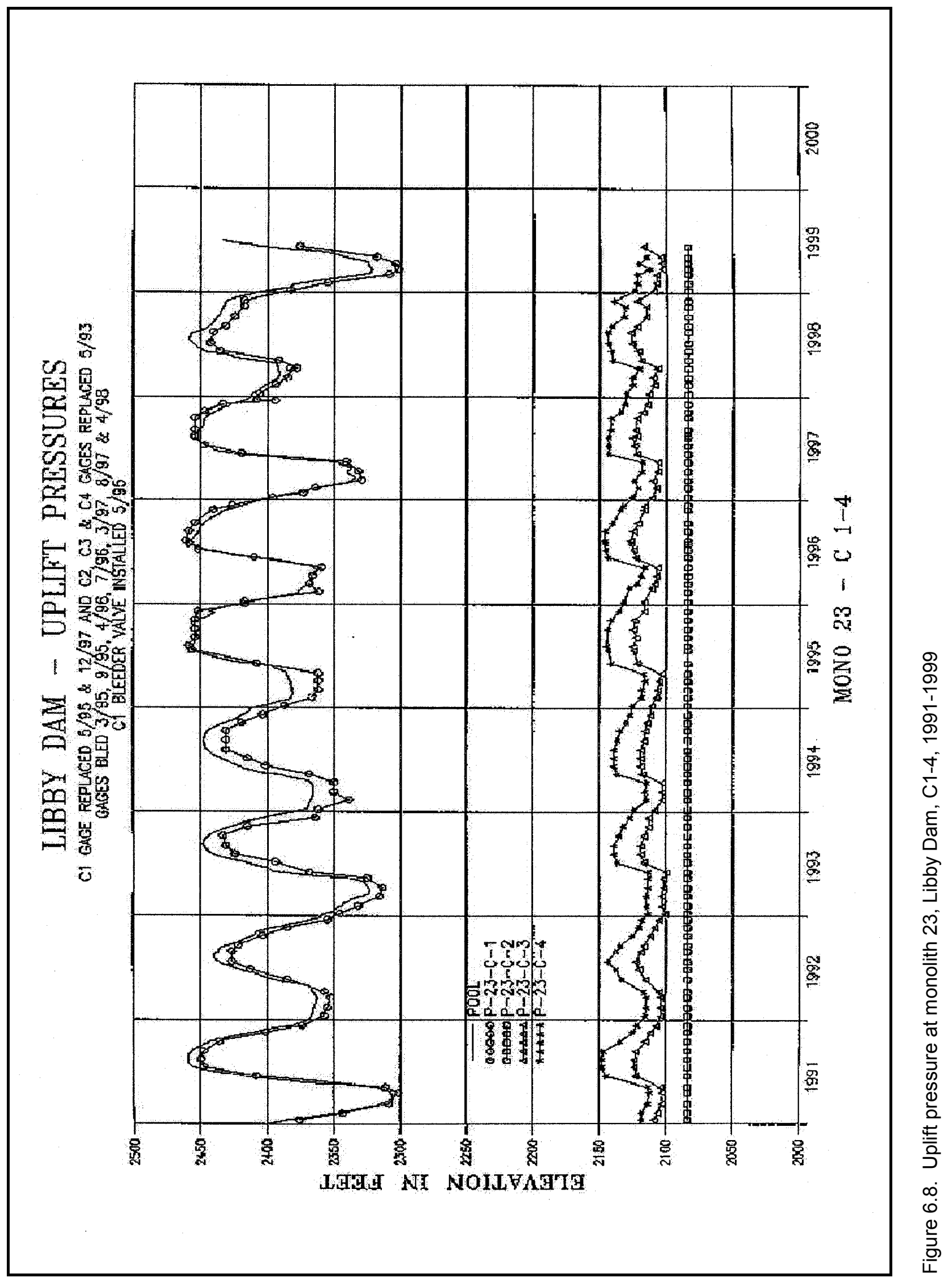




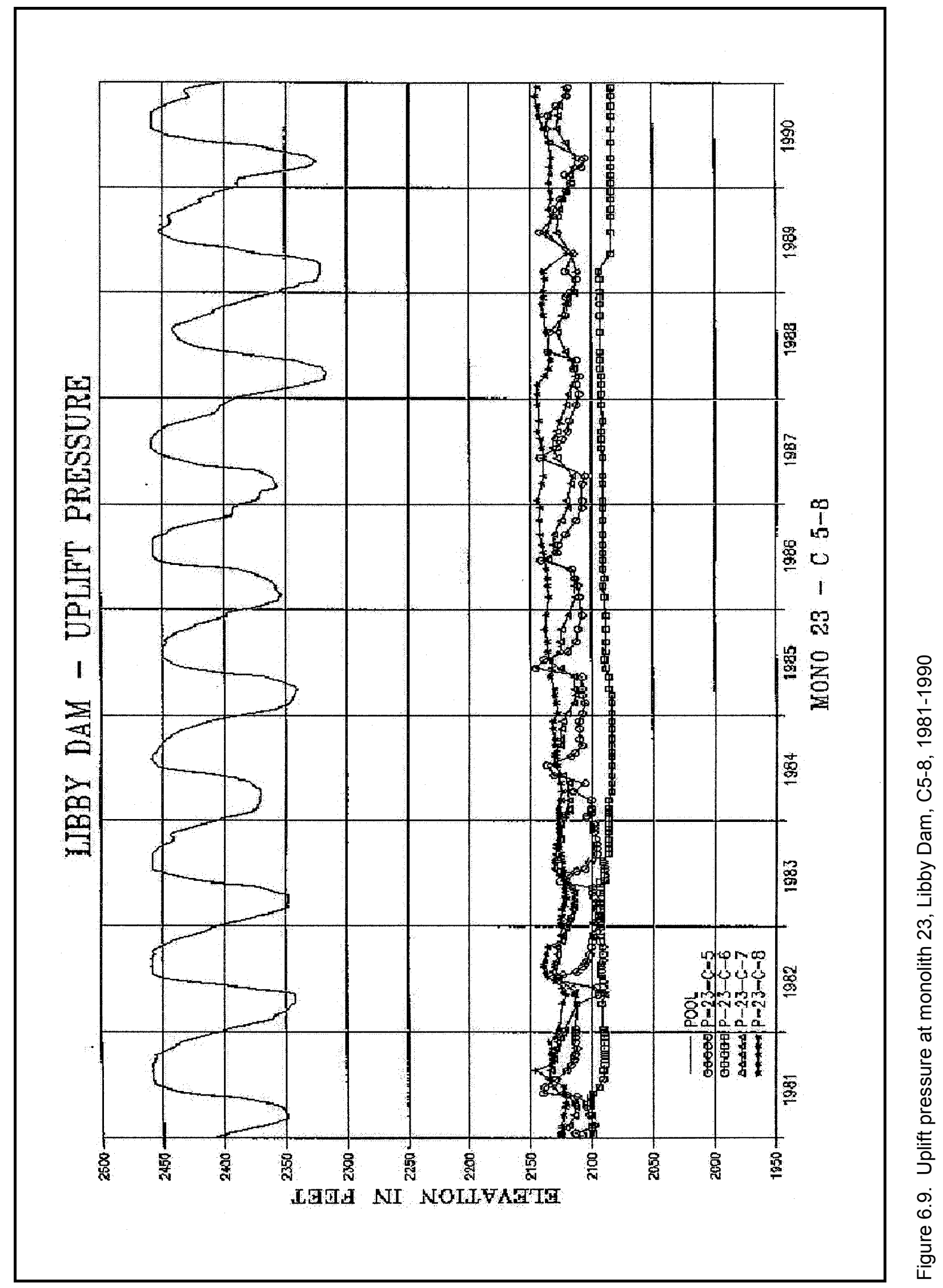




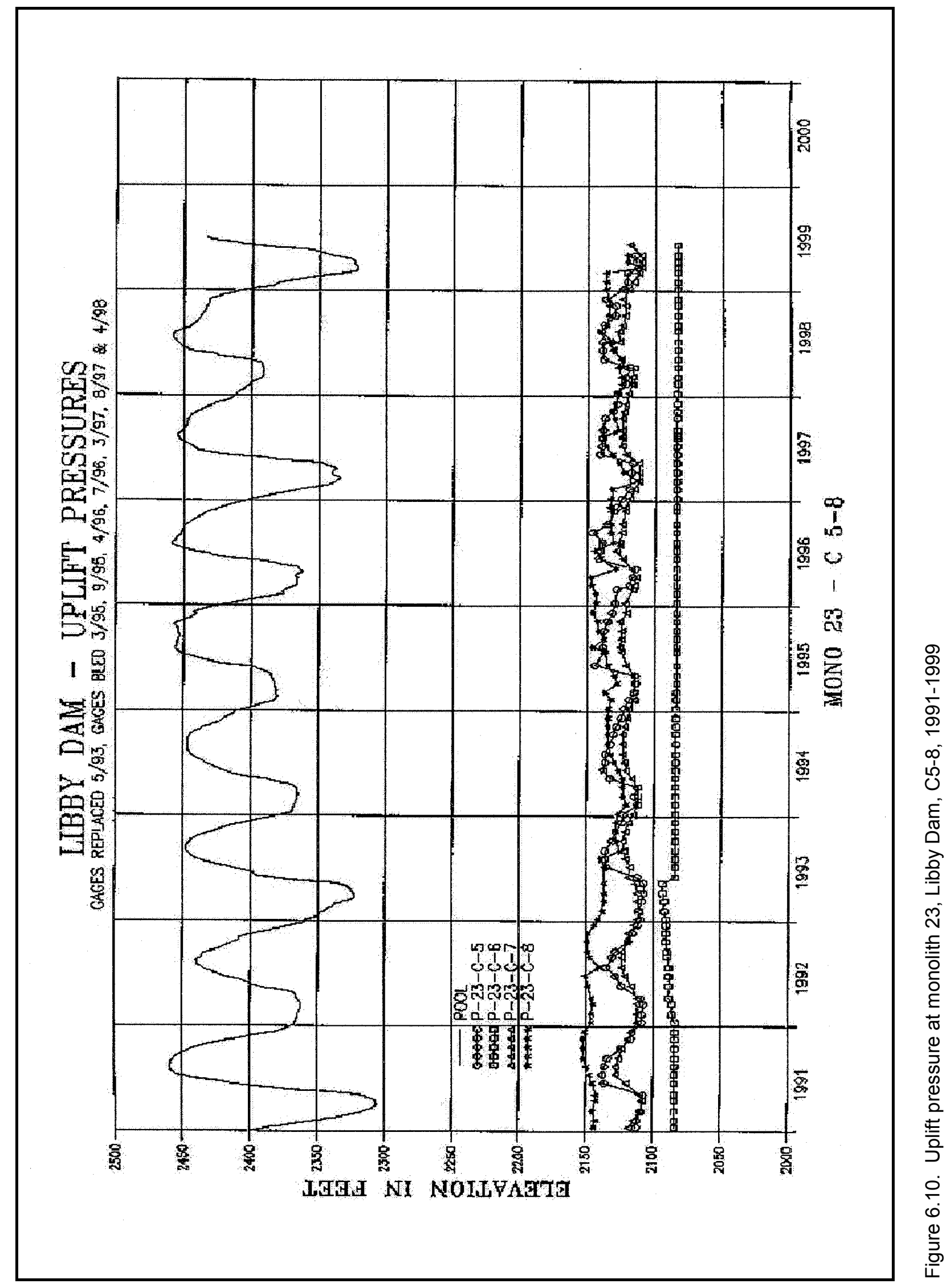




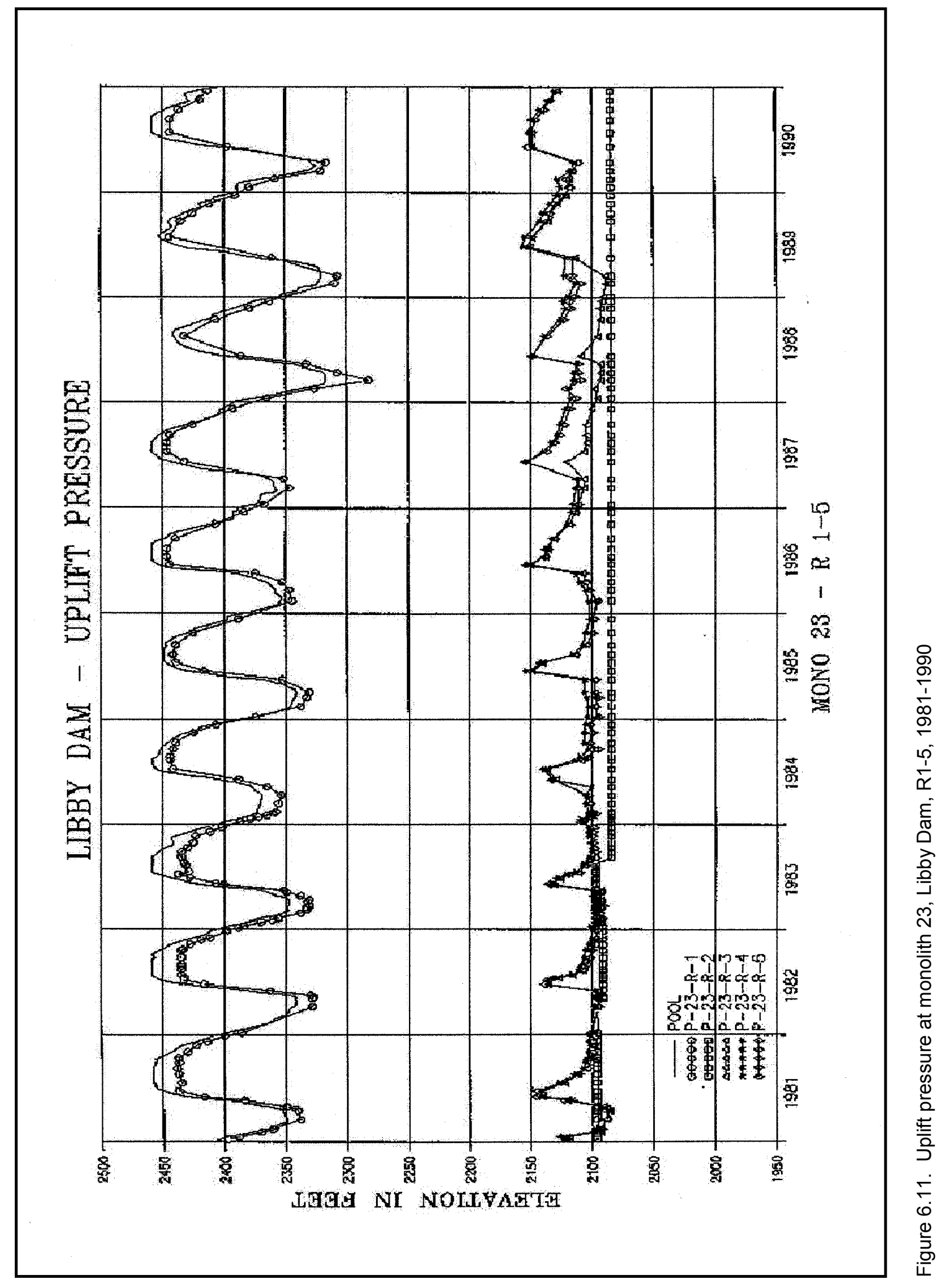




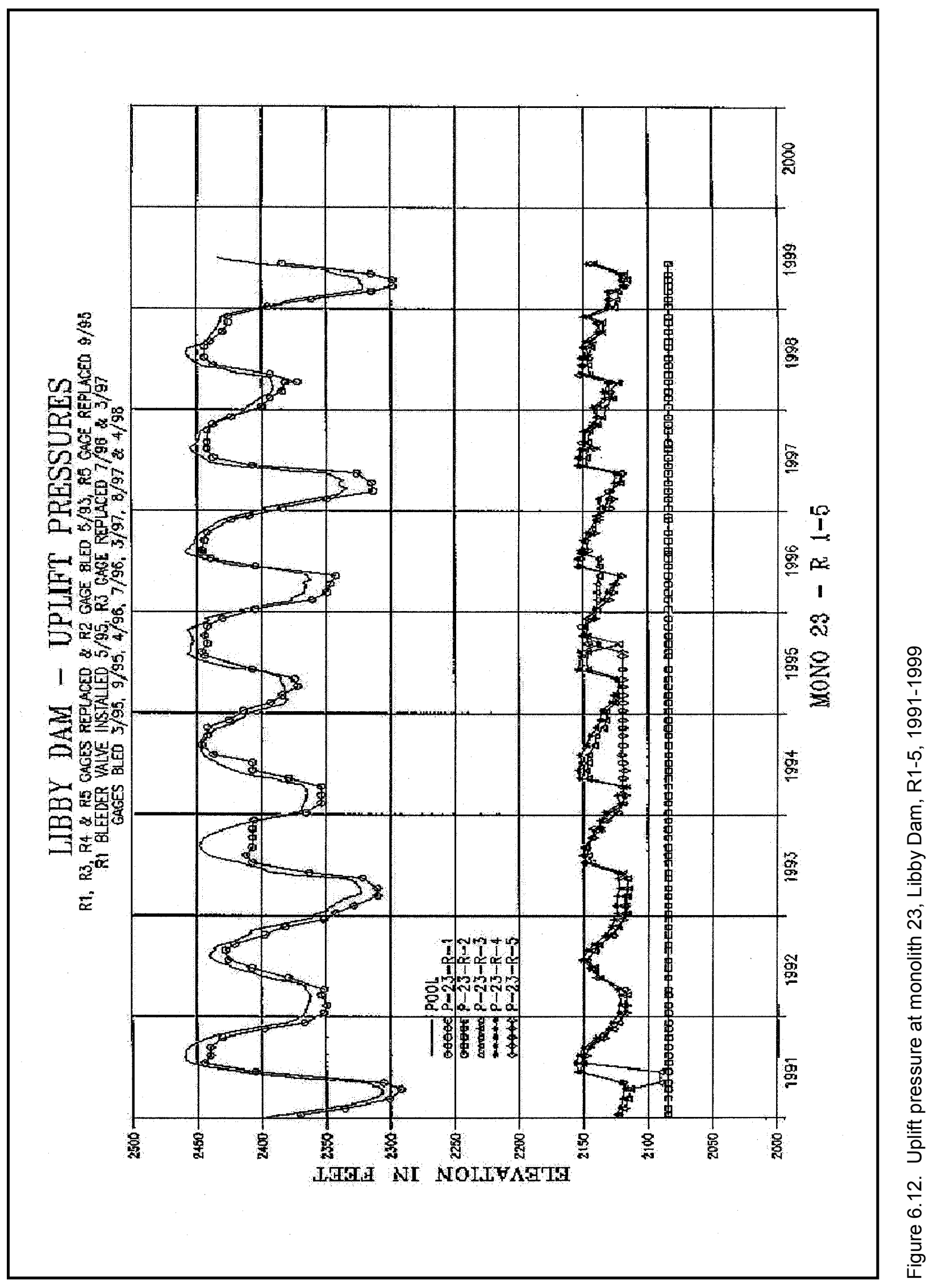


Gauges L1 through L5 were replaced in May 1993 and bled in March and September of 1995, in July 1996, in March and August 1997, and in April 1998. Gauge L1 was replaced twice, in March 1995 and in May 1995, when a bleeder was also installed.

Figures 6.5 through 6.12 are the time plots of the gauge readings in monolith 23 and forebay readings for 1981 through July 1999. During the period 1981 through 1989, of all L gauges, only L1 gauge readings matched changes in forebay elevations. Gauges L2, L3, L4, and L5 did not reflect the forebay fluctuation in any consistent manner. Beginning in year 1989, gauges L3 and L4 more nearly followed the trends of the forebay fluctuation. After mid-1990, gauges L1 and L4 closely matched the forebay elevation changes. Gauge L2 followed forebay changes correctly after year 1991, except for the time between 1992 and 1994.

Gauge L3 followed the trends of the forebay until the early part of 1995, becoming completely irregular afterwards. Gauge R1 showed close similarity in readings to the forebay fluctuation for the whole period of 1981-1999. Gauge R2 provided a zero reading, displaying a value for the elevation of the tip of the gauge. Gauges R3, R4, and R5 matched fluctuation of the forebay only in the rising pool phase of the forebay cycle, showing a rapid increase in readings during the first 9 years of the records. However, this portion of the yearly cycle was followed by an immediate rapid decrease of gauge readings although the forebay still maintained a high pool elevation. The readings became more regular after 1989 until 1994 when readings of gauge R5 became constant for 3 years. Since the summer of 1996, gauges R3 through R5 showed a good match between their readings and the forebay elevations.

Of all $\mathrm{C}$ gauges, only gauge $\mathrm{C} 1$ records matched forebay elevations during the period 1981-1984. Gauge C2 recorded zero pressures for the whole period 19811999. After 1985, gauge readings of C3 and C4 followed forebay fluctuations very closely. Gauge $\mathrm{C} 6$ gave zero reading for the entire available period of recording. Gauges C5, C7, and C8 behaved irregularly until the summer of 1985 . Gauge C8 remained irregular with some vague response to forebay fluctuation until 1999. Gauges C5 and C7 gave good readings between 1989 and the spring of 1993 when only C7 continued with reasonably good response to forebay fluctuation.

For further analysis, a set of plots for gauges L1, C1, and R1 were fitted for each yearly cycle between 1981 and 1999. The graphs consisted of recorded forebay elevation, in feet, plotted on the horizontal axis and respective gauge readings, in feet, plotted on the vertical axis. Every gauge reading of L1, C1, and R1 was plotted for a complete 1-year cycle, separately for each gauge. Each cycle represented an increasing and decreasing forebay water elevation. The resulting graph showed a very flat hysteretic curve.

Two representative years, based on time records in Figure 6.5, were selected to investigate changes in cyclic behavior in the selected time interval. The first complete yearly cycle occurred in 1990 (Figure 6.13). For comparison, a similar plot for year 1999 is included as Figure 6.14. An increase in forebay hydrostatic pressure was reflected in a proportionate increase in respective gauge-monitored 


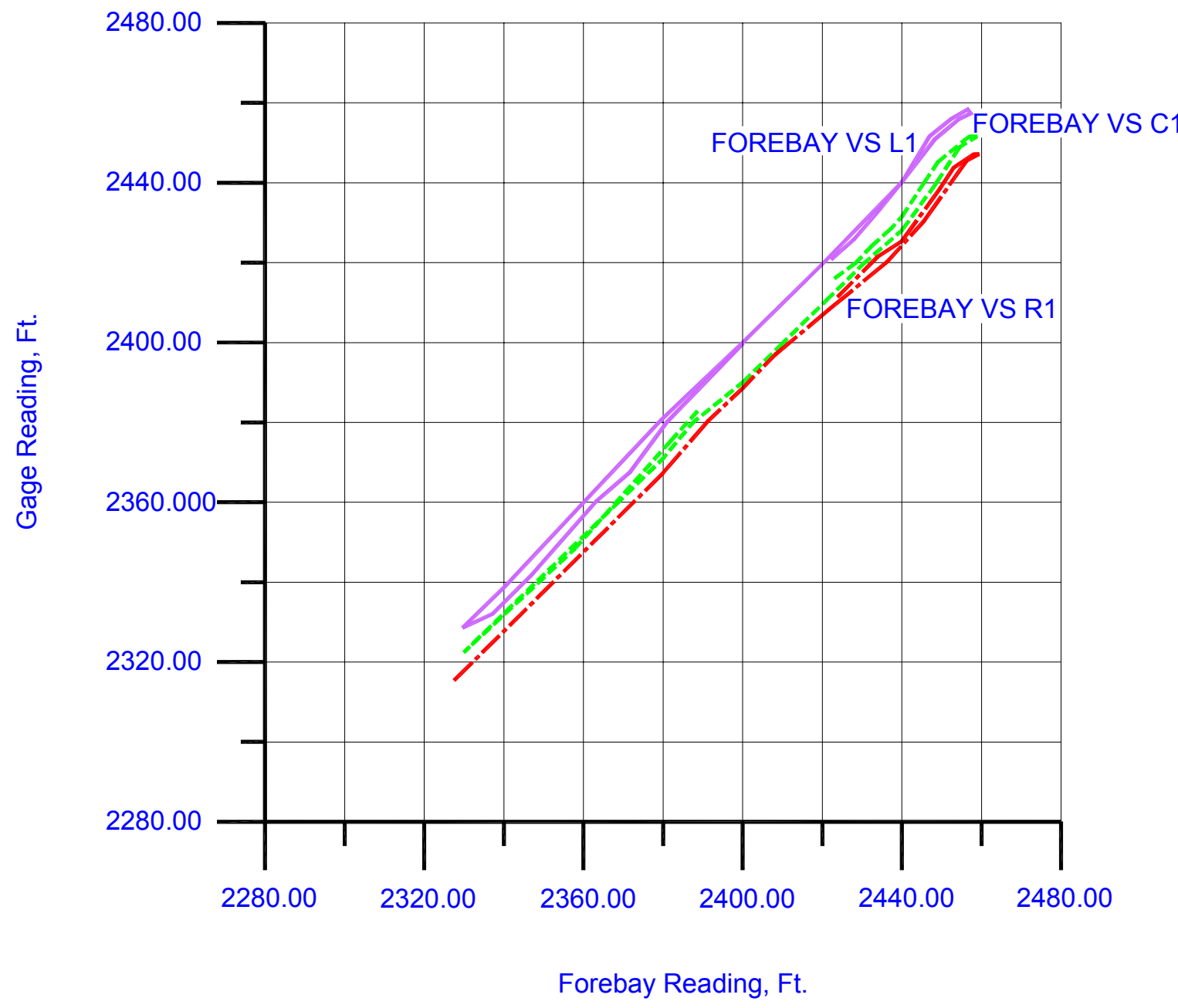

Figure 6.13. Uplift pressure at monolith 23, Libby Dam, for calendar year 1990

pressures. A decrease of the forebay hydrostatic pressure as a result of pool emptying was reflected in proportionately lower monitored gauge pressures on all three gauges, L1, C1, and R1. The rising portions of the curves plotted very close to the descending portion of the curve.

The second observation made from the plots in Figures 6.13 and 6.14 was with respect to the slopes of the obtained curves. The slope did not increase or decrease with the increased forebay pool level, but was constant. The third observation made in these two figures was that curves for respective plots of gauges L1, C1, and R1 were almost identical to plots for years 1990 and 1999.

The last observation made from Figures 6.13 and 6.14 was the mutual location of the plots for L1, C1, and R1. The plots for each of these gauges were not identical but were slightly offset and parallel. 


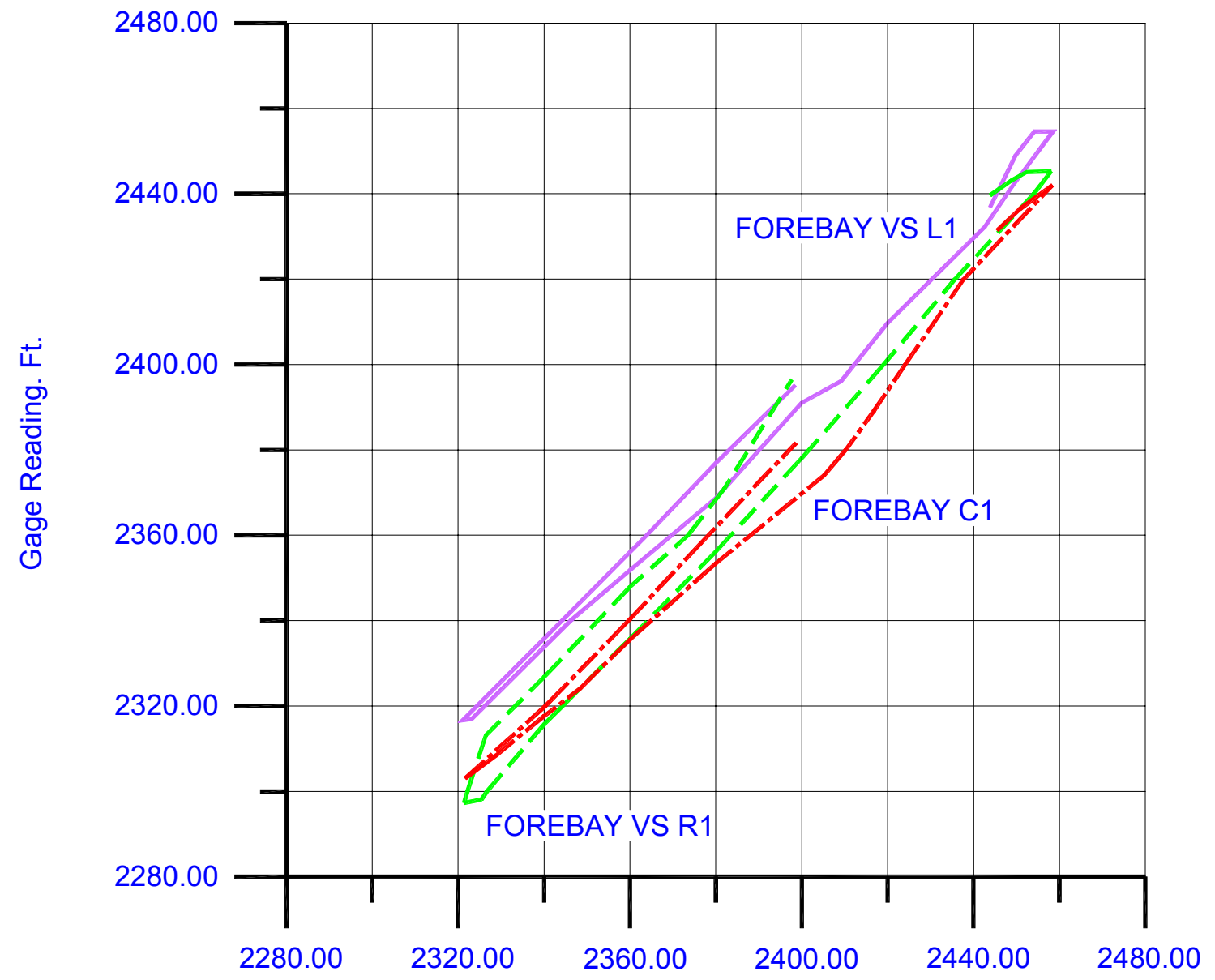

Forebay Reading, Ft.

Figure 6.14. Plot of dependence of $\mathrm{L} 1, \mathrm{C} 1$, and $\mathrm{R} 1$ (in $\mathrm{ft}$ ) on forebay elevation (ft), monolith 23, Libby Dam, for calendar year 1999

\subsection{Variation in Uplift Pressure Within the Foundation}

Figures 6.15 and 6.16 plot the distributions of the recorded uplift pressures across monolith 23. Year 1990 data are plotted in Figure 6.15 and year 1999 data are plotted for comparison in Figure 6.16. Only four selected readings were included in the plots: for maximum forebay pool, for minimum forebay pool, and for two intermediate stages of the forebay pool for both years. Gauges L1, C1, and $\mathrm{R} 1$, in the first row of the forebay, responded very closely to fluctuations of the forebay pool elevation in both years. Readings in the first row of gauges exceeded design uplift pressures in both years, 1990 and 1999. 


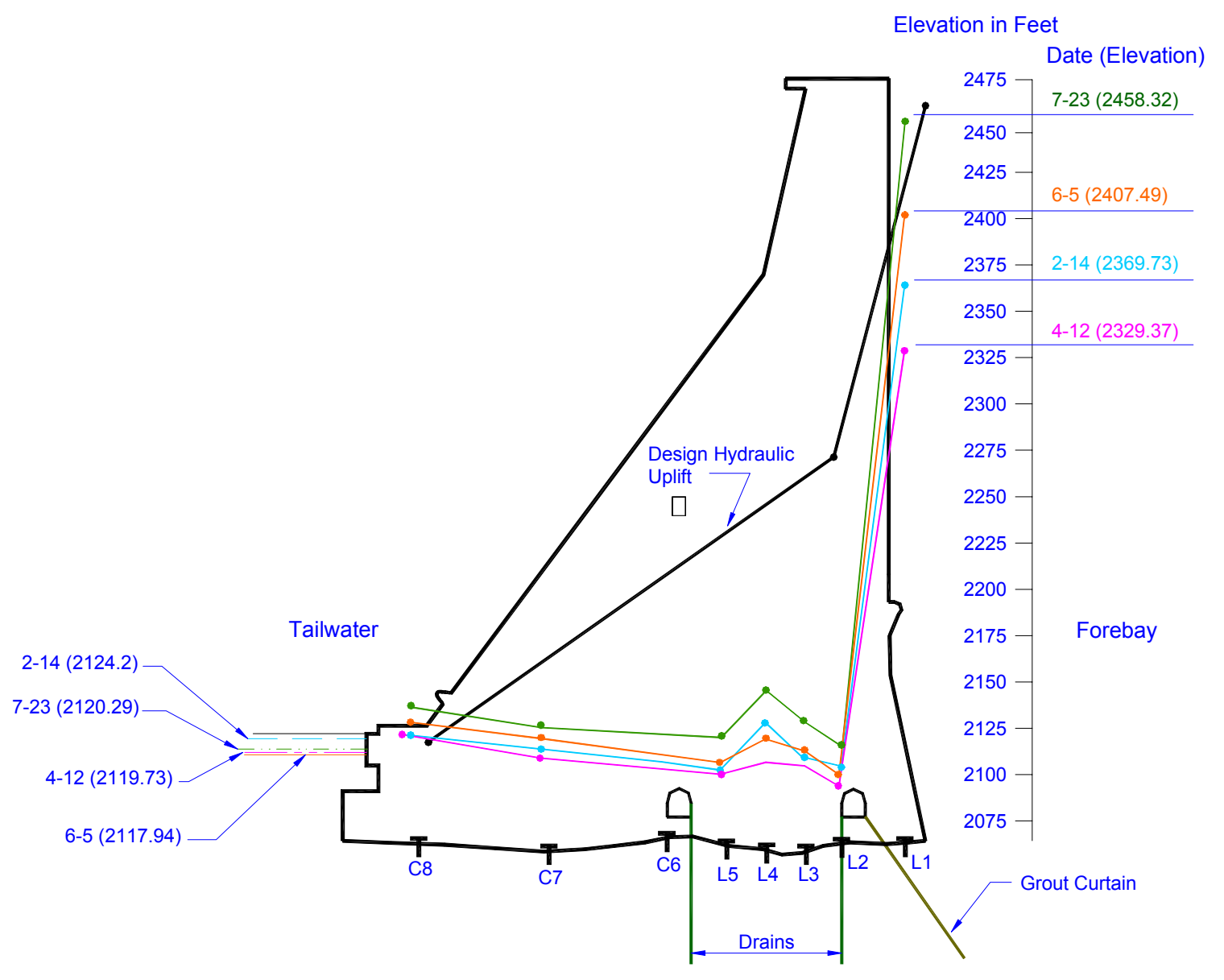

Figure 6.15. Recorded uplift pressures in 1990 versus design pressures, monolith 23, Libby Dam

Of the gauges in the second row, L2, C2, and R2, only gauge L2 recorded nonzero pressure readings. Gauge L2 readings are explained in the next section. Gauge C6 showed a zero reading for all dates.

The design uplift pressure (shown in Figures 6.15 and 6.16 as a solid line above the dotted lines) much exceeded the recorded gauge pressure. Uplift pressure at gauge L3 was lower than gauge L4, even though gauge L4 is farther from the forebay. Gauges $\mathrm{C} 7$ and $\mathrm{C} 8$ gave readings above the tailwater level, and the gauge $\mathrm{C} 8$ reading was higher than the reading for gauge $\mathrm{C} 7$. There is no significant difference in the uplift pressure profiles of Figure 6.15 and 6.16. There was no noticeable difference between data collected in 1990 and 1999 at the various gauges.

Table 6.1 sums the observation at individual gauges for 1990 and 1999.

The average pool elevation of the forebay was $5 \mathrm{ft}$ higher in 1990 than in 1999, explaining why all readings of gauges in 1999 were lower than those taken in 1990. As shown in Table 6.1, relative to forebay pool elevation, the gauge 


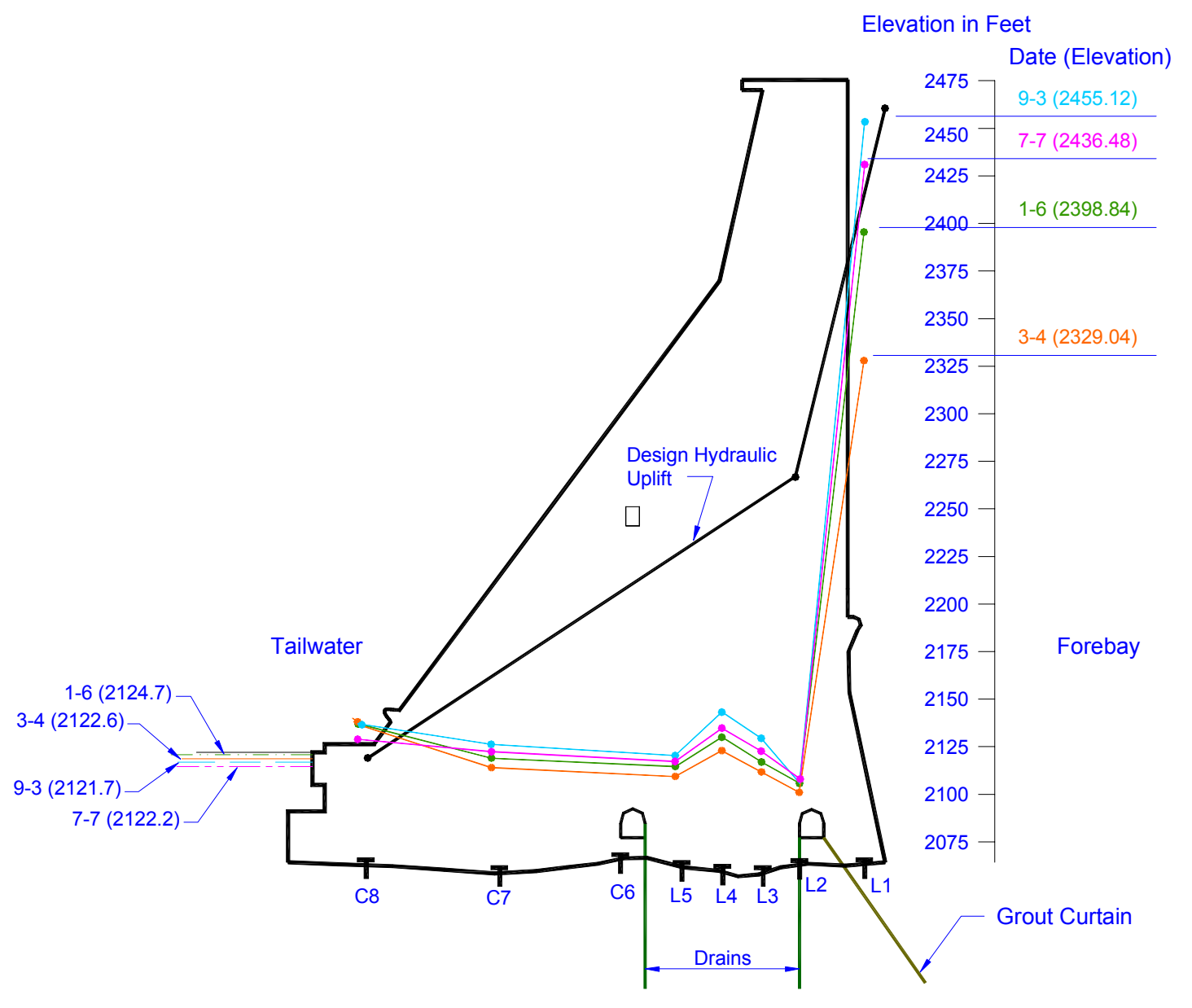

Figure 6.16. Recorded uplift pressures in 1999 versus design pressures, monolith 23, Libby Dam

readings are very stable in a span of 10 years. The most controlling effect is the location of gauges with respect to the grout curtain and to drains in the drainage and grout gallery. Gauge L1, like the other gauges in the first row (C1 and R1), is located between the forebay and grout curtain (Figures 6.15 and 6.16). The effect of the drains at this location is minimal. Gauge L2 coincides to a lesser extent with drains in the drainage and grout gallery, but is affected much less than gauges $\mathrm{C} 2$ and $\mathrm{R} 2$ in the same row and at the same distance from the dam axis.

Gauge L2 occasionally reads a positive (nonzero) value, but in the same row installed gauges R2 and C2 always yield zero readings. Gauge L2 may read nonzero data at peak to average pool forebay elevations. Readings in gauge L4 exceed those in gauges L3 and L5, since the latter are closer to drains on both sides than gauge L4 (Figures 6.15 and 6.16). Gauge C6 yields no meaningful data. Readings in gauge $\mathrm{C} 7$ farther from the forebay exceed readings from gauge L5, since gauge L5 is closer to the second row of the drains (at the drainage gallery). The readings on gauge $\mathrm{C} 8$ exceed the tailwater elevations. 


\begin{tabular}{|c|c|c|c|c|c|c|}
\hline \multicolumn{7}{|c|}{$\begin{array}{l}\text { Table } 6.1 \\
\text { Pressure Observations in } 1990 \text { and } 1999\end{array}$} \\
\hline Site & $\begin{array}{l}1990 \\
\text { Range } \\
\text { Reading } \\
\text { ft } \\
\end{array}$ & $\begin{array}{l}1990 \\
\text { Average } \\
\text { Reading } \\
\mathrm{ft} \\
\end{array}$ & $\begin{array}{l}\text { Percent } \\
\text { Forebay }\end{array}$ & $\begin{array}{l}1999 \\
\text { Range } \\
\text { Reading } \\
\mathrm{ft} \\
\end{array}$ & $\begin{array}{l}1999 \\
\text { Average } \\
\text { Reading } \\
\mathrm{ft}\end{array}$ & $\begin{array}{l}\text { Percent } \\
\text { Forebay }\end{array}$ \\
\hline Forebay & $2,329-2,459$ & 2,394 & 100 & $2,321-2,458$ & 2,389 & 100 \\
\hline L1 & $2,328-2,458$ & 2,393 & 99 & $2,320-2,458$ & 2,387 & 99 \\
\hline L2 & $2,095-2,118$ & 2,106 & 88 & $2,096-2,112$ & 2,104 & 88 \\
\hline L3 & $2,109-2,130$ & 2,120 & 89 & $2,109-2,128$ & 2,118 & 89 \\
\hline L4 & $2,105-2,142$ & 2,124 & 89 & $2,107-2,144$ & 2,126 & 89 \\
\hline L5 & $2,099-2,120$ & 2,110 & 88 & $2,098-2,116$ & 2,107 & 88 \\
\hline $\mathrm{C} 7$ & 0 & 0 & 0 & 0 & 0 & 0 \\
\hline $\mathrm{C} 7$ & $2,112-2,128$ & 2,120 & 89 & $2,110-2,127$ & 2,118 & 89 \\
\hline $\mathrm{C} 8$ & $2,132-2,146$ & 2,139 & 89 & $2,111-2,137$ & 2,124 & 89 \\
\hline Tailwater & $2,118-2,125$ & 2,122 & 89 & $2,118-2,125$ & 2,122 & 89 \\
\hline
\end{tabular}

\subsection{Significance of Uplift Variations}

A comparison of Figures 6.13 and 6.14, representing the relationship between forebay pool elevations and gauge readings (in $\mathrm{ft}$ ), for $\mathrm{L} 1, \mathrm{C} 1$, and $\mathrm{R} 1$, suggests that no significant changes in readings of these gauges took place between 1990 and 1999. The almost identical slope of the hysteretic curves in both plots suggests that increased forebay elevation causing higher hydrostatic pressure in front of the dam does not cause accelerated increase of the uplift pressure. The pressure recorded at higher forebay readings is proportional to the pressure at lower forebay readings. There is no downward shift in the curve location in the graph between 1990 and 1999. This supports the assumption that the gauges are fully functioning.

Gauge L1 (Figures 6.13 and 6.14, purple) recorded higher readings than gauge $\mathrm{C} 1$ (green), which recorded slightly higher readings than gauge R1 (red). The difference is not substantial and can be explained by the particular location of each of these three gauges with respect to the location of drains. The spacing of the drains at the foundation/rock interface is not exactly the same as the spacing of the gauges, resulting in a different collective effect of the drains on each of the front row gauges.

There are three curves in each of Figures 6.13 and 6.14. They are similarly shaped, and the loading side and unloading side of the hysteresis (forebay rising and forebay lowering) of the gauge responses are very similar, or almost parallel. This fact suggests that the gauge reading is, for all practical purposes, independent of the direction of pressure increment. The underground flow is not accelerated out of proportion when the forebay pool peaks.

Figures 6.15 and 6.16 provide a comparison of the design uplift pressure and recorded uplift pressures in a cross section of the dam in years 1990 and 1999. 
The figures show that expected uplift pressure was significantly overestimated at the time of design on all gauges L2 through $\mathrm{C} 8$. Because of its position near the line of drain holes, gauge L2 might be expected to reflect just the elevation head (i.e., to reflect full drainage). Figures 6.17 and 6.18 help explain why gauge L2 shows a pressure higher than elevation head. The right side of Figure 6.17 is a cross section through the first row of drain holes, which are shown as black lines angled from the vertical. Gauge L2 is in a vertical hole the base of which is offset from the angled drain hole. At the position of the gauge, the arching of the piezometric surface between drain holes (projected along the red line in Figure 6.17) causes the gauge to read a positive pressure in addition to the elevation head. A three-dimensional diagram in Figure 6.18 provides another perspective on the shape of the piezometric surface around the drains. The idealized surface in Figure 6.18 assumes that the foundation is relatively homogeneous and that the spacing and apertures of rock discontinuities are uniform throughout the monolith foundation.

The grouting curtain and drains in both galleries were perhaps much more effective than expected. The uplift pressures recorded on gauges between drains correctly peak at gauge L4, located in the middle between drains. This further supports the explanation given in Figures 6.17 and 6.18 in the case of gauge L2.

Recorded uplift pressures on gauge C8 indicate that the uplift pressure at the tailwater exceeds the hydrostatic pressure of the tailwater for higher stages of the tailwater.

\subsection{Summary}

Monolith 23 of Libby Dam has a total of 18 pressure gauges that are in good condition and that are supplying and have supplied useful readings over the dam's 20 -year monitoring history. The Seattle District was able to furnish the authors a complete set of data containing uplift pressure gauge readings, recorded forebay elevations, volume discharge, and recorded tailwater elevations. These data permitted a thorough evaluation of the response of the foundation to reservoir level fluctuations and to changes in response with time.

Responses of installed uplift pressure gauges in monolith 23 of Libby Dam were linear for the monitoring period 1990 to 1999. Linear response is an indication that gauge readings are independent of the direction of pressure change. Linear response also implies that foundation discontinuities have a sufficiently high aperture that reservoir loading and unloading do not significantly affect flow through them. 


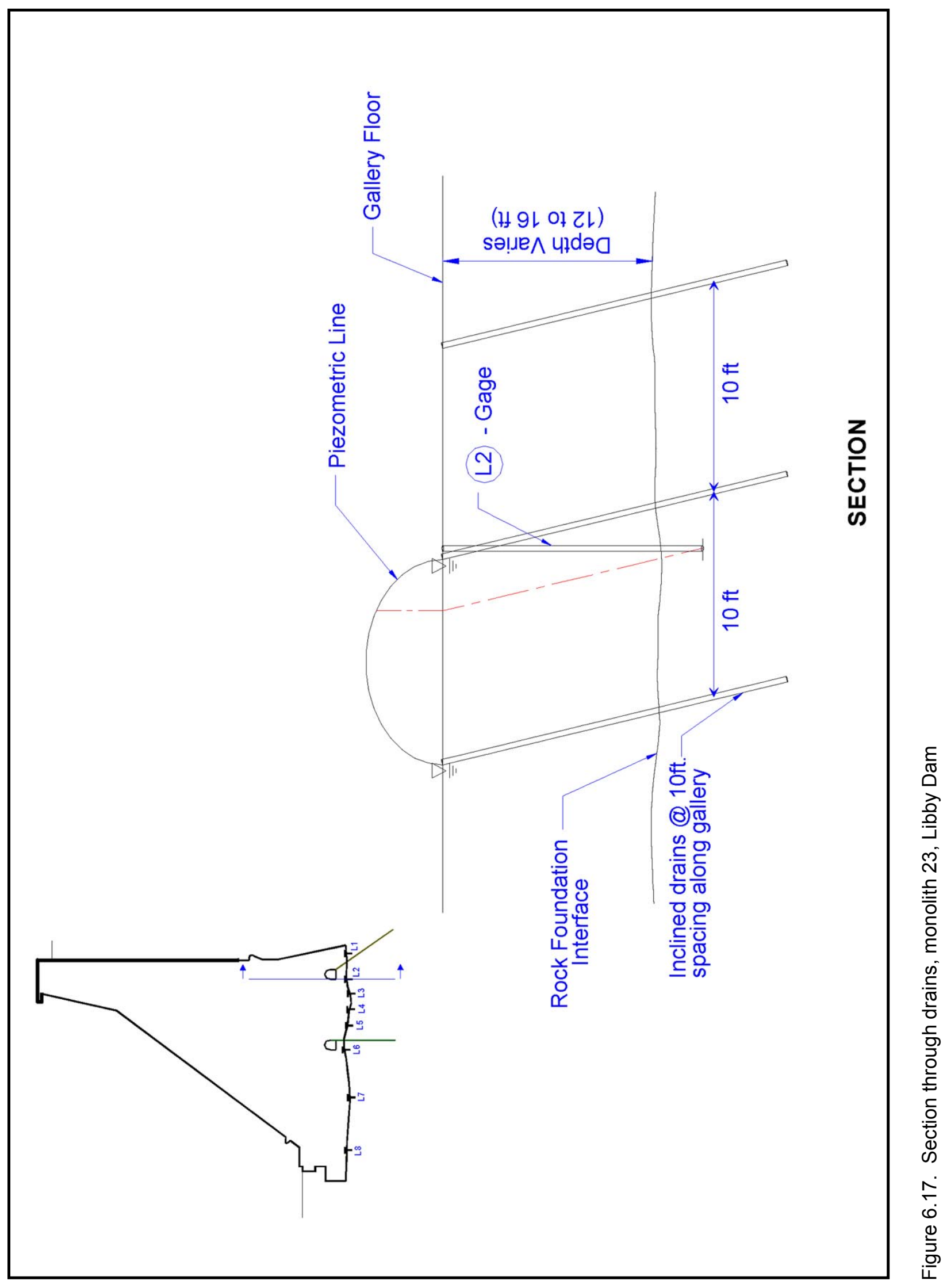




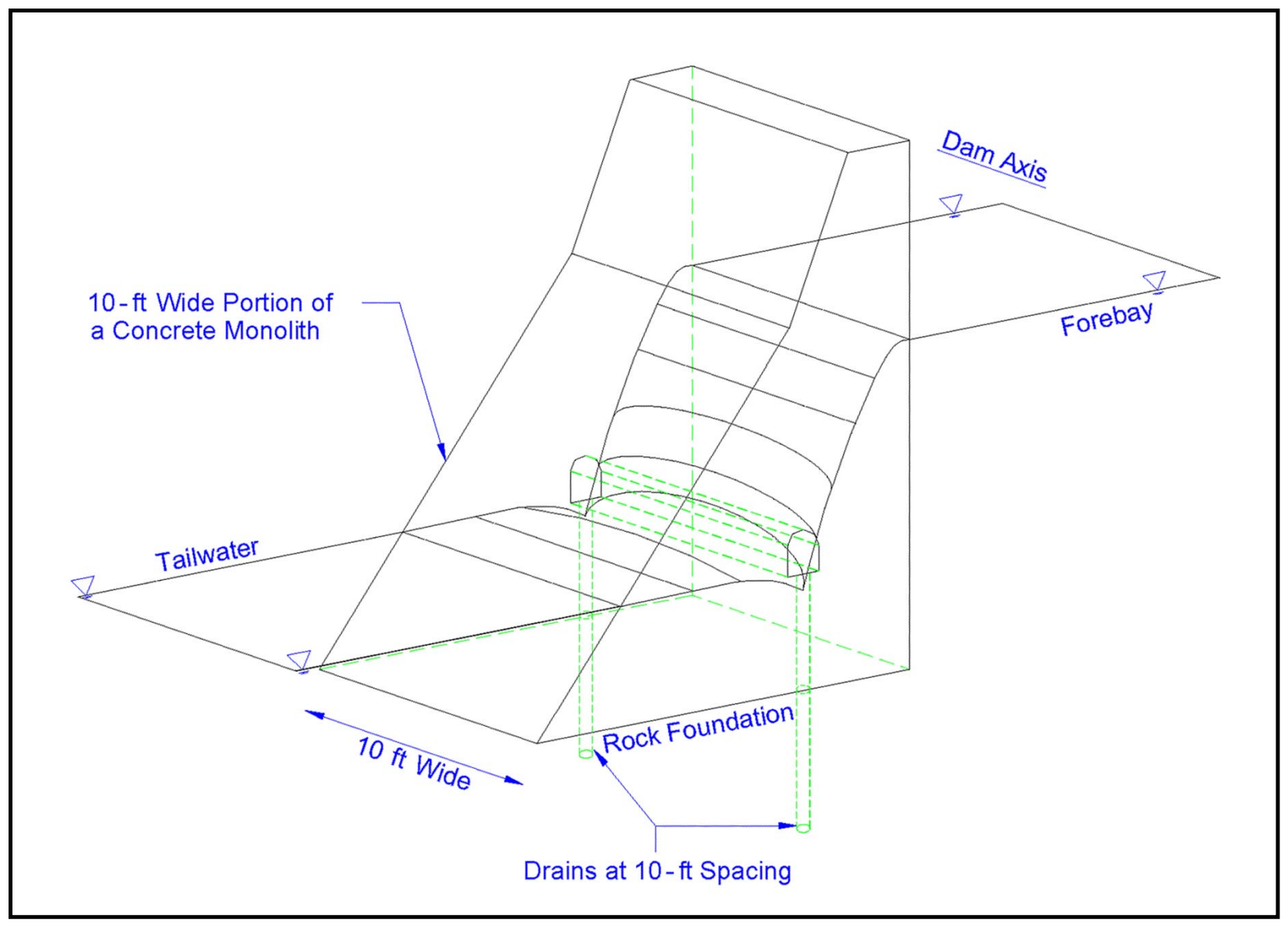

Figure 6.18. Effect of drains on piezometric surface (idealized) 


\section{Conclusions and Recommendations}

\subsection{Conclusions}

Uplift is a major force affecting the stability of rock-founded concrete dams. The flow regime within a rock foundation controls uplift pressures. Both the geological interpretation and the analytical procedures used to calculate flow within the foundation produce uncertainty in the calculation and prediction of uplift pressures. Uncertainty in modeling uplift pressure manifests itself in three areas: geologic uncertainty, material uncertainty, and spatial uncertainty.

\subsubsection{Geologic uncertainty}

Geologic uncertainty arises in mapping and describing the stratigraphy, geologic structure, and degree of weathering that characterize a foundation. Questions to be asked when gathering geologic information at the dam site include the following:

a. Does the stratigraphy cause rock properties to vary within the foundation?

b. Are the stratigraphic sequence of rock units and their corresponding hydraulic properties adequately described?

c. How does weathering affect the hydraulic conductivity throughout the foundation? Careful planning and execution of site investigation address these issues. The engineering geologist should have a preconceived idea, a conceptual model, of what the site geology is before beginning site investigation. The conceptual model is then continuously updated as new information becomes available. In this way, investigators know where data are lacking and can take steps to fill in where needed to describe adequately the foundation rock mass.

d. Have all joint sets been adequately described and sampled? Has bias in drill hole alignment failed to sample a particular orientation? Vertical boreholes, for example, fail to intercept most joints of a vertical joint set. Alignment of exploration borings should be adjusted to ensure that all sets are sampled. 


\subsubsection{Material uncertainty}

Material uncertainty pertains primarily to estimates of the hydraulic conductivity of the rock mass. These are mostly field-test uncertainties from data scatter in measurements caused by natural variations in material properties and in problems with test precision. Thoroughness of site investigation is another source of material uncertainty, for example:

a. Is the engineering geologist sure that the rock itself does not account for significant flow in addition to flow through rock discontinuities? That is, is rock primary porosity (intergranular porosity) contributing to flow? This is one area where laboratory permeability tests on core samples would be useful in quantifying rock hydraulic conductivity as distinguished from rock mass conductivity through discontinuities.

b. Has site investigation isolated or detected the major flow conduits or flow zones in the rock mass? Have major joint sets or areas of enlarged openings such as karst solution passages been identified and characterized? In other words, is the field investigation thorough? Preparing a conceptual model of site geology with emphasis on locations of groundwater flow paths and quantities of flow helps assure that field investigations are adequately designed. Structural and stratigraphic cross sections showing hydraulic characteristics of mapped geologic units should be prepared and continuously modified as field investigations proceed.

Field measurements of groundwater properties must address several issues:

a. Are assumptions of flow theory met? Is there laminar, radial, and symmetric flow to the borehole in borehole aquifer tests? Is the rock mass sufficiently homogenous and isotropic to warrant the use of Darcy's law in computing aquifer properties? Do boundary conditions, such as the presence of impermeable barriers to flow, exist that would alter the shape of the drawdown curve in a pumping test? These issues should be addressed to determine their impact on numeric estimates of hydraulic conductivity, joint aperture, and other uplift modeling parameters.

b. Are field procedures of aquifer testing consistent, and are measurements of pressure and flow accurate? Personnel conducting field tests in boreholes should exercise quality control in test procedures to ensure that tests are conducted in the same way in every borehole and that measures taken to maintain accuracy of test results are followed consistently. Personnel should test flow gauges and pressure monitoring devices periodically as part of quality control.

c. Do pressure or aquifer test packers leak, and are piezometers or pressure gauges working properly? Packer pressures should be monitored for leakage during pressure testing. Piezometers should be tested periodically to eliminate these kinds of data errors as a source of uncertainty.

d. In pressure testing, has hydrofracturing been prevented? Water injected at pressures exceeding overburden pressure may widen or open existing discontinuities and produce artificially high flows or turbulent flow 
during pressure testing. Subsequently calculated values of hydraulic discontinuity and joint aperture will be in error. Personnel should limit injection pressures to about 0.5 psi per foot of depth for test zones below the water table and 1 psi per foot of depth for tests above the water table.

e. How valid is the reduction of zone hydraulic conductivity $\left(K_{e}\right)$ to specific joint hydraulic conductivity $\left(K_{j}\right)$ and derived values of conducting aperture, $e$, in pressure tests? How reliable are the pressure test data; i.e., is there enough redundancy in the tests to measure statistical variation as a source of uncertainty? These issues might best be addressed in the design and execution of field pressure tests. Tests should be designed with sufficient redundancy to measure the variation in measured quantities in a given test interval or for a specific joint being tested. Joint hydraulic conductivities and conducting apertures derived from pressure tests on packer-isolated rock mass zones can be compared with field or laboratory tests on individual joints to determine the degree of discrepancy in calculated and measured values.

\subsubsection{Spatial uncertainty}

Spatial uncertainty is represented in the ways properties vary throughout the foundation. Measurements of material properties and geometries of geologic features are made at point or line sources (boreholes), in narrow drifts, or along rock exposure faces. These observations are then extrapolated beyond the sampling point or interpolated between two or more sampling points and applied to the entire foundation rock mass, with accompanying uncertainty. The number of measuring and sampling points should be adjusted for site complexity to accommodate the amount of variation expected as a result of stratigraphy, geologic structure (folding, jointing, and faulting), and the effects of differential weathering.

The characteristics of rock mass discontinuities can be spatially variable. Issues include the following:

a. Do joints persist; i.e., is there a high or low degree of "connectivity" or persistence of joints across the dam base, particularly from the reservoir to the tailwater?

b. Do joint conditions change with distance? These questions might be addressed with careful and complete core logging of boreholes for discontinuities and zones of discontinuities. Careful core logging and complementary observations of the borehole itself using borehole camera techniques may permit correlation of specific discontinuities or jointed intervals between boreholes. Well-planned rock mass pressure tests of specific joints or jointed intervals between adjacent boreholes, for example, in existing drainage galleries of the dam might provide information on which joints or zones persist through the foundation.

There is also a temporal uncertainty inherent in dam foundation properties. Joint conditions may vary with time because of changes in joint aperture caused by stresses of loading and unloading by the reservoir, and by filling in or washing out of materials between the joint walls. Temporal uncertainty is difficult to 
address because it is usually not practical to bore and sample the foundation after dam construction. Conducting pressure testing in existing drainage galleries or other open borings may be one way to determine if joint hydraulic properties have changed. Observation of joint conditions within the boreholes using borehole imaging devices is another potential method to monitor changes in rock mass discontinuities.

\subsection{Recommendations}

\subsubsection{Geologic data for uplift modeling}

The authors recommend a four-step approach to addressing issues of geologic uncertainty in modeling of uplift pressures in rock foundations. The emphasis is on ascertaining hydraulic properties and the condition of rock mass discontinuities as they control distribution of flow and uplift pressures within the foundation. Figure 7.1 illustrates the four steps in the assessment process, explained in the following paragraphs.

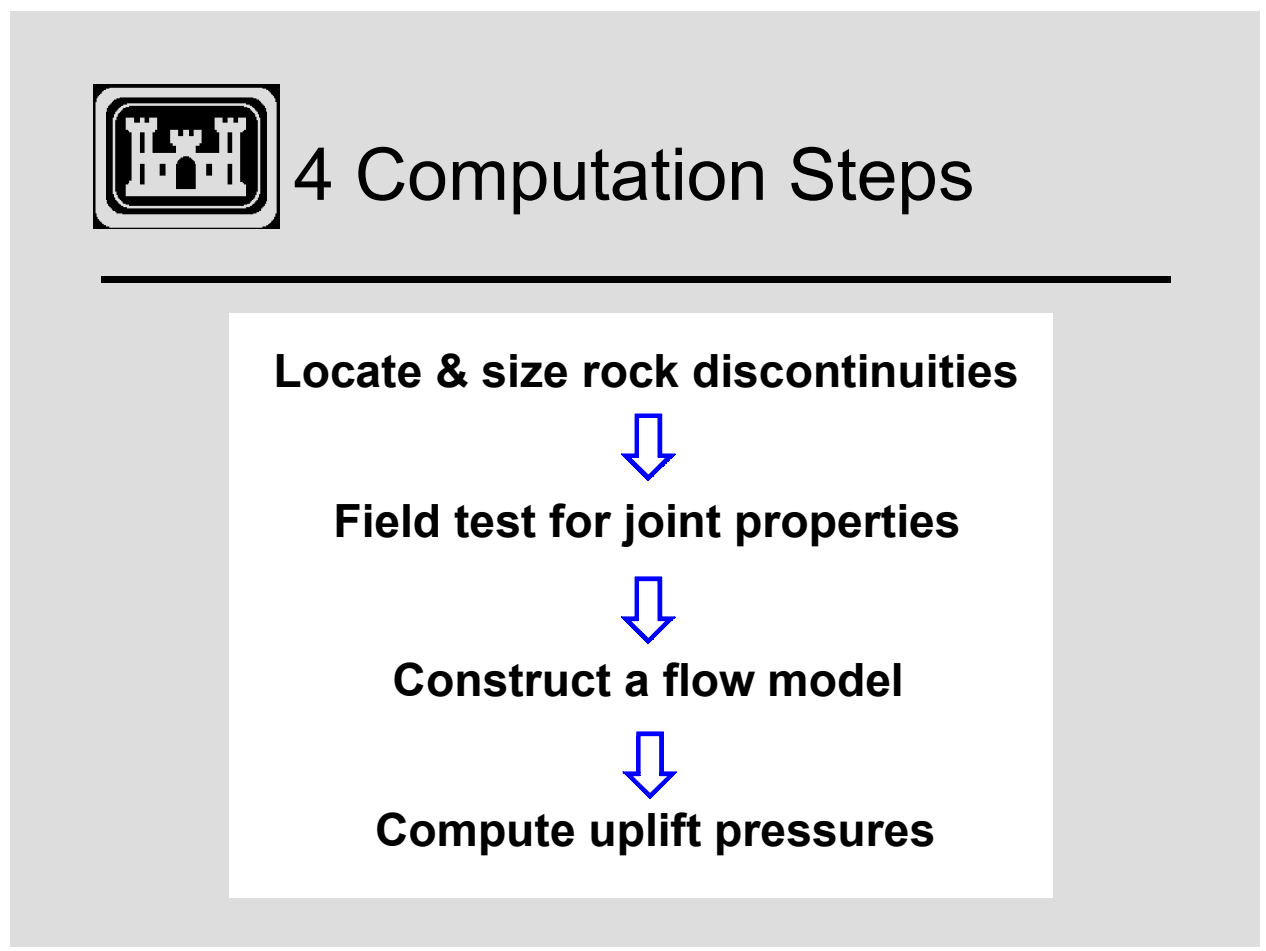

Figure 7.1. Recommended four-step approach to modeling of uplift pressures in rock foundations

The first step is to locate and describe rock discontinuities. The joint system, including bedding plane discontinuities, should be mapped and numbers and orientations of joint sets determined. Tight joints, i.e., joints with mechanical apertures less than about $250 \mu \mathrm{m}$, may cause nonlinear pressure conditions in the foundation. Tight joints are more likely to deform sufficiently under reservoir loading to profoundly affect joint hydraulic conductivity and to produce a 
nonlinear distribution of pressure from heel to toe because of closing of the joints at the toe. Numerical modeling must address the issue of whether linear or nonlinear conditions exist. Predominant joint apertures should be determined through borehole measurements of joint apertures, for example, using borehole-imaging devices, or through measurements of JRC and conducting aperture.

Joint condition (filling, degree of weathering, roughness) should be described using similar borehole measurement methods. A conceptual model, with a representative geologic cross section through the foundation, should be developed to reduce site geology to a workable degree of complexity for numerical modeling. For example, critical zones of discontinuities or specific discontinuities, changes in lithology or stratigraphy that might affect flow or distribution of pressure, and areas of weathered rock should be included in the section to define the conceptual model.

This report documented an exercise in estimating joint hydraulic properties $\left(K_{j}, e\right.$, and $\left.E\right)$ from pre-existing data from pressure tests conducted routinely during the foundation exploration phase of the construction of Libby Dam. While results from this exercise were promising (reasonable values that agreed with published data for other dams), they could be greatly augmented with carefully planned and executed follow-up field tests in the foundation. The next step in the four-step approach addresses this issue.

The second step in addressing uplift modeling uncertainties is to conduct field pressure tests and borehole observation at a rock-founded damsite. The objective of this exercise on a Corps of Engineers dam would be to perform additional field testing to develop in sufficient detail an assessment of the rock discontinuity regime and the parameters needed to perform a site-specific uplift evaluation. In addition, the uncertainty in the parameters would be assessed. Tests should be designed to determine the hydraulic conductivity, persistence, and conducting apertures of specific discontinuities or zones of discontinuities. Testing of this kind has been conducted at Bluestone Dam (FMSM 2000). Ideally, hydraulic straddle packers would be used to isolate a specific joint in two or more existing boreholes in the foundation. Libby Dam presents a unique opportunity to investigate joint persistence and flow properties because its foundation is equipped with two rows of drainage holes, as discussed in Chapter 6 of this report. Individual drain holes are $10 \mathrm{ft}$ apart, parallel to the dam axis, in each row, and the two rows are $100 \mathrm{ft}$ apart perpendicular to the axis. The goal of such field tests would be to develop and refine techniques for extracting flow properties from existing dams that require uplift prediction.

In tests within a single drain row, pressure tests could be conducted between two or more adjacent boreholes to determine the hydraulic conductivity and conducting aperture of specific joints or group of joints within the boreholes. Because the boreholes are only $10 \mathrm{ft}$ apart, there is a high likelihood that the same joint could be identified in each hole. A pair of straddle packers in a central hole would isolate a joint and serve as the injection boring. Pressures in the adjacent hole or holes would be monitored during the pressure test to determine the pressure drop and define the boundary condition of the test. Flow rate and injection pressure would be measured in the central hole. Equations similar to those discussed in 
Chapters 2 and 5 of this report would be applied (adjusted for specific test boundary conditions) to extract values of $K_{e}, K_{j}, e$, and $E$. These numbers can be applied directly to numeric modeling of uplift pressures. By working with a small test area or volume, redundant tests can be used to isolate problems with test procedures and to define the natural variation inherent in test results. Redundancy is necessary to obtain enough test data for statistical analysis of variations in test results that are not caused by material (rock mass, groundwater) variations.

In tests between two rows of drain holes (at Libby Dam), separated by a distance of $100 \mathrm{ft}$ in a direction parallel to flow, the desired result would be a determination of joint persistence. That is, how far does a single joint or set of joints maintain flow through the dam foundation. Pressure tests between two boreholes in different drain rows might reveal where hydraulic connectivity exists between joints or groups of joints isolated by packers. If it is possible to isolate multiple zones with more than one set of straddle packers in a borehole, pressure or flow could be monitored in the downstream line of drains while a selected zone is pressurized in the upstream line. There would be a better chance of detecting flow, and persistence, between lines with multiple monitoring zones than simply trying to correlate a specific joint or jointed interval over the $100-\mathrm{ft}$ distance separating the two rows of drains.

Supplementary data that would complement data from the pressure tests would come from careful borehole imaging logging of the existing open drain holes in the foundation. Selected drain holes would be logged using a highresolution borehole camera or other imaging device that permits measuring of joint aperture on the borehole wall and observation of joint condition. Correlation between boreholes of features in the borehole image log would be critical to selecting test intervals for straddle packer pressure tests.

An interesting procedure performed in the Bluestone Dam data test program consisted of laboratory hydraulic conductivity tests on core samples containing a single joint. A small-diameter hole was drilled in the center of the core sample from the top surface to just below the joint to be tested. The core sample was placed in a permeameter device equipped with a loading platen for varying the normal stress applied to the joint. The annulus surrounding the core in the chamber permitted water to be injected into the joint under pressure. The injection pressure and flow outside the joint and the pressure at the exit within the smalldiameter center hole were measured during the test to allow computation of the joint aperture and hydraulic conductivity. This test provided a direct measurement of conducting aperture of a specific joint at different normal stress levels. This procedure, of course, requires a core taken from intervals of jointed rock. Coring is not recommended for proposed field tests at Libby Dam. However, if suitable core samples of rock near the lines of drain holes are available from the original foundation investigation drilling, laboratory joint pressure tests could be performed on selected joints for comparison of joint characteristics calculated from field tests.

The third step in modeling of uplift pressure distribution and uncertainty is to construct the numeric flow model to conform to the restrictions imposed by the field data and the geologic conceptual model. 
The fourth step is to run the model and compute uplift pressures.

\subsubsection{Additional research exercise for existing dams}

Chapter 4 of this report documented a review of existing Corps dams for assessment of quality of data applicable to research in uplift prediction and modeling. Libby Dam was selected for case history investigation because of the good quality of instrumentation and geologic data available. An exercise was conducted in Chapter 5 to extract hydraulic data from Libby Dam's foundation investigation records. Chapter 4 reported that Green Peter Dam had only limited instrumentation data, but substantial geologic information on stratigraphy, geologic structure, and discontinuities. Green Peter offers an example of a concrete dam founded on a complex assemblage of jointed, faulted, and sheared interbedded volcanic rocks. A rigorous surface and subsurface foundation mapping and investigation program provided detailed and comprehensive information about the geology and engineering characteristics of the foundation rock mass. Core logging of foundation borings was detailed and stressed attention to the numbers, locations, and characteristics of discontinuities in the rock mass. While no data on foundation pressure testing were provided in the foundation report, pressure testing apparently was performed as part of the foundation grouting, drainage, exploration, and instrumentation program.

The authors recommend that a case history exercise similar to that described for Libby Dam in Chapter 5 of this report be conducted for Green Peter Dam. The goal is to construct a conceptual geologic/hydrologic cross-section transverse to the dam axis beneath a monolith selected to provide the best data for a potential uplift numeric model. Any available pressure test data would be used to derive joint aperture and hydraulic conductivity values, in a manner similar to the exercise for Libby Dam. The development of another case history, which requires careful scrutiny of available foundation data, would reinforce or improve conclusions drawn from the Libby Dam exercise concerning the kinds and degree of geologic uncertainty in uplift modeling and prediction. 


\section{References}

Bandis, S. C. (1980). "Experimental studies of scale effects on shear strength and deformation of rock joints," Ph.D. diss., University of Leeds, Department of Earth Sciences.

Banks, D. C. (1977). "Borehole photography analysis, Teton Dam," Letter Report, U.S. Army Engineer Waterways Experiment Station, Vicksburg, MS.

Barton, N. (1973). "Review of a new shear strength criterion for rock joints," Engineering Geology 7, 287-332.

. (1982). "Modelling rock joint behavior from in situ block tests: Implications for nuclear waste repository design," Technical Report, TerraTek, Inc., Salt Lake City, UT, 65-66.

Barton, N., and Choubey, V. (1977). "The shear strength of rock joints in theory and practice," Rock Mechanics 10(1-2), 1-54.

Barton, N., Bandis, S., and Bakhtar, K. (1985). "Strength, deformation and conductivity coupling of rock joints," International Journal of Rock Mechanics, Mining Science, and Geomechanics Abstracts 22(3), 121-140.

Bellier, J. (1977). "The Malpasset Dam" (presented by Pierre Londe). The evaluation of dam safety, Engineering Foundation Conference proceedings, Pacific Grove, California, November 28-December 3, 1976. American Society of Engineers, New York.

Bennett, R. D., and Anderson, R. F. (1982). "New pressure test for determining coefficient of hydraulic conductivity of rock masses," Technical Report GL-82-3, U.S. Army Waterways Experiment Station, Vicksburg, MS.

Bock, R. W., Harber, W. G., and Arai, M. (1974). "Problems encountered in construction of dam foundations." Foundations for dams, an Engineering Foundation conference, Pacific Grove, California, March 17-21, 1974. American Society of Civil Engineers, New York.

Brekke, T. L., and Howard, T. R. (1972). "Stability problems caused by seams and faults." Proceedings, North American Rapid Excavation and Tunneling Conference, Chicago, IL. American Institute of Mining, Metallurgical, and Petroleum Engineers, New York, 1, 25-64. 
Davis, S. N., and DeWiest, R. J. M. (1966). Hydrogeology. John Wiley \& Sons, New York.

Deere, D. U. (1964). "Technical description of rock cores for engineering purposes," Rock Mechanics and Engineering Geology 1(1), 17-22.

. (1981). "Engineering geology for concrete dam foundations."

Recent developments in geotechnical engineering for hydro projects:

Embankment dam instrumentation performance, engineering geology aspects, rock mechanics studies, Proceedings sponsored by the Geotechnical Engineering Division, ASCE International Convention, New York City, May 11 and 12, 1981. Fred H. Kulhawy, ed., American Society of Civil Engineers, New York, 166-176.

Ebeling, R. M., and Pace, M. E. (1996a). "Uplift pressures resulting from flow along tapered rock joints," The REMR Bulletin, February, 13(1), U.S. Army Engineer Waterways Experiment Station, Vicksburg, MS.

. (1996b). "Variation in uplift pressures with changes in loadings along a single rock joint below a gravity dam," The REMR Bulletin, February, 13(1), U.S. Army Engineer Waterways Experiment Station, Vicksburg, MS.

Ebeling, R. M., Pace, M. E., and Morrison, E. E., Jr. (1997). "Evaluating the stability of existing massive concrete gravity structures founded on rock," Technical Report REMR-CS-54, U.S. Army Engineer Waterways Experiment Station, Vicksburg, MS.

Ebeling, R. M., Nuss, L. K., Tracy, F. T., and Brand, B. (2000). "Evaluation and comparison of stability analysis and uplift criteria for concrete gravity dams by three Federal agencies," Technical Report ERDC/ITL TR-00-1, U.S. Army Engineer Research and Development Center, Vicksburg, MS.

Ebeling, R. M., Wahl, R. E., and Pace, M. E. (1997). "Analysis of flow and pore pressures within rock foundations using steady state seepage models," Draft Report.

Freeze, A. R., and Cherry, J. A. (1979). Groundwater. Prentice-Hall, Inc., Englewood Cliffs, NJ.

Fuller, Mossbarger, Scott and May Engineers, Inc. (2000). "Draft report of subsurface exploration and data interpretation, Bluestone Dam, Hinton, West Virginia," Lexington, KY.

Geotechnical Laboratory (1993). "Part II. In Situ Test Methods, E. Determination of rock mass permeability." Rock Testing Handbook. U.S. Army Engineer Waterways Experiment Station, Vicksburg, MS.

Goodman, R. E. (1968). "Effects of joints on the strength of tunnels," Technical Report No. 5, U.S. Army Engineer District, Omaha, Omaha, NE. 
Goodman, R. E. (1990). "Rock foundations for dams: A summary of exploration targets and experience in different rock types," Keynote Address: Dam Foundation Engineering Tenth Annual USCOLD Lecture, New Orleans, LA, March 6-7, 1990. U.S. Committee on Large Dams, Denver, CO.

Grenoble, B. A., and Amadei, B. (1990). "Evaluation of uplift pressure for concrete gravity dams founded on jointed rock: Analytical results." Dam Foundation Engineering Tenth Annual USCOLD Lecture, New Orleans, LA, March 6-7, 1990. U.S. Committee on Large Dams, Denver, CO.

Grenoble, B. A., Harris, C. W., Meisenheimer, J. K., and Morris, D. I. (1995). "Influence of rock joint deformations on uplift pressure in concrete gravity dam foundations: Field measurements and interpretation." Fractured and jointed rock masses, Proceedings of the Conference on Fractured and Jointed Rock Masses, Lake Tahoe, California, USA, 3-5 June 1992.

A. A. Balkema/Rotterdam/Brookfield.

Headquarters, U.S. Army Corps of Engineers. (1993). "Seepage analysis and control for dams," EM 1110-2-1901, Washington, DC. . (1994). "Rock foundations," EM 1110-1-2908, Washington, DC. . (1995a). "Geophysical exploration for engineering and environmental investigations," EM 1110-1-1802, Washington, DC. . (1995b). "Gravity dam design," EM 1110-2-2200, Washington, DC. Washington, DC.

Hietanen, A. M. (1962). "Metasomatic metamorphism in western Clearwater County, Idaho," U.S. Geological Survey Professional Paper 344-A, U.S. Government Printing Office, Washington, DC.

Hvorslev, M. J. (1951). "Time lag and soil hydraulic conductivity in ground-water observations," Bulletin No. 36, U.S. Army Engineer Waterways Experiment Station, Vicksburg, MS.

International Society for Rock Mechanics. (1978). "Suggested methods for the quantitative description of discontinuities in rock masses," International Journal of Rock Mechanics, Mining Science and Geomechanical Abstracts 15, 319-368.

Iwai, K. (1976). "Fundamental studies of fluid flow through a single fracture," Ph.D. diss., University of California, Berkeley.

Lee, C.-H., and Farmer, I. (1993). Fluid flow in discontinuous rocks. Chapman \& Hall, London.

Lohman, S. W. (1972). "Ground-water hydraulics," Geological Survey Professional Paper 708, U.S. Government Printing Office, Washington, DC. 
Louis, C. A. (1969). "A study of groundwater flow in jointed rock and its influence on the stability of rock masses," Rock Mechanics Research Report No. 10, Imperial College, London.

Murphy, W. L. (1985). "Geotechnical descriptions of rock and rock masses," Technical Report GL-85-3, U.S. Army Engineer Waterways Experiment Station, Vicksburg, MS.

Pace, M. E., and Ebeling, R. M. (1998). "Interaction of a gravity dam, rock foundation, and rock joint with uplift pressures," Dam Engineering IX(3), 265-305.

Pahl, A., Bräuer, V., and Liedtke, L. (1995). "Fracture flow systems and structural geology." Fractured and jointed rock masses, Proceedings of the Conference on Fractured and Jointed Rock Masses, Lake Tahoe, California, USA, 3-5 June 1992. A. A. Balkema/Rotterdam/Brookfield.

Robinson, E. S. (1982). Basic physical geology. John Wiley \& Sons, New York.

Schruben, P. G., Arndt, R. E., Bawiec, W. J., and Ambroziak, R. A. (1997). Geology of the conterminous United States at 1:2,500,000 scale-A digital representation of the 1974 P.B. King and H.M. Beikman map. U.S. Geological Survey Digital Data Series DDS-11, Release 2, U.S. Geological Survey, Map Distribution, Denver, CO.

Schultz, J. R., and Cleaves, A. B. (1955). Geology in engineering. John Wiley \& Sons, New York.

Sears, F. W., and Zemansky, M. W. (1955). University physics. Addison-Wesley, Inc., Reading, MA, 1031 pp.

Sharp, J. C. (1970). "Fluid flow through fissured media," Ph.D. diss., Imperial College, London.

Snow, D. T. (1965). "A parallel plate model of fractured permeability media," Ph.D. diss., University of California, Berkeley.

. (1968). "Rock fracture spacings, openings, and porosities," Journal of the Soil Mechanics and Foundations Division, Proceedings of the American Society of Civil Engineers, SM1, 73-91, January.

Stone and Webster Engineering Corporation. (1992). "Uplift pressures, shear strengths, and tensile strengths for stability analysis of concrete gravity dams," TR-100345-V1, Volume 1, Project 2917-05, Final Report, August, Denver, $\mathrm{CO}$, prepared for Electric Power Research Institute (EPRI), Palo Alto, CA.

Todd, D. K. (1980). Groundwater hydrology. 2d ed., John Wiley \& Sons, New York, $535 \mathrm{pp}$.

U.S. Army Engineer District, Portland. (1969). "Green Peter Dam, Middle Santiam River, Oregon, foundation report," Portland, OR. 
U.S. Army Engineer District, Rock Island. (1965). "Red Rock Reservoir, Des Moines River, Iowa, Dam - Foundation Report, Binder 1 of 4," U.S. Army Engineer District, Rock Island, Rock Island, IL.

U.S. Army Engineer District, Seattle. (1979). "Libby Dam, Foundation Report," June, 31 pp plus plates.

. (1987). "Libby Dam, Lake Koocanusa Project, Kootenai River, Montana," Periodic Inspection Report No. 10, Seattle, WA.

. (1993). "Libby Dam, Lake Koocanusa Project, Kootenai River, Montana," Periodic Inspection Report No. 13, Seattle, WA.

U.S. Army Engineer District, Walla Walla. (1964). "Dworshak Dam and reservoir, North Fork Clearwater River, Idaho, Design Memorandum No. 6, main dam, foundation grouting and drainage, and instrumentation," Walla Walla, WA.

. (1979). "Dworshak Dam and Reservoir, North Fork Clearwater River, Idaho, foundation report," Walla Walla, WA.

Zeigler, T. W. (1976). "Determination of rock mass permeability," Technical Report S-76-2, U.S. Army Engineer Waterways Experiment Station, Vicksburg, MS. 


\section{Appendix A Explanation of Snow's Equation for Flow Through Fractures}

Snow (1968) derived expressions describing flow through smooth-walled fractures and computing permeability, fracture spacing, and porosity. Figure A.1 describes Snow's conceptual model and nomenclature.

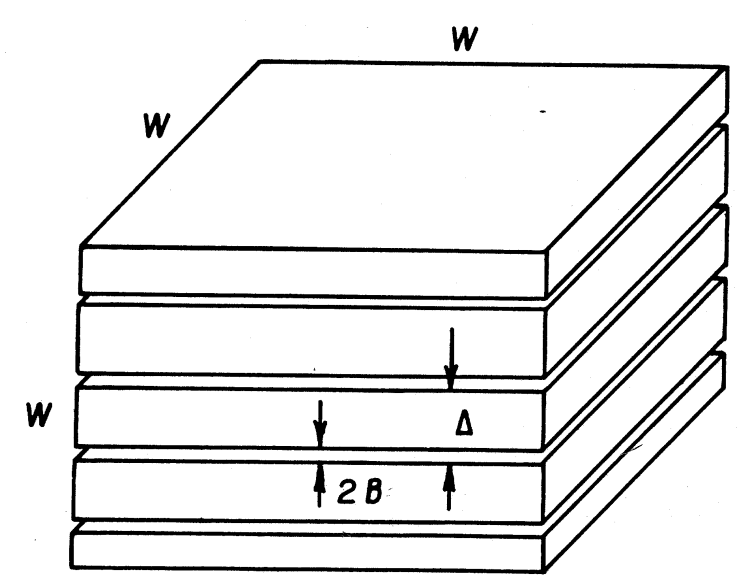

Figure A.1. Snow's solid of dimensions $W$, broken by parallel plane fractures (after Snow 1968)

From Figure A.1, the (laminar) volume discharge between two smooth parallel plates of opening $2 B$ is

$$
q=-\left(B^{2} / 3\right)\left(\gamma_{w} / \mu_{w}\right)(2 B W) i
$$

where $i$ is the hydraulic gradient. The term $-\left(B^{2} / 3\right)$ is the intrinsic permeability, $k$, but $B$ is $1 / 2 e$ (the fracture aperture of Figure A.1), so $\left.k=(1 / 2 e)^{2} / 3\right)=e^{2} / 12$. 


\section{Appendix B}

\section{Derivation of Darcy's Equation of Radial Flow to a Borehole (Equation 2.11)}

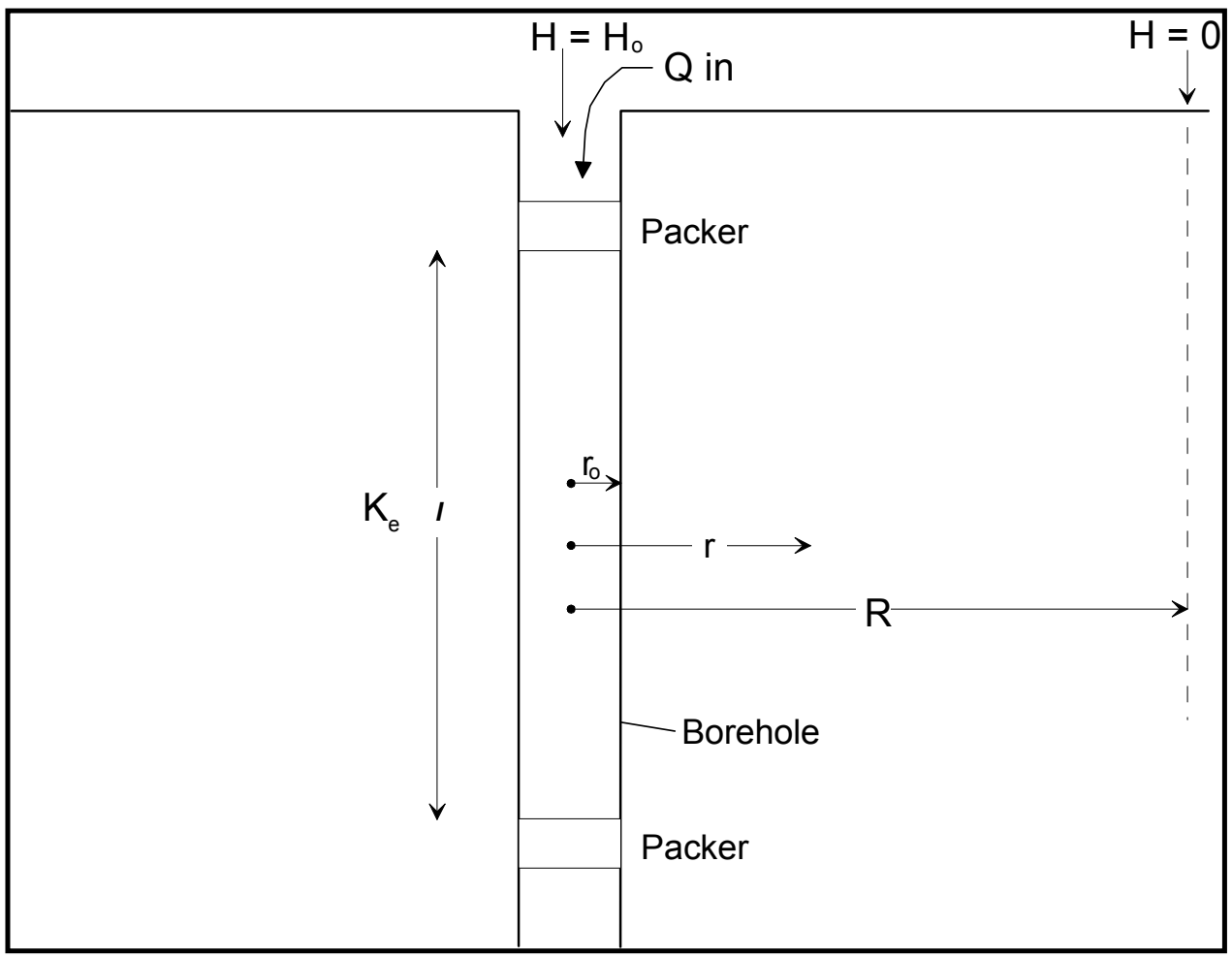

where

$H=$ excess pressure head

$H_{o}=$ excess pressure head at the well

$Q=$ flow rate

$K_{e}=$ interval hydraulic conductivity 
$r_{o}=$ well radius

$r=$ radius of flow

$R=$ radius of influence

$l=$ length of test interval.

Darcy's law says:

$$
Q=K i A
$$

where

$$
\begin{aligned}
K & =\text { hydraulic conductivity } \\
i & =\text { hydraulic gradient } \\
A & =\text { cross-sectional area through which flow occurs }
\end{aligned}
$$

For radial flow to the well through a cylindrical interval,

$$
Q=K_{e} \bullet d h / d r \bullet 2 \pi r l
$$

This can be rewritten as:

$$
d r / r=K_{e} \bullet 2 \pi l / Q \bullet d h
$$

Integrate at the boundary conditions, where $H=H_{o}$ at the well and $H=0$ at the radius of influence, $R$ (by definition); $r=r_{o}$ at the well, and $r=R$ at $H=0$ :

$$
\int_{r=r_{o}}^{r=R} d r / r=K_{e} 2 \pi l / Q \bullet \int_{h=H_{o}}^{h=0} d h
$$

$$
\begin{aligned}
& \text { so } \quad \ln R-\ln r_{o}=K_{e} 2 \pi l / Q \bullet\left(0-H_{o}\right) \\
& \text { or } \quad \ln \left(R / r_{o}\right)=-K_{e} 2 \pi l / Q \bullet H_{o} \\
& \text { and } \quad Q=K_{e} 2 \pi l H_{o} / \ln \left(R / r_{o}\right)
\end{aligned}
$$

(the negative sign is dropped by choosing flow away from the borehole to be positive). 


\section{Appendix C Glossary}

\section{Engineering and Hydraulics Terms}

Permeability $(\boldsymbol{k})$ : A general term for ability of a soil or rock to transmit fluid under a pressure gradient. Intrinsic permeability is independent of the fluid properties, i.e., it is a property of the medium alone. Intrinsic permeability $k=$ $C d^{2}$, where $C$ is a dimensionless shape factor describing the geometry and other characteristics of the flow path and $d$ is the average pore size of the medium (Davis and DeWiest 1966) or the mean grain diameter (Lohman 1972). Unit is $L^{2}$ or darcy, where 1 darcy $=1.062 E^{-11} \mathrm{ft}^{2}$ (Davis and DeWiest 1966) or 0.987 $(\mu \mathrm{m})^{2}$.

Hydraulic conductivity $(K)$ : Ability of a medium to transmit fluid considering the properties of the fluid. $K=C d^{2} \gamma / \mu=k \gamma / \mu$. Units are $L / T$, e.g., $\mathrm{ft} / \mathrm{day}$. Also, $K=Q / i A$, where $i=\delta h / \delta l$. Actual units for $K$ are $L^{3} / L^{2} / T$, as $\mathrm{ft}^{3}$ per $\mathrm{ft}^{2}$ per min, which reduces to units of velocity, $L / T$. Formerly called coefficient of permeability or permeability.

Equivalent hydraulic conductivity $\left(K_{e}\right)$ : The hydraulic permeability of a zone of jointed (discontinuous) rock in which flow is considered to occur in a continuum. In a borehole test section in a jointed rock mass, flow is assumed to occur over the entire length of the test section, not just through the open joints. Units are those of hydraulic conductivity. For a pressure test in a zone of jointed rock, $K_{e}=$ $(Q / 2 \pi L H) \ln \left(R / r_{o}\right)$. Formerly called equivalent coefficient of permeability.

Equivalent joint hydraulic conductivity $\left(\boldsymbol{K}_{j}\right)$ : The equivalent hydraulic conductivity of a single joint determined from pressure or other tests in a zone of jointed rock. $K_{j}$ is derived from calculations of conducting aperture $e$ using the cubic law ( $Q$ is proportional to the cube of the joint conducting aperture).

Joint mechanical aperture $(E)$ : The actual distance separating the walls of an open joint. Most mechanical apertures have a degree of roughness, or asperity, manifested by irregularities or undulations in the joint walls.

Joint conducting aperture (e): The distance between two smooth, parallel plates that would allow the same flow as a mechanical joint aperture with rough walls. Conducting aperture $e$ is always smaller than mechanical aperture $E$ except in the 
case of a smooth-walled joint. Also called parallel plate aperture or equivalent joint aperture.

Cubic law: A relationship stating that rate of flow $Q$ is proportional to the cube of the joint conducting aperture $e . Q=\left(\gamma_{w} / 12 \mu_{w}\right) \cdot e^{3} \cdot i$ for a single joint and $e^{3}=$ $Q / 2 \pi N H\left(12 \mu_{w} / \gamma_{w}\right) \ln \left(R / r_{o}\right)$ for a borehole test interval containing $N$ joints.

Open joint: A joint having a mechanical (true) aperture greater than about 150 microns $(0.150 \mathrm{~mm})$.

Tight joint: A joint having a mechanical (true) aperture less than about 150 microns $(0.150 \mathrm{~mm})$.

Reynolds number $\left(\boldsymbol{R}_{\boldsymbol{e}}\right)$ : A dimensionless number expressing the ratio of inertial to viscous forces in flow. The critical Reynolds number is the number at which nonlinear flow starts to occur.

Laminar flow: Flow in which the specific discharge is proportional to hydraulic conductivity.

Turbulent flow: Flow in which the specific discharge is not proportional to hydraulic conductivity.

Porosity: The volume of void space in a rock or soil per total unit volume.

Viscosity: The internal friction of a fluid (Sears and Zemansky 1962). The resistance to flow of a fluid. Dynamic viscosity $\mu$ is expressed in units of $F T / L^{2}$, e.g., dyne sec/ $\mathrm{cm}^{2}$ or $\mathrm{lbf} \mathrm{min} / \mathrm{ft}^{2}$, or in poise. One poise $=1 \mathrm{dyne} \mathrm{sec} / \mathrm{cm}^{2}$. The dynamic viscosity of water at $20{ }^{\circ} \mathrm{C}$ is 0.0101 poise. Kinematic viscosity $v$ is the ratio of dynamic viscosity to density and is expressed in units of $L^{2} / T$, as $\mathrm{ft}^{2} / \mathrm{min}$. Kinematic viscosity $\nu=g \mu / \gamma_{w}$.

\section{Selected Geologic Terms}

Alluvial: Describing sediments carried by and deposited in streams and stream valleys.

Amphibolite: A metamorphic rock consisting of dark-colored plagioclase feldspar minerals and having little or no quartz.

Andesite: A dark-colored igneous extrusive rock.

Anhydrite: A sedimentary rock consisting almost wholly of anhydrous calcium sulfate. An evaporite rock. Also the mineral anhydrite.

Aperture: A measurement of the distance separating the walls of a discontinuity.

Argillite: A weakly metamorphosed mudstone. 
Asperity: A protrusion or protrusions on the walls of a discontinuity that impart roughness to the surfaces.

Calcite: A common mineral of calcareous rock, such as limestone and some sandstones. Also found as fillings in discontinuities. Calcium carbonate, $\mathrm{CaCO}_{3}$.

Clastic: Referring to sedimentary rocks consisting of particles of older rock accumulating through erosion and subsequent deposition.

Columnar jointing: A kind of joint system developed in volcanic lava flows and characterized by near-vertical, polygonal sets of fractures formed by cooling of the lava, particularly basalt.

Dike: A relatively thin, tabular, near-vertical igneous intrusion cutting transversely through older rock.

Dip: The vertical angle between a discontinuity plane and the horizontal.

Discontinuity: A natural planar or curved feature that physically separates a rock mass. Examples of discontinuities are joints, bedding planes, faults, shears and shear zones, planes of schistosity, and mineral veins.

Extrusive rock: Those igneous rocks ejected onto the surface of the earth or into the earth's atmosphere from below in a molten or gaseous form. Extrusive rocks are normally characterized by a fine-grained texture.

Fault: A discontinuity along which the opposite walls have moved past each other.

Feldspar: A common silicate mineral of igneous rocks, and the most common mineral in the earth's crust. Light-colored igneous rocks usually contain sodiumor potassium-rich feldspar (commonly orthoclase); dark-colored igneous rocks usually contain calcium-rich feldspars (commonly plagioclase).

Foliation: A general term for structures in metamorphic rocks having platy, layered, or planar aspects.

Gneiss (adj. gneissic): A metamorphic rock consisting of generally parallel bands of minerals.

Gypsum: A sedimentary rock consisting almost wholly of hydrated calcium sulfate. Also the mineral gypsum.

Intrusive rock: Those igneous rocks injected into the earth's crust from below in a molten form. Intrusive rocks are normally characterized by a coarse-grained texture.

Joint: A discontinuity along which there has been no movement or displacement parallel to the plane of the discontinuity. 
Joint set: A group of approximately parallel joints.

Joint system: Two or more joint sets in a consistent pattern.

Kaolinization: The replacement or alteration of minerals to the clay mineral kaolin. A result of weathering or hydrothermal alteration.

Karst: Terrain characterized by sinkholes and closed topographic depressions, disrupted surface drainage and disappearing streams, solution-enlarged discontinuities, caves, and underground drainage systems. Karst is most common in areas underlain by water-soluble rock.

Lacustrine: Sediments deposited in a lake.

Limestone: A sedimentary rock consisting primarily of the mineral calcite (calcium carbonate).

Massive: A loosely defined term describing a rock deposit having no visible bedding or bedding planes spaced greater than a specified thickness.

Metasediments: Certain very old sedimentary rocks that have been sufficiently altered through time under heat and pressure that they have lost their original texture.

Porphyry: An igneous rock texture characterized by large mineral crystals in a matrix of fine crystals.

Pyroclastic: Referring to deposits formed by ejection of molten and gaseous material from a volcanic vent and subsequently deposited by wind, water, and gravity. Examples of pyroclastic deposits are ash and tuff, agglomerate, volcanic breccia, and welded tuff.

Quartz: A common mineral of igneous rocks. Silicon dioxide. Also a major component of many clastic sedimentary rocks such as sandstone.

Schist (adj. schistose): A metamorphic rock with a strongly foliated texture that can be readily split into thin flakes or slabs along parallel-oriented minerals.

Shear zone: A narrow zone of intense fracturing, sometimes accompanied by a gouge of broken and altered rock, along a fault.

Slaking: The tendency of some shales, mudstones, or claystones to disintegrate in the presence of changing moisture conditions.

Slickensided: Pertaining to striations and grooves on the surface of a discontinuity indicating movement of the walls of the discontinuity past each other.

Stratigraphy: That branch of geology that describes the sequence of deposition, relative age, and lithology of sedimentary and volcanic rocks. 
Strike: The direction, with respect to north, of the line of intersection of a discontinuity plane with the horizontal.

Tectonic: Referring to forces within the earth that cause mountain building, uplift, structural basins, earthquakes, and displacement of the earth's crust.

Tuff: A hardened deposit of volcanic ash. A pyroclastic rock.

Weathering: The in-place disintegration, decomposition, or change in physical properties of rock by natural processes. 


\section{Appendix D Notation}

\begin{tabular}{ll}
\hline & \\
$\gamma$ & Unit weight of fluid \\
$\gamma_{w}$ & Unit weight of water \\
$\mu$ & Dynamic viscosity of fluid \\
$\mu_{w}$ & Dynamic viscosity of water \\
$\sigma$ and $\sigma_{n}$ & Normal stress component \\
$\tau$ & Shear strength, shear stress \\
$v$ & Kinematic viscosity \\
$\varphi$ & Angle of internal friction \\
$A$ & Area \\
$B$ & One-half of the conducting joint aperture (Snow 1968) \\
$c$ & Cohesion \\
$C$ & Dimensionless shape factor \\
$d$ & Pore size \\
$D_{h}$ & Equivalent hydraulic diameter \\
$e$ & Conducting aperture, parallel plate aperture \\
$E$ & Mechanical aperture \\
$\mathrm{E}^{\mathrm{x}}$ & Scientific notation, power (x) of 10 \\
$\mathrm{F}$ & Units of force \\
$g$ & Acceleration due to gravity \\
$h$ & Head \\
$H$ & Excess pressure head \\
$H_{g}$ & Head produced by height of water in pressure-test flow pipe \\
$i$ & Hydraulic gradient \\
$\mathrm{I} . \mathrm{D}$. & Inside diameter \\
$\mathrm{JCS}$ & Joint wall compressive strength \\
$\mathrm{JRC}$ & Joint roughness coefficient \\
$k$ & Intrinsic permeability \\
$K$ & Hydraulic conductivity \\
$K_{e}$ & Equivalent hydraulic conductivity \\
$K_{j}$ & Joint hydraulic conductivity \\
$K_{j}^{\prime}$ & Turbulent fissure hydraulic conductivity \\
$l$ & Length of borehole test section \\
$L$ & Units of length \\
$\mathrm{MSL}$ & Mean sea level \\
$N$ & Number of joints \\
$P$ & Pressure \\
\hline &
\end{tabular}




$\begin{array}{ll}P_{t} & \text { Pressure measured at surface gage } \\ Q & \text { Volume flow rate } \\ r_{o} & \text { Borehole radius } \\ R & \text { Radius of influence } \\ \mathrm{R}_{\mathrm{e}} & \text { Reynolds number } \\ R_{r} & \text { Height of surface asperities } \\ \text { RQD } & \text { Rock quality designation } \\ S & \text { Surface roughness index } \\ T & \text { Units of time } \\ u & \text { Pore, or uplift, pressure } \\ v & \text { Mean specific discharge } \\ V_{j} & \text { Joint closure } \\ V_{m} & \text { Maximum joint closure }\end{array}$




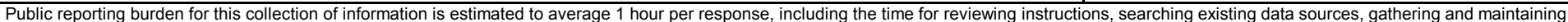

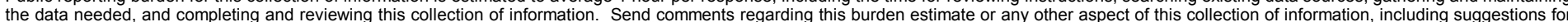

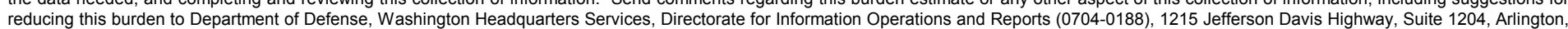

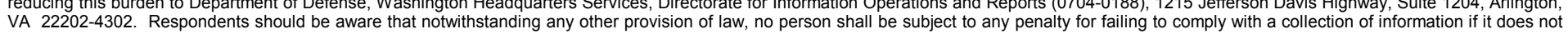
display a currently valid OMB control number. PLEASE DO NOT RETURN YOUR FORM TO THE ABOVE ADDRESS.

\begin{tabular}{l|c}
$\begin{array}{l}\text { 1. REPORT DATE (DD-MM-YYYY) } \\
\text { March } 2002\end{array}$ & $\begin{array}{c}\text { 2. REPORT TYPE } \\
\text { Final report }\end{array}$ \\
\hline
\end{tabular}

\section{TITLE AND SUBTITLE}

Assessment of Geology as it Pertains to Modeling Uplift in Jointed Rock: A Basis for Inclusion of Uncertainty in Flow Models

3. DATES COVERED (From - To)

5a. CONTRACT NUMBER

5b. GRANT NUMBER

5c. PROGRAM ELEMENT NUMBER

5d. PROJECT NUMBER

5e. TASK NUMBER

5f. WORK UNIT NUMBER

6

7. PERFORMING ORGANIZATION NAME(S) AND ADDRESS(ES)

U.S. Army Engineer Research and Development Center

Geotechnical and Structures Laboratory and Information Technology Laboratory

3909 Halls Ferry Road

Vicksburg, MS 39180-6199

9. SPONSORING / MONITORING AGENCY NAME(S) AND ADDRESS(ES)

U.S. Army Corps of Engineers

Washington, DC 20314-1000

8. PERFORMING ORGANIZATION REPORT NUMBER

ERDC TR-02-2

10. SPONSOR/MONITOR'S ACRONYM(S)

11. SPONSOR/MONITOR'S REPORT NUMBER(S)

\section{DISTRIBUTION / AVAILABILITY STATEMENT}

Approved for public release; distribution is unlimited.

\section{SUPPLEMENTARY NOTES}

\section{ABSTRACT}

Uplift is one of the major forces affecting stability of rock-founded concrete dams. Problems occur in determining the magnitude and distribution of uplift pressures within rock foundations and in extrapolating uplift pressures to reservoir levels above the pool of record. Uplift is controlled by the flow regime within the rock foundation. The flow regime is a function of the geology. The goal of research in uplift uncertainty and probabilistic modeling is to develop a methodology, analytical procedures, and software to assess uplift pressures and forces within rock foundations for use in the assessment of the reliability of rock-founded concrete gravity dams. The objectives of this study were to identify geological factors affecting the prediction and modeling of flow and the development of uplift pressures in rock foundations; to identify the kinds of uncertainty in uplift prediction resulting from geological investigations, particularly in testing and description of rock discontinuities; and to select a case history for assessing the uncertainties associated with geological and uplift analysis of a large dam. Much uplift prediction uncertainty is caused by insufficient investigation or treatment of rock discontinuities, or by deformation of discontinuities with resulting changes in discontinuity aperture and in the flow regime caused by stresses imposed by the dam and reservoir. Tight discontinuities, those with mechanical apertures less than about 250 microns, may cause a nonlinear response in uplift pressure with rising headwater. Apertures can be estimated from foundation borehole pressure

\section{SUBJECT TERMS}

(Continued)

See reverse.

16. SECURITY CLASSIFICATION OF:

\section{a. REPORT}

UNCLASSIFIED

b. ABSTRACT
UNCLASSIFIED

c. THIS PAGE

UNCLASSIFIED
17. LIMITATION OF ABSTRACT

\begin{tabular}{|l|} 
18. NUMBER \\
OF PAGES \\
\cline { 2 - 2 }
\end{tabular}

19a. NAME OF RESPONSIBLE PERSON

19b. TELEPHONE NUMBER (include area code) 


\section{4. (Concluded)}

tests using the cubic law, which relates flow rate to joint aperture. There is uncertainty in determining the persistence of aperture and condition of discontinuities through the foundation rock mass. Other geologic factors contributing to uncertainty in uplift prediction include variation in rock mass hydraulic conductivity, effects of weathering, stratigraphic complexity, and variable properties inherent in different rock types. Uplift pressures measured in gauges in Corps dams commonly reflect pressures only in the upper few feet of the foundation and may not represent uplift pressures developed in deeper discontinuities. Design engineers usually assume a linear pressure distribution, when actual pressures may vary nonlinearly both temporally and spatially. Calculation of joint apertures and joint hydraulic conductivity from pressure tests conducted at Libby Dam show decreasing aperture and hydraulic conductivity with depth, similar to studies at other dams. Apertures calculated for Libby Dam were generally in the range of "open" joints. Responses of installed pressure gauges at Libby Dam were linear over a 10 -year monitoring period, also indicative of open joints.

\section{5. (Concluded)}

Dam foundations

Foundation geology

Foundation instrumentation

Hydraulic conductivity

Joint properties

Libby Dam

Pore pressure

Pressure tests

Uncertainty

Uplift

Uplift pressure 